\title{
ASEISMIC PILE FOUNDATION DESIGN ANALYSIS
}

\author{
M. J. Pender ${ }^{1}$
}

\begin{abstract}
SUMMARY
Methods of assessing, for preliminary design purposes, the stiffness and capacity of pile foundations under seismic forces are presented. Although the main thrust of the paper is to aseismic design the methods are applicable to other forms of dynamic excitation of pile foundations. Emphasis is placed on expressions for pile stiffness and capacity in the form of simple formulae that can be incorporated into spreadsheet or similar types of software. The use of the equations is illustrated with a number of worked examples. Where possible the methods are justified by data from field testing of foundations at prototype scale.
\end{abstract}

\section{PREFACE}

The methods presented herein are the outgrowth of the Pile Foundation Study Group set up by the Society in 1986. The members of the Study Group were: M. J. Pender (convenor), H. Chapman, T. Matuschka, and D. V. Toan. The group met a number of times and agreed that topics such as those covered herein needed to be presented in a unified manner before other more design related matters could be treated. M. J. Pender was assigned that task. In the event it has taken rather longer than anticipated to gather the material on analysis together, in no small measure a consequence of the rapid strides that have been made in the topic of pile foundation response, both static and dynamic, in the last five or six years. The methods presented here cover only the first part of the original plans of the study group. A report at this stage is in response to the wish of the Society that the work of the group be published and because, at this stage, other commitments of the group preclude proceeding with earlier plans.

\section{CONTENTS}

\subsection{Introduction}

2.0 Observed seismic response of pile foundations

2.1 Pile damage and failure

2.2 Pile stiffness behaviour

3.0 Standard models for pile lateral stiffness

3.1 Winkler model

3.2 Elastic continuum model

3.3 Comparison between the elastic continuum and Winkler analyses

3.4 Equivalent cantilever concept
3.5 Pile head stiffness

4.0 Standard models for pile vertical stiffness

4.1 Winkler model

4.2 Elastic continuum model

4.3 Raked piles

5.0 Stiffness of pile groups

5.1 Vertical stiffness

5.2 Rotational stiffness of a free head free standing pile group

5.3 Lateral stiffness of pile groups

5.4 Stiffness of a fixed head free standing pile group

5.5 Torsional stiffness of a free standing free head pile group

5.6 Stiffness of pile-rafts

5.7 Effects of nonlinear soil behaviour

6.0 Subgrade properties and penetration resistance

6.1 Small strain behaviour

6.2 Design load correlations

7.0 Nonlinear lateral pile-soil interaction

7.1 Local failure

7.2 Nonlinear soil reaction and layered soil profiles

7.3 Effect of pile diameter

7.4 Case studies

8.0 Dynamic stiffness of pile foundations

8.1 Results of dynamic tests on prototype scale piles and pile groups

8.2 Dynamic response of single piles

8.3 Kinematic soil-pile interaction

8.4 Dynamic response of pile groups

1 Civil Engineering Department, University of Auckland (Fellow) 
9.0 Capacity of pile foundations

9.1 Vertical capacity of a single pile

9.2 Lateral capacity of a single pile

9.3 Pile group capacity

\subsection{Summary}

\subsection{Acknowledgements}

\subsection{References}

\subsection{Notation}

\subsection{INTRODUCTION}

The objective of this paper is to provide a series of techniques which will be of use for the analysis of pile foundations which require aseismic design. The use of the term design analysis in the title indicates that the information presented in this document will be of use to an engineer designing a pile foundation system but that the design process involves much more than use of techniques for analysis.

The thrust of the methods presented is towards preliminary design, consequently approaches that are amenable to use with a spreadsheet or similar software are emphasised. More sophisticated methods may be used in the final design for a given structure, such methods are referenced in the paper but not discussed in detail. Even so the simple methods given herein are still useful (perhaps even essential) as a preliminary to more sophisticated analyses.

This report extends and updates the material presented in section 4 of the report of the Seismic Design of Bridges Discussion Group, Edmonds et al (1980). The present document reflects the very considerable developments in the understanding of the dynamic behaviour of pile foundations that were achieved in the 1980's. Useful surveys of states-ofthe-art prior to the 80's are Nair (1969) and Tajimi (1977), while Novak (1991) gives an assessment of the current understanding of the dynamic behaviour of pile groups in elastic soils. Some of the material presented herein was given in summary form by Pender (1990).

An earthquake applies a dynamic horizontal shear and moment to a pile foundation, and may also apply vertical loading. In addition the applied moment may be equilibrated by developing equal and opposite axial loads in the piles on opposite sides of the structure. These axial forces, shear forces and moments generate displacements and rotations in the pile shaft. Evaluation of these displacements is discussed herein but no consideration is given to the structural requirements of the pile section, such as reinforcing details, hence the main emphasis in the report is geotechnical. Methods for estimating the stiffness and capacity of single piles and pile groups are presented. Where possible the techniques recommended are supported by information from field tests on single piles and pile foundations or from post earthquake observations of the performance of pile foundations.
Any presentation of pile design analysis techniques must be able to handle layered soil profiles which tend to be the rule rather than the exception at most sites. In addition realistic estimation of the lateral stiffness of single piles and pile groups requires that the nonlinear interaction between the pile shaft and adjacent soil be considered. Some techniques for handling this are illustrated briefly.

A number of worked examples are included. These are mostly simple cases intended to illustrate the use of the various formulae rather than design calculations.

There are two levels of loading that current limit state ideas mandate for consideration in the design of a pile foundation: a serviceability limit state and an ultimate limit state. The requirements of each of these are:

(i) in the serviceability limit state the design requirement is that the pile remains essentially elastic and that the deformations be acceptable;

(ii) in the ultimate limit state yielding of the pile is permitted (although it may be a design decision for important structures that yielding of piles should not occur at locations for which repair would be difficult).

We will see in section 7 that there may be nonlinear deformation of the soil adjacent to the pile shaft if the serviceability limit state takes the pile shaft maximum moment towards yield. This suggests an additional minor category of seismic excitation in which the entire system, including the soil around the piles, remains elastic. Such a case is of significance because it identifies the upper bound on the natural frequency of the pile foundation.

Two special topics are not specifically addressed in the paper The behaviour of piles in a liquefied soil profile is not covered. (It may be a design decision to prevent this occurrence and therefore improve the ground before construction, or it may decided that liquefaction is unlikely and therefore the risks are acceptable. In either case a means of assessing the effects of liquefaction on a pile foundation would be useful.) Also the paper does not cover pile foundations loaded by soil deformation coming from a nearby embankment (such as fill behind a bridge abutment).

\section{A note about units}

Using $\mathrm{kN}$ and $\mathrm{m}$ as standard units gives us stiffnesses in $\mathrm{kN} / \mathrm{m}$ or $\mathrm{kNm} /$ radian and displacements in metres and radians. More convenient are $\mathrm{mm}$ and $\mathrm{mrad}(\mathrm{mrad}=$ milli-radian $\approx$ $0.06^{\circ}$ ) for displacements and $\mathrm{kN} / \mathrm{mm}$ and $\mathrm{kNm} / \mathrm{mrad}$ for stiffnesses. This is achieved if soil moduli are expressed in terms of MPa whilst loads and moments are in $\mathrm{kN}$ and $\mathrm{kNm}$, then the calculated stiffnesses are in $\mathrm{kN} / \mathrm{mm}$ and $\mathrm{kNm} / \mathrm{mrad}$ (the same as $\mathrm{MN} / \mathrm{m}$ and $\mathrm{MNm} /$ radian), the displacements in $\mathrm{mm}$, and the rotations in mrad. However, when doing dynamic calculations, such as those in examples 8.1, 8.2 and 8.8 , we cannot use the above stiffnesses as a consistent set of units is required. Our mass unit is the tonne which is coupled with the $\mathrm{kN}$ as a unit of force. Thus for dynamic calculations the stiffnesses are expressed as $\mathrm{kN} / \mathrm{m}$ and $\mathrm{kNm} / \mathrm{radian}$. 


\section{0}

\section{RESPONSE OF PILE FOUNDATIONS TO SEISMIC LOADING}

The intention of this section is to review briefly some published data on the response of pile foundations during earthquakes and so provide background to various aspects of pile behaviour discussed in the remainder of this paper.

Observations of damage caused to pile foundations by earthquakes

\subsubsection{Piles in sand}

Ross et al (1969) document failures of bridge foundations in the 1964 Alaskan earthquake. The paper gives numbers of failures, descriptions of damage, details of SPT profiles, and length of piles but not much is given in the way of actual foundation details. The paper presents convincing evidence, Fig. 2.1, that large foundation displacements during earthquakes are associated with foundations in saturated sands. Bridge foundations in gravels and gravelly sands sustained much less damage, foundations on rock were undamaged, and foundations formed by piling through sands to bedrock had minor damage. Nishizawa et al (1984) document an interesting case of pile damage related to the 1964 Niigata earthquake. Details of the structure are given Fig. 2.2. Some of the columns were supported on pile groups with 5 piles in each (a $2 \times 2$ group with a central pile). Piles 30

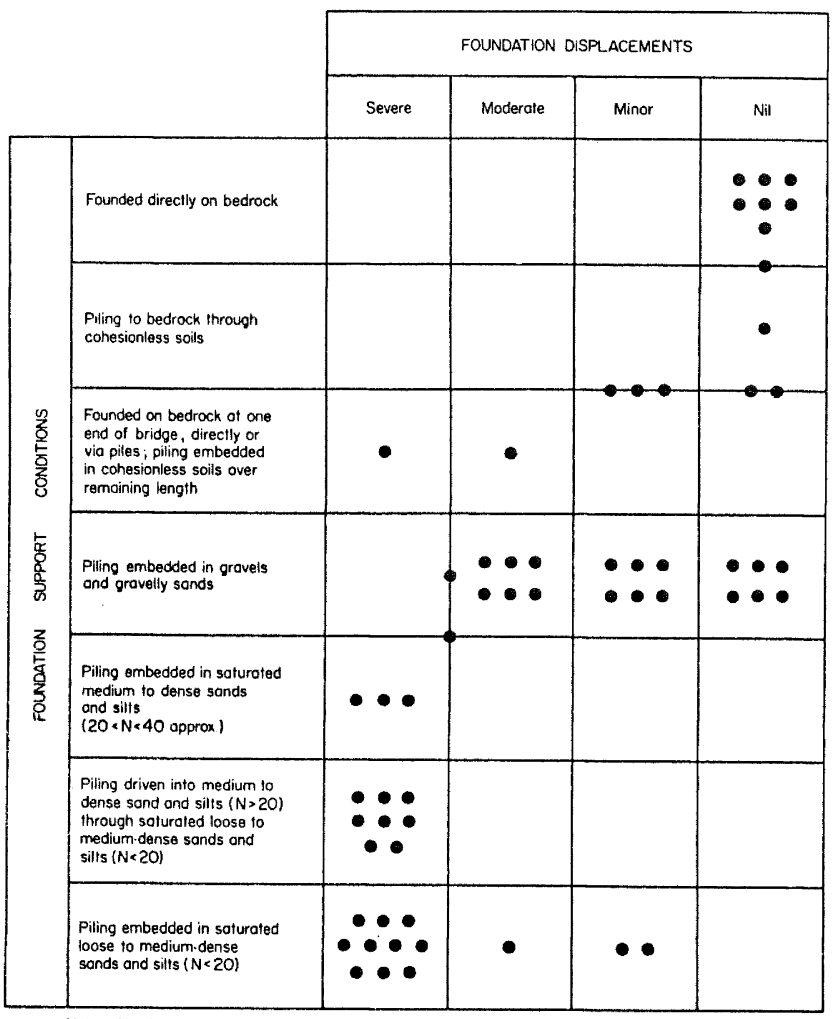

Note: Number of coses classified was limited by avoilability of dato to 60 from a total of approximately
120 bridges ion the three highways.

Fig. 2.1 Correlation between foundation displacements and support conditions for bridges affected by the 1964 Alaska earthquake (after Ross et al (1969)). $\mathrm{cm}$ diameter and $10 \mathrm{~m}$ long had been driven through fine sand with low $\mathrm{N}$ values and about $1.5 \mathrm{~m}$ into a sand layer with $\mathrm{N}$ around 20 . Many years after the earthquake four of the piles were removed to ascertain the type of damage. The damage pattern and the penetration resistance profile are shown in Fig. 2.3. Cracks extended over most of the pile shafts available for inspection. Damage was most severe 3.1 to $3.5 \mathrm{~m}$ beneath the underside of the pile head and between 1.5 and $2.3 \mathrm{~m}$ above the tip, where the density of the sand increased. Cracking towards the bottom of the pile shafts is probably a consequence of the lateral support beneath the liquefied layer from the sand with an N-value of about 20 .

These two cases serve to emphasise the severe effect liquefaction has on pile foundations. Further insights, gained from simple mathematical modelling, into the effect of liquefaction induced lateral movements of sand past pile shafts are given by Miura et al (1991). Liquefaction effects cannot be addressed by the methods presented in this report.

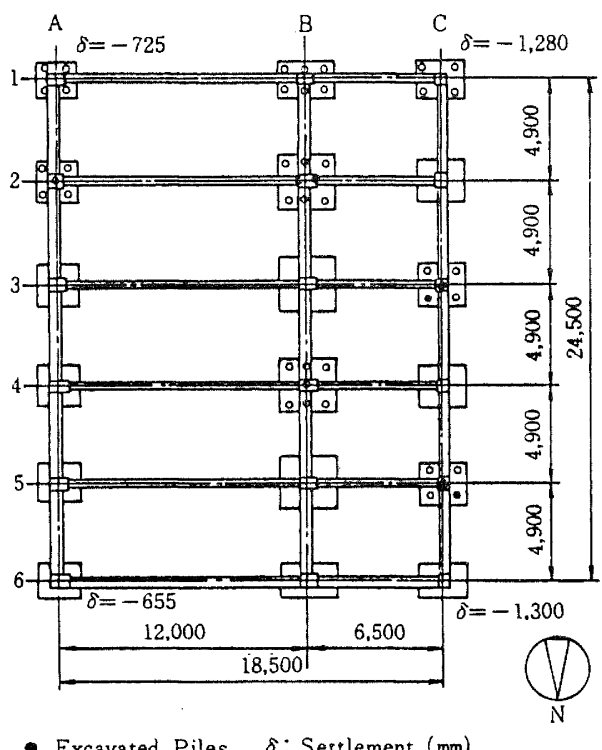

- Excavated Piles $\delta:$ Sertlement $(\mathrm{mm})$

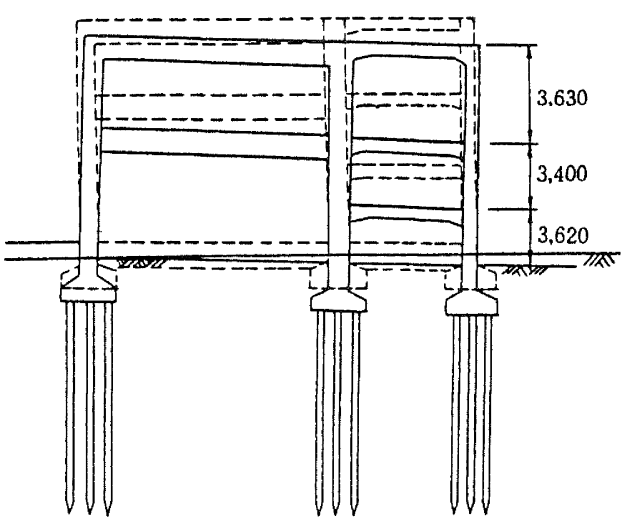

Fig. 2.2 Details of the piled structure from which damaged piles were extracted (after Nishizawa et al (1984)). 

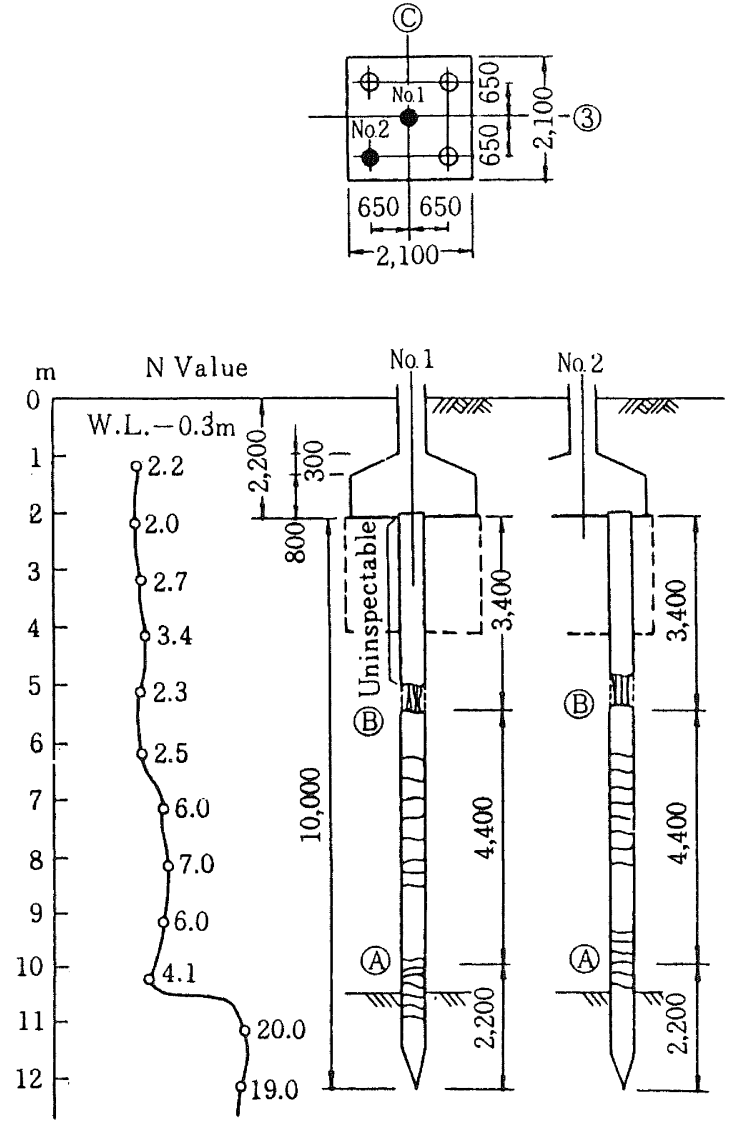

Fig. 2.3 Soil profile and pile damage details for the Niigata liquefaction site (after Nishizawa et al (1984)).

\subsubsection{Piles in silts and cohesive soils}

Nishizawa et al (1984), Ohira et al (1984) and Abe et al (1984) all report that pile foundations embedded in soil profiles with silt and clays were severely damaged in the 1968 Off-Tokachi and 1978 Off-Miyagi Prefecture earthquakes. Sugimura (1984) gives further details of the failures from the 1978 Off-Miyagi Prefecture earthquake. In addition Mizuno (1988) gives an extensive survey of Japanese pile foundation damage caused by earthquakes between 1923 and 1983 .

Girault (1986) discusses pile foundations in Mexico City which experienced large movements as a result of the 1985 earthquake. Some 25 buildings supported on friction piles suffered sudden, and in some cases large, settlements during the earthquake with tilting. Buildings founded on end bearing piles fared much better with smaller settlements and tilting. Zeevaert (1991), in his Terzaghi lecture, discusses the sudden settlement and tilting of foundations on these friction piles. $\mathrm{He}$ attributes the movements to the existence of a gap between the underside of the foundation and the top of the soil profile. During the earthquake induced cyclic axial loading the shaft capacity of the piles was mobilised and the plunging deformation occurs until the gap at the underside of the foundation is closed. Zeevaert concludes that friction pile foundations should not be constructed in a free-standing (q.v.
Fig. 5.1) configuration. He recommends a pile-raft (q. v. Fig. 5.1) with all the vertical capacity of the pile shafts mobilised under static loading, then the earthquake cyclic load resistance is provided by bearing on the soil under the foundation. This might be easier to state than achieve in practice as the distribution of vertical load will depend on the relative vertical stiffness of the pile group and the raft. Furthermore an accurate assessment of the vertical capacity of the piles under cyclic loading will be required. In section 9 it is explained that the cyclic vertical capacity of pile shafts is likely to be significantly less than the static capacity. Thus we can generalise Zeevaert's ideas to offer two alternatives for the design of floating pile foundations in clay, in either case the basic need is to ensure that the foundation system has the capacity to perform satisfactorily under both static and seismic loading. Firstly one could use a pile-raft as suggested by Zeevaert and design so that the combined capacity of the piles and the underside of the foundation is adequate, alternatively a free-standing foundation could be used which requires all the capacity to come from the pile shafts. A careful assessment would then be needed of the cyclic axial capacity of the pile shafts.
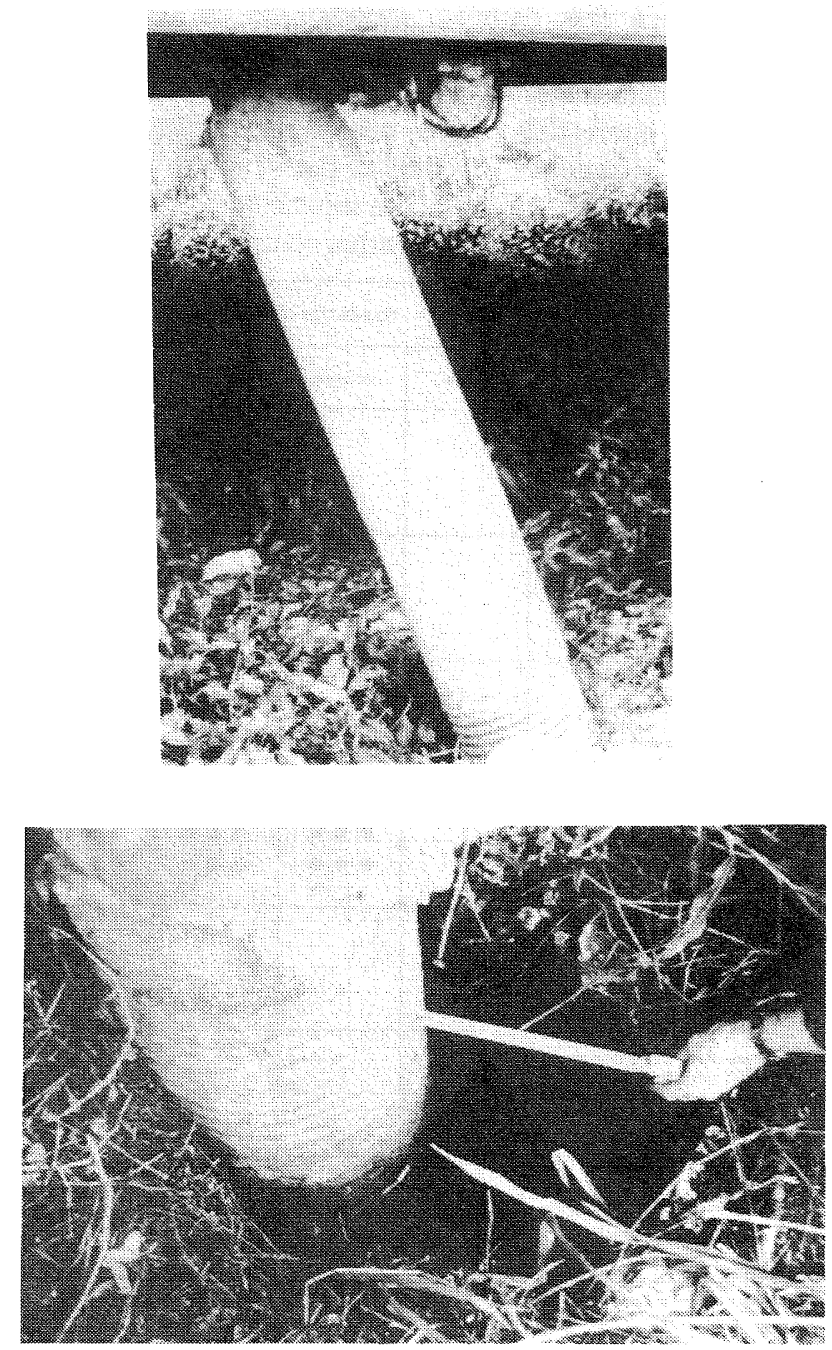

Fig. 2.4 Bridge foundation pile which failed laterally during the Loma Prieta earthquake in 1989. 

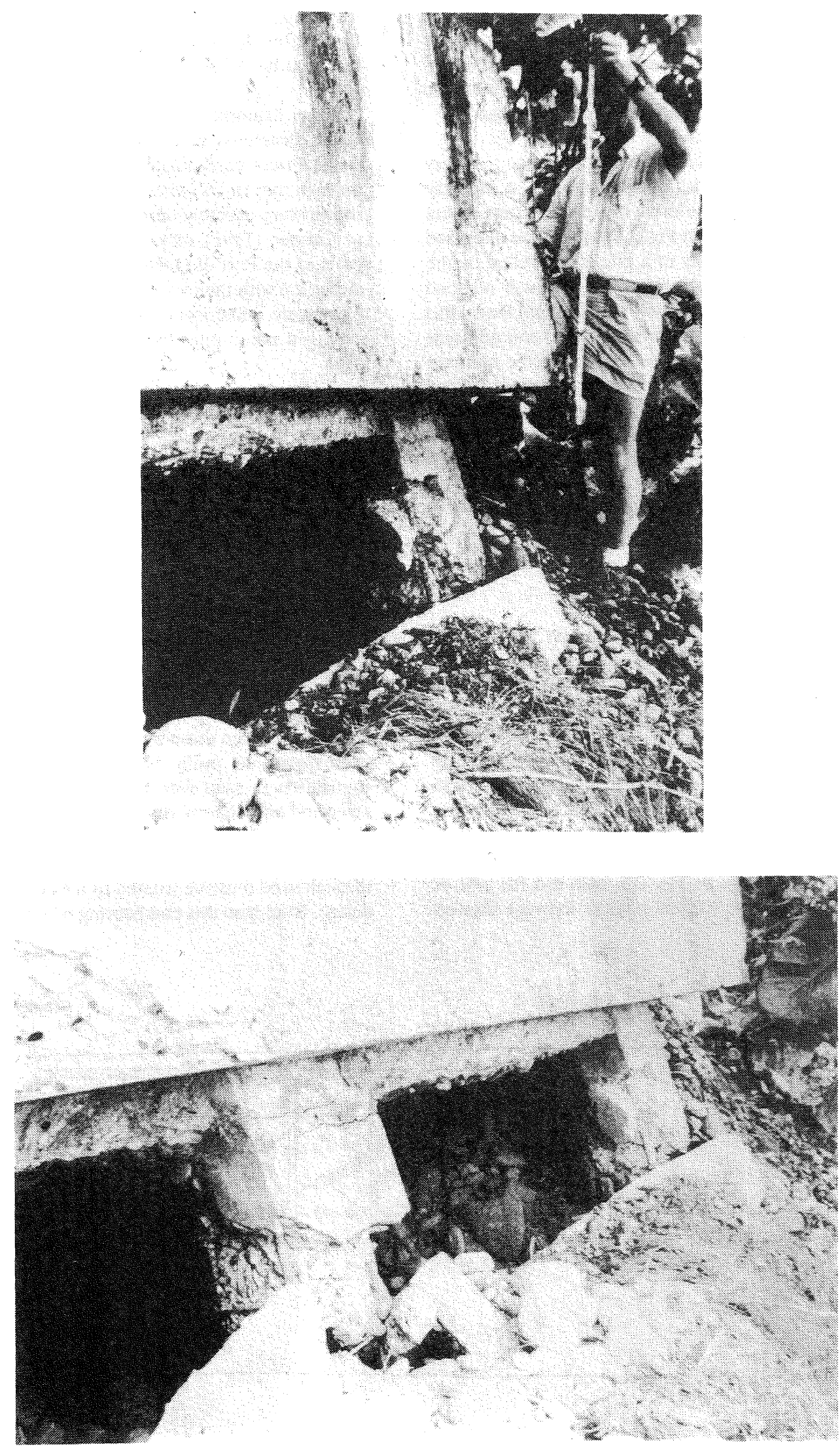

Fig. 2.5 Damage to the raked piles of the Rio Banano bridge abutment during the 1991 Costa Rican earthquake (after Priestley et al (1991)). 
Zeevaert (1991) discusses friction piles in clay, no doubt some of his recommendations are a consequence of the unusual soil conditions in Mexico City. However, similar conclusions should be valid for friction pile foundations in sand. (Note the discussion in section 2.2.1 for end bearing piles in sand.)

Pile failure is also possible under lateral loading. A very clear example, associated with the collapse of a highway bridge near Watsonville in California during the Loma Prieta earthquake in 1989, is shown in Fig. 2.4. As will be discussed in section 7 the lateral capacity of a pile is controlled by the ultimate capacity of the pile section. A pile will respond approximately elastically to relatively small lateral loads, this will be followed by nonlinear behaviour of the soil adjacent to the pile shaft for increasing loads, eventually the ultimate load is reached when the maximum bending moment carried by the pile shaft reaches the capacity of the section. At this load there is no limitation on deformation and failures such as that shown in Fig. 2.4 can occur. From the foundation performance point of view nonlinear pile-soil interaction might be acceptable but unlimited deformation at the pile head is not.

\subsubsection{Raked piles}

Margasen and Holloway (1977) comment on the damage experienced by raked piles during earthquakes. Large reaction forces seem to be generated at the pile head which causes cracking and spalling of the concrete. An example from a bridge foundation damaged in the 1991 Costa Rica earthquake is given by Priestley et al (1991). The abutments of the Rio Banano bridge were supported on two rows of 36 $\mathrm{cm}$ square driven precast concrete piles, the front row having a rake of 1:5. As a result of the earthquake the south abutment of the bridge was rotated $9^{\circ}$ by soil movement. The raked piles, illustrated in Fig. 2.5, suffered flexural as well as shear failures. The vertical piles at the rear showed less damage. Several other examples of damage to pile bridge foundations from the 1991 Costa Rica earthquake are also reported by Priestley et al (1991).

Another example of damage to raked piles comes from the wharf structures at the Port of Oakland during the 1989 Loma Prieta earthquake, Seed et al (1991). A cross-section through part of the wharf is given in Fig. 2.6, the raked piles shown were severely damaged in the earthquake. According to Cooper (1991) more modern wharf structures in other parts of the Port of Oakland were similar to those illustrated in Fig. 2.6 with the exception that they had vertical piles only, these were undamaged in the Loma Prieta earthquake. The damaged raked piles have since been replaced with vertical piles.

The bad seismic performance record for raked piles may be a consequence of incorrect assessment of the true seismic loads (early design methods estimated pile loads using simple graphical methods). The design of satisfactory raked pile foundations should be straightforward with proper estimates of the actions which will be generated during an earthquake.

\subsection{Observations of pile foundation stiffness behaviour during earthquakes}

\subsubsection{End bearing piles in sand}

Sands, other than those with very high relative densities, settle in response to cyclic shearing. If we have a pile-raft foundation in sand with the piles passing through the sand layer and end bearing on a stiffer stratum, then the sand will settle away from the underside of the raft creating a gap. Thus a pile raft-foundation with end bearing piles passing through sand must be treated as a free-standing structure for design. Note how this end bearing pile behaviour differs from

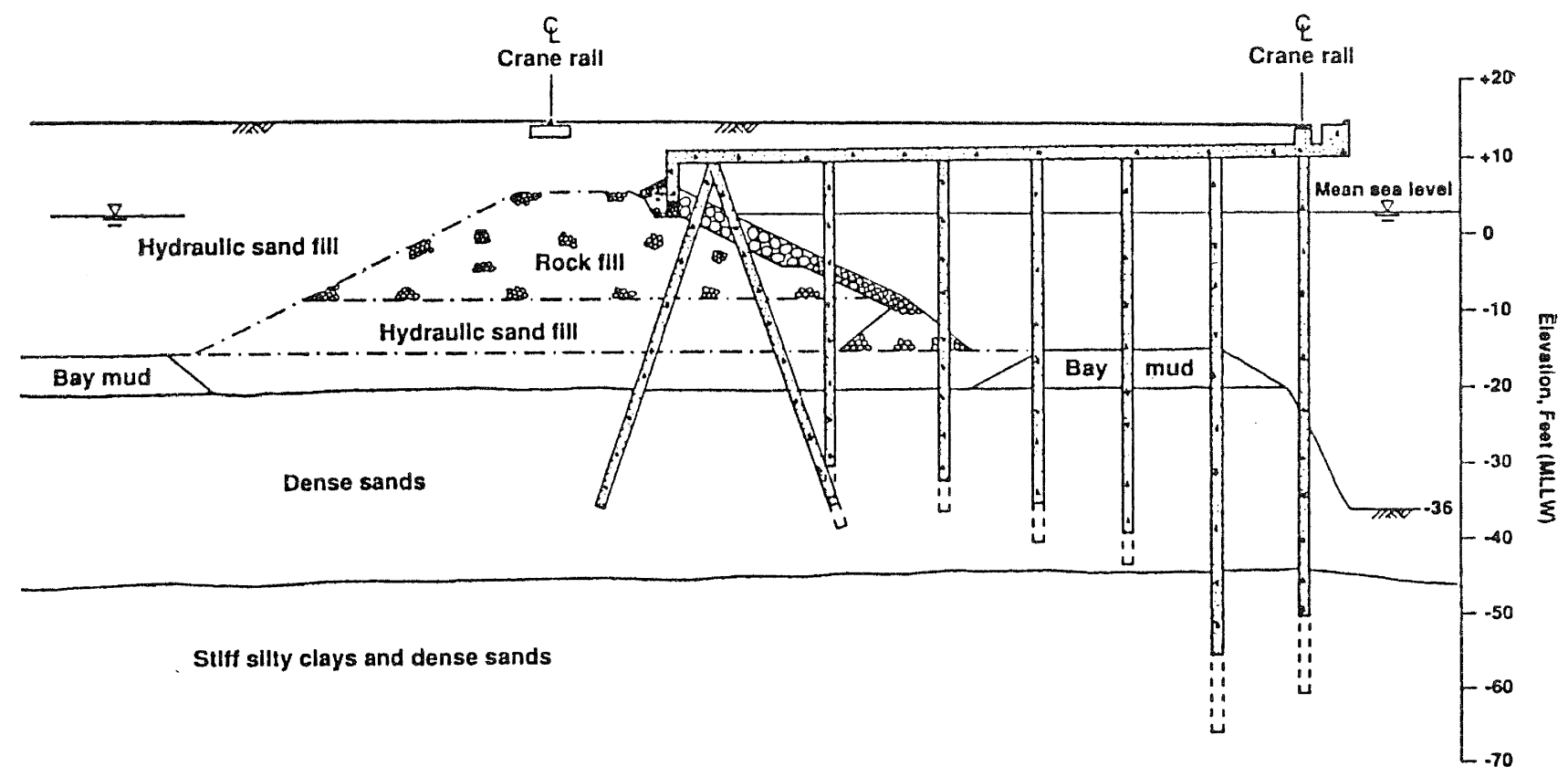

Fig. 2.6 Raked pile configuration of the Port of Oakland which was damaged in the 1989 Loma Prieta earthquake (after Seed et al (1991)). 
that for floating piles discussed in section 2.1.2.

Support for this comment comes from observations after the Edgecumbe earthquake, Pender and Robertson (1987). The ground surface adjacent to several piled structures in the Bay Milk complex in Edgecumbe was observed to have settled away from the foundation slab. Further evidence gained from observations in San Francisco following the Loma Prieta earthquake is given in Fig. 2.7. This photograph is of the side of a building in the South-of-Market region of the city in which the upper soil layers are known to consist of sand. The building is in two parts, a multi-storey section apparently founded on end bearing piles and an annex apparently supported with a shallow foundation. The colour change in the paint scheme gives a reference line which shows how the annex has settled about $150 \mathrm{~mm}$ relative to the piled structure. Further evidence of this type of behaviour in San Francisco was apparent with settlement of the pavement surface relative to the piled sewer lines which had been laid along the centre of some of the streets. The settlement caused the breakage of many sewer connections to adjacent buildings.

\subsubsection{Gapping}

Figure 2.8a shows a bridge foundation pier (diameter about $2 \mathrm{~m}$ ) in the vicinity of Watsonville in California after the Loma Prieta earthquake in 1989. It is evident that the cyclic loading has opened a gap at the ground surface and below between the pier shaft and the surrounding soil. Similar gapping for nearby timber piles is shown in Fig. $2.8 \mathrm{~b}$.

This phenomenon is discussed further in section 8.3.6.

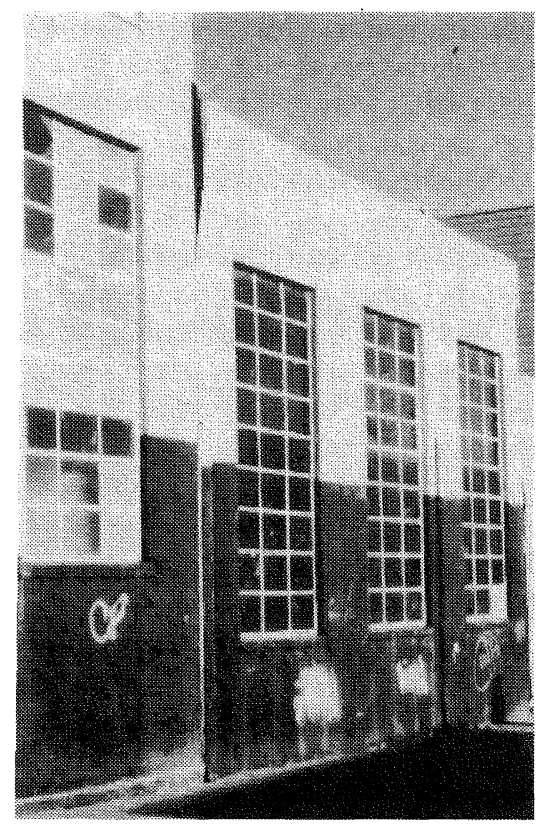

Fig. 2.7 Relative settlement between a pile supported structure and an annex with a shallow foundation in the South-of-Market area of San Francisco.

\subsubsection{Imperial County Services Building}

Hall (1984) reports on investigation of the foundation stiffness of the Imperial County Services building in El Centro California which was damaged in the 1979 earthquake (magnitude 6.3) and subsequently demolished. The details of the building and foundation are presented in Fig. 2.9, more information can be found in Hadjian et al (1990). At the base of each column is a $3 \times 3$ pile group with raked piles, all the pile caps were connected with tie beams. The piles extend

a

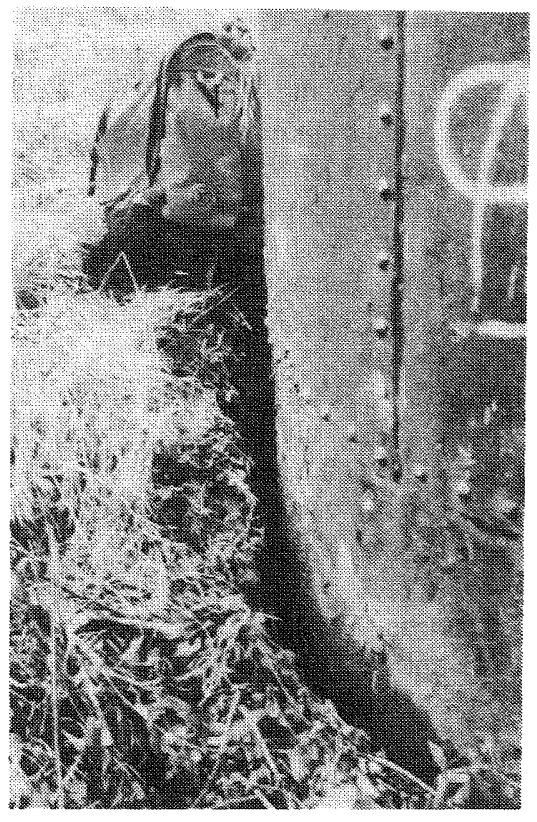

b

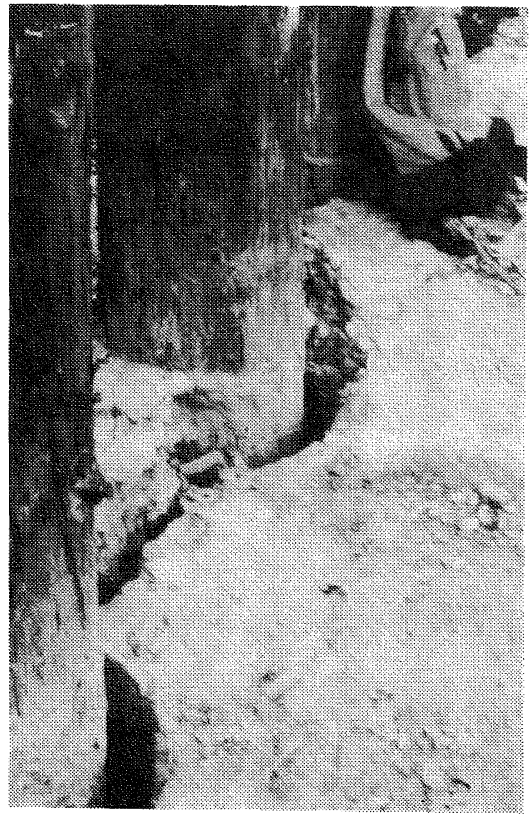

Fig. 2.8 Gapping after the Loma Prieta earthquake: (a) adjacent to a $2 \mathrm{~m}$ diameter bridge pier, and $(b)$ adjacent to timber piles at the foundations of a railway bridge near Watsonville. 
$14 \mathrm{~m}$ into the alluvium consisting of sand and clay layers. The shear wave velocity of the foundation soil at the pile caps was about $180 \mathrm{~m} / \mathrm{sec}$ increasing to about $400 \mathrm{~m} / \mathrm{sec}$ at the pile tips.

Forced vibration tests were done on two pile caps after the building had been demolished. The stiffnesses so obtained were used as part of the input for computing the response of the structure to the earthquake motion recorded at the ground floor level. The calculated response of various parts of the building was then compared with the recorded response. The response computed using the measured pile group dynamic stiffnesses differed in two ways from that recorded. Firstly the initial stiffness inferred from the recorded response indicated that the foundation stiffness was about half that from the pile cap tests. This is likely to be a consequence of much greater forces being applied to the pile caps during the earthquake shaking. Secondly during the course of the earthquake it appeared that there was a decrease in stiffness of the foundation by a factor of about 4 .

The free field peak ground acceleration, recorded at an instrument about $100 \mathrm{~m}$ from the building, was $0.21 \mathrm{~g}$ in the $\mathrm{N}-\mathrm{S}$ direction and $0.24 \mathrm{~g} \mathrm{E}-\mathrm{W}$. At the west end of the structure the PGA was $0.34 \mathrm{~g}$ in the N-S direction and $0.33 \mathrm{~g}$ E-W. At the east end the recorded PGA was $0.29 \mathrm{~g}$. Hadjian et al (1990) present a plot of the ratio of the response spectra obtained from E-W motions recorded at the base of the structure and from the free field instrument. The ratio is close to unity for frequencies up to $2 \mathrm{~Hz}$, for higher frequencies it
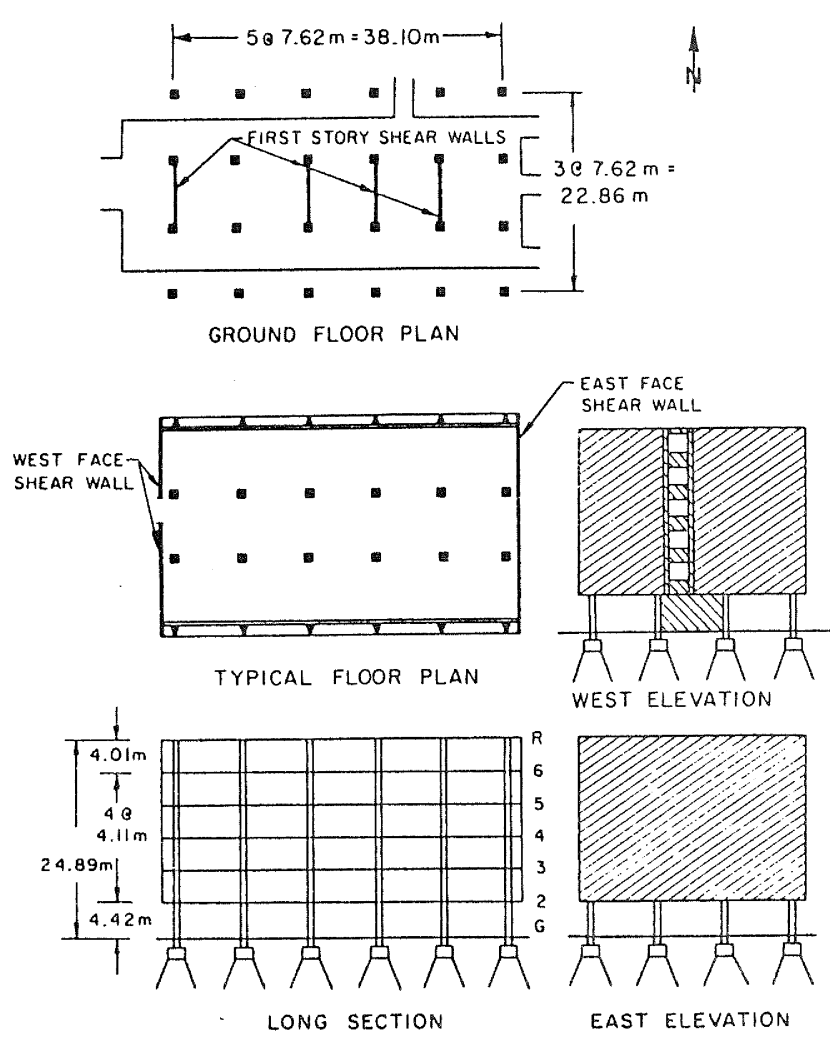

Fig. 2.9 Configuration of the Imperial County Services Building (after Hall (1984)). has a maximum value a little greater than 2 .

\subsubsection{Japanese observations}

A number of very important measurements have been made in Japan on the response of piled foundations during earthquakes. Recordings have been made at the pile head and also of the adjacent free field and in some cases the motion at the base of the piles has also been recorded. We will discuss four examples to illustrate the general trend of the results.

Hagio et al (1977) present observations of the seismic response of three towers mounted on a common concrete base mat which in turn is founded on end bearing steel tube piles driven through a complex soil profile. The base mat is $15.8 \mathrm{~m}$ by $8.6 \mathrm{~m}$, the piles are $400 \mathrm{~mm}$ in diameter and $45 \mathrm{~m}$ long, and the towers are 50,30 and $15 \mathrm{~m}$ in height. The details of the structure and soil profile are shown in Fig. 2.10. Also shown in Fig. 2.10 are the positions of the various instruments for recording the earthquake response of the structure and ground. A "free field" instrument is located at the ground surface about $20 \mathrm{~m}$ from the structure. Over a 15 month period from the beginning of 1974 forty earthquakes were recorded with peak horizontal ground surface accelerations up to $0.03 \mathrm{~g}$.

Figure 2.11 plots the Fourier spectral amplitude ratio of the horizontal motion at the side of the base mat (instrument FH1) to that of the ground surface (instrument S00) about 25 $\mathrm{m}$ from the structure. For periods up to about $0.5 \mathrm{sec}$. the spectral amplitude of the base mat is seen to be about half that of the ground surface.

Abe et al (1984) present result of monitoring the earthquake performance of 2 storey building founded on a deep deposit of sandy silt. Instruments instalied in the building and at various depths in the soil profile recorded 40 earthquakes in an 18 month period from 1982 . The recorded peak ground accelerations ranged from between 0.008 to $0.075 \mathrm{~g}$. The building configuration, soil profile, and instrument locations are shown in Fig. 2.12. A string of "free field" instruments is 5 to $10 \mathrm{~m}$ from the corner of the building. The piles extend to a depth of $45 \mathrm{~m}$ and are 1.0 and $1.1 \mathrm{~m}$ in diameter. The ratio of the "free field" Fourier spectral amplitudes between a depth corresponding to the base of the piles (G3) and close to the ground surface (G1) was essentially unaffected by the construction of the building. Fig. $2.13 \mathrm{a}$ shows a noticeable decrease in amplification as PGA increases, the largest spectral ratios in the figure correspond to a PGA of $0.013 \mathrm{~g}$ and the solid line, the lowest, is for an earthquake having a PGA of $0.075 \mathrm{~g}$. Figure $2.13 \mathrm{~b}$ gives the Fourier spectral ratio between the top of the piles (B2) and the free field (G1), a noticeable effect of PGA on the peak amplification is apparent and also period shifts.

Kawamura et al (1977) report on the response of a multistorey pile supported building during a number of small earthquakes. The details of the building and soil profile are reproduced in Fig. 2.14. A string of "free field" instruments is located $15 \mathrm{~m}$ from the side of the building. The building has 


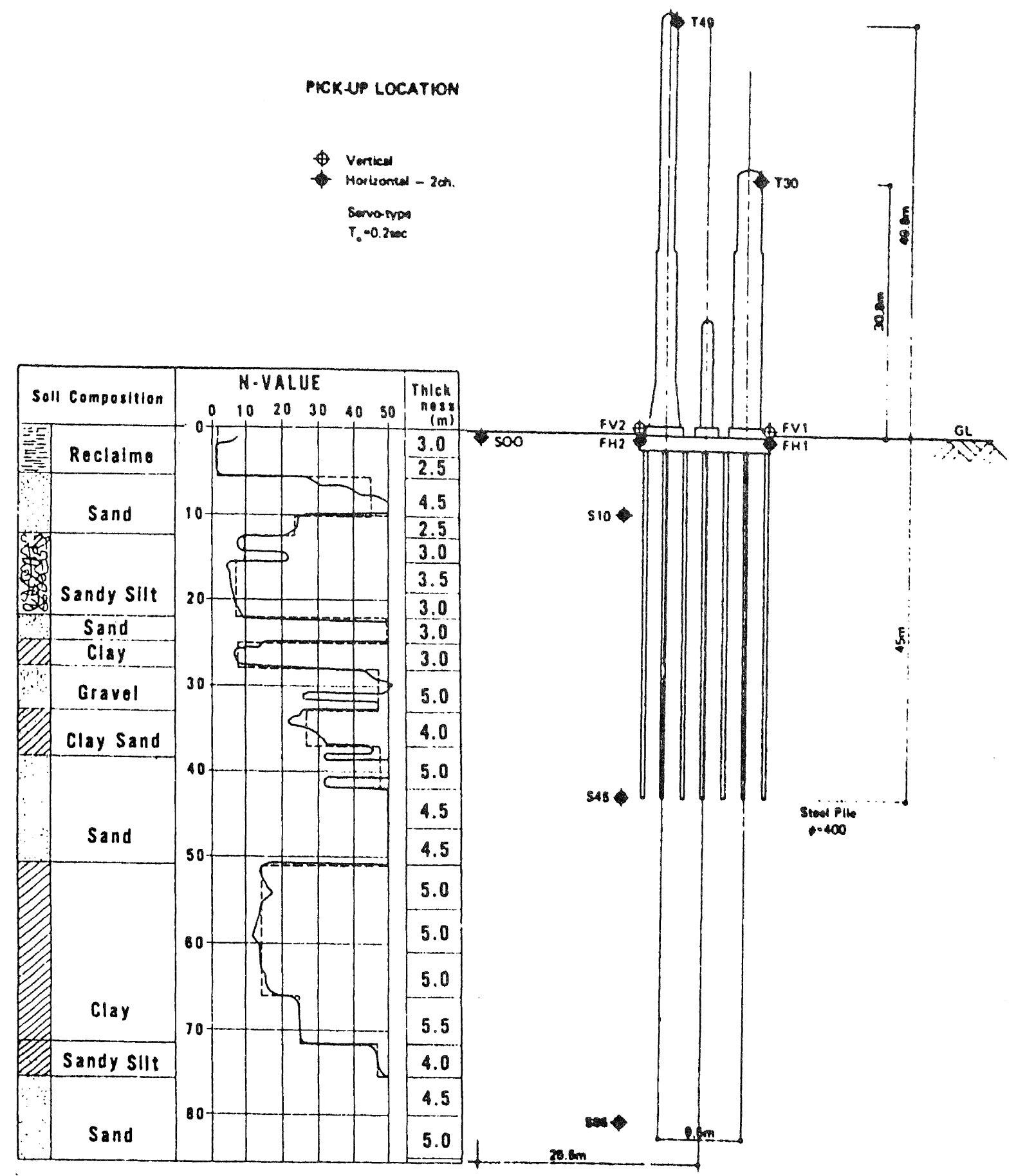

Fig. 2.10 Tower configuration, soil profile, and instrument positions for the structure monitored by Hagio et al (1977). 


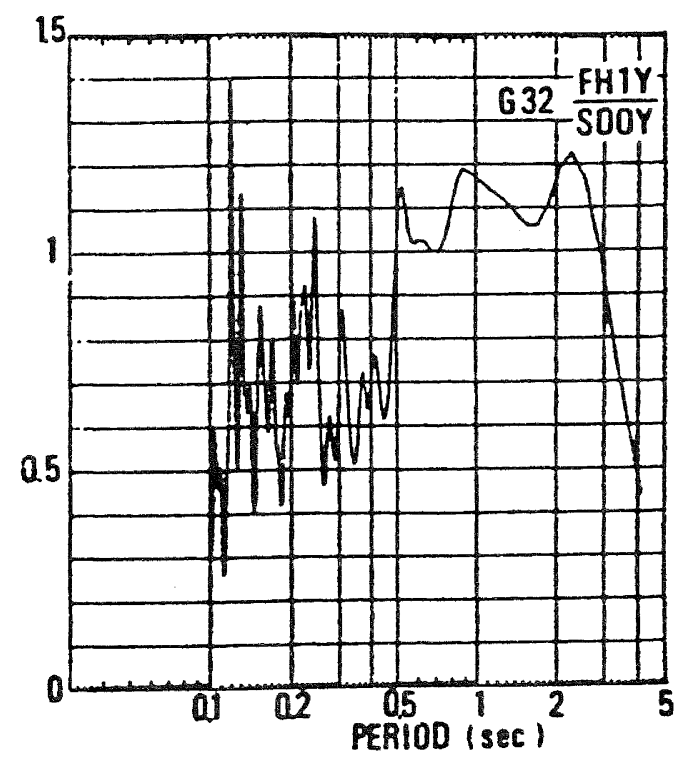

Fig. 2.11 Fourier spectral amplitude ratio between the horizontal motion at the base mat and the adjacent ground surface (after Hagio et al (1977)).

no basement and supported on precast piles driven to a dense sand layer at a depth of $12 \mathrm{~m}$. In all 80 earthquakes had been recorded up to the time of writing the paper, these were very small events with peak ground accelerations up to about $0.008 \mathrm{~g}$. The ratio of the Fourier amplitude spectra at the foundation and free field shown in Fig. 2.15 gives values less than unity up to a period of about 0.3 secs.

Ohira et al (1984) and Tazoh et al (1988a and 1988b) present results of the monitoring of the earthquake response of the pile group foundation for a major bridge structure. The details of the bridge, instrumentation and soil profile are presented on Fig. 2.16. For this case "free field" instruments are located $70 \mathrm{~m}$ and $98 \mathrm{~m}$ to the side of the bridge. Fig. 2.17 shows the Fourier amplitude spectra of the recorded motions in two directions for the free field and the top of the pile group. For periods up to about 2 seconds the response at the top of the pile foundation is less than that at the surface of the soil profile.

The recorded ground motions discussed in this section have small peak ground accelerations, the maximum value was $0.075 \mathrm{~g}$, consequently the soil-pile interaction will have been elastic with perhaps minor excursions into nonlinear behaviour. The seismic response of the four pile group foundations illustrated in Figs. 2.10 to 2.17 show that the pile group response is less than that of the adjacent ground surface at high frequencies. Conversely the observed seismic response at the foundation level of the Imperial County Services building was greater than that of the adjacent free field. This topics are discussed further in section 8.3.7. 


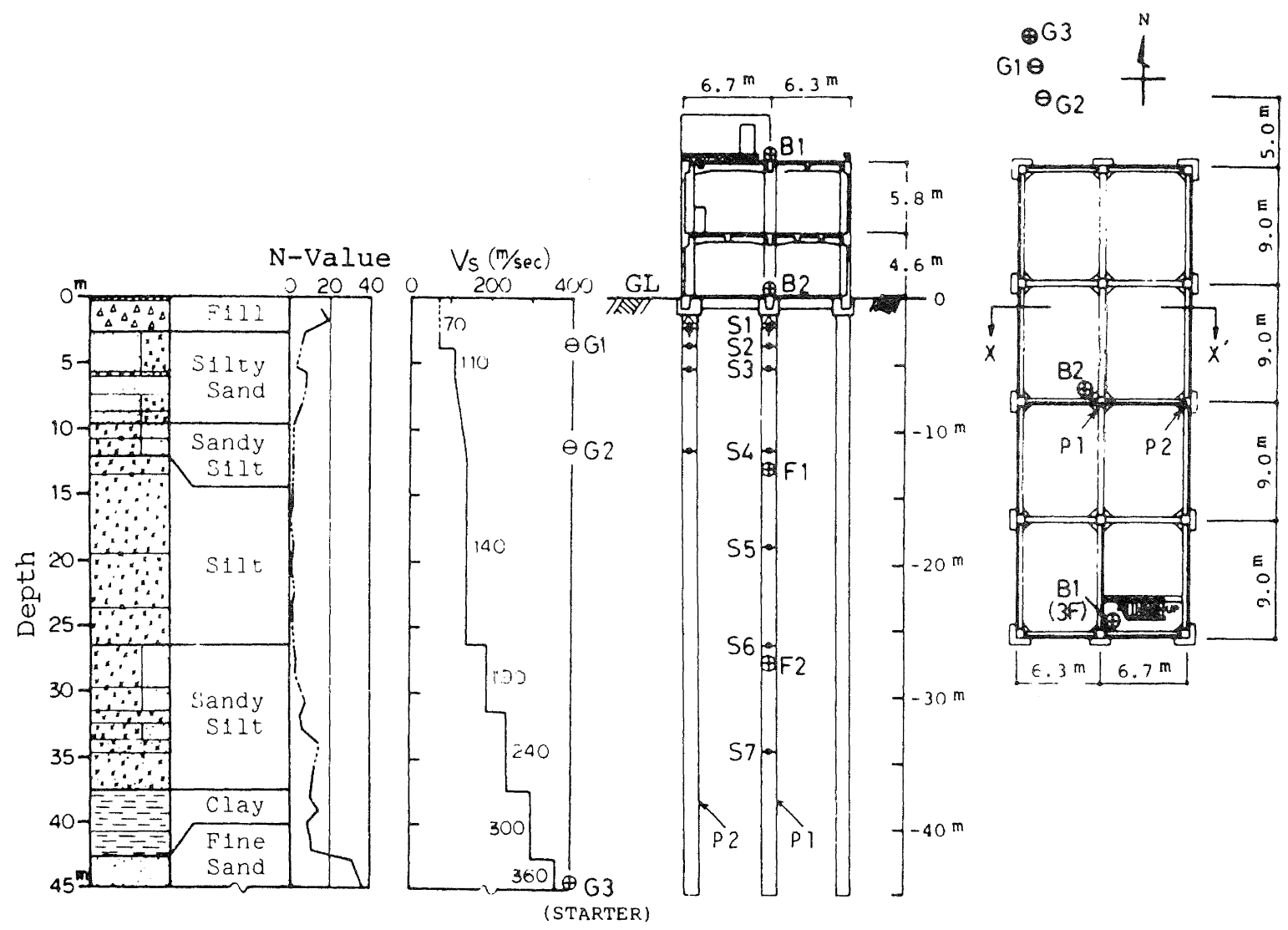

Fig. 2.12 Structural configuration, soil profile, and instrument positions for the building monitored by Abe et al (1984).

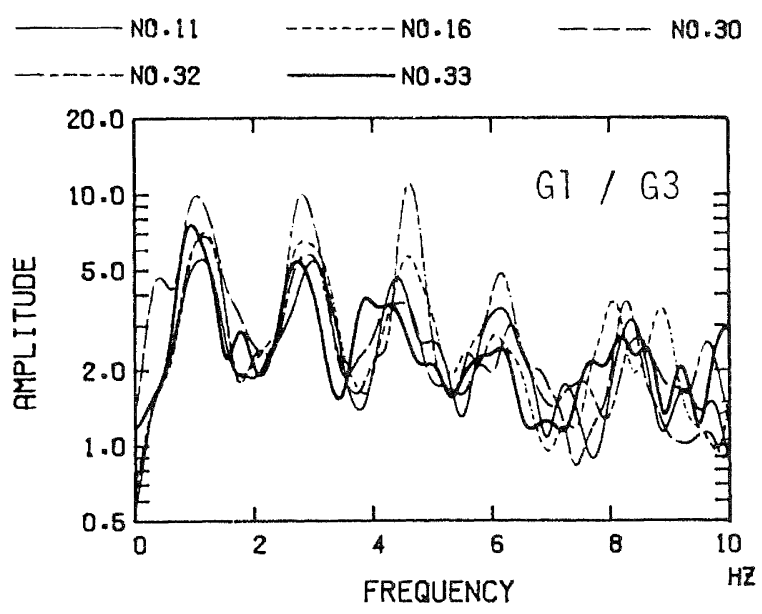

a

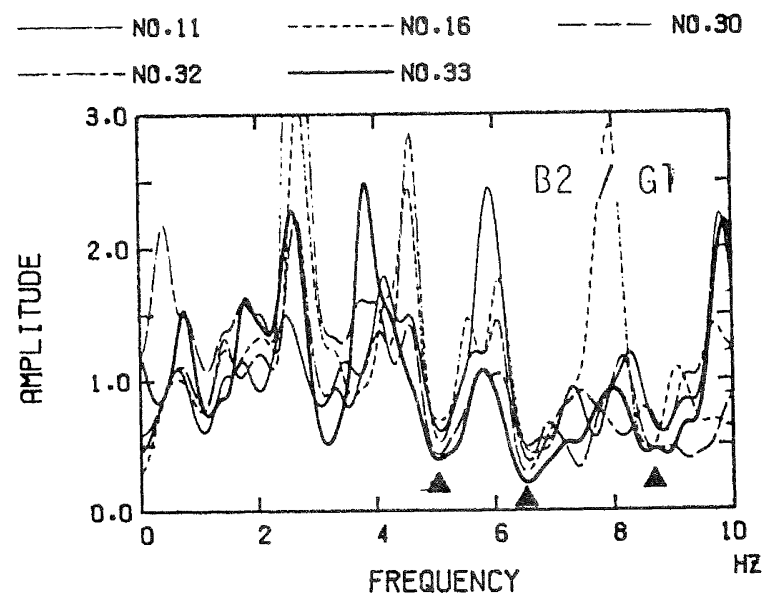

b

Fig. 2.13 Ratios of Fourier amplitude spectra; (a) G1/G3, (b) B2/G1, (PGA for record No.11 = 23.6, 16=15.9, 30 $=11.4,32=13.3$ gal.), (after Abe et al (1984)). 

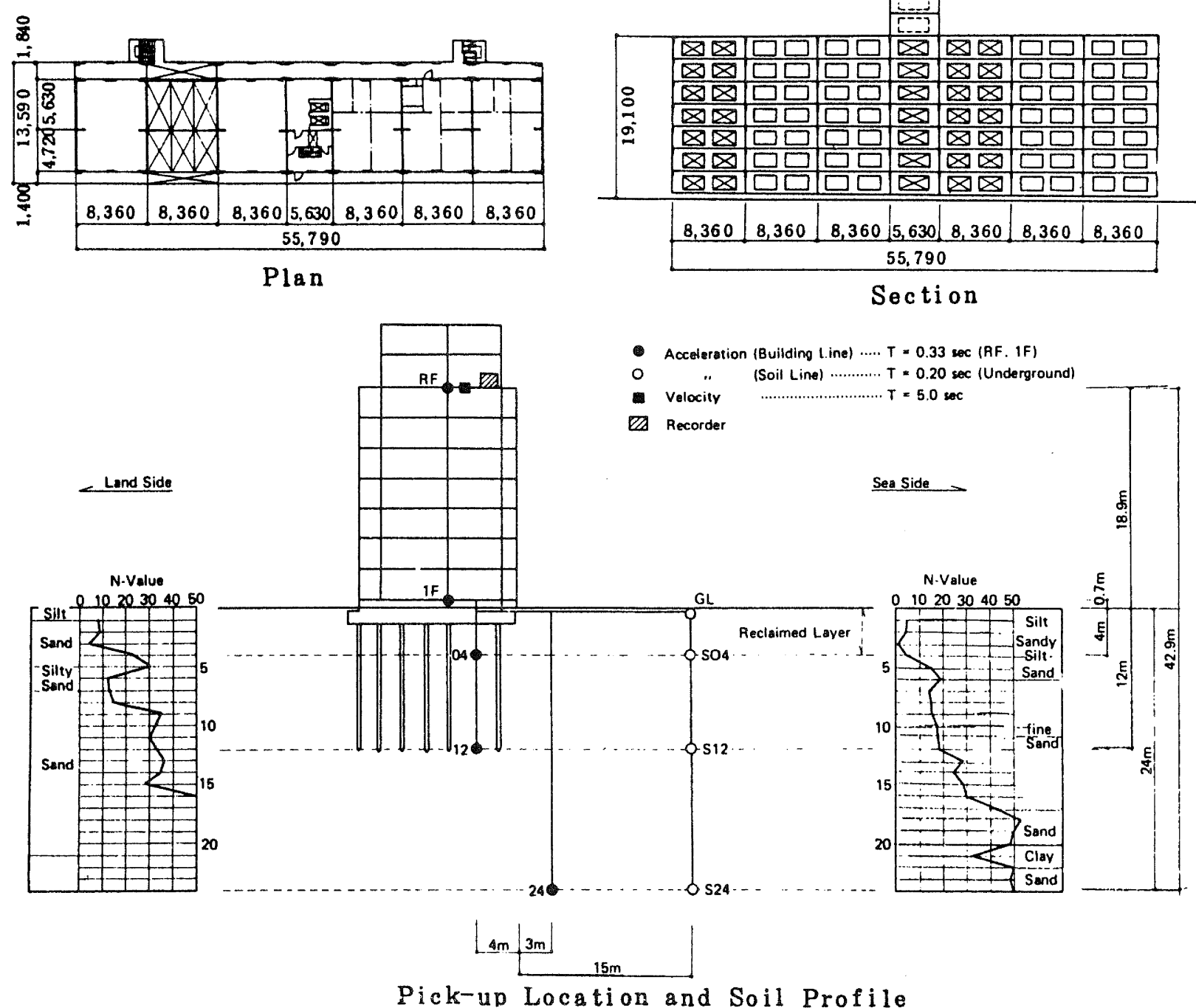

Fig. 2.14 Building details, soil profile and instrument locations for the structure monitored by Kawamura et al (1977).

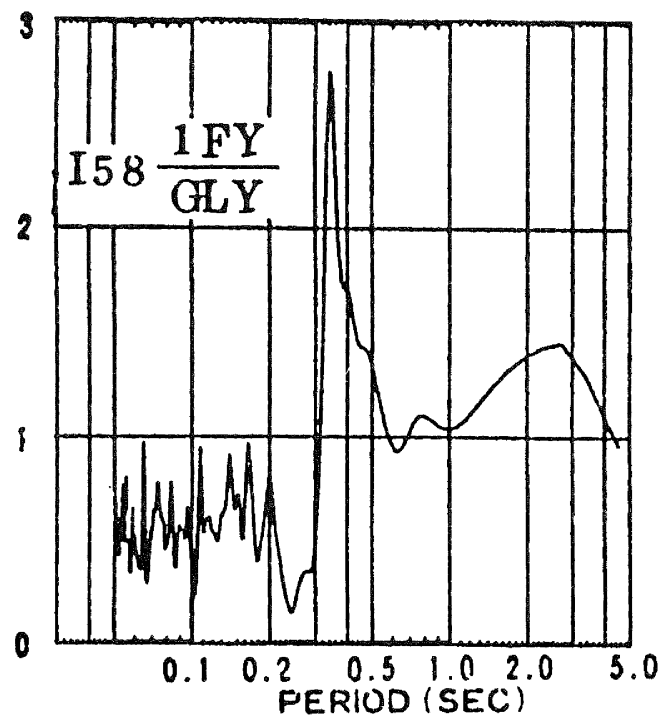

Fig. 2.15 Fourier amplitude spectral ratio for the horizontal motions at the foundation to that of the ground surface (after Kawamura et al (1977)).

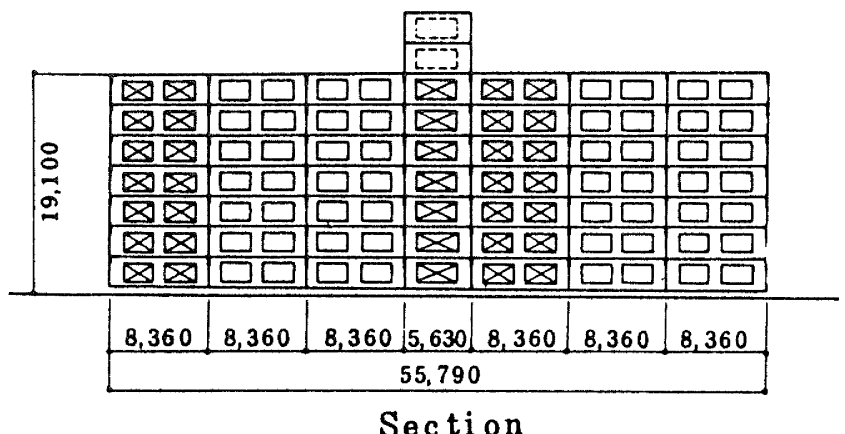

- Acceleration (Building t.ine) ..... T $=0.33 \sec$ (AF. IF)

$0.20 \mathrm{sec}$ (Underground)

Recorder 

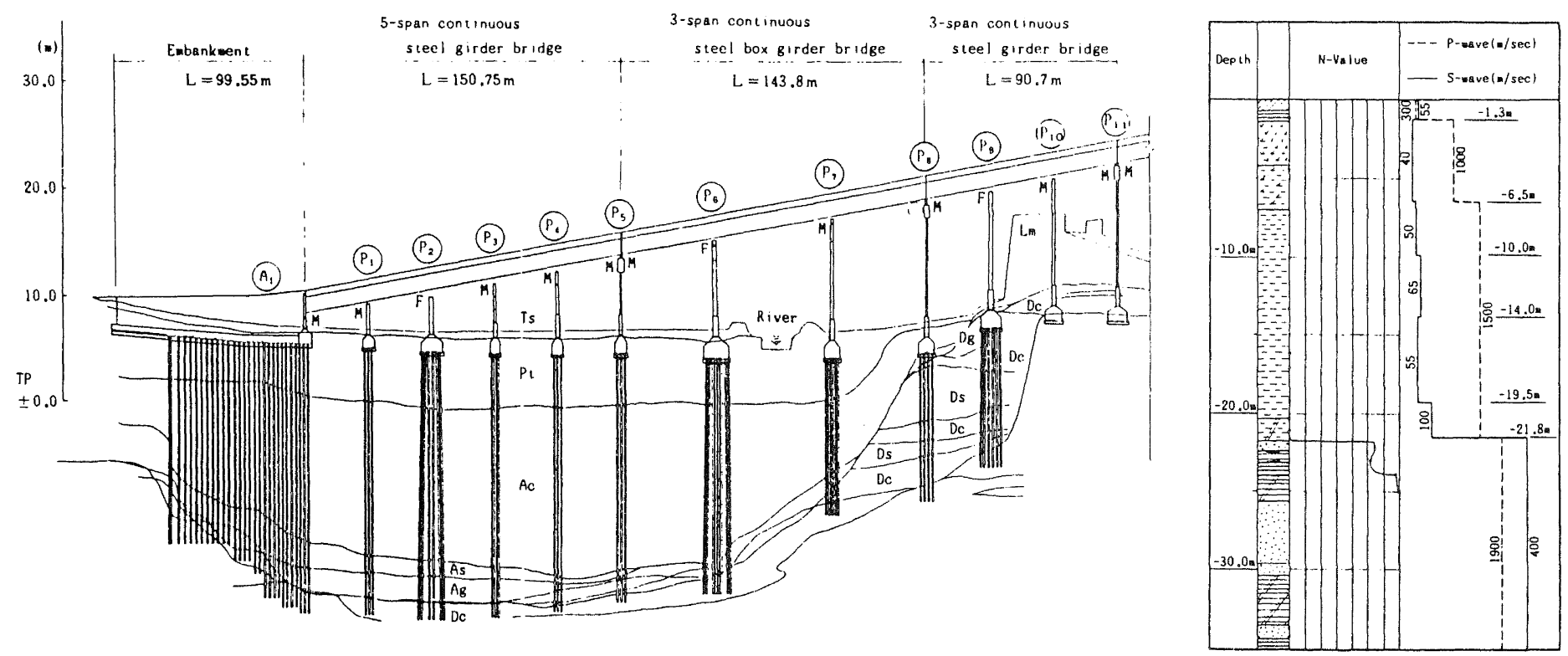

Soil conditions
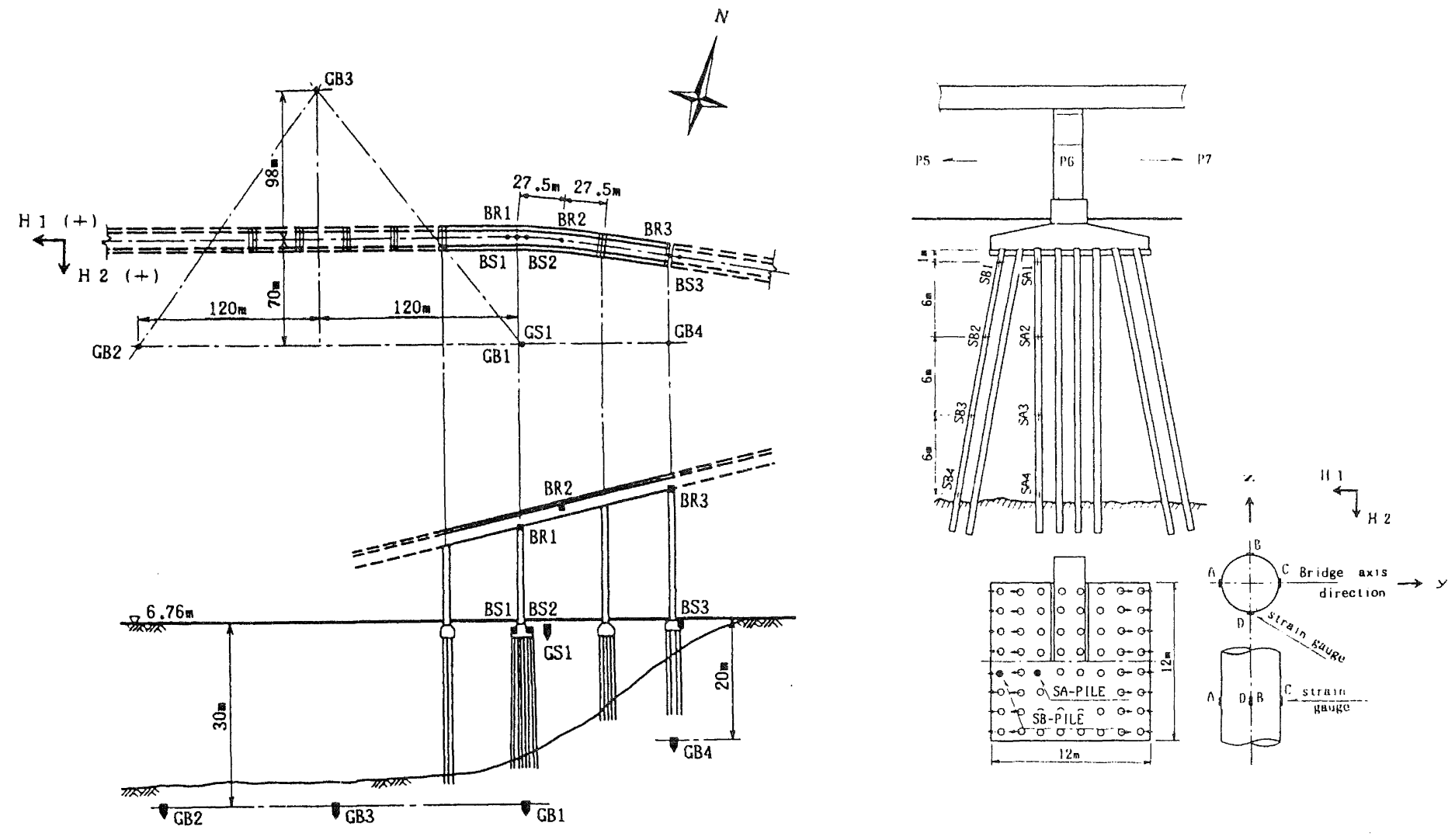

Installation of accelerometers

Installations of strain meters

Fig. 2.16 Structural details, soil profile and instrument locations for the bridge monitored by Ohira et al (1984). 

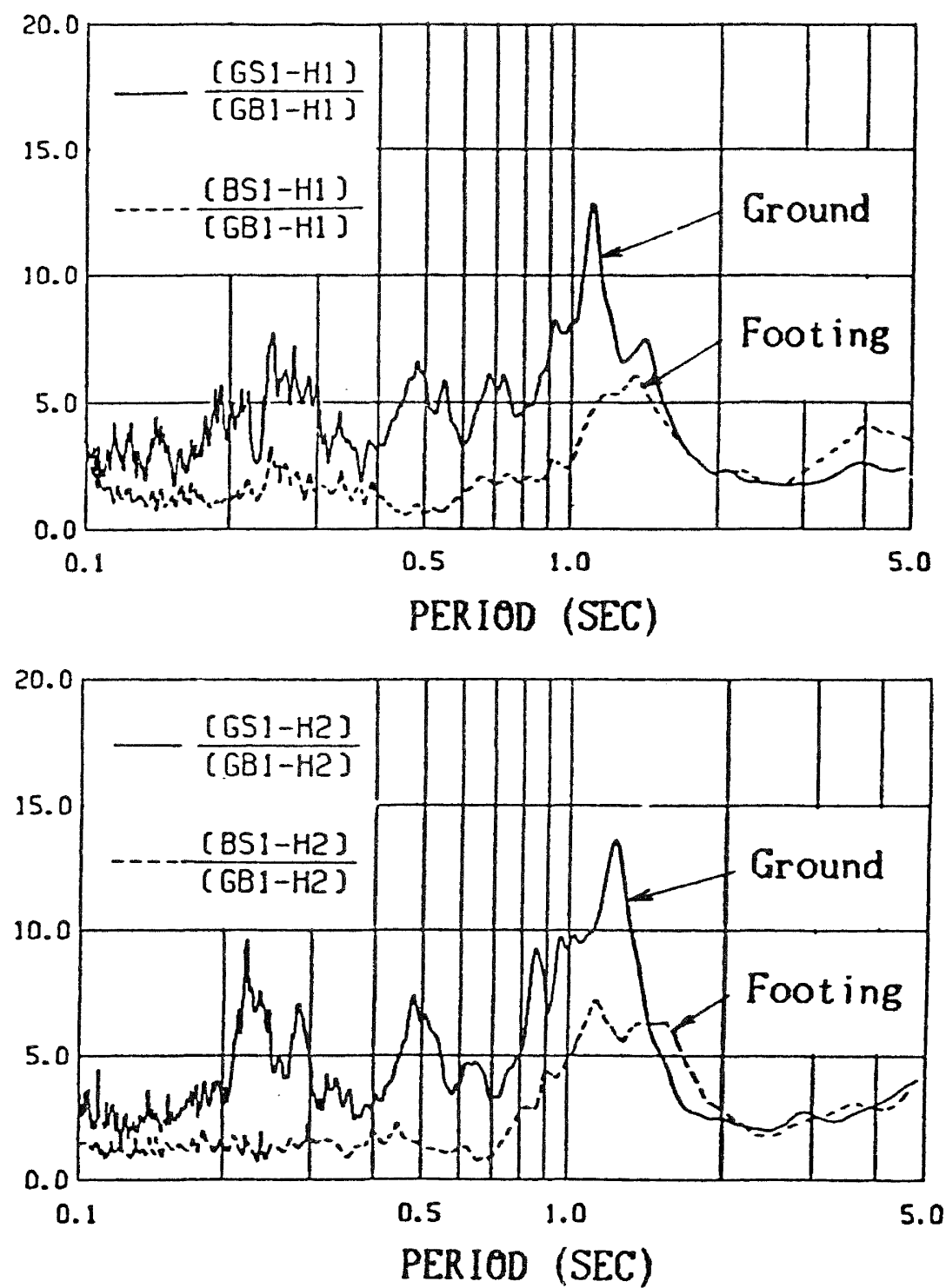

Fig. 2.17 Fourier amplitude spectral ratios for the horizontal motions at the foundation and the ground surface with respect to the recorded motion at the base of the piles (after Ohira et al (1984)). 


\subsection{STANDARD MODELS FOR PILE LATERAL STIFFNESS}

There are two standard linear models for estimating the behaviour of laterally loaded piles. These are the elastic continuum approach, which envisages the soil in which the pile is embedded to be a continuous elastic medium in which stresses and displacements spread outward and diminish with distance from the point of application of a force, and the Winkler model, which is a bed of independent and discrete springs. Both are considered herein. The elastic model has resulted in a number of simple equations which are easily evaluated and hence useful for preliminary design. The Winkler model is useful for soil profiles which are highly inhomogeneous because of complex layering. In recent years the Winkler model has been useful in coming to an understanding of the dynamic response of pile groups.

\subsection{Winkler Model}

\subsubsection{Background}

In this case the soil surrounding the pile shaft is modelled as a bed of independent springs. Thus the displacement of one spring has no effect on any other spring. In this way the Winkler model greatly simplifies the mathematical analysis at the expense of neglecting the continuity of the soil in which the pile is embedded. The analysis is based on an equation relating the displacement at a given point to the contact pressure at that point. Thus:

$$
\mathrm{p}=\mathrm{k}_{\mathrm{S}} \mathrm{w} \text {. }
$$

where: $\mathrm{p}$ is the contact pressure, $\mathrm{w}$ is the deflection,

$\mathrm{k}_{\mathrm{S}}$ is the coefficient of subgrade reaction.

When examining the behaviour of a pile embedded in a Winkler medium, we are usually interested in the distributed reaction, i.e. load per unit length, rather than the pressure, so the coefficient of subgrade reaction is multiplied by the width of the pile. For a pile of width $\mathrm{D}$ the product $\mathrm{k}_{\mathrm{S}} \mathrm{D}$ is called the modulus of subgrade reaction and is denoted by $\mathrm{k}$.

It is important to distinguish the units associated with the various approaches to the Winkler model. For an isolated spring, the force and displacement are related by the spring stiffiness: $\mathrm{F}=\mathrm{Kw}$ (or $\mathrm{F}=\mathrm{K} \delta$ ).

For a Winkler medium, the pressure and the displacement are related by the coefficient of subgrade reaction, equation 3.1 .

For a pile in a Winkler medium, the load per unit length (i.e. pressure $\mathrm{x}$ width), $\mathrm{q}$, and displacement are related by the modulus subgrade reaction:

$$
\mathrm{q}=\mathrm{pD}=\mathrm{k}_{\mathrm{S}} \mathrm{wD}=\mathrm{kw} \text { thus } \mathrm{k}=\mathrm{k}_{\mathrm{S}} \mathrm{D} \quad 3.2
$$

The three parameters thus have the following units and common symbols:
Stiffness:

K

$\mathrm{FL}^{-1}$

Coefficient of Subgrade reaction: $\mathrm{k}_{\mathrm{S}}$

Modulus of Subgrade reaction:

$\mathrm{k}$

$\mathrm{FL}^{-2}$

The terminology used in the literature for $\mathrm{k}_{\mathrm{S}}$ and $\mathrm{k}$ can be confusing. Some authors refer to $\mathrm{k}_{\mathrm{S}}$ (units: $\mathrm{FL}^{-3}$ ) as the soil modulus or modulus of subgrade reaction whilst others call it the coefficient of subgrade reaction. The term coefficient seems preferable for $\mathrm{k}_{\mathrm{S}}\left(\mathrm{FL}^{-3}\right)$ and modulus for $\mathrm{k}\left(\mathrm{FL}^{-2}\right)$, if only to keep the units for a parameter referred to as a modulus consistent with the usage of the word modulus associated Young's modulus or the shear modulus. This is followed herein.

The solution for the pile in a Winkler medium is expressed in terms of the following parameter:

$$
\lambda=\sqrt[4]{\frac{k}{4 E_{p} I_{p}}}
$$

where: $E_{p}$ is the Young's modulus for the pile material, and $\quad I_{p}$ is the second moment of area of the pile section.

The parameter $\lambda$ has dimensions $\mathrm{L}^{-1}$ and is a function of both the properties of the subgrade and the pile. When the pile is very stiff in comparison with the surrounding soil, $\lambda$ is small and a load at the pile head will cause deformations a considerable distance from the pile head. Alternatively, for a pile which is flexible relative to the subgrade $\lambda$ is large and a load will have only a local effect on the deflections and stresses.

Hetenyi (1946) has suggested the following classification of beam stiffness, based on the parameter $\lambda \mathrm{L}$ (where $\mathrm{L}$ is the length of the beam):

$\begin{array}{llr}\text { I } & \text { Short beams: } & \lambda \mathrm{L} \leq \pi / 4 ; \\ \text { II } & \text { Beams of medium length: } & \pi / 4<\lambda \mathrm{L} \leq \pi ; \\ \text { III } & \text { Long beams: } & \lambda \mathrm{L}>\pi .\end{array}$

For beams or piles in Group I, the bending can be neglected since this is very small in comparison with the deformation of the surrounding soil. Thus design can proceed on the basis that the pile is rigid so the displaced shape is simple and consequently the reaction pressures are easily evaluated. For piles of group III, the flexibility is such that when a load is applied at one end there is no carry over to the other. The intervening group II requires a more elaborate solution as actions applied at one end of the beam have a carry over effect at the other.

In the next section solutions are presented for a semi-infinite beam on a Winkler subgrade. Hetenyi (1946) and Lee and Harrison (1970) give solutions for a variety of finite beam cases.

\subsubsection{The Semi-infinite beam}

The semi-infinite case is a first approximation to a long pile. The solution, with $\mathrm{z}$ increasing from zero at the pile head, is 
A positive moment produces a horizontal displacement and rotation of the pile head in the same sense as positive horizontal force at the pile head.

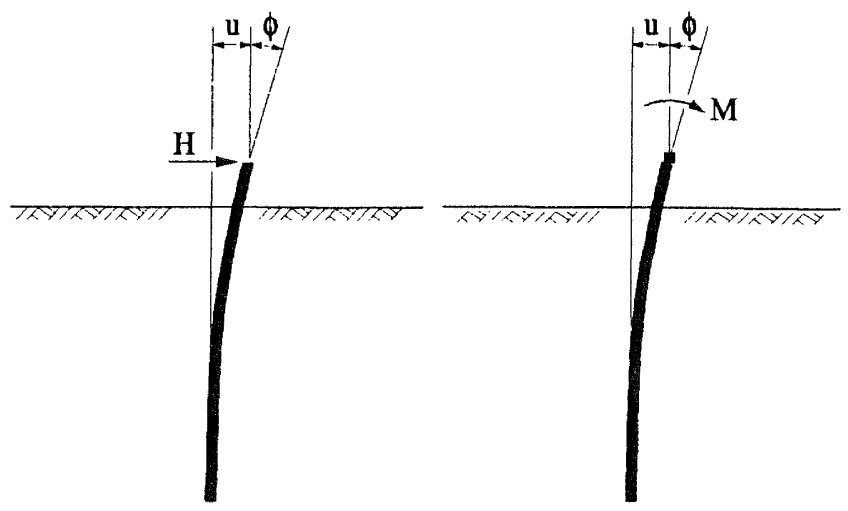

Fig. 3.1 Sign convention for positive actions and displacements at a pile head.

given by Scott (1981). The sign convention for positive actions at the pile head is given in Fig. 3.1. The sign convention in Fig. 3.1 is different from that used by Hetenyi and Scott. It might seem rather casual not to be concerned about the direction of a positive shear force, but as we are concerned about cyclic actions it is the maximum value rather than the direction which is of greatest concern. The reason for using a sign convention that is different from that in the standard literature on the Winkler model is to accommodate an important pile loading situation; that is when a horizontal force is applied to the pile shaft some distance above the ground surface. The deflection and rotation at the ground surface then each have components from the shear force and the moment induced at the ground surface, our sign convention needs to be such that each of these displacement components has the same sign. The equations below use the following relationships: slope: $\phi=\mathrm{du} / \mathrm{dz}$, moment: $\mathrm{M} / \mathrm{EI}=$ $\mathrm{d} \phi / \mathrm{dz}$, and shear: $\mathrm{S}=\mathrm{dM} / \mathrm{dz}$. For a positive head displacement the slope is always negative at the pile head because the displacement decreases as $\mathrm{z}$ increases. For consistency with what comes below we wish the rotation at the pile head to be positive. This is achieved by defining the rotation of the pile section to be equal and opposite to the slope, i.e. $\theta=-\phi$.

For a horizontal load, $\mathrm{H}$, applied to the pile head the variations of displacement etc. along the pile shaft are given by:

$$
\begin{gathered}
\mathrm{u}(\mathrm{z})=\frac{2 \lambda \mathrm{H}}{\mathrm{k}}(\cos \lambda \mathrm{z}) \mathrm{e}^{-\lambda \mathrm{z}} \\
\theta(\mathrm{z})=\frac{2 \lambda^{2} \mathrm{H}}{\mathrm{k}}(\cos \lambda \mathrm{z}+\sin \lambda \mathrm{z}) \mathrm{e}^{-\lambda \mathrm{z}} \\
\mathrm{M}(\mathrm{z})=\frac{\mathrm{H}}{\lambda}(\sin \lambda \mathrm{z}) \mathrm{e}^{-\lambda \mathrm{z}} \\
\mathrm{S}(\mathrm{z})=-\mathrm{H}(\cos \lambda \mathrm{z}-\sin \lambda \mathrm{z}) \mathrm{e}^{-\lambda \mathrm{z}}
\end{gathered}
$$

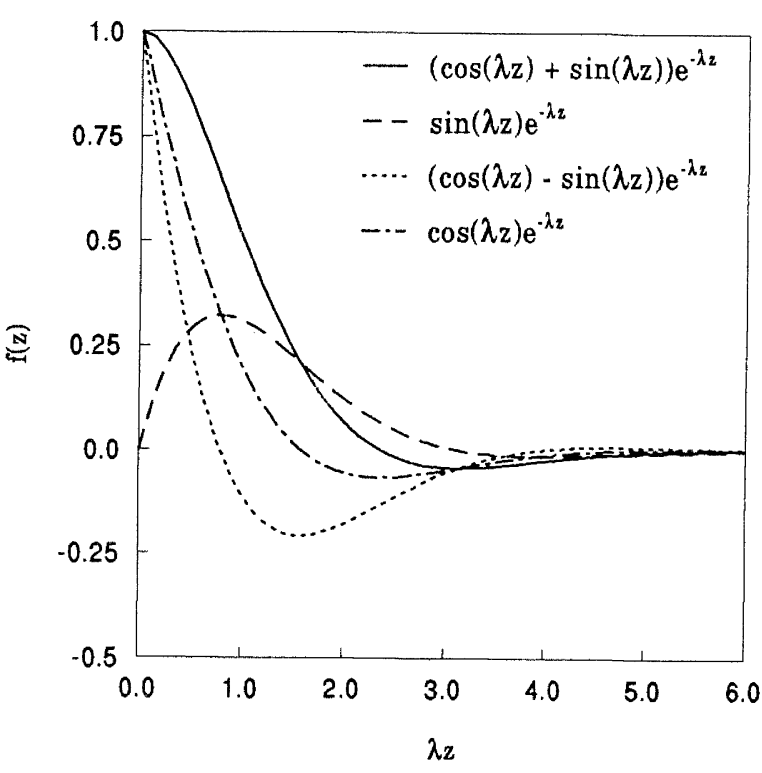

Fig. 3.2 Functions for the variation of displacement, slope, and moment and shear in a semi-infinite beam on a Winkler Subgrade.

where: $u(z)$ is the lateral displacement of the pile,

$\theta(\mathrm{z})$ is the rotation of the pile shaft (minus the slope),

$\mathrm{M}(\mathrm{z})$ is the bending moment,

and $S(z)$ is the shear.

For a semi-infinite pile loaded with a shear force the displacement of the beam depends on $\mathrm{k}^{-3 / 4}$, and thus varies almost directly with the reciprocal of $\mathrm{k}$, whereas the moment is much less sensitive to the coefficient, being related to $\mathrm{k}^{-1 / 4}$. The choice of the modulus of subgrade reaction is consequently more important for the calculation of displacements than moments.

For a moment, $\mathrm{M}$, applied to the pile head:

$$
\begin{gathered}
\mathrm{u}(\mathrm{z})=\frac{2 \lambda^{2} \mathrm{M}}{\mathrm{k}}(\cos \lambda \mathrm{z}-\sin \lambda \mathrm{z}) \mathrm{e}^{-\lambda \mathrm{z}} \\
\theta(\mathrm{z})=\frac{4 \lambda^{3} \mathrm{M}}{\mathrm{k}}(\cos \lambda \mathrm{z}) \mathrm{e}^{-\lambda \mathrm{z}} \\
\mathrm{M}(\mathrm{z})=\mathrm{M}(\cos \lambda \mathrm{z}+\sin \lambda \mathrm{z}) \mathrm{e}^{-\lambda \mathrm{z}} \\
\mathrm{S}(\mathrm{z})=-2 \lambda \mathrm{M}(\sin \lambda \mathrm{z}) \mathrm{e}^{-\lambda \mathrm{z}}
\end{gathered}
$$

The functions of $\lambda z$ occurring in equations 4 to 7 are the same as those in equations 8 to 11 , they are presented together in Fig. 3.2.

The location of the maximum moment, found from manipulation of equations 3.5 and 3.9 , is given by: 


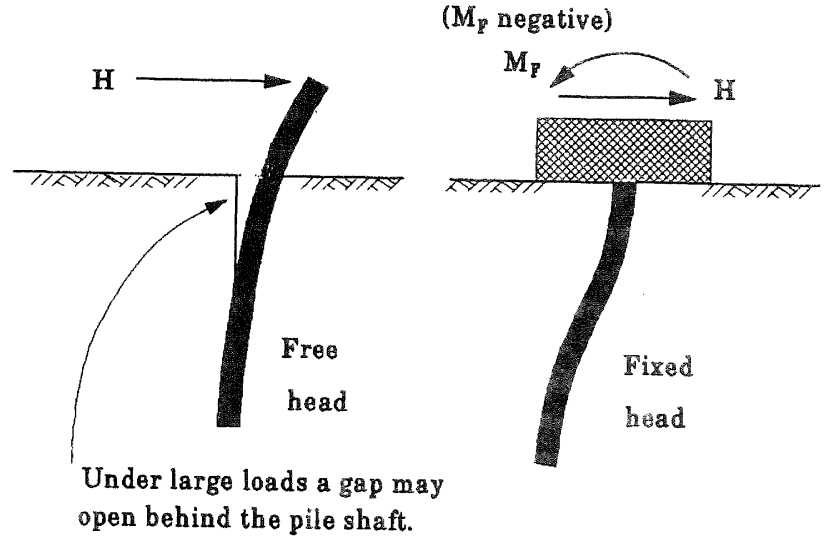

Fig. 3.3 Free and fuxed head piles.

$$
\lambda z=\tan ^{-1}\left(\frac{1}{1+2 \lambda \frac{\mathrm{M}}{\mathrm{H}}}\right)
$$

Substitution of this value into the above equations gives the maximum moment.

Example 3.1 Consider a reinforced concrete pile $0.75 \mathrm{~m}$ in diameter and $20 \mathrm{~m}$ in length. The Young's modulus for the pile is $25 \mathrm{GPa}$ and the modulus of subgrade reaction for the soil in which the pile is embedded is $31.4 \mathrm{MPa}$. Find the lateral displacement and rotation of the pile head when a horizontal force of $100 \mathrm{kN}$ and a moment of $150 \mathrm{kNm}$ are applied.

In line with common practice we will use the gross section properties to get the $I$ value: $I_{p}=\pi D^{4} / 64=0.0155 \mathrm{~m}^{4}$.

From equation 3.3 we have: $\lambda=(31.4 / 4 \times 25,000 \times 0.0155)^{0.25}$ $=0.38$ and $\lambda \mathrm{L}=0.38 \times 20=7.6$. Thus the pile is long and so we can use the semi-infinite equations to estimate the displacements. At the pile head $\lambda z=0$, so combining equations 3.4 and 3.8 we have for the lateral displacement:

$u=2 \times 0.38 \times 100 / 31.4+2 \times 0.38^{2} \times 150 / 31.4=3.8 \mathrm{~mm}$

and combining equations 3.5 and 3.9 gives the head rotation:

$\theta=2 \times 0.38^{2} \times 100 / 31.4+4 \times 0.38^{3} \times 150 / 31.4=1.9 \mathrm{mrad}$.

Note that by using $\mathrm{kN}$ units for the applied shear and moment and $\mathrm{MPa}$ for the modulus of subgrade reaction the displacement is in millimetres and the head rotation in mrad $\left(0.06^{\circ}\right)$.

From equation 3.12 the position of the maximum moment is:

$\lambda \mathrm{z}_{\mathrm{Mmax}}=\tan ^{-1}[1 /(1+2 \times 0.38 \times 150 / 100)]=0.44$

$\mathrm{z}_{\mathrm{Mmax}}=0.44 / 0.38=1.2 \mathrm{~m}$
Substitution of this into the combination of equations 3.6 and 3.10 gives the maximum moment:

$$
\begin{aligned}
M_{\max }= & {[(150+100 / 0.38) \times \sin (0.44)+150 \times \cos (0.44)] } \\
= & \times \exp (-0.44) \\
& 201 \mathrm{kNm} .
\end{aligned}
$$

\subsubsection{Free head and fixed head piles}

At the ground surface a pile may be free to rotate or connected to some structure so that rotation is constrained. These are the so-called free head and fixed head piles. The idea is illustrated in Fig. 3.3. For the fixed head pile a moment is required to enforce the compatability requirement that the rotation of the pile bead is equal to that of the pile cap. As can be seen from the diagram the fixing moment has the opposite sense to a moment caused by the application of the horizontal shear above the soll surface, thus it carries a negative sign.

The fixed head moment is obtained from the sum of equations 3.5 and 3.9 by setting the pile head rotation to zero, the fixed head displacement is then obtained by substitution of this moment into the sum of equations 3.4 and 3.8 . These operations give:

$$
M_{F}=-\frac{H}{2 \lambda} \quad, \quad u_{F}=\frac{\lambda H}{k}
$$

where: $\mathrm{M}_{\mathrm{F}}$ and $\mathrm{u}_{\mathrm{F}}$ are the fixing moment and lateral displacement of the pile head respectively.

Example 3.2 Rework example 3.1 when the pile has a fixed head and the applied horizontal shear is $100 \mathrm{kN}$.

From equation 3.13:

$\mathrm{M}_{\mathrm{F}}=-100 /(2: 0.38)=-132.6 \mathrm{kNm}$

$u_{\mathrm{F}}=0.38 \times 100 / 31.4=1.2 \mathrm{~mm}$.

3.2 Elastic continum approach

\subsubsection{Preliminaries}

A popular method for estimating the displacements of loaded piles is to assume that the soil in which the pile is embedded is an elastic material. Poulos and Davis (1980) present a considerable number of useful solutions of this type in chapters 5 and 6 of their book. Since then further developments have generated solutions for elastic displacements of piles in the form of a collection of simple equations. These are easier to use than the influence factor charts in Poulos and Davis. In addition the simple formulae lend themselves to spreadsheet and similar calculation methods.

In this section a number of such sets of equations are presented which give pile head displacements and rotations as well as maximum moments. 
For an elastic pile embedded in an elastic soil and loaded at the pile head the displacement $\mathrm{u}$ and the rotation $\theta$ at the ground line are given by:

$$
\begin{aligned}
& \mathrm{u}=\mathrm{f}_{\mathrm{uH}} \mathrm{H}+\mathrm{f}_{\mathrm{uM}} \mathrm{M} \\
& \theta=\mathrm{f}_{\theta \mathrm{H}} \mathrm{H}+\mathrm{f}_{\theta \mathrm{M}} \mathrm{M}
\end{aligned}
$$

where: $H$ is the applied horizontal load, $\mathrm{M}$ is the applied moment,

and $\mathrm{f}_{\mathrm{uH}}, \mathrm{f}_{\mathrm{uM}}, \mathrm{f}_{\theta \mathrm{H}}, \mathrm{f}_{\theta \mathrm{M}}$ are flexibility coefficients.

Note that, from the reciprocal theorem: $f_{\theta H}=f_{u M}$.

For a long pile (see below) the flexibility coefficients are functions of the ratio of the Young's moduli of the pile and the soil, the Poisson's ratio and Young's modulus of the soil, and the pile diameter. For short piles (see below) the pile length is also required in the expressions for the flexibilities.

The solutions presented below have been obtained from the results of boundary element and/or finite element calculations in which an elastic pile of circular section is embedded in an elastic medium. The pile length and diameter, pile Young's modulus and Poisson's ratio, soil Young's modulus and Poisson's ratio are the main factors affecting the results. The influence of Poisson's ratio of the soil is not great so it will not be considered further herein. Some of the equations quoted below contain Poisson's ratio for the soil as a variable in the source publication. A value of 0.5 has been inserted and the equations reworked as given below.

Having a solution for the head rotation and lateral displacement of a pile of finite length, the effect on the displacements of increasing the length of the pile could be evaluated. It is found that once the length of the pile exceeds some critical value additional length makes negligible difference to the calculated deformations. This suggests the notion of an active length for a pile, when the length is greater than this the pile is long and the flexibility coefficients are independent of pile length. This concept was introduced by Kuhlemeyer (1979), Randolf (1981) who define the effective length as the depth at which the lateral deflections are one-thousandth of the head deflection.

The flexibility coefficients for a long pile are expressed in terms of a modulus ratio:

$$
\begin{aligned}
& K=\frac{E_{p}}{E_{s}} \quad \text { for constant soil modulus } \\
& K=\frac{E_{p}}{E_{s(\text { at } z=D)}} \quad \text { for variable modulus }
\end{aligned}
$$

where: $E_{p}$ is the Young's modulus for the pile material, and $\quad E_{s}$ is the Young's modulus of the soil.

The equations were derived for piles of solid circular section. For sections other than this an equivalent value of $E_{p}$ is obtained by equating $E_{p} I_{p}$ for the actual pile with that for a pile having a diameter equal to the width of the pile. The following is used:

$$
E_{p}=\frac{(E I)_{\text {pile actual }}}{\left(\frac{\pi D^{4}}{64}\right)}
$$

The pile head can be loaded with a shear force, a moment or both. Frequently a shear force is applied to a pile shaft above the ground surface, it is convenient to express the resulting pile head moment in terms of an eccentricity defined in the following two alternative ways:

$$
\mathrm{e}=\frac{\mathrm{M}}{\mathrm{H}} \quad, \quad \mathrm{f}=\frac{\mathrm{M}}{\mathrm{DH}}
$$

\subsubsection{Lateral elastic displacements of long single piles}

In this section results are presented for the three distributions of soil modulus with depth shown in Fig. 3.4. As shown in the figure the three abbreviations con, par, and lin will be used to distinguish the various distributions of Young's modulus with depth. The three modulus distributions are representative of common soil profile conditions. The rationale for these three distributions is: the undrained shear strength and modulus of an overconsolidated clay are very approximately constant with depth, particularly near the ground surface; a normally consolidated clay has a linear increase with depth in undrained shear strength and hence a similar distribution for Young's modulus (a linear distribution is also relevant to a cohesionless soil at moderate strain level); finally the parabolic distribution is representative of a profile of cohesionless soil at small strains.

\section{Constant soil modulus with depth}

The relevant equations for this soil profile model are given by Davies and Budhu (1986). For this case the stiffness ratio is:

$$
K=\frac{E_{p}}{E_{s}}
$$

The active length of the pile is:

$$
L_{a}=0.50 \mathrm{D} \mathrm{K}^{0.36}
$$

If the pile length is greater than that given by the above equation then the pile is "long" and the following equations for the flexibility coefficients are valid:

$$
\begin{aligned}
& f_{u H}=\frac{1.3 \mathrm{~K}^{-0.18}}{E_{s} D} \\
& f_{u M}=f_{\theta H}=\frac{2.2 K^{-0.45}}{E_{s} D^{2}} \\
& f_{\theta M}=9.2 \frac{K^{-0.73}}{E_{s} D^{3}}
\end{aligned}
$$

The location of the maximum moment in the pile section is given by:

$$
\mathrm{L}_{\mathrm{M}_{\max }}=0.40 \mathrm{~L}_{\mathrm{a}}
$$




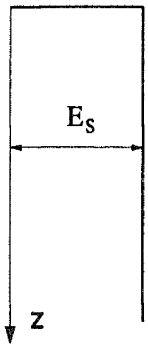

con

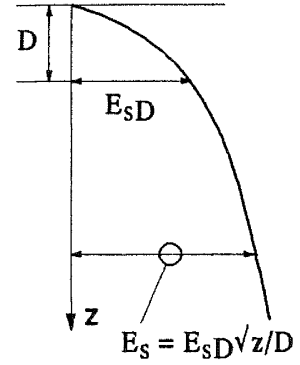

par

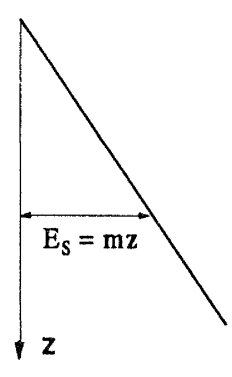

$\operatorname{lin}$
Fig. 3.4 Distribution of Young's modulus with depth for the three soil profile models.

The magnitude of the moment is obtained from:

$$
\begin{aligned}
\mathrm{M}_{\max } & =\mathrm{I}_{\mathrm{MH}} \mathrm{DH} \\
\mathrm{I}_{\mathrm{MH}} & =\mathrm{aK}^{\mathrm{b}} \\
\mathrm{a} & =0.12+0.24 \mathrm{f}+0.1 \mathrm{f}^{2} \\
\mathrm{~b} & =\exp (-1.3-0.34 \mathrm{f})
\end{aligned}
$$

If $\mathrm{I}_{\mathrm{MH}}$ is greater than 6 the maximum moment is equal to the pile head moment, that is $\mathrm{I}_{\mathrm{MH}}=\mathrm{f}$.

Example 3.3 Rework example 3.1 with the elastic continuum approach. Use $E_{S}=25 \mathrm{MPa}$.

From equation 3.18: $f=150 / 100 \times 0.75=2$

From equation 3.19: $\quad K=25 \times 1000 / 25=1000$

From equation 3.20 the active length of the pile is:

$\mathrm{L}_{\mathrm{a}}=0.50 \times 0.75 \times 1000^{0.36}=4.6 \mathrm{~m}$, as $\mathrm{L}>\mathrm{L}_{\mathrm{a}}$ the pile is flexible.

$\mathrm{f}_{\mathrm{uH}}=1.3 \times 1000^{-0.182} / 25 \times 0.75=1.97 \times 10^{-2}$

$f_{u M}=2.2 \times 1000^{-0.455} / 25 \times 0.75^{2}=6.75 \times 10^{-3}$

$\mathrm{f}_{\theta \mathrm{M}}=9.2 \times 1000^{-0.727} / 25 \times 0.75^{3}=5.75 \times 10^{-3}$

Substituting into equation 3.14 gives:

$u=1.97 \times 10^{-2} \times 100+6.75 \times 10^{-3} \times 150=3.0 \mathrm{~mm}$

and from equation 3.15 :

$\theta=6.75 \times 10^{-3} \times 100+5.75 \times 10^{-3} \times 150=1.5 \mathrm{mrad}$

From equation 3.22 the depth to the maximum moment is:

$\mathrm{L}_{\mathrm{Mmax}}=0.4 \times \dot{L}_{\mathrm{a}}=0.4 \times 4.6=1.9 \mathrm{~m}$.

To determine the maximum moment we need to evaluate a and $\mathrm{b}$ from equation 3.23 .

$\mathrm{a}=0.12+0.24 \times 2+0.10 \times 2^{2}=1.0$

$b=\exp (-1.3-0.34 \times 2)=0.138$

$\mathrm{M}_{\mathrm{Mmax}}=1.0 \times 1000^{0.138} \times 0.75 \times 100=194.7 \mathrm{kNm}$.

Note that these results are similar to those obtained for example 3.1, this confirms that the Winkler and elastic continuum models give similar results for free head piles.

Equations 21 to 23 are for the free head case. For fixed head conditions Davies and Budhu give the following for the pile head displacement:

$$
\begin{aligned}
\mathrm{u}_{\mathrm{F}} & =\mathrm{f}_{\mathrm{FH}} \mathrm{H} \\
\mathrm{f}_{\mathrm{FH}} & =\frac{0.80 \mathrm{~K}^{-0.18}}{\mathrm{E}_{\mathrm{s}} \mathrm{D}}
\end{aligned}
$$

The fixing moment is found from:

$$
\begin{aligned}
\mathrm{M}_{\mathrm{F}} & =-\mathrm{I}_{\mathrm{MF}} \mathrm{HD} \\
\mathrm{I}_{\mathrm{MF}} & =0.24 \mathrm{~K}^{0.27}
\end{aligned}
$$

Example 3.4 Use equations 3.14 and 3.15 to derive the above relations for the fixed head condition.

The first step is to use the fixed head condition, that the pile head rotation is zero, to find the fixing moment. Manipulation of equation 3.15 gives:

$\mathrm{M}_{\mathrm{F}}=-\mathrm{f}_{\theta \mathrm{H}} \mathrm{H} / \mathrm{f}_{\theta \mathrm{M}}$

We now substitute this into equation 3.14:

$$
\begin{aligned}
\mathrm{u}_{\mathrm{F}} & =\left(\mathrm{f}_{\mathrm{uH}}-\mathrm{f}_{\mathrm{uM}} \mathrm{f}_{\theta \mathrm{H}} / \mathrm{f}_{\theta \mathrm{M}}\right) \mathrm{H} \\
& =\left(\mathrm{f}_{\mathrm{uH}}-\mathrm{f}_{\theta \mathrm{H}^{2}} / \mathrm{f}_{\theta \mathrm{M}}\right) \mathrm{H}
\end{aligned}
$$

Making appropriate substitutions from equation 3.21 gives the required results.

This example shows that the fixed head case can be solved easily from first principles. Equations such as 3.24 and 3.25 are merely conveniences.

Example 3.5 For the pile analysed in Example 3.3, but now fixed head, find the lateral displacement and fixing moment when a horizontal shear of $100 \mathrm{kN}$ is applied to the pile head.

Using equations 3.24 and 3.25 :

$\mathrm{u}_{\mathrm{F}}=0.80 \times 1000^{-0.18} \times 100 / 25 \times 0.75=1.2 \mathrm{~mm}$

$M_{F}=-0.24 \times 1000^{0.27} \times 100 \times 0.75=-118.6 \mathrm{kNm}$.

Note that these results are similar to those obtained for example 3.2, this confirms that the Winkler and elastic continuum models give similar results for fixed head piles. 
Linear variation of soil modulus with depth

The relevant equations for this soil profile model are given by Budhu and Davies (1987 and 1988). For this case the Young's modulus of the soil and the stiffness ratio is:

$$
\begin{aligned}
E_{s} & =m D \\
K & =\frac{E_{p}}{m D}
\end{aligned}
$$

where: $m$ is the rate of increase in Young's modulus with depth.

Budhu and Davies give values of $m$ for sands of various densities. These are intended for static loading of piles, they are not appropriate for dynamic excitation of piles embedded in loose saturated sands.

The active length of the pile is now:

$$
\mathrm{L}_{\mathrm{a}}=1.3 \mathrm{D} \mathrm{K}^{0.222}
$$

If the pile length is greater than that given by the above equation then the pile is "long" and the following equations for the flexibility coefficients can be used.

The flexibility coefficients are given by:

$$
\begin{aligned}
\mathrm{f}_{\mathrm{uH}} & =\frac{3.2 \mathrm{~K}^{-0.333}}{\mathrm{~m} \mathrm{D}^{2}} \\
\mathrm{f}_{\mathrm{uM}} & =\mathrm{f}_{\theta \mathrm{H}}=\frac{5.0 \mathrm{~K}^{-0.556}}{\mathrm{~m} \mathrm{D}^{3}} \\
\mathrm{f}_{\theta \mathrm{M}} & =13.6 \frac{\mathrm{K}^{-0.778}}{\mathrm{~m} \mathrm{D}^{4}}
\end{aligned}
$$

The location and maximum moment in the pile section are given by:

$$
\begin{aligned}
\mathrm{L}_{\mathrm{M}_{\text {Max }}} & =0.41 \mathrm{~L}_{\mathrm{a}} \\
\mathrm{M}_{\max } & =\mathrm{I}_{\mathrm{MH}} \mathrm{D} \mathrm{H} \\
\mathrm{I}_{\mathrm{MH}} & =\mathrm{a} \mathrm{K} \\
\mathrm{a} & =0.6 \mathrm{f} \\
\mathrm{b} & =0.17 \mathrm{f}^{-0.3}
\end{aligned}
$$

If $\mathrm{I}_{\mathrm{MH}}$ is greater than 8 , a value of 8 is used.

Example 3.6 Continue with the pile and loading from example 3.1. In this case the pile is embedded in a normally consolidated clay the modulus of which increases linearly with depth at 1.5 MPa per metre.

As before $\mathrm{f}=2$.

From equation $3.23: \quad K=25 \times 1000 / 1.5 \times 0.75=22222$

From equation 3.27 the active length of the pile is:

$\mathrm{L}_{\mathrm{a}}=1.30 \times 0.75 \times 22222^{0.222}=9.0 \mathrm{~m}$, as $\mathrm{L}>\mathrm{L}_{\mathrm{a}}$ the pile is flexible.

$$
\begin{aligned}
& f_{u H}=3.2 \times 22222^{-0.333} / 1.5 \times 0.75^{2}=1.35 \times 10^{-1} \\
& f_{u M}=5.0 \times 22222^{-0.556} / 1.5 \times 0.75^{3}=3.06 \times 10^{-2} \\
& f_{\theta M}=13.6 \times 22222^{-0.778} / 1.5 \times 0.75^{4}=1.2 \times 10^{-2}
\end{aligned}
$$

Substituting into equation 3.14 gives:

$\mathrm{u}=1.35 \times 10^{-1} \times 100+3.06 \times 10^{-2} \times 150=18.1 \mathrm{~mm}$

and from equation 3.15

$\theta=3.06 \times 10^{-2} \times 100+1.2 \times 10^{-2} \times 150=4.9 \mathrm{mrad}$.

From equation 3.29 the depth to the maximum moment is:

$\mathrm{L}_{\text {Mmax }}=0.41 \times \mathrm{L}_{\mathrm{a}}=0.41 \times 9.0=3.7 \mathrm{~m}$.

To determine the maximum moment we necd to evaluate a and $b$ from equation 3.30 :

$\mathrm{a}=0.6 \times 2=1.2, \quad \mathrm{~b}=0.17 \times 2^{-0.3}=0.138$

$\mathrm{M}_{\mathrm{Mmax}}=1.2 \times 22222^{0.138} \times 0.75 \times 100=358.5 \mathrm{kNm}$.

Example 3.7 Repeat example 3.6 but in this case the pile is embedded in a medium dense sand profile for which the rate of increase of modulus is $60 \mathrm{MPa}$ per metre.

As before $\mathrm{f}=2$.

From equation 3.23: $\mathrm{K}=25 \times 1000 / 60 \times 0.75=556$

From equation 3.27 the active length of the pile is:

$\mathrm{L}_{\mathrm{a}}=1.30 \times 0.75 \times 556^{0.222}=3.9 \mathrm{~m}$, as $\mathrm{L}>\mathrm{L}_{\mathrm{a}}$ the pile is flexible.

$f_{u H}=3.2 \times 556^{-0.333} / 60 \times 0.75^{2}=1.16 \times 10^{-2}$

$f_{u M}=5.0 \times 556^{-0.556 / 60 \times 0.75^{3}}=5.92 \times 10^{-3}$

$\mathrm{f}_{\theta \mathrm{M}}=13.6 \times 555^{-0.778} / 60 \times 0.75^{4}=5.28 \times 10^{-3}$

Substituting into equation 3.14 gives:

$\mathrm{u}=1.16 \times 10^{-2} \times 100+5.92 \times 10^{-3} \times 150=2.0 \mathrm{~mm}$

and from equation 3.15 :

$\theta=5.92 \times 10^{-3} \times 100+5.28 \times 10^{-3} \times 150=1.4 \mathrm{mrad}$.

From equation 3.29 the depth to the maximum moment is:

$\mathrm{L}_{\mathrm{Mmax}}=0.41 \times \mathrm{L}_{\mathrm{a}}=0.41 \times 9.0=3.7 \mathrm{~m}$.

To determine the maximum moment we need to evaluate a and $\mathrm{b}$ from equation 3.30 :

$\mathrm{a}=0.6 \times 2=1.2, \quad \mathrm{~b}=0.17 \times 2^{-0.3}=0.138$ 
$\mathrm{M}_{\mathrm{Mmax}}=1.2 \times 556^{0.138} \times 0.75 \times 100=215.4 \mathrm{kNm}$.

The above equations are for the free head case. For fixed head conditions Davies and Budhu give the following relation for the displacement:

$$
\begin{aligned}
\mathrm{u}^{\mathrm{F}} & =\mathrm{f}_{\mathrm{FH}} \mathrm{H} \\
\mathrm{f}_{\mathrm{FH}} & =\frac{1.35 \mathrm{~K}^{-0.333}}{\mathrm{~m} \mathrm{D}^{2}}
\end{aligned}
$$

The fixing moment is found from:

$$
\begin{aligned}
& M^{F}=-I_{M F} H D \\
& I_{M F}=0.37 K^{0.222}
\end{aligned}
$$

Example 3.8 For the pile analysed in Example 3.3, but now fixed head, find the lateral displacement and fixing moment when a horizontal shear of $100 \mathrm{kN}$ is applied to the pile head.

Using equations 3.31 and 3.32 :

$u_{F}=1.35 \times 556^{-0.333} \times 100 / 60 \times 0.75^{2}=0.5 \mathrm{~mm}$

$\mathrm{M}_{\mathrm{F}}=-0.40 \times 556^{0.222} \times 100 \times 0.75=-112.2 \mathrm{kNm}$.

Parabolic variation of soil modulus with depth

The Young's modulus of the soil and the stiffness ratio is:

$$
\begin{aligned}
E_{s} & =E_{s D} \sqrt{\frac{z}{D}} \\
K & =\frac{E_{p}}{E_{s D}}
\end{aligned}
$$

where: $\mathrm{E}_{\mathrm{sD}}$ is Young's modulus in the soil at depth D. In this case the relevant equations are obtained from Gazetas (1991). The active length lies between the values given by equations 3.20 the uniform modulus distribution and by equation 3.27 for the linear variation in modulus (when $\mathrm{E}_{\mathrm{sD}}$ $=\mathrm{mD})$.

The long pile flexibility coefficients, obtained by the inversion of the Gazetas (1990) pile head stiffness coefficients, are given by:

$$
\begin{aligned}
f_{u H} & =\frac{2.14 K^{-0.29}}{E_{s D} D} \\
f_{u M} & =f_{\theta H}=\frac{3.43 K^{-0.53}}{E_{s D} D^{2}} \\
f_{\theta M} & =\frac{12.16 K^{-0.77}}{E_{s D} D^{3}}
\end{aligned}
$$

Simple equations for the position and magnitude of the maximum moment are not available for this case.

Example 3.9 Continue with the pile and loading from example 3.1. In this case the pile is embedded in a cohesionless soil having a parabolic variation of modulus with depth. At a depth of $0.75 \mathrm{~m}$ (one diameter) the modulus is $25 \mathrm{MPa}$.

From equation 3.23: $\quad \mathrm{K}=25 \times 1000 / 25=1000$

For the parabolic variation of modulus we have no equation for the active length of the pile.

$f_{u H}=2.14 \times 1000^{-0.29} / 25 \times 0.75=1.5 \times 10^{-2}$

$f_{u M}=3.43 \times 1000^{-0.53} / 25 \times 0.75^{2}=6.0 \times 10^{-3}$

$f_{\theta M}=12.2 \times 1000^{-0.77} / 25 \times 0.75^{3}=6.0 \times 10^{-3}$

Substituting into equation 3.14 gives:

$u=1.5 \times 10^{-2} \times 100+6.0 \times 10^{-3} \times 150=2.5 \mathrm{~mm}$

and from equation 3.15 :

$\theta=6.0 \times 10^{-3} \times 100+6.08 \times 10^{-3} \times 150=1.5 \mathrm{mrad}$.

As noted above for the parabolic variation we have no equation for the maximum moment.

\subsubsection{Short piles}

When pile lengths are shorter than the active lengths given by equations 3.20 , and 3.27 the pile is short. For this situation, Fig. 3.5, equations have been presented by Carter and Kulhawy (1992).

\subsubsection{Short piles in constant modulus soil}

When the stiffness of the pile is much larger than the stiffness of the soil in which it is embedded the deformation of a short pile is essentially rigid and the analysis is consequently simplified. Carter and Kulhawy suggest that this is so when the following inequality is satisfied:

$$
\mathrm{L}_{\mathrm{r}} \leq 0.07 \mathrm{D}\left(\frac{\mathrm{E}_{\mathrm{p}}}{\mathrm{E}_{\mathrm{s}}}\right)^{0.5}
$$

The length to diameter ratio is an important parameter for short piles, we use the following symbol:

$$
\mathscr{P}=\frac{\mathrm{L}}{\mathrm{D}}
$$

The flexibility coefficients are given by:

$$
\begin{aligned}
& \mathrm{f}_{\mathrm{uH}}=\frac{0.7 \mathscr{L}^{-0.33}}{\mathrm{E}_{\mathrm{s}} \mathrm{D}} \\
& \mathrm{f}_{\mathrm{uM}}=\mathrm{f}_{\theta \mathrm{H}}=\frac{0.4 \mathscr{L}^{-0.88}}{\mathrm{E}_{\mathrm{s}} \mathrm{D}^{2}} \\
& \mathrm{f}_{\theta \mathrm{M}}=0.6 \frac{\mathscr{L}^{-1.67}}{\mathrm{E}_{\mathrm{s}} \mathrm{D}^{3}}
\end{aligned}
$$

Since the pile deforms in an essentially rigid manner the point of apparent rotation $(\mathrm{u}(\mathrm{z})=0)$ is a distance beneath the 


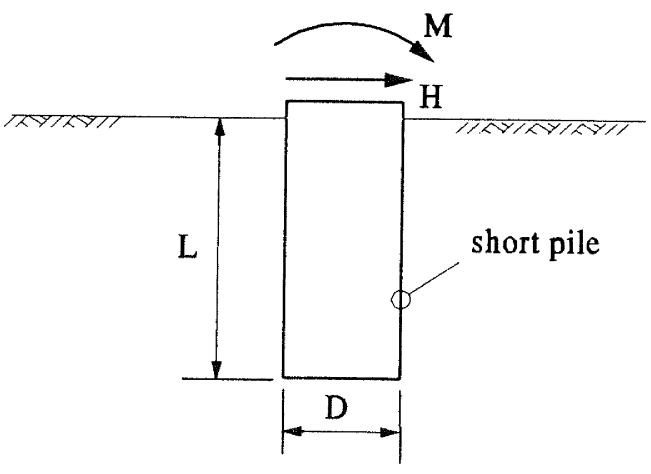

Fig. 3.5 Short pile in a deep soil profile.

ground surface given by:

$$
\frac{\mathrm{z}_{\mathrm{c}}}{\mathrm{D}}=\frac{0.3 \mathscr{L}^{-0.33}+0.5 \mathrm{f} \mathscr{L}^{-0.88}}{0.5 \mathscr{L}^{-0.88}+0.3 \mathrm{f} \mathscr{L}^{-1.67}}
$$

Carter and Kulhawy state that the above equations have been verified for $1 \leq \mathscr{L} \leq 10$ and $\mathrm{E}_{\mathrm{p}} / \mathrm{E}_{\mathrm{S}} \geq 1$.

Example 3.10 Continue with the soil profile and loading for example 3.1, but for this example the pile length is $1.5 \mathrm{~m}$.

As before $\mathrm{K}=1000, \mathrm{f}=2$, and $\mathscr{Q}=2$.

First we use equation 3.35 to check if the pile is short enough to be regarded as rigid:

$\mathrm{L}_{\mathrm{r}}=0.07 \times 0.75 \times 1000^{0.5}=1.7 \mathrm{~m}$, as $\mathrm{L}<\mathrm{L}_{\mathrm{r}}$ the pile is rigid.

$\mathrm{f}_{\mathrm{uH}}=0.70 \times 2^{-0.22} / 25 \times 0.75=3.2 \times 10^{-2}$

$f_{u M}=0.40 \times 2^{-0.88} / 25 \times 0.75^{2}=1.5 \times 10^{-2}$

$f_{\theta M}=0.60 \times 2^{-1.67} / 25 \times 0.75^{3}=1.8 \times 10^{-2}$

Substituting into equation 3.14 gives:

$\mathrm{u}=3.2 \times 10^{-2} \times 100+1.5 \times 10^{-2} \times 150=5.5 \mathrm{~mm}$

and from equation 3.15 :

$\theta=1.5 \times 10^{-2} \times 100+1.8 \times 10^{-2} \times 150=4.2 \mathrm{mrad}$.

We now use equation 3.37 to find the depth of the point of rotation for the short pile:

$$
\begin{aligned}
& \mathrm{z}_{\mathrm{c}}=0.75 \times\left[\left(0.3 \times 2^{-0.33}+0.5 \times 2 \times 2^{-0.88}\right)\right. \\
& \left./\left(0.5 \times 2^{-0.88}+0.32 \times 2 \times 2^{-1.67}\right)\right]=1.3 \mathrm{~m} .
\end{aligned}
$$

Looking back to example 3.3 we find that the displacements for this short pile $(1.5 \mathrm{~m}$ in length) are only moderately greater than those for the long pile ( $20 \mathrm{~m}$ length). This is further confirmation that, for laterally loaded piles, the major part of the deformation occurs close to the pile head.

\subsubsection{Intermediate length piles}

Equation 3.35 in effect gives an upper bound on the length of an approximately rigid pile and equation 3.20 gives a lower bound on the length of a flexible pile. Between these limits we have piles of intermediate length. The lateral deflections of these will be greater than those of the long pile and also greater than those of the short pile (as the intermediate length pile will not be rigid). Carter and Kulhawy (1992) suggest that an estimate of the deflection of an intermediate length pile can be taken as 1.25 times either: the predicted lateral displacement of a rigid pile with the same length to diameter ratio $(\mathscr{P})$ as the actual pile, or the predicted displacement of a flexible shaft with the same modulus ratio $\left(\mathrm{K}=\mathrm{E}_{\mathrm{p}} / \mathrm{E}_{\mathrm{S}}\right)$ as the actual pile.

\subsubsection{Socketed piles}

Carter and Kulhawy also suggest an approach for the case where a short pile shaft passes through a clay or sand profile and is socketed into much stiffer material (they had rock in mind). This assumes that the soil adjacent to the pile shaft reaches a lateral bearing failure, the soil reaction distributions used are the same as those discussed in section 9.2. Further details are given in the Carter and Kulhawy paper.

\subsection{Comparison of the elastic continuum and Winkler analyses.}

The calculation of the interaction between a laterally loaded pile and an elastic half space is complicated because of the continuity of the material surrounding the pile shaft. It is clear that the same calculation is much simpler when the subgrade is modelled (as shown above) as a Winkler medium. The question then arises as to how the two solutions compare. Vesic (1961) has addressed this for flexible piles.

Vesic compared the solution for an infinite beam resting on an elastic half space with that for an infinite beam on a Winkler subgrade. This enabled him to arrive at the following relation between $\mathrm{k}$ to be used in the Winkler analysis and the material properties for an elastic continuum:

$$
k=\frac{0.65 \mathrm{E}_{S}}{\left(1-v_{S}^{2}\right)} \sqrt[12]{\frac{\mathrm{E}_{S} \mathrm{D}^{4}}{\mathrm{E}_{\mathrm{p}} \mathrm{I}_{\mathrm{p}}}}
$$

Where $\mathrm{E}_{\mathrm{S}}$ and $v_{\mathrm{S}}$ refer to the properties of the subgrade. This relation gives values of $\mathrm{k}$ that are roughly equal to $\mathrm{E}_{\mathrm{S}}$.

To compare the Winkler and elastic continuum pile cases we need to go one step further and allow for the fact that the soil acts all around the pile rather than just on one side. This means that the modulus of subgrade reaction for use in the pile case is double that given by equation 3.39. It is not possible to get exact matching of both the displacements and maximum moments, although the comparison of examples 3.1 and 3.3 suggests reasonable matching of both is achieved with $\mathrm{k}$ obtained from equation 3.39 doubled to account for the surrounding effect of the soil. 
Makris and Gazetas (1992) propose that $\mathrm{k}=1.2 \mathrm{E}_{\mathrm{S}}$. This gives a value for $k$ about double that obtained with equation 3.39 , and so it presumes interaction with the soil behind and in front of the pile.

The above comments are based on the idea that the soil is in contact with both the front and the rear of the pile shaft. Near the ground surface this may not be true, particularly for large loads, as separation may occur (cf. Fig. 3.3). This "gapping" alters the stiffness of the pile. One approach to this is considered in section 7.1.

\subsection{Equivalent cantilever concept}

Representation of the pile head as an equivalent cantilever has been popular and is presented by Edmonds et al (1980) and reproduced by Dowrick (1987). This procedure is clearly unsatisfactory in that different cantilever lengths are needed depending on whether it is maximum moment or maximum deflection that is being modelled. In fact, the concept may be quite misleading as the cantilever length is shorter than the active pile shaft length given in section 3.3.2.

With the advent of the equations set out above there is no need for the equivalent cantilever concept.

\subsection{Pile head stiffness}

The pile head stiffness matrix is determined by inversion of the $2 \times 2$ matrix of flexibility coefficients:

$$
\left(\begin{array}{ll}
K_{H H} & K_{H M} \\
K_{M H} & K_{M M}
\end{array}\right)=\frac{1}{\left(f_{u H} f_{\theta M}-f_{u M}^{2}\right)}\left(\begin{array}{cc}
f_{\theta M} & -f_{u M} \\
-f_{\theta H} & f_{u H}
\end{array}\right) 3.40
$$

where: $\mathrm{K}_{\mathrm{HH}}, \mathrm{K}_{\mathrm{HM}}, \mathrm{K}_{\mathrm{MH}}, \mathrm{K}_{\mathrm{MM}}$ are the pile head stiffness coefficients.

Note that, similarly to the pile head flexibility coefficients, the reciprocal theorem requires that: $\mathrm{K}_{\mathrm{HM}}=\mathrm{K}_{\mathrm{MH}}$.

Example 3.10 From the flexibility coefficients found in examples 3.3 and 3.7 evaluate the pile head stiffness matrix.

(a) example 3.3, pile in constant modulus soil:

$$
\begin{aligned}
& \mathrm{f}_{\mathrm{uH}} \mathrm{f}_{\theta \mathrm{M}}-\mathrm{f}_{\mathrm{uM}}{ }^{2}=6.78 \times 10^{-5} \\
& \mathrm{~K}_{\mathrm{HH}}=5.75 \times 10^{-3} / 6.78 \times 10^{-5}=84.8 \mathrm{kN} / \mathrm{mm} \\
& \mathrm{K}_{\mathrm{MM}}=1.97 \times 10^{-2} / 6.78 \times 10^{-5}=291 \mathrm{kNm} / \mathrm{mrad} \\
& \mathrm{K}_{\mathrm{HM}}=-6.75 \times 10^{-3} / 6.78 \times 10^{-5}=-99.6 \mathrm{kNm} / \mathrm{mm} .
\end{aligned}
$$

(b) example 3.7, pile in medium dense sand:

$$
\begin{aligned}
& \mathrm{f}_{\mathrm{uH}} \mathrm{f}_{\theta \mathrm{M}}-\mathrm{f}_{\mathrm{uM}}{ }^{2}=2.60 \times 10^{-5} \\
& \mathrm{~K}_{\mathrm{HH}}=5.28 \times 10^{-3} / 2.60 \times 10^{-5}=200 \mathrm{kN} / \mathrm{mm}
\end{aligned}
$$

$\mathrm{K}_{\mathrm{MM}}=1.16 \times 10^{-2} / 2.60 \times 10^{-5}=450 \mathrm{kNm} / \mathrm{mrad}$

$\mathrm{K}_{\mathrm{HM}}=-5.92 \times 10^{-3} / 2.60 \times 10^{-5}=-230 \mathrm{kNm} / \mathrm{mm}$.

The first column of the stiffness matrix gives the pile head actions generated when unit horizontal displacement is applied to the pile head with zero rotation. The second column is the actions generated by unit rotation with zero displacement. Often we require stiffnesses for other constraints.

Often structural analysis programs allow spring supports. This facility can be used to represent foundation elements. In the case of a fixed head pile all that is required is the stiffness of an equivalent lateral spring which is the $\mathrm{K}_{\mathrm{HH}}$ from the pile head stiffness matrix.

Example 3.11 Return to example 3.5 and determine the equivalent lateral spring stiffness for the fixed head pile.

A shear of $100 \mathrm{kN}$ produced a lateral displacement of $1.2 \mathrm{~mm}$. Thus the equivalent spring stiffness is:

$\mathrm{K}_{\mathrm{HF}}=100 / 1.2=83.3 \mathrm{kN} / \mathrm{mm}$.

Note that in example 3.4 the expression for the fixed head stiffness is exactly that given for $\mathrm{K}_{\mathrm{HH}}$ in equation 3.40. (The slight difference between the value calculated in this example and $\mathrm{K}_{\mathrm{HH}}$ in example $3.10 \mathrm{a}$ is a consequence of minor rounding errors.)

The next case is the free head pile in which a horizontal force may be applied at or above the ground surface. In this case the pile head will also rotate so the equivalent horizontal stiffness will be less than $\mathrm{K}_{\mathrm{HH}}$ and the equivalent rotational stiffness less than $\mathrm{K}_{\mathrm{MM}}$.

We can obtain the equivalent stiffnesses by expanding the pile head actions in terms of the stiffnesses and displacements:

$$
\begin{aligned}
\mathrm{H} & =\mathrm{K}_{\mathrm{HH}^{\mathrm{u}}}+\mathrm{K}_{\mathrm{HM}^{\theta}} \\
\mathrm{M} & =\mathrm{K}_{\mathrm{HM}^{\mathrm{u}}}+\mathrm{K}_{\mathrm{MM}^{\theta}} \theta
\end{aligned}
$$

Firstly, solve for $\theta$ from equation (b):

$$
\theta=\left(\mathrm{M}-\mathrm{K}_{\mathrm{HM}} \mathrm{u}\right) / \mathrm{K}_{\mathrm{MM}}
$$

Now substitute into (a), following the notation introduced in equation 3.18 express $\mathrm{M}$ as $\mathrm{eH}$, and rearrange:

$$
\mathrm{H}\left(1-\mathrm{eK}_{\mathrm{HM}} / \mathrm{K}_{\mathrm{MM}}\right)=\mathrm{u}\left(\mathrm{K}_{\mathrm{HH}}-\mathrm{K}_{\mathrm{HM}^{2}} / \mathrm{K}_{\mathrm{MM}}\right)
$$

From which the equivalent pile head lateral stiffness is:

$$
\mathrm{K}_{\mathrm{h}}=\frac{\mathrm{K}_{\mathrm{HH}} \mathrm{K}_{\mathrm{MM}}-\mathrm{K}_{\mathrm{HM}}^{2}}{\mathrm{~K}_{\mathrm{MM}}-\mathrm{e} \mathrm{K}_{\mathrm{HM}}}
$$

where: $K_{h} \quad$ is the horizontal stiffness of a free head pile. 


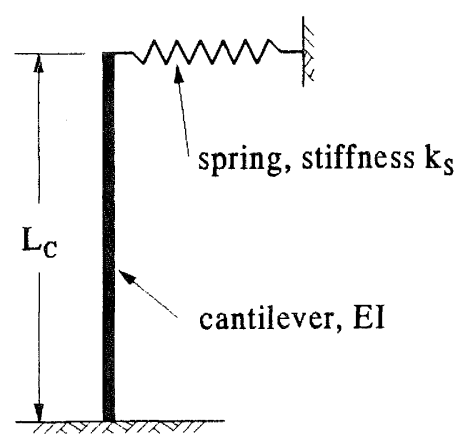

Fig. 3.6 Cantilever plus spring representation of pile head stiffness.

The equivalent pile head rotational stiffness is obtained in a similar manner starting with equation (a) and solving for $\mathrm{u}$ which is then substituted into the equation (b):

$$
\mathrm{K}_{\theta}=\frac{\mathrm{K}_{\mathrm{HH}} \mathrm{K}_{\mathrm{MM}}-\mathrm{K}_{\mathrm{HM}}^{2}}{\mathrm{~K}_{\mathrm{HH}}-\mathrm{K}_{\mathrm{HM}} / \mathrm{e}}
$$

where: $\mathrm{K}_{\theta}$

is the rotational stiffness of a free head pile.

Note that the equivalent pile head stiffnesses given in equations 3.41 and 3.42 are functions of the ratio of the moment to horizontal force, e.

Example 3.12 Return to example 3.3 and evaluate the lateral and rotational stiffness of the free head pile.

The components of the pile head stiffness matrix are given in Example 3.10a. From the applied actions in example 3.3 we obtain e:

$\mathrm{e}=\mathrm{M} / \mathrm{H}=150 / 100=1.5 \mathrm{~m}$

Using equation 3.41 :

$K_{h}=\left(84.8 \times 291-99.6^{2}\right) /(291-1.5 \times(-99.6))$

$=33.5 \mathrm{kN} / \mathrm{mm}$

Using equation 3.42 :

$\mathrm{K}_{\theta}=\left(84.8 \times 291-99.6^{2}\right) /(1.5 \times 84.8-(-99.6))$

$=65.1 \mathrm{kNm} / \mathrm{mrad}$

The various terms in the pile head stiffness matrix calculated in example 3.10 have similar magnitudes, thus the off diagonal terms are important. The input for a typical structural analysis program will allow linear and rotational springs. Thus we can specify $\mathrm{K}_{\mathrm{HH}}$ and $\mathrm{K}_{\mathrm{MM}}$ easily enough, but a difficulty arises because $\mathrm{K}_{\mathrm{HM}}$ is not modelled with springs.

It is possible to get the relative stiffness effects correct if the pile is represented as a cantilever with a horizontal spring at the tip as shown in Fig. 3.6. A method of handling this has been suggested by Webb (1986). The stiffness matrix for the cantilever spring combination is:

$$
[K]=\left(\begin{array}{cc}
\frac{12 \mathrm{EI}}{\mathrm{L}_{\mathrm{C}}^{3}}+\mathrm{k}_{\mathrm{S}} & \frac{-6 \mathrm{EI}}{\mathrm{L}_{\mathrm{C}}^{2}} \\
-\frac{6 \mathrm{EI}}{\mathrm{L}_{\mathrm{C}}^{2}} & \frac{4 \mathrm{EI}}{\mathrm{L}_{\mathrm{C}}}
\end{array}\right)
$$

where: EI is the section property of the cantilever, $\mathrm{L}_{\mathrm{C}}$ is the length of the cantilever, and $\quad k_{S}$ is the stiffness of the spring at the cantilever tip.

We can determine the three unknowns in equation 3.43 by equating with the terms of the pile head stiffness matrix as is done in example 3.13.

The cantilever in Fig. 3.6 is reminiscent of the equivalent cantilever concept dismissed in section 3.4. However, equation 3.43 merely uses the device of a cantilever and a spring to represent correctly the pile head stiffness coefficients. The equivalent cantilever concept is not capable of representing the pile head stiffness coefficients correctly.

Example 3.13 Find an equivalent spring-cantilever system to represent the pile head stiffnesses matrix found in the first part of example 3.10 .

Matching the individual terms in 3.43 with the components of the pile head stiffness matrix found in example $3.10 \mathrm{a}$ we perform the following operations:

From the ratio of the terms $(2,2)$ and $(2,1)$ in equation 3.43 we find $\mathrm{L}_{\mathrm{C}}$ :

$\mathrm{L}_{\mathrm{C}}=-1.5 \mathrm{~K}_{\mathrm{MM}} / \mathrm{K}_{\mathrm{HM}}=1.5 \times 2.91 \times 10^{5} / 9.96 \times 10^{4}=4.4 \mathrm{~m}$

Substituting this back into term $(2,2)$ gives EI:

$\mathrm{EI}=\mathrm{L}_{\mathrm{C}} \mathrm{K}_{\mathrm{MM}} / 4=4.4 \times 2.91 \times 10^{5} / 4=3.2 \times 10^{5} \mathrm{kNm}^{2}$

From term $(1,1)$ we obtain $\mathrm{k}_{\mathrm{S}}$ :

$$
\begin{aligned}
\mathrm{k}_{\mathrm{S}} & =\mathrm{K}_{\mathrm{HH}}-12 \mathrm{EI} / \mathrm{L}_{\mathrm{C}}{ }^{3}=8.48 \times 10^{4}-12 \times 3.2 \times 10^{5} / 4.4^{3} \\
& =4.0 \times 10^{4} \mathrm{kN} / \mathrm{m}
\end{aligned}
$$

Note that the properties of this cantilever are very different from those of the actual pile section; for the pile section $E_{p} I_{p}$ $=6.2 \times 10^{6}$ whilst for the cantilever EI $=3.2 \times 10^{5} \mathrm{kNm}^{2}$. 


\section{0 \\ STANDARD MODELS FOR PILE AXIAL STIFFNESS}

\subsection{Winkler Model}

In this case the interaction between the soil and pile shaft is modelled by discrete springs. The concept is just like that for the lateral loading of the pile discussed in section 3 with the excepting that the springs are now oriented along the pile shaft rather than normal to it. Scott (1981) gives solutions for this case.

\subsection{Elastic continuum}

In this section expressions are presented for the vertical stiffness (or in the case of a battered pile the axial stiffness) of piles in the three soil profiles illustrated in Fig. 3.4. Pile axial stiffness differs from the lateral stiffness in that the interaction with the surrounding soil is not localised near the pile head but extends over a longer length of the pile shaft. Thus the active length concept does not apply to the axial stiffness of piles. The stiffness expressions are given by Gazetas (1991). In addition Randolf and Wroth $(1978,1979)$ give an expression for the axial stiffness of a pile in a soil profile with an arbitrary variation of modulus with depth. Cases not covered in this section, for example piles with under-reams, can be handled using the techniques in Poulos and Davis (1980).

\subsubsection{Floating piles}

A floating pile is one for which there is no abrupt change in the properties of the material at the end of the pile. The opposite of this is an end bearing pile where the pile shaft passes through a soil profile and the tip bears on something much stiffer such as rock.

\section{Constant soil modulus with depth}

For this case Gazetas (1991) gives the following expression for the axial stiffness of a pile:

$$
\mathrm{K}_{\mathrm{V}}=1.9 \mathrm{E}_{\mathrm{S}} \mathrm{D} \mathscr{L}^{0.67} \mathrm{~K}^{-\mathrm{b}}
$$

where: $K_{V}$ is the axial stiffness of the pile,

$$
\mathrm{b}=\mathscr{L} / \mathrm{K} \text {, }
$$

and the remaining notation is the same as that used in section 3 .

Example 4.1 Estimate the axial stiffness of the pile specified in Example 3.3 and compare the axial stiffness with the pile head stiffness components calculated in Example 3.11.

From the data for example 3.3 we have $\mathrm{K}=1000$ and $\mathscr{L}=$ 26.7. From these $b=26.7 / 1000=0.027$

Substitution into equation 4.1 :

$$
\begin{aligned}
\mathrm{K}_{\mathrm{V}} & =1.9 \times 25 \times 0.75 \times 26.7^{0.67} \times 1000^{-0.027} \\
& =267.0 \mathrm{kN} / \mathrm{mm}
\end{aligned}
$$

With reference to example 3.11 we find that this stiffness is about three times the lateral stiffness components of the pile head; it is usual for the vertical stiffness of a pile to be greater than the lateral stiffness.

\section{Linear variation of soil modulus with depth}

For this case Gazetas (1991) gives the following expression for the axial stiffness of a pile:

$$
\mathrm{K}_{\mathrm{V}}=1.8 \mathrm{E}_{\mathrm{SL}} \mathrm{D} \mathscr{L}^{0.55} \Re^{-\mathrm{b}}
$$

where: $E_{S L}$ is the soil modulus at the pile tip $=\mathrm{mL}$, and $\quad \Re=\mathrm{E}_{\mathrm{p}} / \mathrm{E}_{\mathrm{SL}}$.

Example 4.2 Estimate the axial stiffness of the pile specified in Example 3.7 and compare the axial stiffness with the pile head stiffness components calculated in Example 3.11.

From the data for example 3.7 we have $\mathscr{L}=20 / 0.75=26.7$ and $\Re=25 \times 1000 /(60 \times 20)=20.8$. From these $b=26.7 / 20.8$ $=1.28$.

Substitution into equation 4.2:

$$
\begin{aligned}
\mathrm{K}_{\mathrm{V}} & =1.8 \times 60 \times 20 \times 1000 \times 0.75 \times 26.7^{0.55} \times 20.8^{-1.28} \\
& =203 \mathrm{kN} / \mathrm{mm}
\end{aligned}
$$

with reference to example 3.11 we find that this stiffness is of considerably greater magnitude than the lateral and rotational stiffness components of the pile head.

Parabolic variation of soil modulus with depth

For this case Gazetas (1991) gives the following expression for the axial stiffness of a pile:

$$
\mathrm{K}_{\mathrm{V}}=1.9 \mathrm{E}_{\mathrm{SL}} \mathrm{D} \mathscr{L}^{0.60} \Re^{-\mathrm{b}}
$$

where: $\quad E_{S L}$ is the soil modulus at the pile tip $=E_{S D} \sqrt{\mathscr{L}}$.

Example 4.3 Use equations 4.1 to 4.3 to investigate the effect of different $\mathscr{L}$ ratios on the vertical stiffness of floating piles in the three soil profiles when modulus of the soil at the pile tip is $25 \mathrm{MPa}$. Assume the pile properties, other than length, are the same as in example 3.3 .

The comparison is made in the table and figure below. As an illustration of the calculations needed to generate the table we give those for $\mathscr{L}=10$.

For all cases we have $\Re=1000$ and $\mathscr{L}=10$ we obtain $\mathrm{b}=$ 0.01 .

Equation 4.1 The vertical stiffness is:

$$
\mathrm{K}_{\mathrm{V}}=1.9 \times 25 \times 0.75 \times 10^{0.67} \times 1000^{-0.01}
$$

$$
=155.5 \mathrm{kN} / \mathrm{mm}
$$

Equation 4.2 The vertical stiffness is:

$\mathrm{K}_{\mathrm{V}} \quad=1.8 \times 25 \times 0.75 \times 10^{0.55} \times 1000^{-0.01}$

$=111.8 \mathrm{kN} / \mathrm{mm}$ 
Equation 4.3 The vertical stiffness is:

$$
\begin{aligned}
\mathrm{K}_{\mathrm{V}} & =1.9 \times 25 \times 0.75 \times 10^{0.60} \times 1000^{-0.01} \\
& =132.4 \mathrm{kN} / \mathrm{mm}
\end{aligned}
$$

The complete set of results is:

\begin{tabular}{|c|c|c|c|}
\hline \multirow{2}{*}{$\mathscr{2}$} & \multicolumn{3}{|c|}{ Vertical stiffness $\mathrm{kN} / \mathrm{mm}$} \\
\cline { 2 - 4 } & $\mathrm{K}_{\mathrm{V}}(4.1)$ & $\mathrm{K}_{\mathrm{V}}(4.3)$ & $\mathrm{K}_{\mathrm{V}}(4.2)$ \\
\hline 2 & 56 & 53 & 49 \\
\hline 4 & 88 & 80 & 70 \\
\hline 7 & 125 & 109 & 94 \\
\hline 10 & 156 & 132 & 112 \\
\hline 20 & 231 & 187 & 153 \\
\hline 40 & 320 & 247 & 195 \\
\hline 60 & 366 & 275 & 212 \\
\hline
\end{tabular}

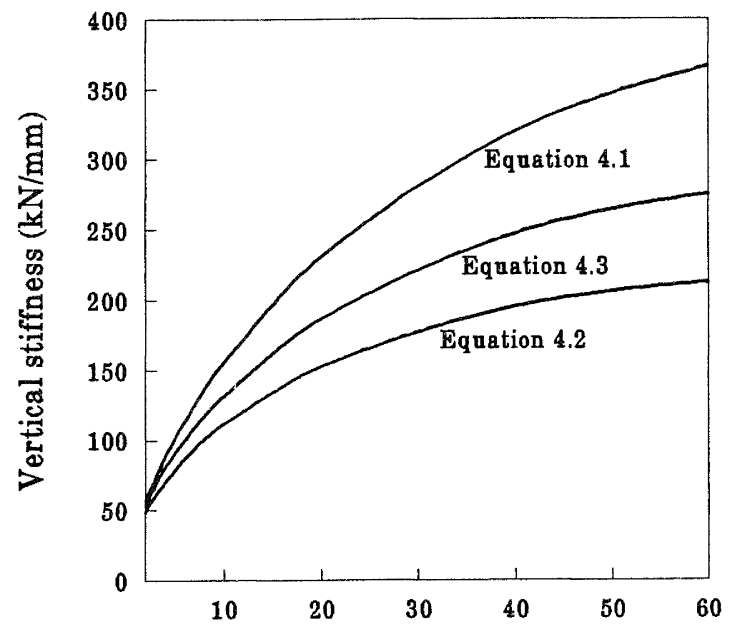

Pile length to diameter ratio

These results show that the soil profile having a uniform distribution of $E_{S}$ gives the greatest vertical stiffness and the linear distribution gives the smallest. Randolf and Wroth (1978) give a method for estimating vertical stiffnesses in a soil profile with arbitrary variation of $E_{S}$ with depth. The decreasing rate of increase in $\mathrm{K}_{\mathrm{V}}$ with increasing $\mathscr{L}$ is a consequence of the compressibility of the pile.

\subsubsection{End bearing piles}

Kulhawy and Carter (1991) adapt the expression for the axial stiffness of a compressible pile given by Randolf and Wroth (1978) to the case where the pile is underlain by stiffer material. Figure 4.1 shows the situation modelled. Rearranging terms of the notation used herein, their equation becomes:

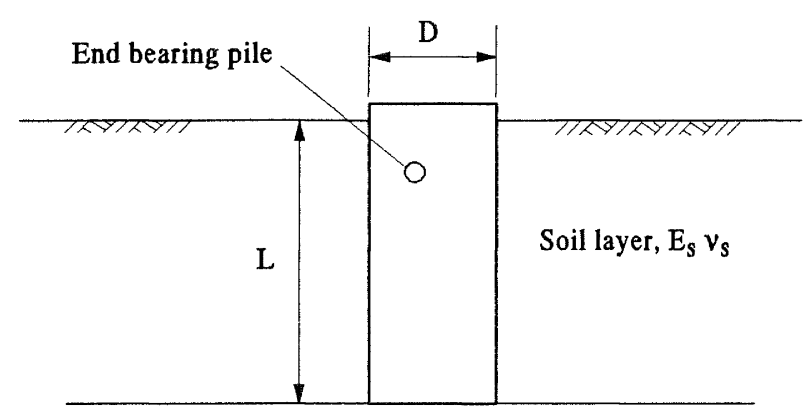

Bearing stratum, $E_{b} v_{b}$

Fig. 4.1 End bearing pile in a two layer soil profile.

$$
\mathrm{K}_{\mathrm{V} \text { end bearing }}=\left(\frac{\mathrm{E}_{\mathrm{S}} \mathrm{D}}{1+v_{\mathrm{S}}}\right) \frac{\Omega+\frac{\mathscr{L} \Xi}{\zeta}}{1+\frac{4 \Omega \mathscr{L} \Xi}{\pi \mathrm{K}\left(1+v_{S}\right)}}
$$

where:

$$
\begin{aligned}
& \Omega \quad \text { is } \xi\left(1+v_{\mathrm{S}}\right) /\left(1-v_{\mathrm{B}}^{2}\right), \\
& \xi \quad \text { is ratio of Young's modulus of }
\end{aligned}
$$
and $\zeta \quad$ is $\ln \left[5\left(1-\nu_{\mathrm{S}}\right) \mathscr{Q}\right]$.

This equation applies to the case where the modulus of the soil is constant with depth.

Example 4.4 Use equations 4.1 and 4.4 to illustrate the effect of different $\mathscr{L}$ ratios on the vertical stiffness of floating piles and end bearing piles. Assume that the soil properties and pile properties other than length are the same as in example 3.3. Take the modulus of the bearing stratum to be 1000 times that of the soil and Poisson's ratios for the soil and bearing stratum to be 0.5 .

Taking as an illustration $\mathscr{L}=10$, the calculations for equation 4.4 are:

$$
\begin{array}{ll}
\Omega & =1000 \times 1.5 /\left(1-0.5^{2}\right)=2000 \\
\zeta & =\ln (5 \times 0.5 \times 10)=3.22 \\
\sqrt{(3.22 \times 1.5} \times 1000) \\
=69.47 \\
\mathrm{~T} \quad=2 \times 10 / 69.47=0.288 \\
\tanh (\mathrm{T})=\left(\mathrm{e}^{\mathrm{T}}-\mathrm{e}^{-\mathrm{T}}\right) /\left(\mathrm{e}^{\mathrm{T}}+\mathrm{e}^{-\mathrm{T}}\right)=0.280 \\
\begin{aligned}
\Xi \quad & 0.280 / 0.288=0.973 \\
\mathrm{E}_{\mathrm{S}} \mathrm{D} /(1+ & \left.v_{\mathrm{S}}\right) \\
& =25 \times 0.75 / 1.5=12.5 \\
& =12.5 \times(2000+10 \times 0.972 / 3.22) \\
\mathrm{K}_{\mathrm{V}} \quad & /(1+4 \times 2000 \times 10 \times 0.972 / 3.14 \times 1000 \times 1.5) \\
& =1430.3 \mathrm{kN} / \mathrm{mm}
\end{aligned}
\end{array}
$$


The results from the full set of calculations is presented in the following plot and table.

\begin{tabular}{|c|c|c|}
\hline \multirow{2}{*}{$\mathscr{L}$} & \multicolumn{2}{|c|}{ Vertical stiffness $\mathrm{kN} / \mathrm{mm}$} \\
\cline { 2 - 3 } & $\mathrm{K}_{\mathrm{V}}(4.1)$ & $\mathrm{K}_{\mathrm{V}}(4.4)$ \\
\hline 2 & 56 & 5710 \\
\hline 4 & 88 & 3235 \\
\hline 7 & 125 & 1975 \\
\hline 10 & 156 & 1430 \\
\hline 20 & 231 & 783 \\
\hline 40 & 320 & 471 \\
\hline 60 & 366 & 384 \\
\hline
\end{tabular}

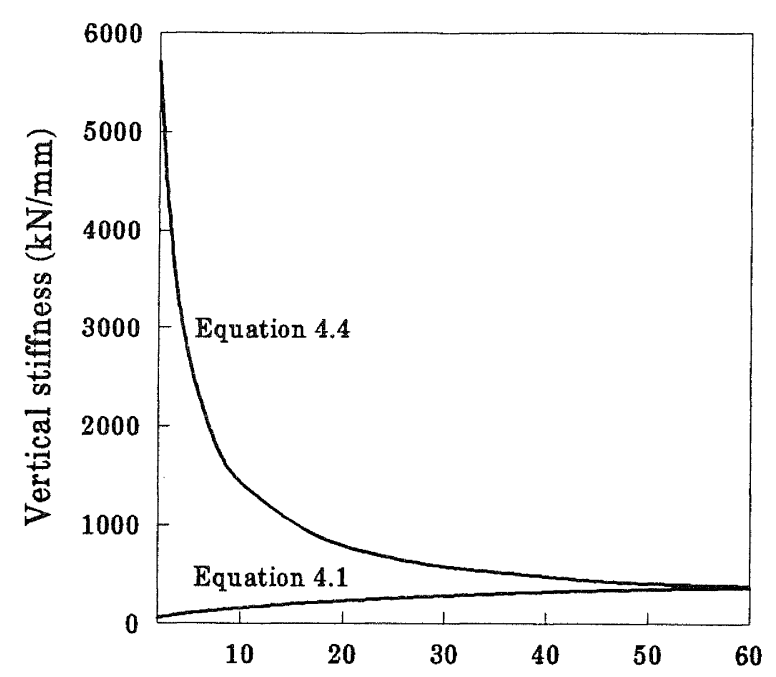

Pile length to diameter ratio

This example relates to a reinforced concrete pile through a stiff soil profile. The modulus of the bearing stratum is about the same as that of concrete which would correspond to a good quality rock mass. The calculations show that for long piles the effect of the firm bearing layer is negligible and the vertical stiffness of the pile approaches that of the floating pile given by equation 4.1. As the stiffness of the soil layer decreases the effect of the firm bearing layer becomes significant for longer piles.

\subsection{Raked piles}

In some situations piles are installed at an angle to the vertical. The angle of rake is commonly in the $10^{\circ}$ to $15^{\circ}$ range. The effect of the raking a pile is to contribute a portion of the axial stiffness (referred to above as vertical stiffness) of the pile to the horizontal direction. We assume that the rake angle is sufficiently small that the pile head stiffness matrix is not affected. What is required is a new pile head stiffness matrix expressed in terms of the global coordinate system rather that the local pile coordinate system

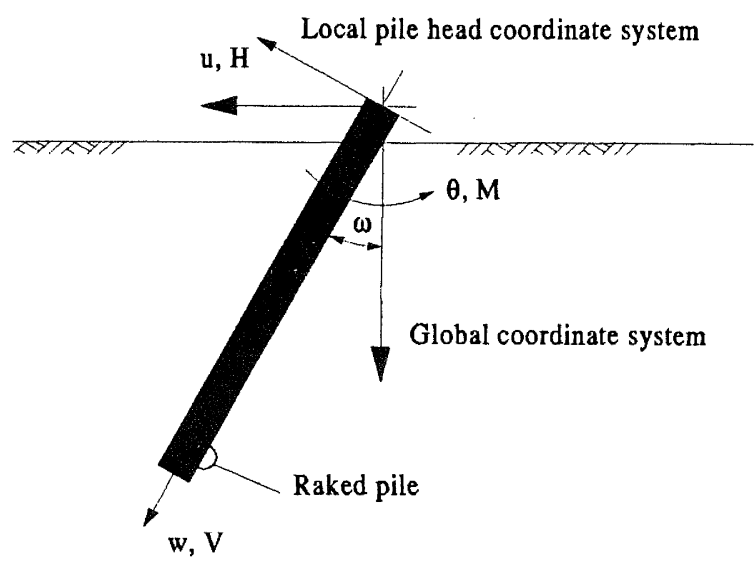

Fig. 4.2 Global and local pile head coordinate systems.

as illustrated in Fig. 4.2.

With the inclusion of pile axial stiffness the pile head stiffness matrix for a vertical pile is:

$$
[\mathrm{K}]=\left(\begin{array}{ccc}
\mathrm{K}_{\mathrm{HH}} & \mathrm{K}_{\mathrm{HM}} & 0 \\
\mathrm{~K}_{\mathrm{HM}} & \mathrm{K}_{\mathrm{MM}} & 0 \\
0 & 0 & \mathrm{~K}_{\mathrm{V}}
\end{array}\right)
$$

where: $[\mathrm{K}]$ is the pile head stiffness matrix.

This matrix gives the following actions when the pile head is displaced: $\mathbb{F}=[\mathrm{K}] \mathrm{v}$, where $\mathbb{F}$ is a vector of pile head actions the transpose of which is $(\mathrm{H}, \mathrm{M}, \mathrm{V})$, and $\mathrm{v}$ is a vector of pile head displacements which, transposed, is $(\mathrm{u}, \theta, \mathrm{w})$.

When the angle of rake is $\omega$ to the vertical the pile head stiffness matrix becomes:

$$
[\mathrm{K}]=\left(\begin{array}{lcr}
\left(\mathrm{C}^{2} \mathrm{~K}_{\mathrm{HH}}+\mathrm{S}^{2} \mathrm{~K}_{\mathrm{V}}\right) & \mathrm{C} \mathrm{K}_{\mathrm{HM}} & \mathrm{CS}\left(\mathrm{K}_{\mathrm{V}}-\mathrm{K}_{\mathrm{HH}}\right) \\
\mathrm{C} \mathrm{K}_{\mathrm{HM}} & \mathrm{K}_{\mathrm{MM}} & -\mathrm{S} \mathrm{K}_{\mathrm{HM}} \\
\mathrm{CS}\left(\mathrm{K}_{\mathrm{V}}-\mathrm{K}_{\mathrm{HH}}\right) & -\mathrm{S} \mathrm{K} \mathrm{K}_{\mathrm{HM}}\left(\mathrm{S}^{2} \mathrm{~K}_{\mathrm{HH}}+\mathrm{C}^{2} \mathrm{~K}_{\mathrm{V}}\right)
\end{array}\right)
$$

where: $\mathrm{C}=\cos \omega$ and $\mathrm{S}=\sin \omega$.

Example 4.5 Compare the pile head stiffness matrices for a vertical end bearing pile and a raked pile. Use the pile diameter and properties from example 3.3. The pile is to be end bearing with $\mathscr{L}=10$ and the modulus of the end bearing stratum is to be 1000 times that of the soil. The soil and bearing stratum Poisson's ratio is 0.5 . Take a rake angle of $15^{\circ}$.

From example 3.3 we have the following stiffness components:

$$
\begin{aligned}
& \mathrm{K}_{\mathrm{HH}}=84.8 \mathrm{kN} / \mathrm{mm}, \\
& \mathrm{K}_{\mathrm{HM}}=-99.6 \mathrm{kNm} / \mathrm{mm}, \mathrm{K}_{\mathrm{MM}}=291 \mathrm{kNm} / \mathrm{mrad} .
\end{aligned}
$$


From example 4.4 we have for a pile with $\mathscr{L}=10$ $\mathrm{K}_{\mathrm{V}}=1350 \mathrm{kN} / \mathrm{mm}$.

For the vertical pile the pile head stiffness matrix is thus:

$$
[K]=\left(\begin{array}{rrr}
84.8 & -96.6 & 0 \\
-96.6 & 291.0 & 0 \\
0 & 0 & 1350.0
\end{array}\right)
$$

For the raked pile when $\omega=15^{\circ} \mathrm{S}=0.26$ and $\mathrm{C}=0.97$. Substituting these values into equation 4.5 gives the pile head stiffness matrix for the raked pile:

$$
[K]=\left(\begin{array}{rrr}
169.5 & -96.1 & 316.3 \\
-96.1 & 291.0 & 25.8 \\
316.3 & 25.8 & 1265.0
\end{array}\right)
$$

An important consequence of the raking of the pile is that the stiffness term at position 1,1 in the matrix is about twice that for the vertical pile. But even more significant are the large terms in positions 1,3 and 3,1 of the matrix. The first column of the above stiffness matrix gives the actions generated when the pile head is given unit horizontal displacement while the rotation and vertical displacement are constrained to be zero. The magnitude of the $\mathrm{K}_{3,1}$ means that a large vertical force will be generated at the head of the raked pile if it is restrained against vertical movement when a horizontal force is applied. This conclusion may go some way to explaining the observation noted in section 2.1.3 that raked piles are frequently observed to suffer more damage than vertical piles during earthquake loading.

\subsection{STIFFNESS OF PILE GROUPS}

We have two ways of representing soil-pile interaction. The Winkler model has no interaction between adjacent piles. On the other hand the elastic continuum model recognises that the deformation of a pile under load is accompanied by deformations of the surrounding soil which decrease with distance from the pile. This means that the application of load to one pile will cause movement of adjacent piles. The amount of the movement depends on the spacing between the piles and the pile properties in relation to those of the soil in which the pile is embedded. The effect of adjacent piles is quantified with the use of interaction factors defined, Poulos and Davis (1980), by:

$$
\begin{aligned}
& \alpha= \\
& \frac{\text { Movement caused by unit action on an adjacent pile }}{\text { Movement of the pile under unit head action }}
\end{aligned}
$$

The value of $\alpha$ depends on the spacing to diameter ratio of piles and the relative stiffness of the pile and soil. As the spacing increases $\alpha$ tends to zero. The displacement of a particular pile group is obtained by application of the principle of superposition. Poulos and Davis provide a number of charts from which the interaction factors can be obtained, alternatives are presented below.

A number of different configurations for pile groups are illustrated in Fig. 5.1. The fixed-head case is simply and extension of the idea given in Fig. 3.3. The free-standing and pile-raft cases are necessary to differentiate pile groups having contact with the underlying soil from those which do not.

Interaction factors are needed for pile - pile interaction under vertical, horizontal, and moment loading. The various cases are treated separately below. The example calculations are done for $2 \times 2$ and $3 \times 3$ pile groups. Extension to groups which are not square or which have more than a few piles is straight forward. In addition all the example calculations assume that the pile cap is rigid.
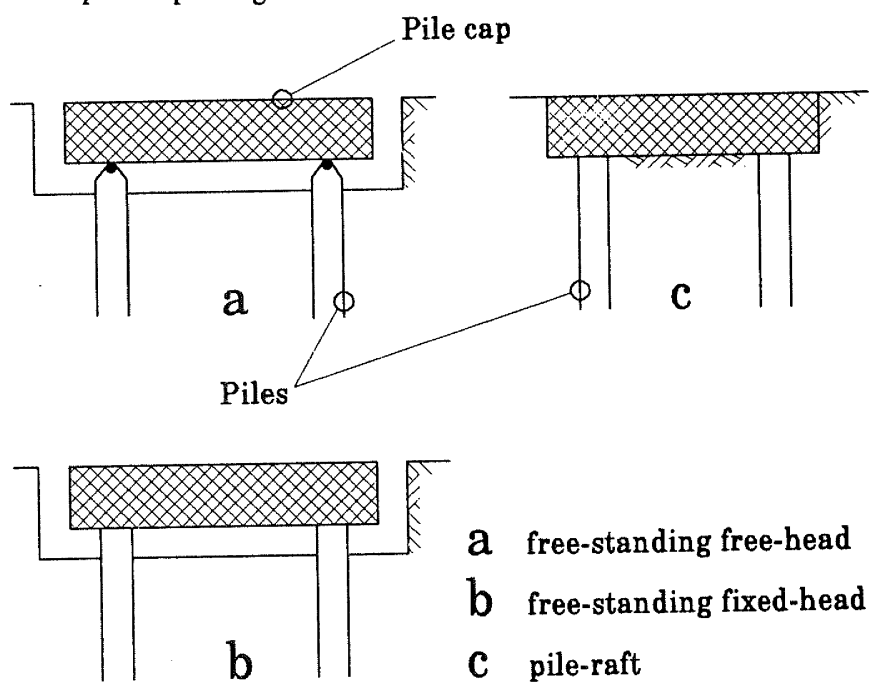

Fig. 5.1 Various pile group configurations. 


\subsection{Vertical stiffness of pile groups}

The vertical settlement of a particular pile in a group is given by:

$$
w_{k}=w_{1}\left(\sum_{j=1}^{n}\left(v_{j} \alpha_{v_{k j}}\right)\right)
$$

where: $w_{1}$ is the settlement of the pile under unit load

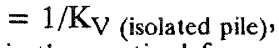

$V_{j}$ is the vertical force carried by the jth pile,

and $\alpha_{V_{k j}}$ is the interaction factor between piles $k$ and $j$,

$$
=1 \text { when } \mathrm{k}=\mathrm{j} \text {. }
$$

Randolf and Wroth (1979) provide a simple means for estimating interaction factors between rigid piles. They developed expressions for the vertical stiffness of a single pile and a $2 \times 1$ pile group. From these the interaction factor is obtained from:

$$
\alpha_{\mathrm{v}}=\frac{1-\frac{\mathrm{s}}{(\mathrm{D} / \pi+\mathrm{s})}+\pi(1-\nu) \rho \mathscr{L}\left(\frac{1}{\mathrm{\Upsilon}}-\frac{1}{\Gamma}\right)}{1+\pi(1-v) \rho \mathscr{L} / \Upsilon}
$$

where: $\mathrm{s}$ is the pile spacing (centre to centre),

$\rho$ is the ratio $\mathrm{E}_{\mathrm{SL} / 2} / \mathrm{E}_{\mathrm{SL}}$ (a measure of the inhomogeneity of the soil profile along the pile shaft $=1$ for a constant modulus profile, $=0.5$ for a linear distribution of modulus with depth, $\mathrm{E}_{\mathrm{SL}}$ is the soil modulus at the pile tip and $\mathrm{E}_{\mathrm{SL} / 2}$ is the modulus at a depth of $\mathrm{L} / 2$ ),

$\Upsilon$ is $\ln \left(2 r_{m} / D\right)$ with $r_{m}=2.5(1-v) \rho L$,

$\Gamma$ is $\ln \left(2 r_{m}^{2} / D s\right)$.

As an example of the use of this equation we will develop an expression for the vertical stiffness of a $2 \times 2$ pile group, the details of which are shown in Fig. 5.2. If unit load is applied to all the piles the settlement of each pile is:

$$
\mathrm{w}=\mathrm{w}_{1}\left(1+\alpha_{\mathrm{v} 12}+\alpha_{\mathrm{v} 13}+\alpha_{\mathrm{v} 14}\right)
$$

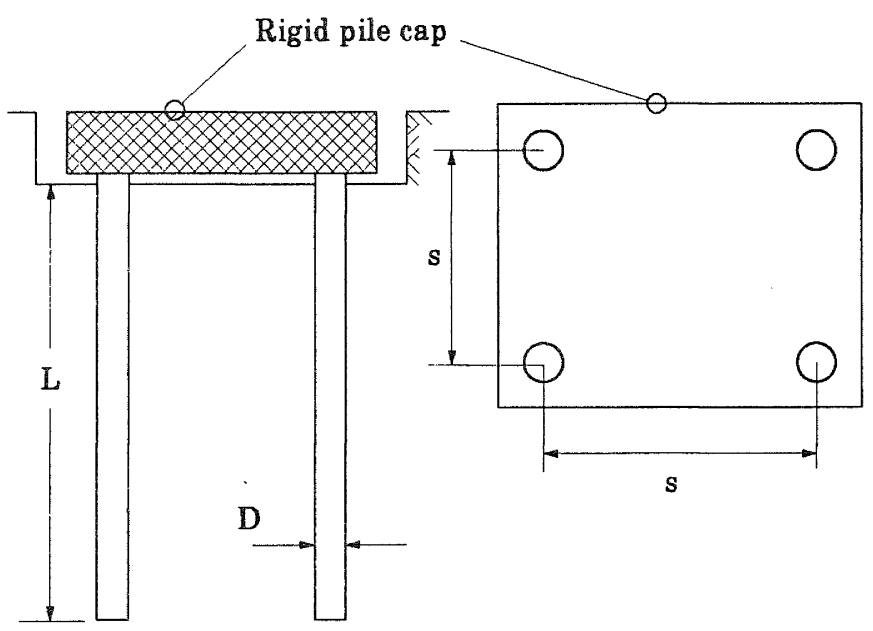

Fig. 5.2 Definition diagram for a free-standing fuxed-head $2 \times 2$ pile group. because of symmetry $\alpha_{\mathrm{v} 12}=\alpha_{\mathrm{v} 14}$, so that:

$$
\mathrm{w}=\mathrm{w}_{1}\left(1+2 \alpha_{\mathrm{v} 12}+\alpha_{\mathrm{v} 13}\right)
$$

Because we have a $2 \times 2$ pile group the load carried by all piles is the same, so the vertical stiffness of the group becomes:

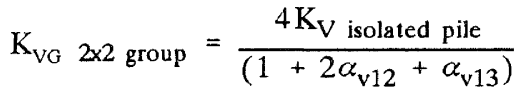

This result is easily generalised to cater for a group with $n$ piles:

$$
\mathrm{K}_{\mathrm{VG}} \text { n pile group }=\mathrm{K}_{\mathrm{V} \text { isolated pile }}\left(\sum_{\mathrm{i}=1}^{\mathrm{n}}\left(\frac{1}{\sum_{\mathrm{j}=1}^{\mathrm{n}} \alpha_{\mathrm{v}_{\mathrm{ij}}}}\right)\right)
$$

Example 5.1 Consider a $2 \times 2$ pile group having piles with the same dimensions and properties as those in example 4.1 and which are also embedded in the same soil profile. Estimate the vertical stiffness of the group when (i) the spacing is 5 pile diameters and (ii) when it is 10 pile diameters.

From the earlier example $K=1000$ and, from equation 4.1 ,

$$
\begin{aligned}
\mathrm{K}_{\mathrm{V}} & =1.9 \times 25 \times 0.75 \times 26.7^{0.67} \times 1000^{-0.03} \\
& =267.4 \mathrm{kN} / \mathrm{mm} \\
\mathrm{r}_{\mathrm{m}} & =2.5 \times(1-0.5) \times 20=25 \mathrm{~m} \\
\mathrm{\Upsilon} & =\ln (2 \times 25 / 0.75)=4.2 \\
\text { (i) } & 5 \text { pile diameters }
\end{aligned}
$$

Spacing between piles $1 \& 2$ and $1 \& 4$ is $5 \times 0.75=3.75 \mathrm{~m}$ This gives $\Gamma_{12}=\ln \left(2 \times 25^{2} / 0.75 \times 3.75\right)=6.10$.

Substitution into equation 5.3 gives $\alpha_{\mathrm{v} 12}=0.288$

Spacing between piles $1 \& 3$ is $5 \times \sqrt{2} \times 0.75=5.30 \mathrm{~m}$. This gives $\Gamma_{13}=\ln \left(2 \times 25^{2} / 0.75 \times 5.30\right)=5.75$.

Substitution into equation 5.3 gives $\alpha_{\mathrm{v} 13}=0.249$

$$
\begin{aligned}
\mathrm{K}_{\mathrm{VG}}= & 4 \times 267.4 /(1+2 \times 0.288+0.249) \\
& =586 \mathrm{kN} / \mathrm{mm}
\end{aligned}
$$

Considering the "efficiency" of the group as the ratio of the group vertical stiffness to the sum of the individual stiffnesses of the isolated piles, we find that the group has a vertical stiffness efficiency of $55 \%$.

(ii) 10 pile diameters

Spacing between piles $1 \& 2$ and $1 \& 4$ is $10 \times 0.75=7.5 \mathrm{~m}$ This gives $\Gamma_{12}=\ln \left(2 \times 25^{2} / 0.75 \times 3.75\right)=5.40$.

Substitution into equation 5.3 gives $\alpha_{\mathrm{v} 12}=0.205$

Spacing between piles $1 \& 3$ is $10 \times \sqrt{2} \times 0.75=10.6 \mathrm{~m}$. This gives $\Gamma_{13}=\ln \left(2 \times 25^{2} / 0.75 \times 5.30\right)=5.06$.

Substitution into equation 5.3 gives $\alpha_{\mathrm{v} 13}=0.156$ 
From equation 5.4:

$$
\begin{aligned}
\mathrm{K}_{\mathrm{VG}} & =4 \times 267.4 /(1+2 \times 0.205+0.156) \\
& =683 \mathrm{kN} / \mathrm{mm} .
\end{aligned}
$$

With this group stiffness we find that the group has a vertical stiffness efficiency of $64 \%$.

Usually the settlement of all the piles in a group will be the same, as the piles are connected to a rigid cap. This means that the vertical load will not be distributed equally amongst the piles of a group having many piles. Example 5.1 for a $2 \times 2$ group does not illustrate this.

Example 5.2 Consider a $3 \times 3$ pile group with a rigid pile cap carrying a vertical load of $1000 \mathrm{kN}$. The piles are the same as those for example 5.1. Find the vertical settlement of the group and the load carried by each pile for a pile spacing of 5 diameters.

The details of the example are given in the following diagram:

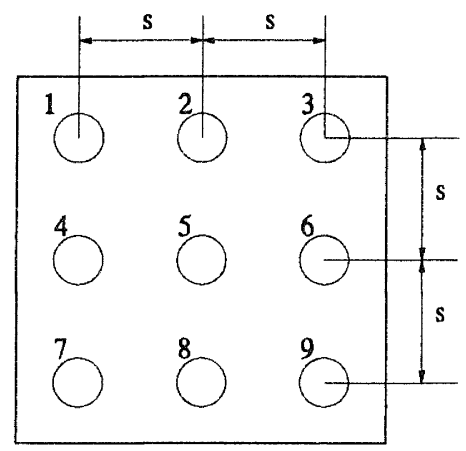

Piles $1,3,7, \& 9$ carry the same vertical load, $\mathrm{V}_{\mathrm{a}}$

Piles $2,4,6, \& 8$ carry the same vertical load, $\mathrm{V}_{\mathrm{b}}$

Piles 5 carries $V_{c}$

The preliminary details are as for example 5.1.

There is symmetry in the group so there are only three different pile forces, the force carried by the corner piles, that by the mid-side piles, and that by the centre pile. There are 5 different interactions to consider: $1 \Rightarrow 2,1 \Rightarrow 3,1 \Rightarrow 5,1 \Rightarrow$ 6 , and $1 \Rightarrow 9$. The steps in the calculation of the interaction factors with equation 5.3 are:

\begin{tabular}{|c|c|c|c|}
\hline $\begin{array}{c}\text { Inter- } \\
\text { action }\end{array}$ & $\begin{array}{c}\text { Spacing } \\
(\mathrm{m})\end{array}$ & $\Gamma$ & $\alpha_{\mathrm{v}}$ \\
\hline $1 \Rightarrow 2$ & 3.75 & 6.097 & 0.288 \\
\hline $1 \Rightarrow 3$ & 7.50 & 5.404 & 0.205 \\
\hline $1 \Rightarrow 5$ & 5.30 & 5.750 & 0.249 \\
\hline $1 \Rightarrow 6$ & 8.39 & 5.292 & 0.190 \\
\hline $1 \Rightarrow 9$ & 10.61 & 5.057 & 0.156 \\
\hline
\end{tabular}

As there are three different forces we need three equations to solve the system. Firstly from vertical equilibrium:

$$
V_{c}+4 V_{a}+4 V_{b}=V
$$

Since the pile cap is rigid the settlement of all the piles must be the same. From $w_{a}=w_{c}$

$$
\begin{gathered}
\left(1+2 \alpha_{\mathrm{v} 13}+\alpha_{\mathrm{v} 19}\right) \mathrm{V}_{\mathrm{a}}+2\left(\alpha_{\mathrm{v} 12}+\alpha_{\mathrm{v} 16}\right) \mathrm{V}_{\mathrm{b}}+\alpha_{\mathrm{v} 15} \mathrm{~V}_{\mathrm{c}}= \\
4 \alpha_{\mathrm{v} 15} \mathrm{~V}_{\mathrm{a}}+4 \alpha_{\mathrm{v} 12} \mathrm{~V}_{\mathrm{b}}+\mathrm{V}_{\mathrm{c}}
\end{gathered}
$$

From $w_{b}=w_{c}:$

$$
\begin{gathered}
2\left(\alpha_{\mathrm{v} 12}+\alpha_{\mathrm{v} 16}\right) \mathrm{V}_{\mathrm{a}}+\left(1+\alpha_{\mathrm{v} 13}+2 \alpha_{\mathrm{v} 16}\right) \mathrm{V}_{\mathrm{b}}+\alpha_{\mathrm{v} 12} \mathrm{~V}_{\mathrm{c}}= \\
4 \alpha_{\mathrm{v} 15} \mathrm{~V}_{\mathrm{a}}+4 \alpha_{\mathrm{v} 12} \mathrm{~V}_{\mathrm{b}}+\mathrm{V}_{\mathrm{c}}
\end{gathered}
$$

Making the required substitutions and solving the three equations gives:

$\mathrm{V}_{\mathrm{a}}=130, \mathrm{~V}_{\mathrm{b}}=102$, and $\mathrm{V}_{\mathrm{c}}=72 \mathrm{kN}$.

We see that the centre pile carries the smallest force and the corner piles the largest. The settlement of the group (evaluated for the centre pile) is:

$\mathrm{w}=\left(4 \alpha_{\mathrm{v} 15} \mathrm{~V}_{\mathrm{a}}+4 \alpha_{\mathrm{v} 12} \mathrm{~V}_{\mathrm{b}}+\mathrm{V}_{\mathrm{c}}\right) / 267.4=1.2 \mathrm{~mm}$.

The vertical stiffness of the group is:

$\mathrm{K}_{\mathrm{VG}}=1000 / 1.2=833 \mathrm{kN} / \mathrm{mm}$.

The stiffness efficiency of the group is: $833 \times 100 / 9 \times 267.4=$ $35 \%$.

\subsection{Rotational stiffness of a free-head free-standing pile group}

The mechanism by which this stiffness is generated is shown in Fig. 5.3. As the piles of the group are of the free-head variety the piles themselves offer no rotational restraint. Thus the rotational stiffness of the group is generated by the vertical stiffness of the piles. If the moment acts about an axis parallel to one the sides of the group then two of the piles will receive an increment of downward force and two will

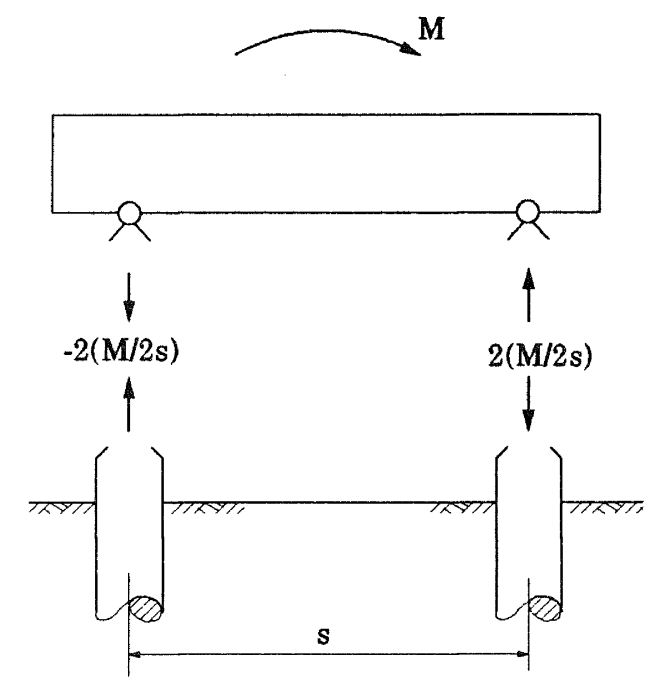

Fig. 5.3 Rotational stiffness mechanism for a free-standing free-head pile group. 
receive an increment of upward force i.e. the loading is asymmetrical. The vertical force increments carried by the piles of a $2 \times 2$ group, as a consequence of the moment $M$, are $\pm \mathrm{M} / 2 \mathrm{~s}$. The vertical displacement of the piles caused by the moment is now:

$$
\mathrm{w}= \pm \mathrm{V}_{1} \mathrm{w}_{1}\left(1+\alpha_{\mathrm{v} 14}-\alpha_{\mathrm{v} 12}-\alpha_{\mathrm{v} 13}\right)
$$

because of symmetry $\alpha_{14}=\alpha_{12}$, so the pile displacement is:

$$
\mathrm{w}=\frac{ \pm M w_{1}\left(1-\alpha_{\mathrm{v} 13}\right)}{2 \mathrm{~s}}
$$

The rotation of the pile group is:

$$
\theta=\frac{\mathrm{Mw}_{1}\left(1-\alpha_{\mathrm{v} 13}\right)}{\mathrm{s}^{2}}
$$

Thus the rotational stiffness from the asymmetric axial loading of the piles becomes:

$$
\mathrm{K}_{\theta \mathrm{V} 2 \times 2 \text { group }}=\frac{\mathrm{K}_{\mathrm{V} \text { isolated pile }} \mathrm{s}^{2}}{\left(1-\alpha_{\mathrm{v} 13}\right)}
$$

Example 5.3 Consider a $2 \times 2$ free standing free head pile group with a moment applied about an axis parallel to the side. The piles and soil profile are the same as in examples 5.1 and 5.2 , the pile spacing is 5 diameters. Evaluate the rotational stiffness of the group.

Substituting into equation 5.5 gives:

$\begin{aligned} \mathrm{K}_{\theta \mathrm{V}} & =267.4 \times(5 \times 0.75)^{2} /(1-0.249) \\ & =5007 \mathrm{kNm} / \mathrm{mrad} .\end{aligned}$

Example 5.4 Consider the same pile group as in example 5.3 but now evaluate the rotational stiffness about a diagonal axis.

The applied moment is equilibrated by vertical forces generated in the piles off the diagonal about which the moment is applied. The piles on the diagonal axis carry no force generated by the the moment. If the force is denoted by $\Delta \mathrm{V}$ then the settlement of the corner piles is:

the rotation is:

$$
\mathrm{w}=\mathrm{w}_{1} \Delta \mathrm{V}\left(1-\alpha_{\mathrm{v} 13}\right)
$$

the moment is:

$$
\theta=2 \mathrm{w} / \sqrt{2} \mathrm{~s}
$$

The rotational stiffness is:

$$
\mathrm{M}=\sqrt{2} \mathrm{~s} \Delta \mathrm{V}
$$

$$
\begin{aligned}
\mathrm{K}_{\theta \mathrm{V} \text { diag }} & =\mathrm{M} / \theta=\mathrm{s}^{2} / \mathrm{w}_{1}\left(1-\alpha_{\mathrm{v} 13}\right) \\
& =5007 \mathrm{kNm} / \mathrm{mrad}
\end{aligned}
$$

\subsection{LATERAL STIFFNESS OF PILE GROUPS}

Poulos and Davis (1980) introduce interaction factors for laterally loaded piles:

$$
\alpha_{\mathbf{u}}=
$$

Displacement caused by unit action on an adjacent pile Displacement from unit action applied at pile head

$\alpha_{\theta}=$

Rotation caused by unit action on an adjacent pile Rotation from unit action applied at the pile head

There are a number of different types of lateral interaction factors:

$\alpha_{\mathrm{uH}} \alpha_{\theta \mathrm{H}}$ : values of $\alpha_{\mathrm{u}}$ and $\alpha_{\theta}$ for a free head pile subject to horizontal load only,

$\alpha_{\mathrm{uM}} \alpha_{\theta \mathrm{M}}:$ values of $\alpha_{\mathrm{u}}$ and $\alpha_{\theta}$ for a free head pile subject to moment loading only,

$\alpha_{\mathrm{uF}}: \quad$ value of $\alpha_{\mathrm{u}}$ for a fixed head pile group.

Values of $\alpha$ for various conditions are given by Poulos and Davis. For a two pile group 17 diagrams are needed to cover the range of possibilities. The use of the simple formulae given below is thus an attractive alternative.

The horizontal displacements for a group containing more than two piles are obtained from an equation similar to that for the vertical displacement of a vertically loaded pile group. For a pile group with $\mathrm{n}$ free head piles the displacement of pile $\mathrm{k}$ is given by:

$$
u_{k}=u_{1}\left(\sum_{j=1}^{n}\left(H_{j} \alpha_{u H_{k j}}\right)\right)
$$

where: $\mathrm{u}_{1}$ is the displacement of an isolated free head pile under unit horizontal force $\left(=\mathrm{f}_{\mathrm{uH}}\right)$,

$\mathrm{H}_{\mathrm{j}}$ is the horizontal force carried by pile $\mathrm{j}, \alpha_{\mathrm{uHkj}}$ is the value of $\alpha_{\mathrm{uH}}$ for piles $\mathrm{k}$ and $\mathrm{j}$ corresponding to the spacing between them and the angle between the direction of loading and the line joining the centres of the piles, Fig. 5.4, $\alpha_{\mathrm{uHkj}}=1$ when $\mathrm{j}=\mathrm{k}$.

In addition there is an equilibrium equation for the group:

$$
H=\sum_{j=1}^{n} H_{j}
$$

In a free head pile group with $\mathrm{n}$ piles, each sustaining a

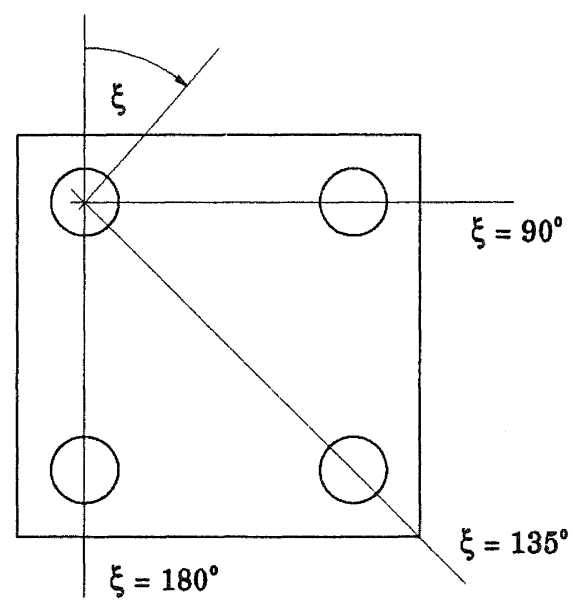

Fig. 5.4 Angular relationship between various piles in a group. 
known force, there are $\mathrm{n}$ unknown pile displacements. In a fixed head pile group there are $n+1$ unknowns: the $n$ pile forces and the displacement. Symmetry of a pile group can be used to reduce the number of unknowns. The displacement of a fixed head group is obtained with equation 5.8 in which the appropriate unit reference displacement for a single pile in the group.

Randolf (1981) gives the following equation for $\alpha_{\mathrm{uF}}$ :

$$
\alpha_{\mathrm{uF}}=0.3\left(\frac{\mathrm{D}}{\mathrm{s}}\right)[2(1+v) \mathrm{K}]^{0.143}\left(1+\cos ^{2} \xi\right) \quad 5.10 \mathrm{a}
$$

where: $\xi$ is defined in Fig. 5.4.

If the values for $\alpha_{\mathrm{uF}}$ calculated with equation 5.10a exceed 0.5 Randolf substitutes the following:

$$
\alpha_{\mathrm{uF}}=1-\frac{1}{4 \alpha_{\mathrm{uF}} \text { from } 5.10 \mathrm{a}}
$$

The value of $\alpha_{\mathrm{uF}}$ given by equation 5.10 is applicable to a soil profile having a constant modulus with depth. Randolf suggests that for a profile with a linear distribution of modulus with depth that $\alpha_{\mathrm{uF}}$ is half that from the above equation.

Example 5.5 Consider a $2 \times 2$ fixed-head pile group with the same properties as that in example 5.1. For a pile spacing of 5 diameters and zero rotation of the pile cap determine the lateral stiffness of the groupK $\mathrm{K}_{\mathrm{HFG}}$.

The layout of the pile group is as follows:

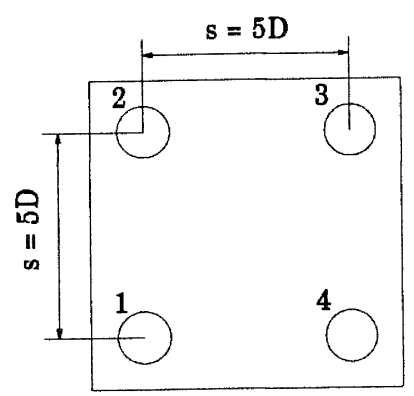

From the inverse of equation 3.24 the lateral stiffness of an isolated fixed head pile in a uniform soil profile is:

$\mathrm{K}_{\mathrm{HF}}=25 \times 0.75 / 0.8 \times 1000^{-0.18}=81.3 \mathrm{MN} / \mathrm{m}(\mathrm{kN} / \mathrm{mm})$.

The constant term for the interaction factors is:

$C=0.3 \times 0.75 \times(2 \times(1+0.5) \times 1000)^{0.143}=0.707$

The steps in the calculation of the interaction factors with equation 5.10 are given in the table at the top of the next column.

Using these interaction factors the lateral stiffness of the group is:

$\mathrm{K}_{\mathrm{HFG}}=4 \times 81.3 /(1+0.377+0.189+0.20)=184.1 \mathrm{kN} / \mathrm{mm}$.

\begin{tabular}{|c|c|c|c|}
\hline $\begin{array}{c}\text { Inter- } \\
\text { action }\end{array}$ & $\begin{array}{c}\text { Spacing } \\
\text { metres }\end{array}$ & $\xi$ & $\alpha_{\mathrm{uF}}$ \\
\hline $1 \Rightarrow 2$ & 3.75 & 0 & 0.377 \\
\hline $1 \Rightarrow 3$ & 5.30 & 45 & 0.189 \\
\hline $1 \Rightarrow 4$ & 3.75 & 90 & 0.200 \\
\hline
\end{tabular}

Example 5.6 Extend example 5.5 to cover a $3 \times 3$ fixed head pile group which is subject to a horizontal force of $1000 \mathrm{kN}$.

There are now nine piles and each interacts with the other eight. The full matrix of $\xi$ angles is:

$$
=\left(\begin{array}{rrrrrrrrr}
0 & 0 & 0 & 90 & 45 & 27 & 90 & 63 & 45 \\
180 & 0 & 0 & 135 & 90 & 45 & 117 & 90 & 63 \\
180 & 180 & 0 & 153 & 135 & 90 & 135 & 117 & 90 \\
90 & 45 & 27 & 0 & 0 & 0 & 90 & 45 & 27 \\
135 & 90 & 45 & 180 & 0 & 0 & 135 & 90 & 45 \\
153 & 135 & 90 & 180 & 180 & 0 & 153 & 135 & 90 \\
90 & 63 & 45 & 90 & 45 & 27 & 0 & 0 & 0 \\
117 & 90 & 63 & 135 & 90 & 45 & 180 & 0 & 0 \\
135 & 117 & 90 & 153 & 135 & 90 & 180 & 180 & 0
\end{array}\right)
$$

The first row of the $\xi$ matrix deals with the interactions for pile 1 (using the numbering of the figure in example 5.2). The first entry in the row is the angle between pile 1 and itself, the second is between pile 1 and 2, the third between pile 1 and 3 , the fourth entry in row one is the angle from pile 1 to pile 4 , the seventh is the angle from pile 1 to pile 7, and the final value in the first row is the angle from pile 1 to pile 9 . Each succeeding row deals with the interaction angles for one of the other piles, the second row for pile 2 and the third for pile 3 etc. The pattern of values in the matrix indicates the symmetry of the pile group.

The interaction factors calculated with equation 5.10 are:

$\alpha_{\mathrm{hF}}=$

$\left(\begin{array}{ccccccccc}1 & 0.377 & 0.189 & 0.189 & 0.200 & 0.152 & 0.094 & 0.101 & 0.100 \\ 0.377 & 1 & 0.377 & 0.200 & 0.189 & 0.200 & 0.101 & 0.094 & 0.101 \\ 0.189 & 0.377 & 1 & 0.152 & 0.200 & 0.189 & 0.100 & 0.101 & 0.094 \\ 0.189 & 0.200 & 0.152 & 1 & 0.377 & 0.189 & 0.189 & 0.200 & 0.152 \\ 0.200 & 0.189 & 0.200 & 0.377 & 1 & 0.377 & 0.200 & 0.189 & 0.200 \\ 0.152 & 0.200 & 0.189 & 0.189 & 0.377 & 1 & 0.152 & 0.200 & 0.189 \\ 0.094 & 0.101 & 0.100 & 0.189 & 0.200 & 0.152 & 1 & 0.377 & 0.189 \\ 0.101 & 0.094 & 0.101 & 0.200 & 0.189 & 0.200 & 0.377 & 1 & 0.377 \\ 0.100 & 0.101 & 0.094 & 0.152 & 0.200 & 0.189 & 0.189 & 0.377 & 1\end{array}\right)$

These are interpreted in the same manner as the above matrix for interaction angles. The diagonal terms equal to 1.0 account for each pile interacting with itself. It is apparent that there is symmetry in the table which could be exploited in solving the equations.

The equations which have to be solved to obtain the unknown actions are an equilibrium equation and eight equations obtained by equating horizontal displacements, $\mathrm{u}_{1}=\mathrm{u}_{2}, \mathrm{u}_{2}=$ $\mathrm{u}_{3}$ etc. This gives a system of equations of the form: 


$$
\mathbb{C H}=\mathbb{L}
$$

where: $\mathbb{C}$ is a $9 \times 9$ matrix of coefficients,

$\mathbb{H}$ is a vector of pile loads, with a transpose:

$\left(\mathrm{H}_{1}, \mathrm{H}_{2}, \mathrm{H}_{3}, \mathrm{H}_{4}, \mathrm{H}_{5}, \mathrm{H}_{6}, \mathrm{H}_{7}, \mathrm{H}_{8}, \mathrm{H}_{9}\right)$

and $\mathbb{L}$ is the applied load vector, with a transpose:

$$
(0,0,0,0,0,0,0,0, \mathrm{H}) \text {. }
$$

The coefficient matrix is:

$$
\begin{aligned}
& \mathbb{C}= \\
& \left(\begin{array}{rrrrrrrrr}
0.62 & -0.62 & -0.19 & -0.01 & 0.01 & -0.05 & -0.01 & 0.01 & -0.00 \\
0.19 & 0.62 & -0.62 & 0.05 & -0.01 & 0.01 & 0.00 & -0.01 & 0.01 \\
0.0 & 0.18 & 0.85 & -0.85 & -0.18 & 0.0 & -0.09 & -0.10 & -0.06 \\
-0.01 & 0.01 & -0.05 & 0.62 & -0.62 & -0.19 & -0.01 & 0.01 & -0.05 \\
0.05 & -0.01 & 0.01 & 0.19 & 0.62 & -0.62 & 0.05 & -0.01 & 0.01 \\
0.05 & 0.10 & 0.09 & 0.0 & 0.18 & 0.85 & -0.85 & -0.18 & 0.0 \\
-0.01 & 0.01 & -0.00 & -0.01 & 0.01 & -0.05 & 0.62 & -0.62 & -0.19 \\
0.00 & -0.01 & 0.01 & 0.05 & -0.01 & 0.01 & 0.19 & 0.62 & -0.62 \\
1.0 & 1.0 & 1.0 & 1.0 & 1.0 & 1.0 & 1.0 & 1.0 & 1.0
\end{array}\right)
\end{aligned}
$$

The first row of the coefficient matrix is obtained from equating $u_{1}$ and $u_{2}$, thus it is the difference between the row 1 and 2 of the $\alpha_{\mathrm{hF}}$ matrix; row 2 of $\mathbb{C}$ is the difference between rows 2 and 3 of $\alpha_{\mathrm{hF}}$ etc. The final row of $\mathbb{C}$ is the equilibrium equation.

The solution of this set of equations, with $\mathbb{H}$ expressed as a $3 \times 3$ matrix to show the distribution of load on the piles of the group, is:

$$
\mathrm{H}_{\mathrm{p}}=\left(\begin{array}{lll}
138.1 & 85.8 & 138.1 \\
110.9 & 54.1 & 110.9 \\
138.1 & 85.8 & 138.1
\end{array}\right) \mathrm{kN}
$$

Once the pile head forces have been obtained the head moments can be found using equation 3.25.

The lateral displacement of the group is obtained by substitution of the loads and the influence coefficients into equation 5.8. Performing the calculations for pile 1 gives:

$$
\begin{aligned}
\mathrm{u}_{\mathrm{G}} \quad= & (1 / 81.3) \times(1.0 \times 138.1+0.377 \times 85.8+0.189 \times 138.1 \\
& +0.189 \times 110.9+0.200 \times 54.1+0.152 \times 110.9 \\
& +0.094 \times 138.1+0.101 \times 85.8+0.100 \times 138.1) \\
= & 3.45 \mathrm{~mm} .
\end{aligned}
$$

The lateral stiffness of the pile group is:

$\mathrm{K}_{\mathrm{HFG}}=1000 / 3.45=290 \mathrm{kN} / \mathrm{mm}$.

The efficiency of the group is: $290 \times 100 / 9 \times 81.3=40 \%$.

Randolf gives the following relations for calculating other interaction factors from $\alpha_{\mathrm{uF}}$ : factors are obtained from:

$$
\begin{aligned}
\alpha_{\mathrm{uH}} & =\frac{5 \alpha_{\mathrm{uF}}}{6} \\
\alpha_{\mathrm{uM}} & \approx \alpha_{\theta \mathrm{H}} \approx \alpha_{\mathrm{uH}}^{2} \\
\alpha_{\theta \mathrm{M}} & \approx \alpha_{\mathrm{uH}}^{3}
\end{aligned}
$$

These equations show that rotational interaction between piles is less than that for horizontal displacement.
Example 5.7 Return to example 5.5 and evaluate the lateral stiffness of the group if the pile heads are free.

As we have the free head condition there will be no moment at the pile head. Equation 5.11 gives $\alpha_{\mathrm{uH}}=0.833 \alpha_{\mathrm{uF}}$.

From example 3.3 we have, for the piles in this example, $f_{u h}$ $=1.97 \times 10^{-2}$ (this is the lateral displacement of a free head pile under unit horizontal load). Thus $\mathrm{K}_{\mathrm{h}}$ for an isolated pile is $50.8 \mathrm{kN} / \mathrm{mm}$. The group lateral stiffness is now:

$$
\begin{aligned}
\mathrm{K}_{\mathrm{HG}} & =4 \times 50.8 / 0.833(1+0.377+0.189+0.200) \\
& =138 \mathrm{kN} / \mathrm{mm}
\end{aligned}
$$

The calculation of the group lateral stiffness in this example could be done with an equation similar to 5.4. Equation 5.4 gives the group vertical stiffness and consequently has $\alpha_{\mathrm{v}}$ for the interaction coefficient. An equation of the same form with $\alpha_{\mathrm{uH}}$ instead of $\alpha_{\mathrm{v}}$ would give $\mathrm{K}_{\mathrm{HG}}$ directly. Similarly an equation with $\alpha_{\mathrm{uF}}$ would give $\mathrm{K}_{\mathrm{HFG}}$.

\subsection{Stiffness of a fixed head free standing pile group}

There is now a fixing moment at the pile head so the applied moment is spilt between the part carried by the moments at the pile heads and the part carried by the moment generated by axial force increments in the pile shafts. This axial force mechanism is essentially the same as the free head case illustrated in Fig. 5.5. The coupling between the pile head response to moment and shear complicates the calculation of the response of a fixed head group. For a fixed head pile the rotation of the head is the same as that of the pile cap. This compatibility condition gives a means of dividing the applied moment between the two mechanisms. Note that this broadens our definition of a fixed head group. Thus far a fixed head pile or pile group has been understood to have zero head rotation. Now we allow some rotation of the pile cap (as must occur when moment loading is applied) but still regard the group as having a fixed head if the rotation of the pile cap is the same as that of the pile head.

The material presented in this section is developed for $2 \times 2$ pile groups. Extension to groups with a larger number of piles is along the same lines as the work in examples 5.5 and 5.6 in going from $2 \times 2$ to $3 \times 3$ groups.

Since we have a $2 \times 2$ group the horizontal load and the portion of the moment not equilibrated by axial loading of the piles are shared equally between the 4 piles. Using equations $3.15,3.5$ and 3.10 to write the rotational compatibility conditions gives:

$$
\begin{aligned}
\frac{\mathrm{M}-4 \mathrm{M}_{\mathrm{p}}}{\mathrm{K}_{\theta \mathrm{V}}}= & \mathrm{H}_{\mathrm{p}} \mathrm{f}_{\theta \mathrm{H}}\left(1+\alpha_{\theta \mathrm{H}_{12}}+\alpha_{\theta \mathrm{H}_{13}}+\alpha_{\theta \mathrm{H}_{14}}\right) \\
& +\mathrm{M}_{\mathrm{p}} \mathrm{f}_{\theta \mathrm{M}}\left(1+\alpha_{\theta \mathrm{M}_{12}}+\alpha_{\theta \mathrm{M}_{13}}+\alpha_{\theta \mathrm{H}_{14}}\right)
\end{aligned}
$$

where: $M_{p}$ is the moment generated at the pile head, and $\quad \mathrm{H}_{\mathrm{p}}$ is the horizontal force carried by each pile head.

Once $M_{p}$ is obtained the rotation and lateral displacement of the pile group can be evaluated. 
Example 5.8 Consider the same $2 \times 2$ pile group as in example 5.5. When a horizontal force of $1000 \mathrm{kN}$ and a moment of $1000 \mathrm{kNm}$ are applied to the pile cap find $\mathrm{u}$ and $\theta$, and the actions developed in the pile shafts.

Example 5.3 gives $\mathrm{K}_{\theta \mathrm{V}}=5007 \mathrm{kNm} / \mathrm{mrad}$ and $1 / \mathrm{K}_{\theta \mathrm{V}}=$ $2.0 \times 10^{-4}$. From example 3.3 we have $\mathrm{f}_{\mathrm{uH}}=1.97 \times 10^{-2}, \mathrm{f}_{\theta \mathrm{H}}=$ $6.75 \times 10^{-3}$, and $\mathrm{f}_{\theta \mathrm{M}}=5.57 \times 10^{-3}$.

We can use the $\alpha_{\mathrm{uF}}$ values from example 5.5 and obtain the other values from equation 5.10 , the results are given in the following table:

\begin{tabular}{|c|c|c|c|c|}
\hline $\begin{array}{c}\text { Inter- } \\
\text { action }\end{array}$ & $\alpha_{\mathrm{uF}}$ & $\alpha_{\mathrm{uH}}$ & $\begin{array}{c}\alpha_{\mathrm{uM}}= \\
\alpha_{\theta \mathrm{H}}\end{array}$ & $\alpha_{\theta \mathrm{M}}$ \\
\hline $1 \Rightarrow 2$ & 0.377 & 0.314 & 0.099 & 0.031 \\
\hline $1 \Rightarrow 3$ & 0.189 & 0.158 & 0.025 & 0.004 \\
\hline $1 \Rightarrow 4$ & 0.200 & 0.167 & 0.028 & 0.005 \\
\hline
\end{tabular}

Substituting these interaction values into the terms in the above equation gives:

$$
\begin{aligned}
& \mathrm{f}_{\theta \mathrm{H}}\left(1+\alpha_{\theta \mathrm{H} 12}+\alpha_{\theta \mathrm{H} 13}+\alpha_{\theta \mathrm{H} 14}\right)= \\
& \quad 6.75 \times 10^{-3} \times(1+0.099+0.025+0.028)=7.78 \times 10^{-3} \\
& \mathrm{f}_{\theta \mathrm{M}}\left(1+\alpha_{\theta \mathrm{M} 12}+\alpha_{\theta \mathrm{M} 13}+\alpha_{\theta \mathrm{M} 14}\right)= \\
& \quad 5.57 \times 10^{-3} \times(1+0.031+0.004+0.005)=5.79 \times 10^{-3}
\end{aligned}
$$

Substituting these values into the above compatibility equation leads to the solution for $\mathrm{M}_{\mathrm{p}}$ :

$$
\begin{aligned}
& \mathrm{M}_{\mathrm{p}}\left(5.79 \times 10^{-3}+4 \times 2.0 \times 10^{-4}\right) \\
& \quad=1000 \times 2.0 \times 10^{-4}-250 \times 7.78 \times 10^{-3} \\
& \mathrm{M}_{\mathrm{p}}=-265 \mathrm{kNm} . \\
& \begin{aligned}
\theta= & 250 \times 7.78 \times 10^{-3}-265 \times 5.79 \times 10^{-3} \\
& =0.411 \mathrm{mrad} .
\end{aligned}
\end{aligned}
$$

For the horizontal displacement we need $f_{u H}$ and the appropriate interaction factors:

$$
\begin{aligned}
\mathrm{f}_{\mathrm{uH}}\left(1+\alpha_{\mathrm{uH} 12}+\alpha_{\mathrm{uH} 13}+\alpha_{\mathrm{uH} 14}\right)= \\
\\
\quad 1.97 \times 10^{-2} \times(1+0.314+0.158+0.167)=3.23 \times 10^{-2} \\
\mathrm{u}=250 \times 3.23 \times 10^{-2}-265 \times 7.78 \times 10^{-3} \\
\quad=6 \mathrm{~mm} .
\end{aligned}
$$

The moment carried by the pile axial force mechanism is:

$$
\mathrm{M}_{\mathrm{V}}=\theta \mathrm{K}_{\theta \mathrm{V}}=0.411 \times 5007=2058 \mathrm{kNm}
$$

(Check: $\left.M-4 M_{p}=2060\right)$

Vertical force induced in each of the piles:

$\mathrm{V}=\mathrm{M}_{\mathrm{V}} / 2 \mathrm{~s}=2058 / 2 \times 3.75=274.4 \mathrm{kN}$
The vertical settlement of the piles is obtained from $\theta$ via the rigid pile cap assumption:

$\mathrm{w}=\theta \mathrm{s} / 2=0.411 \times 3.75 / 2=0.8 \mathrm{~mm}$

The calculations in example 5.8 can be extended to handle pile groups with more than 4 piles. Additional work is involved as each pile does not carry the same force. If the pile group stiffness is required for the purpose of obtaining an estimate of the lateral displacement and rotation the following approximation is suggested. We will neglect the variation in pile head and calculate average flexibility values for the group. Calculations for $3 \times 3$ groups have shown that this approximation is acceptable and does away with the need to solve a set of simultaneous equations before the group stiffness can be obtained. As the number of piles in the group increases the distribution of pile head actions tends to become more uniform, so the approximation involved in the assumption is not serious This simplification enables us to write a stiffness matrix for the pile group similar to the pile head stiffness matrix discussed in section 3.5 .

The components of the pile group stiffness matrix, $\mathrm{K}_{\mathrm{HHG}}$, $\mathrm{K}_{\mathrm{HMG}}=\mathrm{K}_{\mathrm{MHG}}$, and $\mathrm{K}_{\mathrm{MMG}}$ are obtained from:

$$
\left[\mathrm{K}_{\mathrm{G}}\right]=\left(\begin{array}{ll}
\mathrm{F}_{\mathrm{uH}} & \mathrm{F}_{\mathrm{uM}} \\
\mathrm{F}_{\theta \mathrm{H}} & \mathrm{F}_{\theta \mathrm{M}}
\end{array}\right]^{-1}
$$

where (the double summation is required to get the average flexibility values for the group):

$$
\begin{gathered}
\mathrm{F}_{\mathrm{uH}}=\frac{\mathrm{f}_{\mathrm{uH} \text { (isolated pile) }}}{\mathrm{n}}\left(\sum_{\mathrm{i}=1}^{\mathrm{n}}\left[\sum_{\mathrm{j}=1}^{\mathrm{n}} \alpha_{\mathrm{uH}}\right]\right) \\
\mathrm{F}_{\mathrm{uM}}=\mathrm{F}_{\theta \mathrm{H}}=\frac{\mathrm{F}_{\mathrm{uM} \text { (isolated pile) }}}{\mathrm{n}}\left[\sum_{\mathrm{i}=1}^{\mathrm{n}}\left[\sum_{\mathrm{j}=1}^{\mathrm{n}} \alpha_{\theta \mathrm{H}_{\mathrm{ij}}}\right]\right) \\
\mathrm{F}_{\theta \mathrm{M}}=\frac{\mathrm{F}_{\theta \mathrm{M} \text { (isolated pile) }}}{\mathrm{n}}\left[\sum_{\mathrm{i}=1}^{\mathrm{n}}\left[\sum_{\mathrm{j}=1}^{\mathrm{n}} \alpha_{\theta \mathrm{M}_{\mathrm{ij}}}\right]\right)
\end{gathered}
$$

In addition to stiffness terms associated with the pile heads the group stiffness matrix includes a term for the rotational stiffness derived from the asymmetric axial loading of the piles, $\mathrm{K}_{\theta \mathrm{V}}$.

Following the steps outlined in section 3.5 we obtain equivalent horizontal and lateral stiffnesses for the pile group. These are given by:

$$
\mathrm{K}_{\mathrm{hG}}=\frac{\tilde{\mathrm{K}}_{\mathrm{HH}} \tilde{\mathrm{K}}_{\mathrm{MM}}-\tilde{\mathrm{K}}_{\mathrm{HM}}^{2}+\mathrm{K}_{\theta \mathrm{V}} \tilde{\mathrm{K}}_{\mathrm{HH}}}{\tilde{\mathrm{K}}_{\mathrm{MM}}-\mathrm{e} \tilde{\mathrm{K}}_{\mathrm{HM}}+\mathrm{K}_{\theta \mathrm{V}}}
$$

where: $\mathrm{K}_{\mathrm{hG}}$ is the horizontal stiffness of the pile group.

$$
\mathrm{K}_{\theta \mathrm{G}}=\frac{\tilde{\mathrm{K}}_{\mathrm{HH}} \tilde{\mathrm{K}}_{\mathrm{MM}}-\tilde{\mathrm{K}}_{\mathrm{HM}}^{2}+\mathrm{K}_{\theta \mathrm{V}} \tilde{\mathrm{K}}_{\mathrm{HH}}}{\tilde{\mathrm{K}}_{\mathrm{HH}}-\tilde{\mathrm{K}}_{\mathrm{HM}} / \mathrm{e}}
$$

where: $\mathrm{K}_{\theta \mathrm{G}}$ is the rotational stiffness of the pile group. 
These two equations can be used to estimate the rotation and horizontal displacement when a moment and a horizontal force are applied to the pile group.

A $3 \times 3$ pile group stiffness matrix could be written including the group vertical stiffness (similar to $[\mathrm{K}]$ in section 4.3 ). However, this has not been done here as there is no coupling between the vertical stiffness terms and those for horizontal and rotational effects.

\subsection{Torsional stiffness of a free standing free head pile group}

The torsional response of a pile group may be needed if there is some asymmetry in the structure supported. Torsional actions applied to a group are resisted by the couples generated by lateral forces induced at the pile heads.

Example 5.9 Evaluate the torsional stiffness of the $2 \times 2$ pile group considered in example 5.5.

The mechanism by which the torsional resistance of a $2 \times 2$ group is mobilised is given in the following diagram:

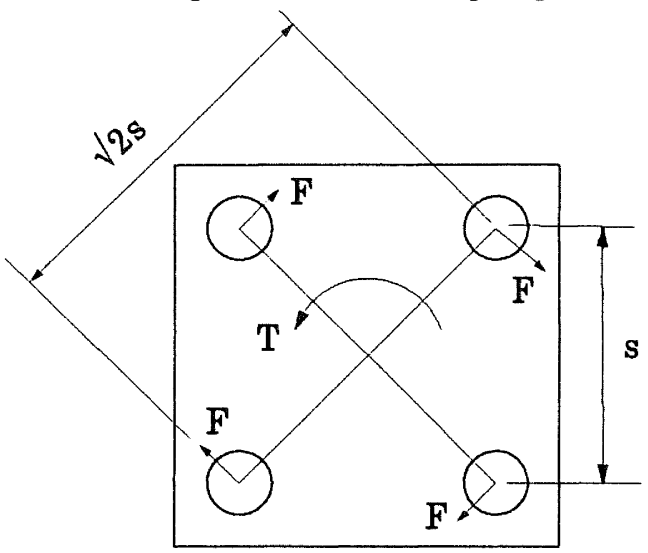

The forces generated by the torque are applied to the pile heads and are perpendicular to the diagonals of the group, we will denote the magnitude of these as F; they are split into components $F / \sqrt{2}$ acting parallel to the sides of the pile group.

We need $\mathrm{f}_{\mathrm{uH}}$; from example 3.5 this is $1.2 \times 10^{-3}$. As the loads induced on each pile have the same magnitude we can sum the $\alpha_{\mathrm{uF}}$ values (tabulated in example 5.8). As the loading is asymmetrical two values of $\alpha_{\mathrm{uF}}$ have a negative sign. Thus:

$$
\begin{aligned}
& \mathrm{f}_{\theta \mathrm{H}}\left(1+\alpha_{\theta \mathrm{H} 12}+\alpha_{\theta \mathrm{H} 13}+\alpha_{\theta \mathrm{H} 14}\right)= \\
& \quad 1.20 \times 10^{-3} \times(1+0.377-0.189-0.200)=1.19 \times 10^{-3}
\end{aligned}
$$

The displacement (due to two orthogonal loads of $F / \sqrt{2}$ ) of each pile head is then:

$\mathrm{u}=\sqrt{2} \times(\mathrm{F} / \sqrt{2}) \times 1.19 \times 10^{-3}$

From these displacements we obtain the torsional rotation of the group:

$$
\phi=2 \mathrm{u} / \sqrt{2} \mathrm{~s}
$$

The total torque applied to the pile group is:
$\mathrm{T}=2(\sqrt{2} \mathrm{Fs})$

The torsional stiffness is:

$$
\begin{aligned}
\mathrm{K}_{\phi \mathrm{G}} & =\mathrm{T} / \phi=2 \mathrm{Fs}^{2} / \mathrm{u}=2 \times 3.75^{2} / 1.19 \times 10^{-3} \\
& =236.3 \mathrm{kNm} / \mathrm{mrad} .
\end{aligned}
$$

\subsection{Stiffness of pile-rafts}

A pile-raft has contact between the underside of the pile cap and the soil in which the piles are embedded. In addition there may be contact between the sides of the raft and the underlying soil. This means there are load sharing mechanisms other than those we have discussed above, as the interface between the soil and raft is capable of providing shear and moment resistance. The compatibility requirement, with the assumption that the structure attached to the piles is rigid, of equality of rotations and displacements can be used to determine how much of the load and moment is carried by the raft. This calculation requires knowledge of the rotational and lateral stiffness of a raft. These stiffnesses are given by Gazetas (1991).

This topic is beyond the scope of this paper.

\subsection{Effects of nonlinear soil behaviour}

The above sections are based on the assumption that the soil in which the pile is embedded behaves elastically. In the last decade there has been a growing consensus that soil behaviour, even at low strains and even for very stiff soil, is nonlinear. The significance of this for the behaviour of pile groups under vertical loading is considered by Jardine et al (1985) and Caputo and Viggiani (1984). The effect of nonlinearity is to localise the deformation near the pile shaft. Hence the $\alpha$ values calculated above will give an upper limit on the interaction between piles.

Equation 5.10 predicts that the interaction factor for lateral loading is the same for $\xi=0$ or $180^{\circ}$. However it is well known from measurements of the distribution of the applied force between the piles of a group that the leading piles carry a greater proportion of the applied action than the rear piles. This suggests that the elastic idealisation might not be fully able to model the actual stiffness behaviour of pile groups. Further evidence for this is available from field tests on prototype structures. Two examples are discussed below.

\section{(a) $3 \times 3$ pile group in sand}

Brown et al (1988) measured the performance of a group of piles installed in a layer of sand. The piles were steel tubes $273 \mathrm{~mm}$ in outside diameter with $9.3 \mathrm{~mm}$ thick walls. The spacing was approximately 3 diameters centre to centre. The sand was saturated and had a dry density of $1570 \mathrm{~kg} / \mathrm{m}^{3}$ approximately (relative density about $50 \%$ ). The piles were attached to a loading frame which provided moment free connections. In addition a single pile was loaded for comparison with the pile group performance. The measured distribution of force and maximum bending moment is plotted against lateral deflection in Fig. 5.5. In Fig. 5.6 the way the applied force is distributed amongst the piles is given after 

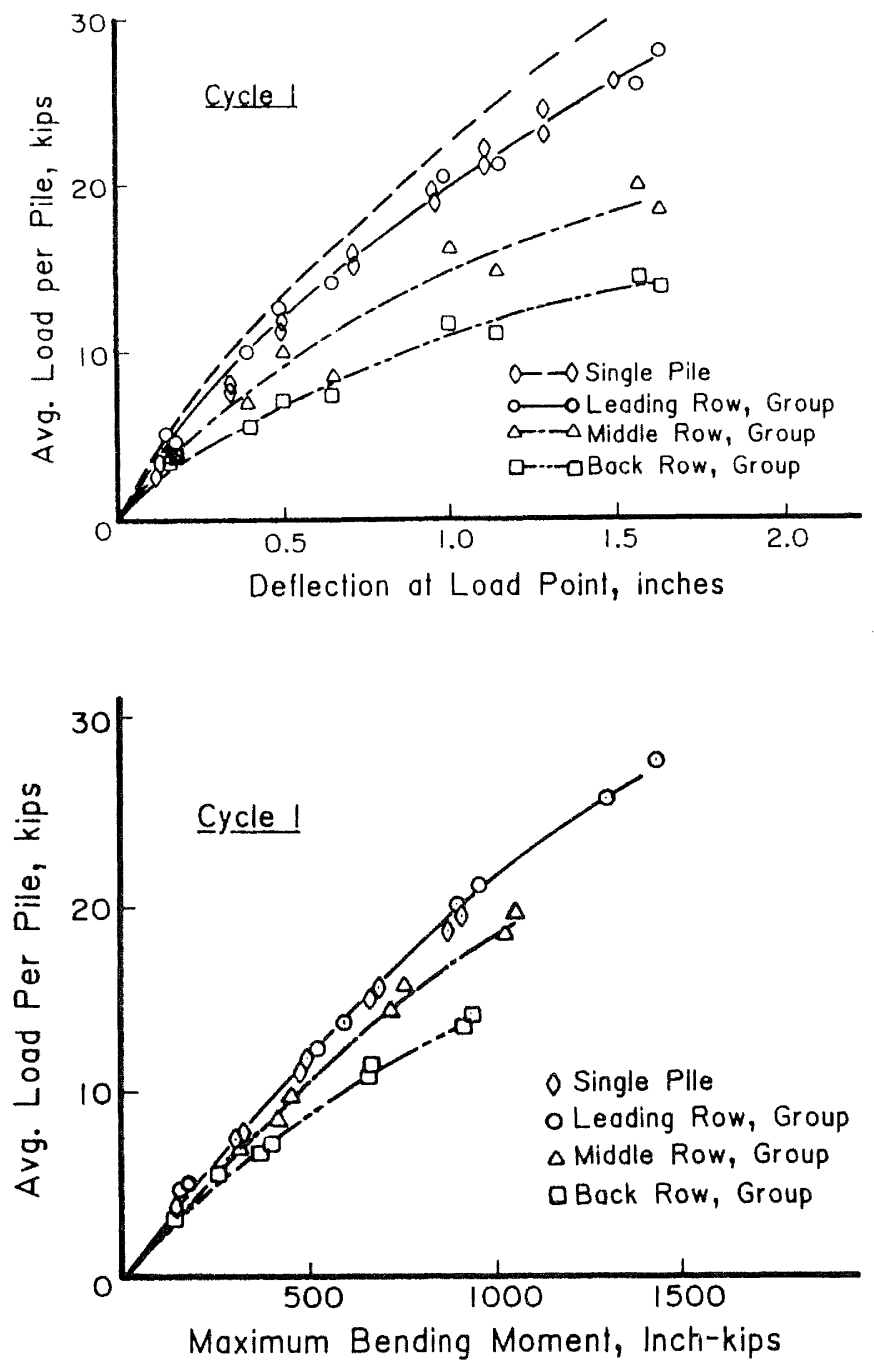

Fig. 5.5 Pile head deflection and maximum moment against average force for a $3 \times 3$ group and a single pile. (after Brown et al 1988) $(1 \mathrm{kip}=4.54 \mathrm{kN}, 1 \mathrm{in} .=25.4 \mathrm{~mm})$

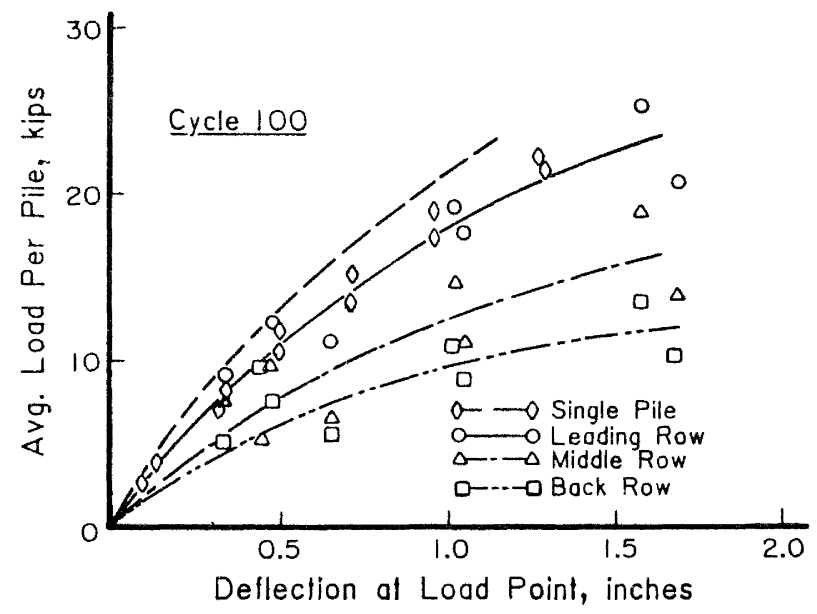

Fig. 5.6 Pile head deflection for a $3 \times 3$ group and a single pile against average force at cycle 100. (after Brown et al 1988).

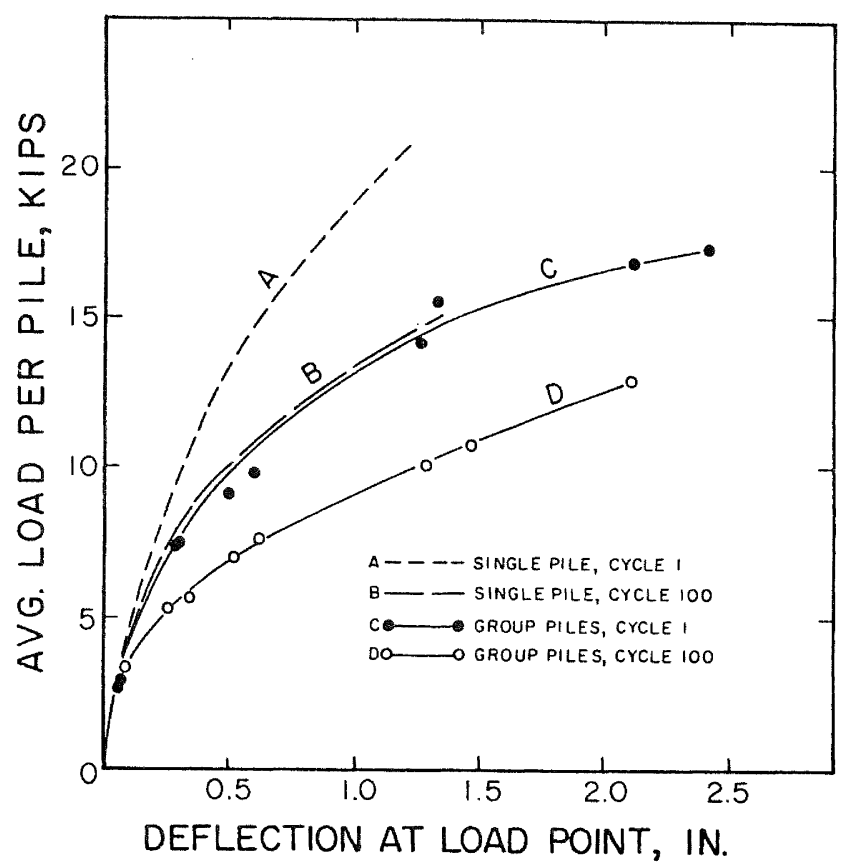

Fig. 5.7 Single pile and pile group force-displacement behaviour in clay (after Brown et al 1987).

100 cycles.

From Fig. 5.5 the "shadowing" effect of the leading piles is very clear in that the force and maximum moment of the leading piles is little different from those of the single pile but those for the middle and rear rows are significantly less. It is also apparent that the deflection of the group for a given average force per pile is greater than that of the isolated pile at the same lateral force. This observation provides some confirmation of the validity of the elastic interaction factors presented earlier in this section even if they do not model the "shadowing" effect. Figure 5.6 shows that there is only a small decrease in the stiffness of the group after 100 cycles of twoway cyclic loading. The authors suggest that the explanation for this might be densification of the sand during the cycling.

\section{(b) $3 \times 3$ pile group in clay}

Brown et al (1987) report an the performance of a $3 \times 3$ pile group in clay. The details of the pile group and loading system were the same as those used for above tests in sand. The piles were driven with closed ends into a layer of overconsolidated clay. The undrained shear strength of the clay at the ground surface was about $50 \mathrm{kPa}$, it increased with depth having an average value of about $100 \mathrm{kPa}$ over a depth equal to the active length of the piles. The site was flooded during the testing.

Figure 5.7 presents the observed force-deflection behaviour for the pile group and single pile both for the first cycle and cycle 100. It is of note that for forces up to about $17.5 \mathrm{kN}$ per pile that there is no apparent difference between the force-deformation of the pile group and a single pile. Figure 5.8 shows how the applied force is distributed between the piles in the group. Degradation of the resistance is clear between cycles 1 and 100 and is more apparent than for the pile group in sand. Figure 5.8 also shows that as the number of cycles increases the distribution of load between the 

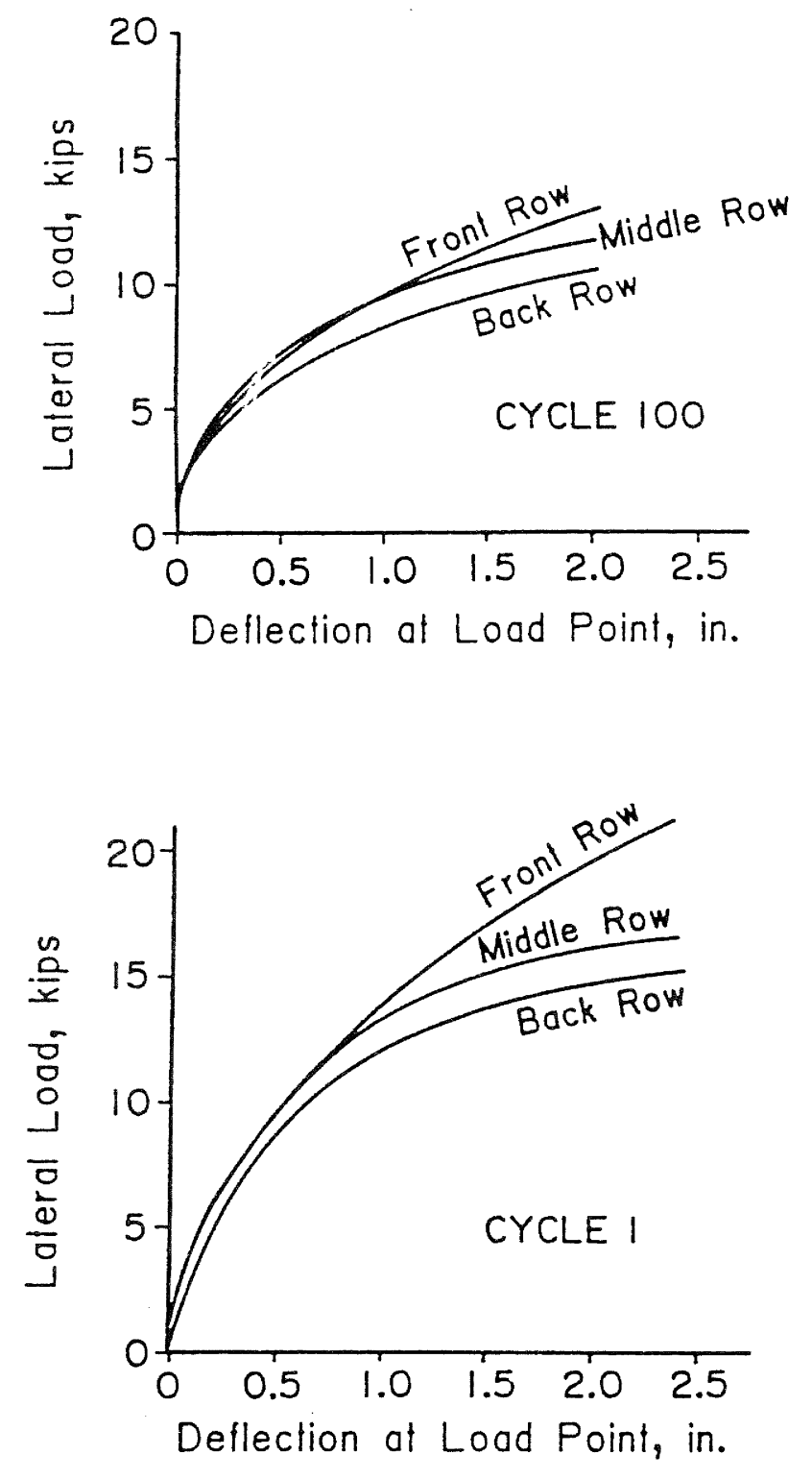

Fig. 5.8 Distribution of force between piles in a $3 \times 3$ group in clay, (a) at cycle 1 (b) at cycle 100 (after Brown et al 1987).

various piles of the group tends to become uniform. Also the distribution of load is not as predicted by the elastic results. Reference to example 5.6 leads to the expectation that the corner piles will carry the greatest forces and the centre pile the smallest. This is not apparent from Fig. 5.8.

\section{0 \\ SUBGRADE PROPERTIES PENETRATION RESISTANCE}

AND

This brief section is intended to give some information on the relationships that have been suggested between penetration resistance of a soil deposit and Young's modulus, or the modulus of subgrade reaction. As penetration resistance is a standard site investigation output it is helpful to use correlations in making preliminary estimates of soil stiffness, the determination of which has long been recognised as a difficult task. At first sight relating soil stiffness to penetration resistance does not seem a promising approach as the penetration resistance will be related to the strength of the soil. The assumption in following this path is that the parameters which control soil strength, and hence penetration resistance, are the same as those which control stiffness, or to put it most simply, soils which are strong will be stiff.

It is not intended in this section to give definitive information. Rather the intention is to give an indication of the wide variations between the correlations found in the literature.

The decision as to value(s) of the soil modulus at a given site is a matter for those involved in interpreting site investigation data bearing in mind the intended application. Judgement which is not easily quantified is required. A brief but useful discussion of the issues involved and the methods of determining dynamic soil modulus is given by Gazetas (1991).

\section{Drained and undrained behaviour}

During seismic loading soil deformation generally occurs under undrained conditions. If soil is being modelled elastically undrained behaviour is achieved by setting Poisson's ratio to 0.5 . For drained conditions a value less than 0.5 is appropriate. However, for small strain behaviour the ratio of the $\mathrm{S}$-wave and $\mathrm{P}$-wave velocities suggests that values of Poisson's ratio closer to 0.4 are required. The analytical calculations from which the dynamic behaviour of single piles and pile groups referred to in section 8 have been dorie using a value of 0.4 .

\section{Small strain behaviour}

A feature of the various correlations that have been suggested between penetration resistance and soil modulus is the wide range of modulus values given. Part of the explanation for this is differing ranges of strains for which they are intended. For small strain behaviour the stiffness will be very much greater than that for larger strains.

Seed et al (1986) relate the small strain shear modulus to Standard Penetration Resistance with the following equation:

$$
\mathrm{G}_{\max }=3.6\left[\sigma_{\mathrm{m}}^{\prime}\right]^{0.50}\left[\left(\mathrm{~N}_{1}\right)_{60}\right]^{0.33} \mathrm{MPa}
$$

where: $\left(\mathrm{N}_{1}\right)_{60}$ is the corrected SPT $\mathrm{N}$ value (refer to Seed et al for more details), $\sigma^{\prime}{ }_{\mathrm{m}}$ is the mean principal effective stress in $\mathrm{kPa}$. 
Similar information is given by Baldi (1989) et al for the CPT resistance of quartz sands:

$$
\mathrm{v}_{\mathrm{s}}=277 \mathrm{q}_{\mathrm{c}}^{0.13}\left(\sigma_{\mathrm{v}}^{\prime}\right)^{0.27} \mathrm{~m} / \mathrm{sec}
$$

where: $\mathrm{q}_{\mathrm{c}}$ is the CPT resistance (MPa), $\sigma^{\prime}{ }_{\mathrm{v}}$ is the vertical effective stress (MPa),

and $\quad v_{\mathrm{s}}$ is the shear wave velocity of the soil.

The shear wave velocity is related to the shear modulus by:

$$
\mathrm{G}=\rho \mathrm{v}_{\mathrm{s}}^{2}
$$

where: $\rho$ is the density of the soil.

The relation between shear and Young's modulus is:

$$
\mathrm{G}=\frac{\mathrm{E}_{\mathrm{S}}}{2(1+v)}
$$

For cohesive soils the small strain shear modulus is given by the approximation:

$$
\mathrm{G}_{\text {clay }}=1000-3000 \mathrm{~s}_{\mathrm{u}}
$$

Example 6.1 Review the Young's modulus and undrained shear strength used in examples 3.3 and 7.1 in the light of the above correlations.

In example 3.3 the soil modulus was taken as $25 \mathrm{MPa}$ and in example 7.1 the undrained shear strength of the clay is taken as $50 \mathrm{kPa}$.

From equation 6.5 assume $\mathrm{G}=1500 \mathrm{~s}_{\mathrm{u}}$, then:

$\mathrm{G}=1500 \times 50=75 \mathrm{MPa}$.

Using equation 6.4 :

$\mathrm{E}_{\mathrm{s}}=2 \times 1.5 \times 75=225 \mathrm{MPa}$

This modulus value corresponds to the small strain shear modulus of the soil which is appropriate for shear strains in the range $10^{-4} \%$.

The value of $\mathrm{E}_{\mathrm{s}}$ used in examples 3.3 and 7.1 is $500 \mathrm{~s}_{\mathrm{u}}$. This has often been suggested as an appropriate value for "working" strain levels.

\section{Larger strain behaviour}

Some correlations attempt to give Young's modulus for the soil directly and others give the coefficient of subgrade reaction. Furthermore some have been developed with pile behaviour in mind but it is more common for the correlation to be developed with the prediction of the vertical settlement of a near surface foundations. Nevertheless these correlations are frequently used for the estimation of the lateral stiffness of pile foundations, assuming the stiffness of the soil in the horizontal direction is the same as that in the vertical.

Firstly correlations for drained modulus of sands. D'Appolonia et al (1970) make the following suggestion for normally consolidated sand:

$$
E_{S}=0.77(N+26) \quad(M P a)
$$

and, for overconsolidated sand:

$$
\mathrm{E}_{\mathrm{S}}=1.02(\mathrm{~N}+41)
$$

These results were derived from measurement of the settlement of near surface foundations at a steel mill on the shores of Lake Michigan in the United states. The earthworks at the site, involving the preparation of a building platform at a required level, were responsible for the normally consolidated and overconsolidated results as some parts of the site had to be cut and others filled.

Schultze and Menzenbach (1961) give a modulus for one dimensional compression of sand, using a Poisson's ratio of 0.3 their expression gives the following relation for Young's modulus:

$$
\mathrm{E}_{\mathrm{S}}=(0.36 \mathrm{~N}+5.3)
$$

In a similar vein Webb (1969) suggests:

$$
\mathrm{E}_{\mathrm{S}}=0.54(\mathrm{~N}+15)
$$

and Trofimenko (1974):

$$
E_{s}=(35 \text { to } 50) \log N
$$

Parry (1971) gives:

$$
E_{S}=5 N
$$

Plotting these equations, as is done in Fig. 6.1, indicates that there is considerable scatter, so that the expression of the moduli to more than one decimal place is hardly warranted. Also the plot suggests that perhaps the Parry relation was

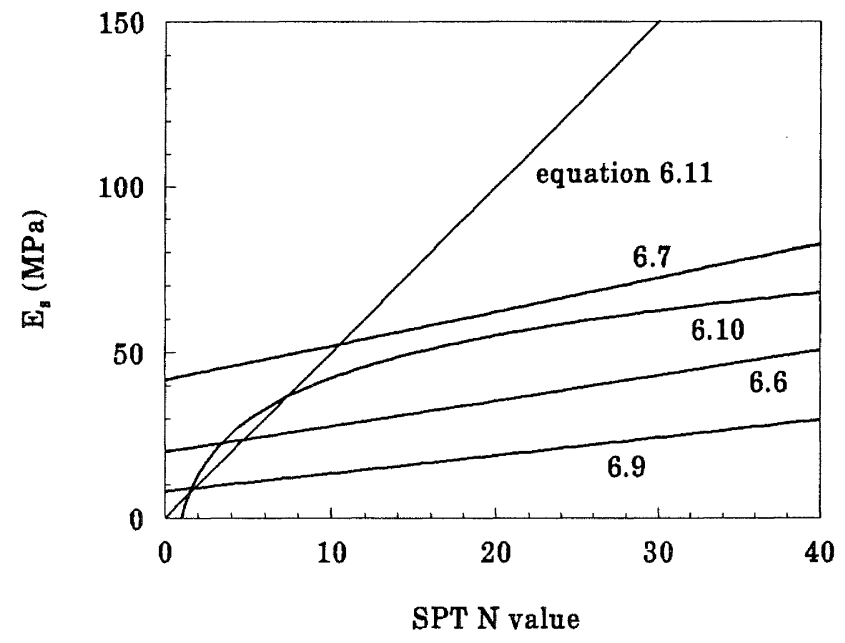

Fig. 6.1 Various correlations between SPT and $E_{S}$. 
intended for soil deposits with small to medium $N$ values, at large $N$ values $E_{S}=5 N$ gives a much greater modulus than is obtained from the other relations.

\section{Relations between $k$ and $N$}

Once the soil modulus is available the modulus of subgrade reaction can be evaluated with equation 3.39 .

The origin of correlations between the coefficient of subgrade reaction and $\mathrm{N}$ is the method, given by Terzaghi and Peck (1948), for estimating the settlement of footings on sands; this implies that:

$$
k_{s}=0.33 \mathrm{~N}(\mathrm{kPa} / \mathrm{mm})
$$

This value was increased in subsequent work by Peck and Bazzara (1970).

The size of the loaded area, the diameter or width of the pile shaft, has an effect on the coefficient of subgrade reaction. Terzaghi (1955) explains how increasing the size of the pile will reduce $\mathrm{k}_{\mathrm{s}}$, he justifies this by considering sizes of stress bulbs. Thus correlations between $\mathrm{N}$ and $\mathrm{k}_{\mathrm{s}}$ are usually given for a circular loaded area of diameter $300 \mathrm{~mm}$.

Meyerhof (1965) gives:

$$
\mathrm{k}_{\mathrm{S}}=0.75 \mathrm{~N}(\mathrm{kPa} / \mathrm{mm})
$$

and Scott (1981) suggests that the values given by Terzagh (1955) be increased by $50 \%$ to give, for submerged sand:

$$
\mathrm{k}_{\mathrm{s}}=1.8 \mathrm{~N}(\mathrm{kPa} / \mathrm{mm})
$$

Some data illustrating the effect of the diameter of the loaded area on the coefficient of subgrade reaction is reproduced in Fig. 6.2. Terzaghi and Peck (1948) proposed that $k_{s}$ be adjusted for the size of the loaded area using:

$$
\mathrm{k}_{\mathrm{s}(\mathrm{B})} / \mathrm{k}_{\mathrm{s}(0.3 \mathrm{~m})}=[2 \mathrm{~B} /(\mathrm{B}+0.3)]^{2}
$$

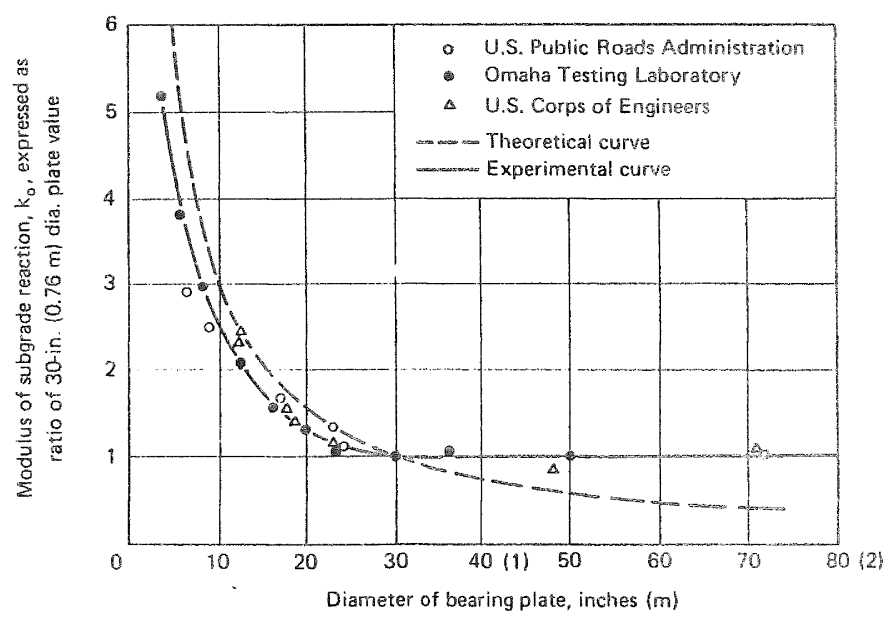

Fig. 6.2 Effect of the size of loaded area on measured values of coefficient of subgrade reacion (after Scott (1981)). where: $\mathrm{B}$ is the width of the loaded area in metres.

According to Sugimura (1986) the Road Bridge Standard Regulation in Japan gives the following estimate for $k_{s}$ :

$$
\mathrm{k}_{\mathrm{s}}=0.8 \mathrm{E}_{\mathrm{S}} \mathrm{D}^{-3 / 4} \quad\left(\mathrm{kgf} / \mathrm{cm}^{3}\right)
$$

Note that the 0.8 term in this equation carries wnits of $\mathrm{cm}^{-0.25}$, that $\mathrm{D}$ (pile diameter) is in $\mathrm{cm}_{\text {, and that }} E_{S}$ is in $\mathrm{kgf} / \mathrm{cm}^{2}$. The term $D^{-3 / 4}$ serves the same purpose as the term $[2 B / C B$ + $0.3)$ ] in the Terzaghi and Peck relation. Note that these wo relations imply that the observed size effect is not simply a consequence of elastic behaviour of the soil as $k_{3}$ does not decrease inversely with the dimension of the loaded area.

For any soil deposit the effective stress will increase with depth. This suggests a corresponding increase in $\mathrm{k}$ with depth, commonly expressed as:

$$
\mathrm{k}=\mathrm{n}_{\mathrm{h}} \mathrm{z}
$$

where: $n_{h}$ is the rate of increase with depth, $z$, in the nodulus of subgrade reaction in the horizontal direction. Edmonds et al (1980) suggest that, under lateral cyclic loading, $n_{\mathrm{h}}$ is 9 $\mathrm{MN} / \mathrm{m}^{3}$ for dense submerged sand, and $1 \mathrm{MN} / \mathrm{m}^{3}$ for loose submerged sand.

Each of the above comelations has been derved rom data un the behaviour of foundations on a given soil deposit, or soll deposits that are closely related geographically and geologically. All refer to soll deposits distant from $\mathrm{NZ}$. It may well be that geological history, composition and current effective stress are the dominant factors in determining the relationship, in which case at least some of the above correlations may be appropriate for $\mathrm{NZ}$ conditions. However, the applicability of any correlation needs to be established, there is no justification for simply assuming the relations are applicable to $\mathrm{NZ}$ conditions. 


\subsection{NONLINEAR LATERAL PILE-SOIL INTERACTION}

The previous sections are based on the assumption of elastic behaviour of the pile and the soil surrounding the pile. In this section we consider the effect of nonlinear lateral interaction and local failure between the pile shaft and the soil in which it is embedded. Initially the extension of the elastic analysis of Davies and Budhu for handling local failure between the soil and pile shaft is presented and this is followed with a section dealing with nonlinear interactions using the Winkler model as the basis for a finite element program.

\subsection{Local failure}

The boundary element calculations used by Davies and Budhu (1986) and Budhu and Davies $(1987,1988)$ in deriving their expressions for the elastic pile head displacements also calculate the contact stresses between the pile shaft and soil. These stresses are only valid if they do not exceed the stresses which would cause local failure of the soil adjacent to the pile shaft. Budhu and Davies modified the elastic analysis when the contact stresses were unacceptable and using an incremental process kept track of how much of the interface was at failure. In this way they were able to modify the purely elastic analysis to account for local failure of the soil (referred to as soil yielding in their papers). This is achieved by treating that part of the pile shaft with the adjacent soil at failure as a cantilever under specified actions, the elastic behaviour of the pile shaft beneath this point then controls the horizontal displacement and rotation of the cantilever support point. The active length of the pile shaft should then be determined beneath the lowest point at which soil-pile shaft failure occurred. Unfortunately no expression is given for this depth.

These equations of Davies and Budhu represent a particularly useful development in the lateral load analysis of pile foundations. Prior to this any investigation of nonlinear effects required the use of nonlinear finite element or similar software. The equations below provide a much simpler means of investigating the likely significance of nonlinear soil behaviour for lateral load response of a particular pile.

\subsubsection{Constant soil modulus with depth}

Davies and Budhu (1986) estimate the effect of local failure at the pile soil interface by calculating a modification factor to be applied to elastic predictions of pile behaviour. For a free head pile they give the following equations for the pile head displacements and maximum moment:

$$
\begin{aligned}
\mathrm{u}_{\mathrm{y}} & =\mathrm{I}_{\mathrm{uy}} \mathrm{u}_{\mathrm{E}} \\
\theta_{\mathrm{y}} & =\mathrm{I}_{\theta_{\mathrm{y}}} \theta_{\mathrm{E}} \\
\mathrm{M}_{\mathrm{My}} & =\mathrm{I}_{\mathrm{My}} \mathrm{M}_{\mathrm{ME}}
\end{aligned}
$$

where: $\quad I_{u y}, I_{\theta y}$, and $I_{M y}$ are yield influence factors, $\mathrm{u}_{\mathrm{E}} \quad$ is the elastic pile head displacement from equations 3.14 and 3.21 ,

$\theta_{\mathrm{E}} \quad$ is the elastic pile head rotation from equations 3.15 and 3.21 , $\mathrm{M}_{\mathrm{ME}} \quad$ is the maximum elastic pile shaft moment from equation 3.23.

The yield influence factors are given by:

$$
\begin{aligned}
& \mathrm{I}_{\text {uy }}=1+\frac{\mathrm{h}-2.9 \mathrm{k}^{0.2}}{10.5 \mathrm{k}^{0.45}} \\
& \mathrm{I}_{\partial \mathrm{y}}=1+\frac{\mathrm{h}-2.9 \mathrm{k}^{0.2}}{12.5 \mathrm{k}^{0.33}} \\
& \mathrm{I}_{\mathrm{My}}=1+\frac{\mathrm{h}-2.9 \mathrm{k}^{0.20}}{20 \mathrm{k}^{0.29}}
\end{aligned}
$$

where: $\quad \mathrm{h}=\mathrm{H} / \mathrm{s}_{\mathrm{u}} \mathrm{D}^{2}$

and $\mathrm{k}=\mathrm{K} / 1000$.

The above term for $\mathrm{h}$ includes the applied horizontal load but not the moment. However the pile head moment is not neglected as it is used in calculating the elastic displacements to which $I_{u y}$ and $I_{\theta y}$ are applied. For small pile loads the yield influence factors calculated with the above equations may be less that unity in which case a value of unity is assumed.

In developing the above equations for a pile embedded in a clay with constant modulus with depth Davies and Budhu suggest that it is unlikely that the soil near the ground surface contributes fully to the resistance of the pile and it will also be subject to seasonal variations in properties. Consequently they ignore the first $600 \mathrm{~mm}$ of the soil profile as shown in Fig. 7.1 where this is denoted by $\mathrm{e}_{0}$. This has the effect of increasing the eccentricity of the loading by $e_{o}$, so that the value used in the calculations is:

$$
\mathrm{e}=\frac{\mathrm{M}}{\mathrm{H}}+\mathrm{e}_{\mathrm{o}} \quad(\mathrm{m})
$$

where: $\mathrm{M}$ is in $\mathrm{kNm}$ and $\mathrm{H}$ in $\mathrm{kN}$.

As the pile head displacements are calculated at a depth of $600 \mathrm{~mm}$ the ground surface displacement and rotation include the following additional terms:

$$
\begin{aligned}
& u_{\text {pilehead }}=u_{d}+e_{o} \theta_{d}+\frac{H e_{o}^{3}}{3 E_{p} I_{p}}+\frac{M_{h} e_{o}^{2}}{2 E_{p} I_{p}} \\
& \theta_{\text {pilehead }}=\theta_{d}+\frac{H e_{o}^{2}}{2 E_{p} I_{p}}+\frac{M_{h} e_{o}}{E_{p} I_{p}}
\end{aligned}
$$

where:

$$
\begin{aligned}
& \mathrm{e}_{\mathrm{o}} \quad \text { is the ground surface to datum } \\
& \text { level distance }(600 \mathrm{~mm}) \text {, } \\
& u_{d} \quad \text { is the deflection at the datum } \\
& \text { level, } \\
& \theta_{\mathrm{d}} \quad \text { is the rotation of the pile shaft at } \\
& \text { the datum level, } \\
& \mathrm{M}_{\mathrm{h}} \quad \text { is the pile shaft moment at the } \\
& \text { ground surface. }
\end{aligned}
$$

The last two terms in each of the equations 7.4 can usually be neglected, particularly if the diameter of the pile shaft is greater than $\mathrm{e}_{\mathrm{o}}$.

As the lateral force increases the length of the pile shaft 
along which local failure is occurring increases, this is reflected in the increase in $\mathrm{I}_{\mathrm{uy}}$ and $\mathrm{I}_{\partial \mathrm{y}}$ with increasing lateral force. In addition the maximum moment in the pile shaft increases and eventually it reaches the yield moment of the pile section.

Example 7.1 For the pile and soil profile of example 3.3 investigate the effect of local failure on the displacements and maximum pile shaft moment. Assume that the ratio of the applied pile head actions, horizontal shear to applied moment, is 2.3 , that the yield moment of the pile section is $1575 \mathrm{kNm}$, and that the undrained shear strength of the soil is $50 \mathrm{kPa}$.

The pile section properties, using $\mathrm{I}_{\mathrm{p}}$ from example 3.1, are:

$E_{p} I_{p}=25 \times 1000 \times 0.01553=388.3 \mathrm{kNm}^{2}$

Some preliminary calculation reveals that a horizontal load of about $550 \mathrm{kN}$ has the pile section close to yield. The response of the pile to loads up to $545 \mathrm{kN}$ is set out in the table below. As an example of the sequence of calculations those for a horizontal load of $218 \mathrm{kN}$ are:

$\mathrm{M}=218 / 2.3=94.8 \mathrm{kNm}$.

Because of the additional $0.6 \mathrm{~m}$ unsupported length assumed by Davies and Budhu the moment applied at the datum level is:

$\mathrm{M}=94.8+218 \times 0.6=225.6 \mathrm{kNm}$

From equation 3.14 the horizontal displacement at the datum level (using the flexibility coefficients obtained in example 3.3) is:

$u_{d}=1.97 \times 10^{-2} \times 218+6.75 \times 10^{-3} \times 225.6=5.82 \mathrm{~mm}$

and from equation 3.15 the rotation is:

$\theta_{\mathrm{d}}=6.75 \times 10^{-3} \times 218+5.75 \times 10^{-3} \times 225.6=2.77 \mathrm{mrad}$.

From equation 3.18: $\mathrm{f}=225.6 / 218 \times 0.75=1.38$

From equation 3.23 the coefficients for the maximum moment are:

$a=0.12+0.24 \times 1.38+0.10 \times 1.38^{2}=0.642$

$\mathrm{b}=\exp (-1.3-0.34 \times 1.38)=0.17$

$\mathrm{M}_{\mathrm{Mmax}}=0.642 \times 1000^{0.17} \times 0.75 \times 218=339.7 \mathrm{kNm}$.

Having obtained these elastic values we now consider the effect of local soil failure. From equation 7.2 we have:

$\mathrm{h}=218 / 50 \times 0.75^{2}=7.75 \mathrm{k}=1000 / 1000=1$

$I_{\text {uy }}=1+(7.75-2.9) / 10.5=1.46$

$I_{\theta y}=1+(7.75-2.9) / 12.5=1.39$

$\mathrm{I}_{\mathrm{My}}=1+(7.75-2.9) / 20.0=1.24$
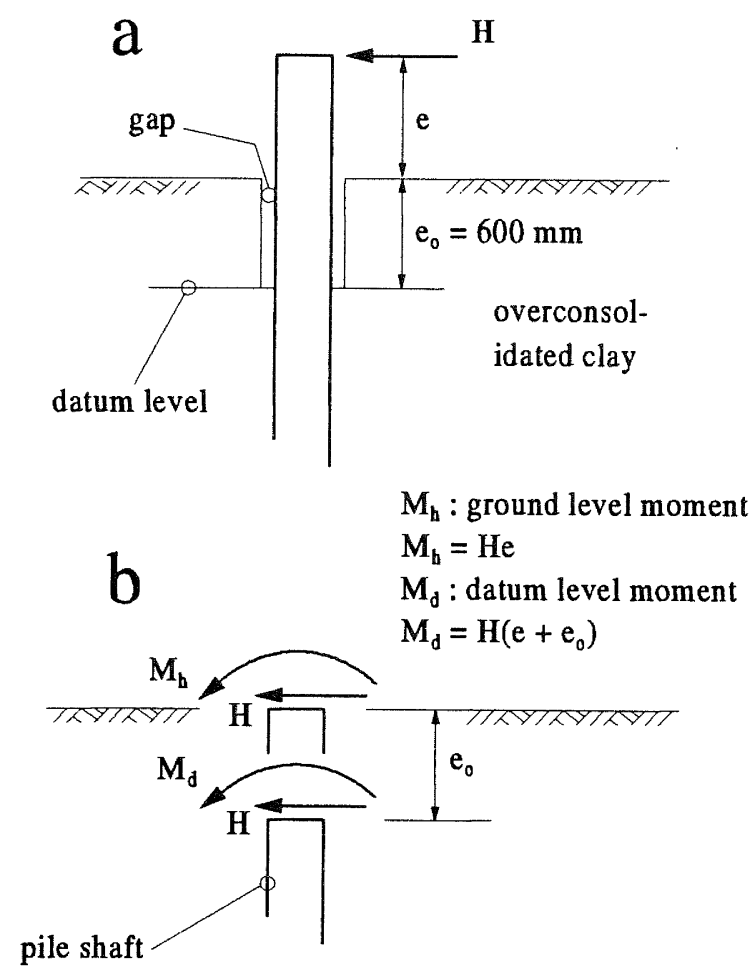

Fig. 7.1 Nonlinear response of a free head pile in a soil having a constant modulus with depth, (a) geometry, (b) datum level actions.

a
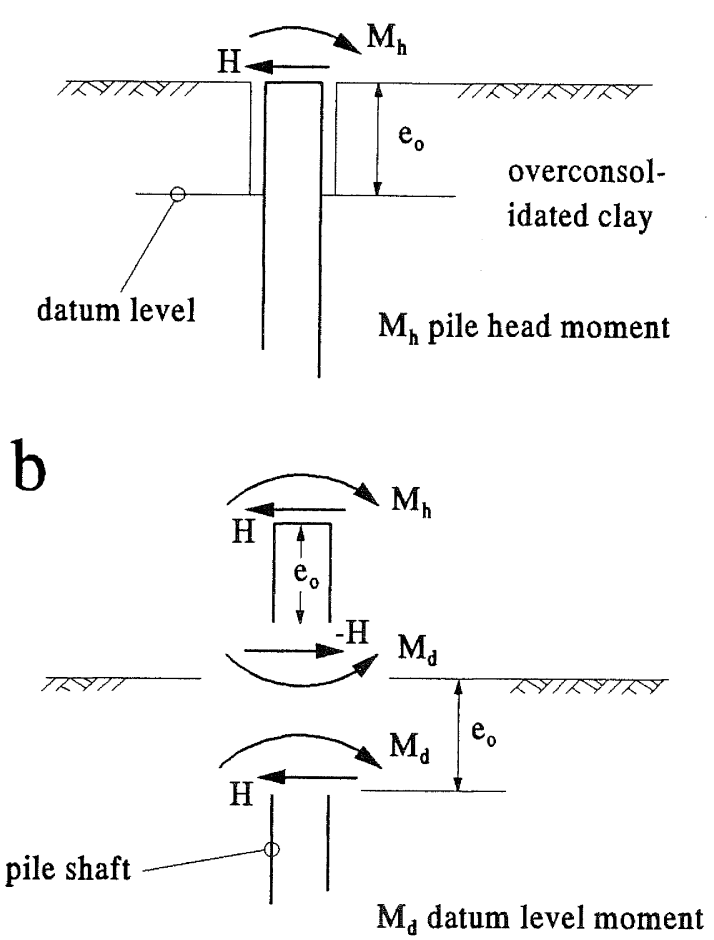

Fig. 7.2 Nonlinear response of a fixed head pile in a soil having a constant modulus with depth, (a) geometry, (b) pile head and datum level actions. 
Thus at the datum level:

$\mathrm{u}_{\mathrm{dy}}=5.82 \times 1.46=8.50 \mathrm{~mm}$

$\theta_{\text {dy }}=2.77 \times 1.39=3.85 \mathrm{mrad}$

At the ground surface:

$\theta_{\mathrm{gs}} \quad=3.85+218 \times 0.6^{2} / 2 \times 388.3+94.8 \times 0.6 / 388.3$

$=4.1 \mathrm{mrad}$

$u_{g s}=8.50+0.6 \times 3.85+218 \times 0.6^{3} / 3 \times 388.3+$

$$
=10.9 \mathrm{~mm}
$$

The maximum pile shaft moment is $339.7 \times 1.24=421 \mathrm{kNm}$.

The above results, calculated for $\mathrm{H}=218 \mathrm{kN}$, correspond to those in the fourth line of the table below.

\begin{tabular}{|c|c|c|c|}
\hline $\mathrm{H}(\mathrm{kN})$ & $\mathrm{u}_{\mathrm{gs}}(\mathrm{mm})$ & $\theta_{\mathrm{gs}}(\mathrm{mrad})$ & $\mathrm{M}_{\max }(\mathrm{kNm})$ \\
\hline 54.5 & 1.89 & 0.75 & 84.9 \\
\hline 109.0 & 4.12 & 1.62 & 178.0 \\
\hline 163.5 & 7.18 & 2.75 & 291.7 \\
\hline 218.0 & 10.90 & 4.09 & 421.8 \\
\hline 272.5 & 15.29 & 5.65 & 568.3 \\
\hline 327.0 & 20.35 & 7.42 & 731.3 \\
\hline 381.5 & 26.07 & 9.41 & 910.7 \\
\hline 436.0 & 32.46 & 11.62 & 1106.6 \\
\hline 490.5 & 39.52 & 14.03 & 1318.9 \\
\hline 545.0 & 47.24 & 16.67 & 1547.7 \\
\hline
\end{tabular}

The following diagrams give plots of the tabulated values. In diagram a the horizontal displacement and rotation at the ground surface are plotted against the applied horizontal force. In diagram $\mathbf{b}$ the maximum pile shaft moment is plotted against the horizontal force.

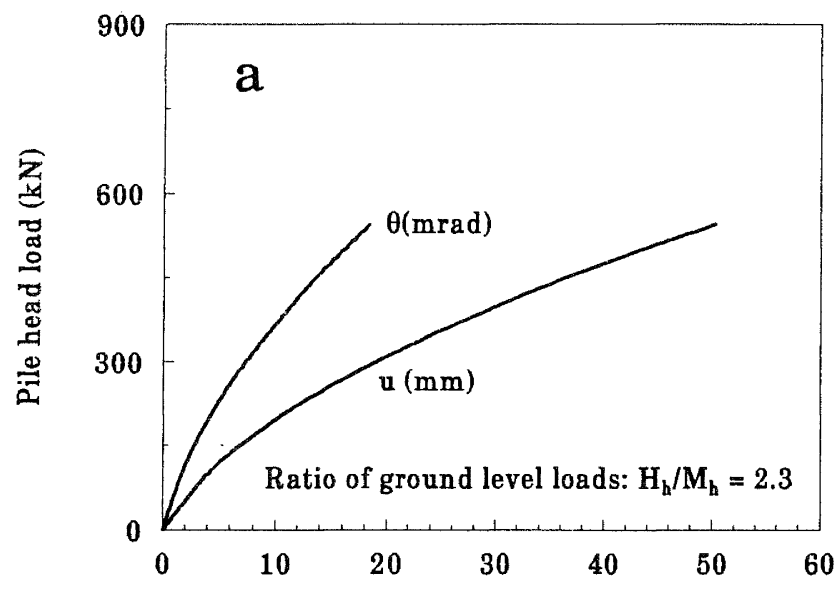

Pile head displacement and rotation

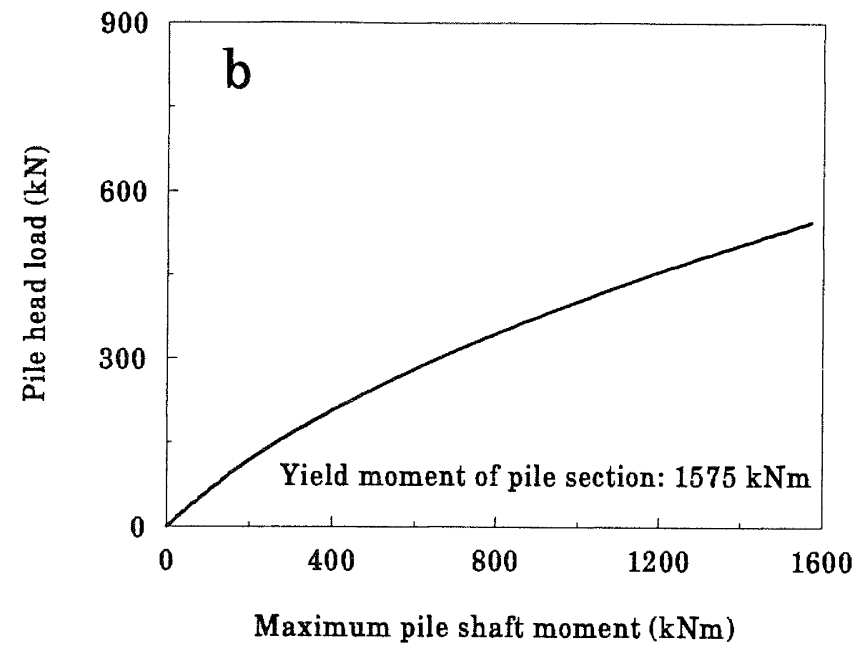

In this example the maximum moment about equal to the yield moment of the pile section has been used to set the range of horizontal forces for which the calculations have been done. In section 9.2 there is further discussion of the lateral capacity of a pile from the point of view of estimating the pile head actions that mobilise the ultimate capacity of the soil in which the pile is embedded.

To be consistent with the free head approach proposed by Davies and Budhu the $600 \mathrm{~mm}$ unsupported length of pile shaft is required. In this case the fixed head condition requires that the rotation at the pile head at the top of the pile stub is zero, the pile head and datum level actions are illustrated in Fig. 7.2. The fixing moment is calculated by taking the expression for the head rotation in equation 7.4 and solving for the moment which gives zero rotation. The process is illustrated in the following example.

Example 7.2 Compare the calculations done in Example 7.1 for the free head pile with fixed head behaviour.

Some preliminary calculation reveals that a horizontal load of about $890 \mathrm{kN}$ has the pile section close to yield. The response of the pile to loads up to $890 \mathrm{kN}$ is set out in the table below. As an example of the sequence of calculations those for a horizontal load of $445 \mathrm{kN}$ are:

$$
\begin{aligned}
& \mathrm{h}=445 / 50 \times 0.75^{2}=15.82 \\
& \mathrm{I}_{\mathrm{uy}}=1+(15.82-2.9) / 10.5=2.231 \\
& \mathrm{I}_{\theta \mathrm{y}}=1+(15.82-2.9) / 12.5=2.034
\end{aligned}
$$

The pile head moment, $\mathrm{M}_{\mathrm{h}}$, is obtained from:

$$
\begin{aligned}
& \left(6.75 \times 10^{-3} \times 445+5.75 \times 10^{-3} \times\left(M_{h}+0.6 \times 445\right)\right) \times 2.034+ \\
& 0.6 \times\left(2 M_{h}+445 \times 0.6\right) / 2 \times 338.3=0
\end{aligned}
$$

This simplifies to:

$0.0135 \mathrm{M}_{\mathrm{h}}+6.1096+3.1227+0.2368=0$

Thus: $\mathrm{M}_{\mathrm{h}}=-9.4691 / 0.0135=-701.4 \mathrm{kNm}$. 
The moment at the datum:

$M_{d}=-701.4+0.6 \times 445=-434.4 \mathrm{kNm}$.

The displacements at the datum level are:

$u_{d}=\left(1.97 \times 10^{-2} \times 445-6.75 \times 10^{-3} \times 434.4\right) \times 2.231=13.02 \mathrm{~mm}$

$\theta_{\mathrm{d}}=\left(6.75 \times 10^{-3} \times 445-5.75 \times 10^{-3} \times 434.4\right) \times 2.034=1.03 \mathrm{mrad}$.

At the ground surface the displacement is:

$u_{h}=13.02+1.03 \times 0.60+445 \times 0.6^{3} / 6 \times 388.3$.

$701.4 \times 0.6^{2} / 2 \times 388.3$

$=13.35 \mathrm{~mm}$.

The above results, calculated for $\mathrm{H}=445 \mathrm{kN}$, are slightly different from the values in line five of the table below. The reason being small differences in rounding between the calculations set out above and the method used to calculate the table.

\begin{tabular}{|c|c|c|c|}
\hline $\mathrm{H}(\mathrm{kN})$ & $\mathrm{u}_{\mathrm{h}}(\mathrm{mm})$ & $\mathrm{M}_{\mathrm{h}}(\mathrm{kNm})$ & $\mathrm{M}_{\mathrm{d}}(\mathrm{kNm})$ \\
\hline 89 & 1.31 & -131 & -77 \\
\hline 178 & 3.29 & -270 & -163 \\
\hline 267 & 5.92 & -415 & -255 \\
\hline 356 & 9.19 & -563 & -349 \\
\hline 445 & 13.11 & -713 & -446 \\
\hline 534 & 17.67 & -815 & -544 \\
\hline 623 & 22.86 & -1017 & -644 \\
\hline 712 & 28.69 & -1171 & -744 \\
\hline 801 & 35.15 & -1325 & -845 \\
\hline 890 & 42.25 & -1480 & -946 \\
\hline
\end{tabular}

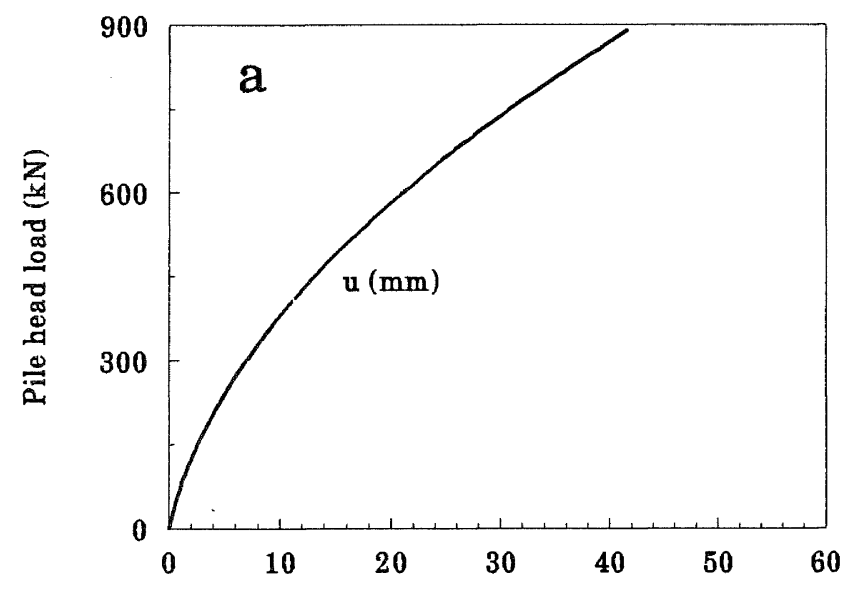

Pile head displacement $(\mathrm{mm})$

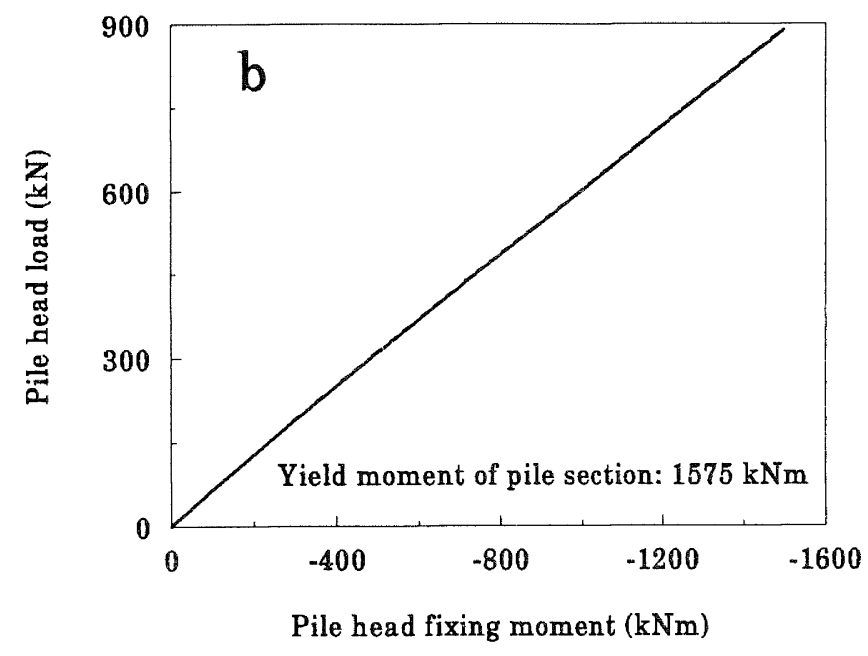

The diagrams above give plots of the tabulated values. In diagram a the horizontal displacement and rotation at the ground surface are plotted against the horizontal load. In diagram $\mathbf{b}$ the maximum pile shaft moment is plotted against the horizontal load.

The above calculations show that the moment with largest magnitude occurs at the pile head. Because the moment produced by the shear force at the datum level is positive and that from the pile head moment negative the fixed head maximum lateral force is greater than that for the free head pile.

Example 7.2 is done from first principles. Davies and Budhu (1986) do give equations for the fixed head pile displacement and fixing moment. These are not reproduced here as they do not account for the $600 \mathrm{~mm}$ unsupported length of pile shaft recommended by Davies and Budhu. Their equation for the pile head fixing moment gives approximately the values in the above table but the predicted displacements are too small.

7.1.2 Linear variation of soil modulus with depth

The case of a linear variation in soil modulus with depth is covered in two contexts by Budhu and Davies (1986 and 1987). The first is for a deposit of normally consolidated clay the undrained shear strength of which increases linearly with depth from zero at the ground surface. The second is for a deposit of sand. In both of these cases the linear increase in stiffness and strength with depth implies reasonably large strains at the ground surface and so it is relevant to the discussion in this section involving local failure of the soil adjacent to the pile shaft. Because the soil has zero strength at the ground surface the additional eccentricity of $600 \mathrm{~mm}$, used with the constant modulus profile, is not required.

The yield influence factors and the definition of the $\mathrm{h}$ and $\mathrm{k}$ terms depends on the type of soil profile.

For a clay profile: 


$$
\begin{aligned}
& \mathrm{I}_{\mathrm{uy}}=1+\frac{\mathrm{h}-14 \mathrm{k}^{0.32}}{40 \mathrm{k}^{0.53}} \\
& \mathrm{I}_{\theta \mathrm{y}}=1+\frac{\mathrm{h}-14 \mathrm{k}^{0.32}}{54 \mathrm{k}^{0.53}} \\
& \mathrm{I}_{\mathrm{My}}=1+\frac{\mathrm{h}-8 \mathrm{k}^{0.32}}{96 \mathrm{k}^{0.48}}
\end{aligned}
$$

where:

$$
\begin{aligned}
& h=\frac{H}{c^{3}} \\
& k=\frac{K}{1000}
\end{aligned}
$$

where: $c \quad$ is the rate of increase of undrained shear strength with depth $\left(\mathrm{kN} / \mathrm{m}^{3}\right)$.

For a sand profile:

$$
\begin{aligned}
& I_{u y}=1+\frac{h-k^{0.35}}{6 k^{0.65}} \\
& I_{\theta y}=1+\frac{h-k^{0.35}}{11 k^{0.35}} \\
& I_{M y}=1+\frac{h}{20 k^{0.35}}
\end{aligned}
$$

where:

$$
\begin{aligned}
\mathrm{h} & =\frac{\mathrm{H}}{\mathrm{K}_{\mathrm{p}} \gamma \mathrm{D}^{3}} \\
\mathrm{k} & =\frac{\mathrm{K} \exp (0.07(\phi-30))}{1000}
\end{aligned}
$$

where: $\phi \quad$ is the friction angle of the sand, 1

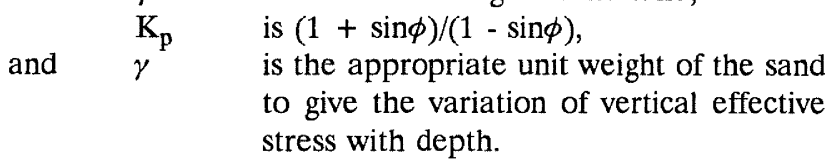

Example 7.3 Investigate the effect of lateral soil failure adjacent to the pile shaft in example 3.7. Take the friction angle of the sand to be $35^{\circ}$, the unit weight of the sand to be $10 \mathrm{kN} / \mathrm{m}^{3}$ (that is the water table is at the ground surface), and $\mathrm{H} / \mathrm{M}=2.3$.

From example $3.7, \mathrm{~K}=556$.

Some preliminary calculation reveals that a horizontal load of about $570 \mathrm{kN}$ has the pile section close to yield. The response of the pile to loads up to $540 \mathrm{kN}$ is set out in the table below. As an example of the sequence of calculations those for a horizontal load of $432 \mathrm{kN}$ are:

$\mathrm{M}=432 / 2.3=187.8 \mathrm{kNm}$.

${ }^{1}$ Budhu and Davies (1987) suggest a modification of the friction angle of the sand prior to using their equations. Pranjoto (1992) obtained better modelling of prototype pile test data without modifying $\phi$.
From equation 3.14 the horizontal displacement at the datum level (using the flexibility coefficients obtained in example 3.7 ) is:

$\mathrm{u}_{\mathrm{d}}=1.16 \times 10^{-2} \times 432+5.92 \times 10^{-3} \times 187.8=6.12 \mathrm{~mm}$

and from equation 3.15 the rotation is:

$\theta_{\mathrm{d}}=5.92 \times 10^{-3} \times 432+5.28 \times 10^{-3} \times 187.8=3.55 \mathrm{mrad}$.

From equation 3.18: $f=187.5 / 432 \times 0.75=0.58$

From equation 3.30 the coefficients for the maximum moment are:

$\mathrm{a}=0.60 \times 0.58=0.35$

$\mathrm{b}=0.17 \times 0.58^{-0.3}=0.20$

$\mathrm{M}_{\mathrm{Mmax}}=0.35 \times 556^{0.20} \times 0.75 \times 432=401.4 \mathrm{kNm}$.

Having obtained these elastic values we now consider the effect of local soil failure. From equation 7.7 we have:

$\mathrm{K}_{\mathrm{p}}=(1+\sin 35) /(1-\sin 35)=3.69$

$h=432 / 3.69 \times 10 \times 0.75^{3}=27.75$

$\mathrm{k}=556 \times \exp (0.07 \times 5) / 1000=0.789$

$I_{u y}=1+\left(27.75-0.789^{0.35}\right) / 6 \times 0.789^{0.65}=6.22$

$\mathrm{I}_{\theta_{\mathrm{y}}}=1+\left(27.75-0.789^{0.35}\right) / 11 \times 0.789^{0.35}=3.65$

$\mathrm{I}_{\mathrm{My}}=1+27.75 / 20 \times 0.789^{0.35}=2.51$

Thus at ground level:

$\mathrm{u}_{\text {hy }}=6.22 \times 6.12=38.1 \mathrm{~mm}$

$\theta_{\text {hy }}=3.65 \times 3.55=13.0 \mathrm{mrad}$.

The maximum pile shaft moment is $401.4 \times 2.51=1008 \mathrm{kNm}$.

\begin{tabular}{|c|c|c|c|}
\hline $\mathrm{H}(\mathrm{kN})$ & $\mathrm{u}_{\mathrm{h}}(\mathrm{mm})$ & $\theta_{\mathrm{h}}(\mathrm{mrad})$ & $\mathrm{M}_{\max }(\mathrm{kNm})$ \\
\hline 54 & 1.14 & 0.56 & 59 \\
\hline 108 & 3.31 & 1.42 & 138 \\
\hline 162 & 6.51 & 2.58 & 234 \\
\hline 216 & 10.75 & 4.05 & 350 \\
\hline 270 & 16.01 & 5.82 & 485 \\
\hline 324 & 22.30 & 7.89 & 638 \\
\hline 378 & 29.62 & 10.27 & 811 \\
\hline 432 & 37.97 & 12.96 & 1002 \\
\hline 486 & 47.35 & 15.94 & 1212 \\
\hline 540 & 57.76 & 19.24 & 1440 \\
\hline
\end{tabular}


The results, calculated for $\mathrm{H}=432 \mathrm{kN}$, correspond to those in the eighth line of the table above.

The following diagrams give plots of the tabulated values. In diagram a the horizontal displacement and rotation at the ground surface are plotted against the applied horizontal force. In diagram $\mathbf{b}$ the maximum pile shaft moment is plotted against the horizontal pile head force.
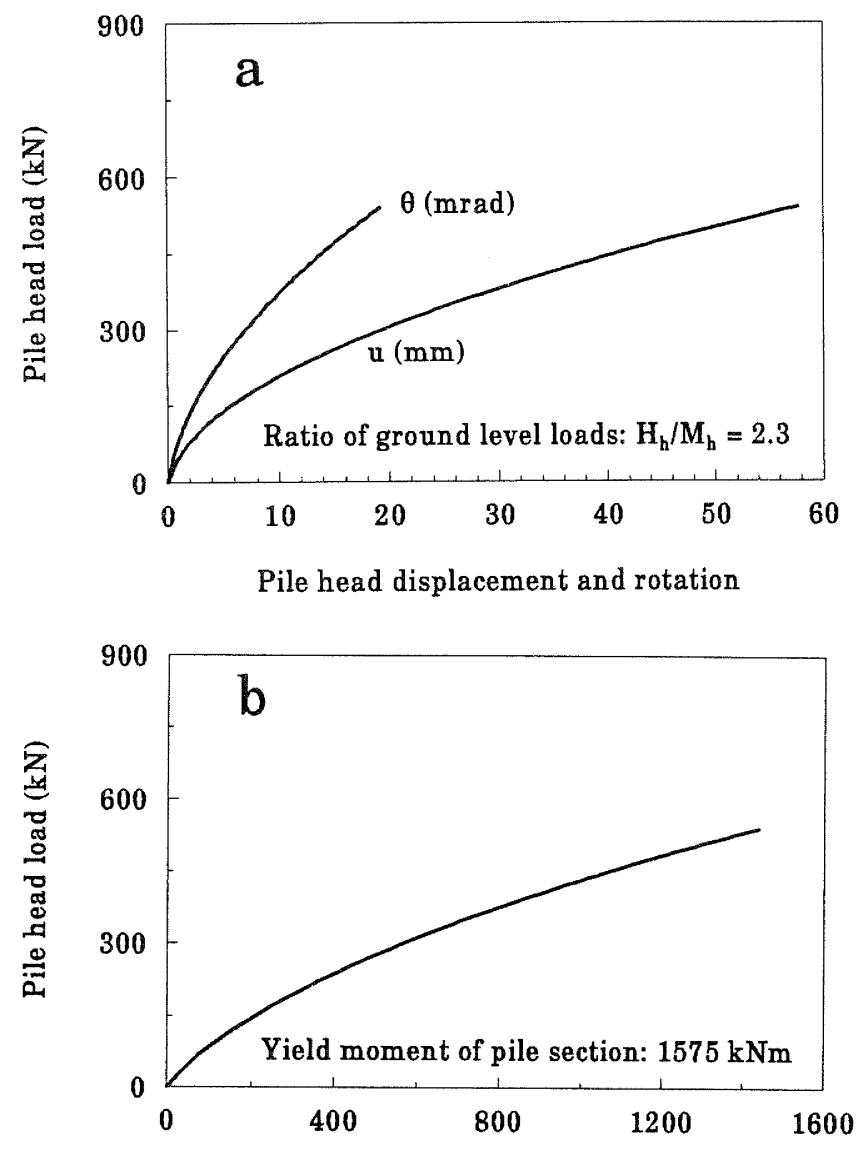

Pile shaft maximum moment $(\mathrm{kNm})$

For the fixed head case Budhu and Davies give the following expressions for the fixed head yield influence factors for piles in normally consolidated clay:

$$
\begin{aligned}
& \mathrm{I}_{\mathrm{uFy}}=1+\frac{\mathrm{h}-32 \mathrm{k}^{0.43}}{105 \mathrm{k}^{0.54}} \\
& \mathrm{I}_{\text {MFy }}=1+\frac{\mathrm{h}-30 \mathrm{k}^{0.53}}{312 \mathrm{k}^{0.56}}
\end{aligned}
$$

And for fixed head piles in a sand profile the Budhu and Davies yield influence factors are:

$$
\begin{aligned}
I_{u F y} & =1+\frac{h-10 k^{0.40}}{15 k^{0.50}} \\
I_{M F y} & =1+\frac{h}{100 k^{0.35}}
\end{aligned}
$$

Some comparisons have been made between the predictions obtained with the equations presented in this section and the output from the nonlinear finite element program discussed in the next section. These show that the two approaches give similar pile head displacements and rotations and similar maximum moments. The largest difference appears to be in the predicted position of the maximum moment.

\subsubsection{Serviceability limit state}

The serviceability limit state may be interpreted as allowing pile head actions that take the maximum pile shaft moment up to, or close to, yield. If this approach is followed then the above examples show that there will be nonlinear soil deformation adjacent to the pile shaft. Equations 7.1, 7.2, and 7.5 to 7.10 provide a convenient method of assessing the effect of this nonlinear behaviour on the pile head displacements.

The ultimate lateral capacity of a pile occurs when the pile shaft is at yield and all the strength of the surrounding soil has been mobilised. Section 9.2 presents a set of equations for the calculation of actions which give the ultimate lateral capacity. These actions can be compared with the actions calculated from the equations of sections 7.1.1 and 7.1.2 at which the pile shaft maximum moment is at yield. For uniform clays the ultimate capacity occurs at actions greater than those which initiate pile shaft yielding. For sand and normally consolidated clay profiles it is found that the ultimate capacity and the actions which initiate pile shaft yielding are sometimes quite close and in some cases even reversed. This means that pile head actions causing the onset of pile shaft yielding need to be checked against the ultimate lateral capacities calculated with the equations of section 9.2.

\subsection{Nonlinear soil reaction and layered soil profiles}

In this section a method of taking into account layered soil profiles and the nonlinear reaction of the soil against the pile shaft is considered. Nonlinear behaviour is modelled by replacing the standard linear Winkler pressure displacement model with a nonlinear relationship. The nonlinear response is controlled by the initial stiffness of the Winkler springs and the lateral pressure at which the soil reaches the maximum pressure it can sustain. Between these two limits the pressure displacement relationship is assumed to have the form of an hyperbola.

A common way of handling nonlinear soil response along a pile shaft is to use the so-called p-y curves for the springs. This technique was first proposed by McCelland and Focht (1956). Since then various forms have been developed, but some of the more recent have become rather complex in their quest for better modelling of observed pile behaviour. Reese (1974) developed a passive wedge type of failure to determine the maximum lateral pressure available near the ground surface in sand. In addition such information as the strain in a triaxial specimen at $50 \%$ of the failure stress are required.

The method proposed in this section was developed in an attempt to simplify the specification of p-y curves. It is incorporated into a finite element program described by Carter (1984). The approach has been verified by applying it 
to published case histories of prototype lateral load testing of piles in sand and clay.

The linear Winkler spring model is replaced by the following equation:

$$
\mathrm{u}=\frac{\mathrm{p}}{\mathrm{k}_{\mathrm{os}}}\left(\frac{\mathrm{p}_{\mathrm{ult}}}{\mathrm{p}_{\mathrm{ult}}-\mathrm{p}}\right)^{\mathrm{n}}
$$

where: $\mathrm{k}_{\mathrm{os}}$ is the small strain coefficient of subgrade reaction,

$\mathrm{p}_{\text {ult }} \quad$ is the maximum lateral pressure that the soil can sustain,

and $\mathrm{n}$ is an index that controls the extent of the nonlinearity.

Fig. 7.3 illustrates the form of this nonlinear spring relationship. Note how this approach is different from that of section 7.1. There, at all points of the interface between the pile shaft and soil, the pressure - displacement relation was linear until the contact stress reached the limiting value after which there could be no further increase in the stress. In this section, as illustrated in Fig. 7.3, the pressure displacement relation is nonlinear long before the limiting pressure is approached.

Broms (1964) proposed that the ultimate lateral bearing pressure, allowing for two dimensional effects, sand could exert against a pile shaft is controlled by $3 \mathrm{~K}_{\mathrm{p}}$. Work with the finite element program has shown that a value of $5 \mathrm{~K}_{\mathrm{p}}$ gives more realistic modelling.

For cohesive soils the limiting value of lateral pressure beneath depths of 3.5 pile diameters is assumed to be constant at $12 \mathrm{~s}_{\mathrm{u}}$. At the ground surface the resistance is taken as $5 s_{u}$ for nonfissured clays and $2 s_{u}$ for fissured clays, it then increases linearly to a depth of 3.5 pile diameters. These recommendations follow broadly those of Stevens and Audibert (1979) and have been verified by applying the finite element program to published case study data. The value of $12 s_{u}$ at depth has been shown to be reasonable for a circular pile shaft with complete adhesion by Randolf and Houlsby (1984), for a smooth interface they obtained $9 \mathrm{~s}_{\mathrm{u}}$. Similar results have been obtained by Murff and Hamilton (1993).

The back analysis of a range of full scale field tests has shown that for sands the parameter $\mathrm{n}$ takes a value of 1.0 , whilst for clays values in the range $0.2-0.3$ seem to give the best fit between the observed and predicted results.

An initial approximation to the small strain modulus of subgrade reaction can be obtained using the techniques discussed in section 6 . For the case histories studied by Carter (1984) and Ling (1988) with piles embedded in clay it was found that the most satisfactory matching of predicted and observed ground level deflections is achieved when $\mathrm{E}_{\mathrm{s}}=$ $300 \mathrm{~s}_{\mathrm{u}}$ and the modulus of subgrade reaction is double (soil contact on both sides of the pile) that calculated from equation 3.39. For sands equation 6.1 or 6.2 is used to determine a small strain shear modulus and hence $\mathrm{E}_{\mathrm{s}}$ for subsequent input to equation 3.39. This very high initial value of $E_{s}$ has been found to lead to good matching of the observed and finite element predictions of the ground level. pile deflections in sands (cf. the Mustang Island test discussed

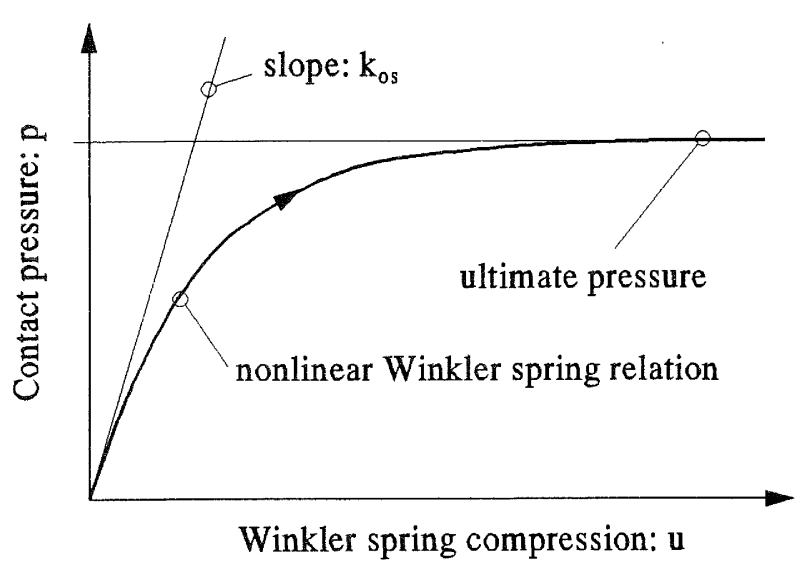

Fig. 7.3 Nonlinear Winkler pressure-displacement relation.

below in section 7.4.2).

The computation of the pile response is done with a finite element program developed by Carter (1984). The pile is subdivided into a convenient number of elements, the length of which increases with depth, and the compliance of the adjacent soil is represented by lateral springs at each nodal point. As the load deformation relation for these springs is nonlinear the analysis has to be done in an incremental fashion. For the first increment the coefficient of subgrade reaction is $\mathbf{k}_{\text {os. }}$. After the first increment has been applied and the displacements calculated, the stiffness of the springs representing the lateral resistance of the soil is updated. The tangent value of the modulus of subgrade reaction is obtained from the differentiation of equation 7.11. From this the updated spring stiffness can be evaluated. The next increment is then applied and the process repeated until the required final load is reached.

\subsection{Effect of pile diameter}

Equation 3.39 suggests a relationship between the modulus of subgrade reaction and pile diameter. It suggests that for given soil properties, $\mathrm{E}_{\mathrm{s}}$ and $v_{\mathrm{s}}$, that $\mathrm{k}$ will be independent of pile dimensions as I for a circular pile is proportional the $\mathrm{D}^{4}$. In looking at a range of case studies in which piles of different diameter were loaded Carter (1984) and Ling (1988) found that this was not the case and the piles actually appear to become stiffer as the pile diameter increases. Carter found that if modulus of subgrade reaction values match the observed behaviour of a pile of given diameter then for other diameters the moduli must be adjusted in proportion to the diameter change. Thus:

$$
\mathrm{k}_{\mathrm{D} 2}=\mathrm{k}_{\mathrm{D} 1}\left(\frac{\mathrm{D}_{2}}{\mathrm{D}_{1}}\right)
$$

where: $\mathrm{k}_{\mathrm{D} 1}$ is the modulus of subgrade reaction for the pile of dimension $D_{1}$ and $k_{D 2}$ is the modulus for the pile of 
dimension $\mathrm{D}_{2}$. Note that this is quite contrary to the suggestion of Terzaghi (1955) who proposes that the product of coefficient of subgrade reaction and pile width is constant, i.e. that the modulus of subgrade reaction is independent of pile diameter. On the other hand equation 7.12 implies that the apparent coefficient of subgrade reaction, determined from the lateral stiffness of pile foundations, is independent of pile diameter.

Fig. 7.4 presents the interpretation, by Ling (1988), of a range of case studies in which piles of different diameter were loaded. These data justify equation 7.12.

\subsection{Case studies}

\subsubsection{RRU Bridge foundation stiffness tests}

Four NZ bridge sites have been used to determine the asbuilt stiffness of bridge foundations. The objective of this work was to compare the stiffness of the foundations with the assumptions made at the design stage. The procedure developed is explained by Wood and Philips (1987). The tests were done when the substructure was complete but prior to the installation of the bridge deck. The loading was in the direction of the bridge axis; prestressing cables were used to achieve mutual loading of adjacent pile foundations. At each site two separate tests were done so that three pile foundations were loaded, the middle foundation element was loaded two ways and the adjacent foundations one way. Both the lateral and rotational displacements at the ground surface were monitored. Resulting from these tests a considerable amount of data about the foundation stiffness was obtained. The maximum lateral loads applied took the bridge columns close to first cracking.

The four bridge foundations tested were for the Maitai and Wai-iti bridges near Nelson, Newmans bridge on State Highway 2 near Eketahuna and the bridge over the Charwell river on $\mathrm{SH} 70$. The details of each bridge and site along with the results are given by Wood and Phillips $(1987,1988)$ and Wood (1989, 1990). The current foundation configurations for bridges in $\mathrm{NZ}$ are simple. The individual foundations consist of single piles/piers having diameters typically in excess of one metre, or, as in the case of the Waiiti bridge, each foundation element consists of a pair of pile/piers oriented at right angles to the axis of the bridge.

Details of the Wai-iti bridge and the dense gravel profile are given in Fig. 7.5a. The measured lateral displacements and rotations of the pile head are reproduced in Fig. $7.5 \mathrm{~b} \& \mathrm{c}$.

An approximation to the information in Fig. $7.5 \mathrm{~b} \& \mathrm{c}$ is that under a lateral load of $300 \mathrm{kN}$ the pile head had displaced $2.4-2.5 \mathrm{~mm}$ and rotated $1.1 \mathrm{mrad}$. The results from the other three tests have not been discussed here, all that needs to be said is that they all give stiffnesses similar to the Wai-iti bridge foundation (and somewhat larger than had been assumed in the design of the bridge foundations).

Example 7.4 Investigate the ground stiffness implied by the results of the pile lateral load test presented in Fig. 7.5. Compare the stiffnesses obtained from use of the Winkler and elastic continuum models of soil behaviour.
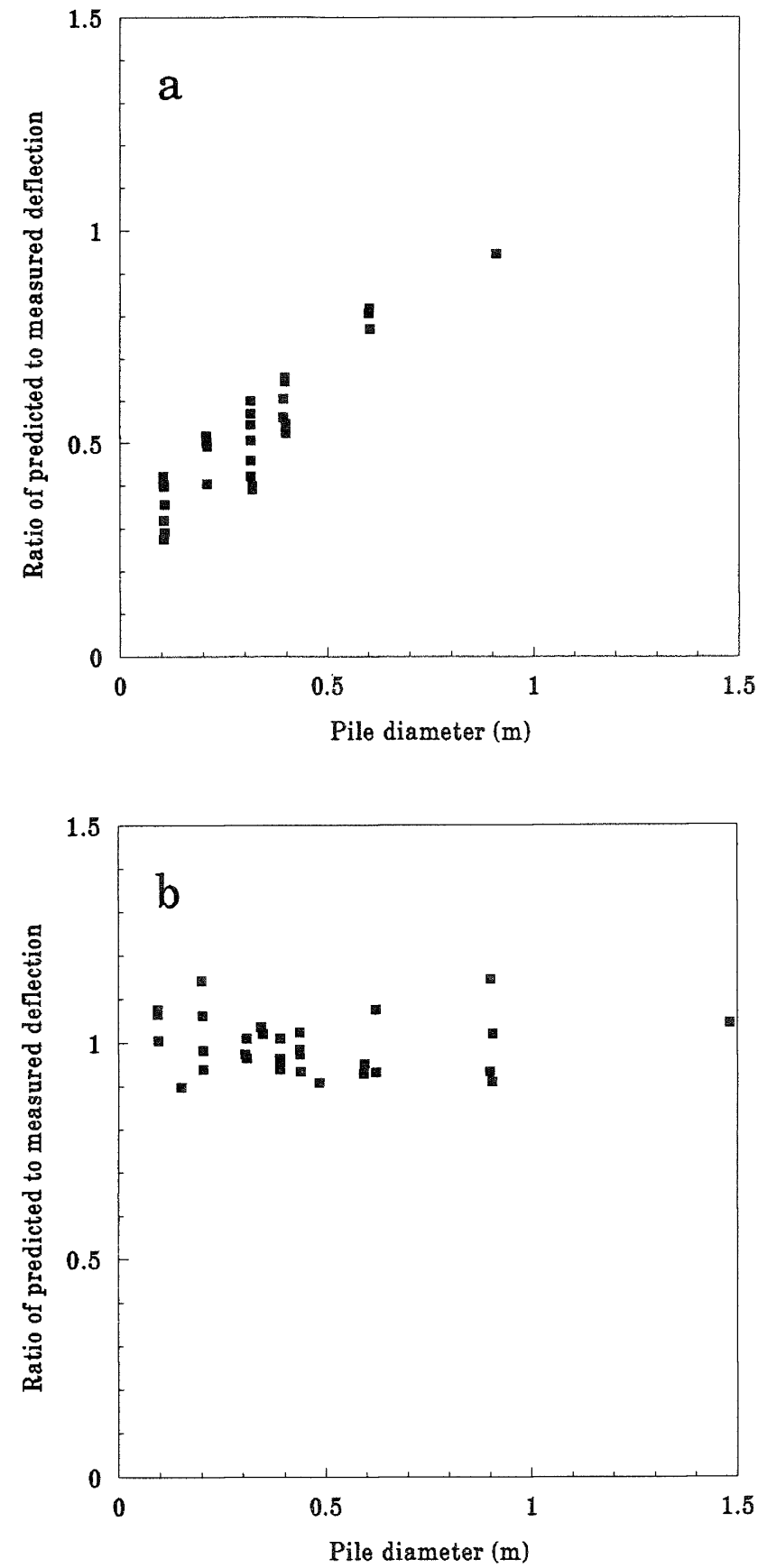

Fig. 7.4 Effect of pile diameter on back analysed modulus of subgrade reaction; (a) following Terzaghi, (b) according Carter and Ling.

The measured displacement of the pile head was $2.4-2.5$ $\mathrm{mm}$ and the rotation was $1.1 \mathrm{mrad}$. The applied horizontal force causing these deformations was $284 \mathrm{kN}$, that is $142 \mathrm{kN}$ per pile.

We will assume that the piles are embedded in soil having uniform properties with depth. The effect of the beam connecting the piles will be ignored as the details of the backfilling are not clear and also as Wood and Phillips (1988) found it had a very small effect in their modelling. Thus the 


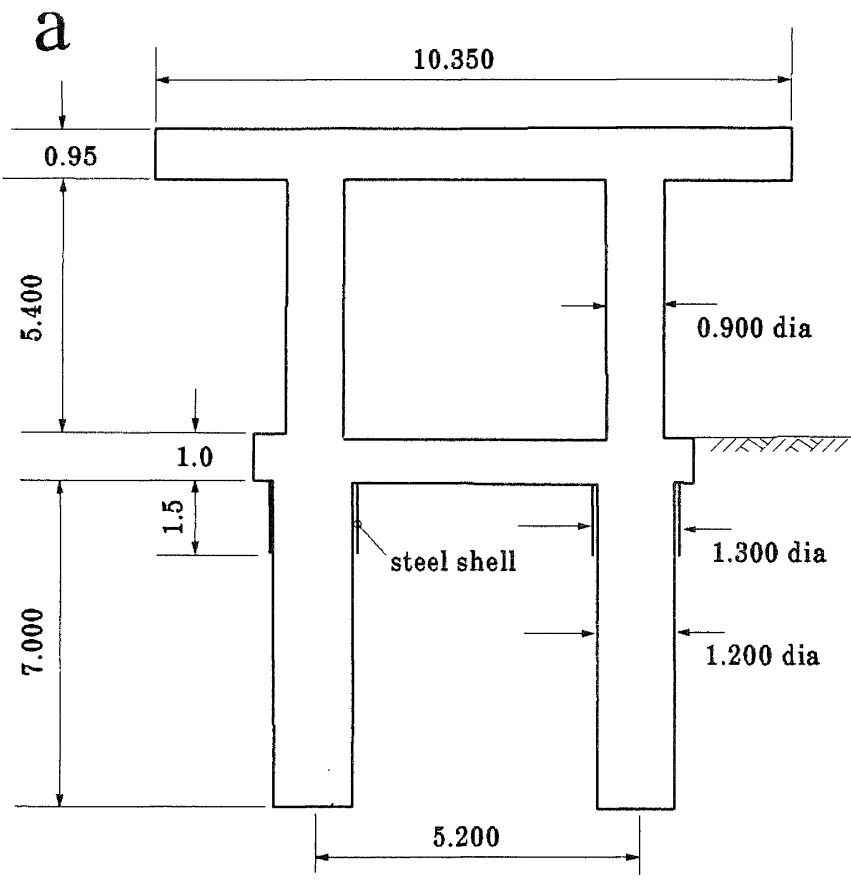

b

Cycles 1 to 3

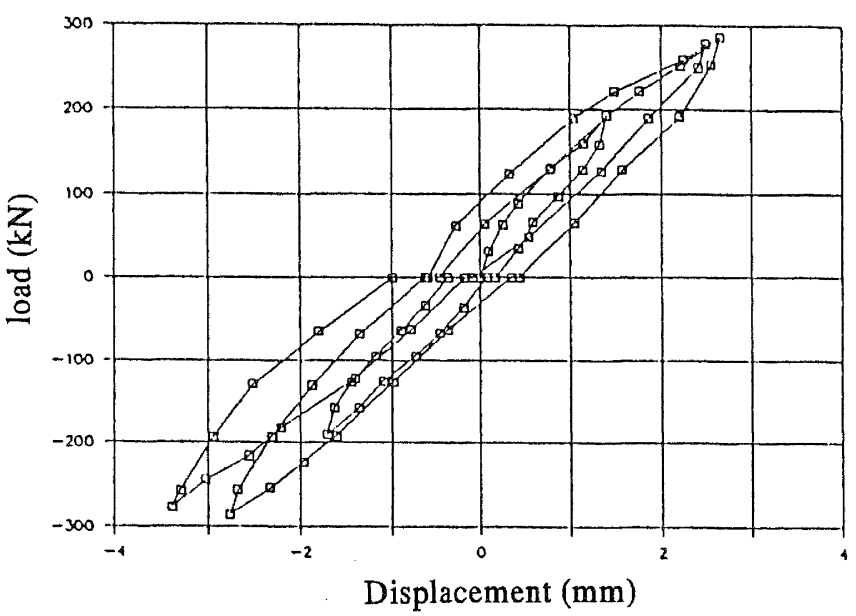

C

Cycles 1 to $\bar{z}$

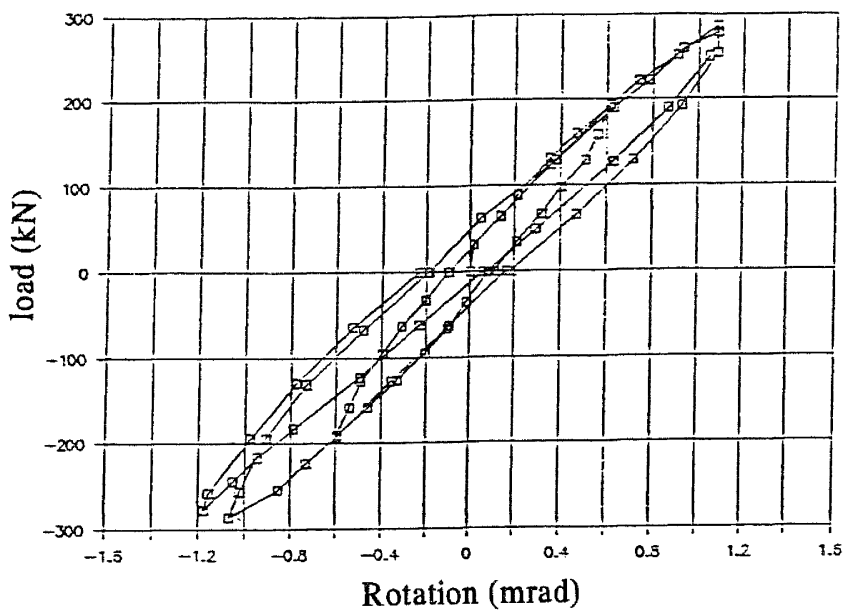

Fig. 7.5 Details and results of the Wai-iti bridge foundation tests; (a) structure details, (b) measured lateral displacements, and (c) measured pile head rotations. effective length of the piles is $7 \mathrm{~m}$, the diameter $1.3 \mathrm{~m}$ and the ratio of moment to horizontal shear 7.6.

Firstly, consider the Winkler approach:

We will use gross section properties to obtain $\mathrm{E}_{\mathrm{p}} \mathrm{I}_{\mathrm{p}}$, assuming the concrete to have Young's modulus of $28 \mathrm{GPa}$ (Wood and Phillips (1988)). The pile diameter is $1.3 \mathrm{~m}$ near the top of the shaft and $1.2 \mathrm{~m}$ below this. This difference is due to the steel jacket used at the top of the shaft. The second moment of area of the pile section allowing for the steel jacket is $0.204 \mathrm{~m}^{4}$ (Phillips and Wood (1988)). This gives $\mathrm{E}_{\mathrm{p}} \mathrm{I}_{\mathrm{p}}=5712$ $\mathrm{kNm}^{2}$

As an initial attempt take $\mathrm{k}=80 \mathrm{MPa}$

From equation 3.3 we have: $\lambda=(80 / 4 \times 5712)^{0.25}=0.24$ and $\lambda \mathrm{L}=0.24 \times 7=1.7$. We will start with the semi-infinite equations even though this value for $\lambda \mathrm{L}$ suggests that there might be movement at the base of the pile. At the pile head $\lambda \mathrm{z}=0$, so combining equations 3.4 and 3.8 we have for the lateral displacement:

$\mathrm{u}=2 \times 0.24 \times 142 / 80+2 \times 0.24^{2} \times 142 \times 7.6 / 80=2.41 \mathrm{~mm}$

and combining equations 3.5 and 3.9 gives the head rotation:

$\theta=2 \times 0.24^{2} \times 142 / 80+4 \times 0.24^{3} \times 142 \times 7.6 / 80=0.95 \mathrm{mrad}$.

If similar calculations are done assuming a finite length pile using the equations on pages 52 an 53 of Hetenyi (1946) the displacements are slightly greater.

The value for $\mathrm{k}$ used above was chosen to get the correct horizontal displacement. An alternative would be to work from the $\mathrm{N}$ value to estimate $\mathrm{k}$. Taking an average value for $\mathrm{N}$ of 35 for the material at the site of the Wai-iti bridge and using equation 6.14 (actually suggested for sands) gives the coefficient of subgrade reaction of $63 \mathrm{kPa} / \mathrm{mm}$. Now this value corresponds to a $0.3 \mathrm{~m}$ diameter plate so, following Terzaghi, we calculate the coefficient for a $1.3 \mathrm{~m}$ diameter pile as:

$$
\mathrm{k}_{\mathrm{s}}=63 \times 0.3 / 1.3=14.5 \mathrm{kPa} / \mathrm{mm} \text {. }
$$

We now convert to the modulus of subgrade reaction by multiplying by the width of the pile, and multiply by a further factor of 2 to account for action on both sides of the pile:

$$
\mathrm{k}=14.5 \times 1.3 \times 2=38 \mathrm{MPa} .
$$

Using this value and repeating the above calculations gives: $\mathrm{u}=3.83 \mathrm{~mm}$ and $\theta=1.24 \mathrm{mrad}$. As these clearly overestimate the displacements the method of equation 7.12 will be applied. Firstly convert the coefficient of subgrade reaction for a $0.3 \mathrm{~m}$ diameter pile to the modulus of subgrade reaction (multiply by 0.3 ), then use equation 7.12 and finally double the result to account for soil in the front and rear of the pile:

$$
\mathrm{k}=(\{63 \times 0.3\} \times 1.3 / 0.3) \times 2=164 \mathrm{MPa} .
$$

Using this value and repeating the above calculations gives: $\mathrm{u}=1.62 \mathrm{~mm}$ and $\theta=0.80 \mathrm{mrad}$. (These values are increased slightly by doing calculations with a finite pile length.) 


\begin{tabular}{|l|c|c|c|}
\hline & $\delta(\mathrm{mm})$ & $\theta(\mathrm{mrad})$ & $\delta / \theta$ \\
\hline Measured & 2.45 & 1.10 & 2.23 \\
\hline $\mathrm{k}=80 \mathrm{MPa}$ & 2.41 & 0.95 & 2.54 \\
\hline $\mathrm{k}=38 \mathrm{MPa}$ & 3.83 & 1.24 & 3.09 \\
\hline $\mathrm{k}=164 \mathrm{MPa}$ & 1.62 & 0.80 & 2.02 \\
\hline
\end{tabular}

The entries in the table provide further justification for the size effect discussed above. The prediction with the modulus of subgrade reaction obtained using the Terzaghi size effect is the least satisfactory of the three in the table. The predictions using equation 7.12 are on the stiff side, improvements might be possible with more realistic modelling of the soil profile rather than assuming a constant soil stiffness with depth.

Now, consider the elastic continuum approach:

We will assume a Young's modulus for the soil of $50 \mathrm{MPa}$.

Using equation 3.17 we calculate and equivalent Young's modulus for the pile:

$\mathrm{E}_{\mathrm{p}}=64 \times 5712 / \pi \times 1.3^{4}=40.7 \mathrm{GPa}$.

$\mathrm{K}=40700 / 50=814$

$\mathrm{L}_{\mathrm{a}}=0.5 \times 1.3 \times 814^{0.36}=7.26 \mathrm{~m}$, the length of the pile is $7 \mathrm{~m}$ so we are right at the bound of the applicability of the long pile equations.

$\mathrm{f}_{\mathrm{uH}}=1.3 \times 814^{-0.18} / 50 \times 1.3=5.99 \times 10^{-3}$

$\mathrm{f}_{\mathrm{uM}}=2.2 \times 814^{-0.45} / 50 \times 1.3^{2}=1.28 \times 10^{-3}$

$f_{\theta M}=9.2 \times 814^{-0.73 / 50 \times 1.3^{3}}=6.28 \times 10^{-4}$

As there are two piles we need to evaluate interaction factors. The pile spacing is $5.2 \mathrm{~m}$ and the angle $\xi$ is $90^{\circ}$, from equation 5.10a:

$\alpha_{\mathrm{uF}}=0.3 \times 1.3 \times[2 \times 1.3 \times 814]^{0.143} / 5.2=0.224$

The pile group does not have a fixed head so the interaction factors we need are obtained from equation 5.11:

$\alpha_{\mathrm{uH}}=5 \times 0.224 / 6=0.187, \alpha_{\mathrm{uM}}=0.187^{2}=0.035$

$\alpha_{\theta \mathrm{M}}=0.187^{3}=0.007$.

Each pile carries the same load so the displacements are:

$$
\begin{aligned}
& \mathrm{u}=5.99 \times 10^{-3} \times 142 \times(1+0.187)+ \\
& 1.28 \times 10^{-3} \times 142 \times 7.6 \times(1+0.035)=2.44 \mathrm{~mm} \\
& \theta=1.28 \times 10^{-3} \times 142 \times(1+0.035)+ \\
& 6.28 \times 10^{-4} \times 142 \times 7.6 \times(1+0.0007)=0.87 \mathrm{mrad}
\end{aligned}
$$

We find that, as with the Winkler model, it is possible to match the measured displacement of the pile head but not the rotation.

If we use equation 3.39 we can determine what value of $k$ is implied by the value of $50 \mathrm{MPa}$ for Es. This gives $\mathrm{k}=48$ $\mathrm{MPa}$ which, from the above table, will lead to an over prediction of the pile displacements. Thus the conversion between $E_{s}$ and $k$ is not as straightforward as the equations in section 3.3 and 6.0 imply.

Apart from the simplicity of assuming a homogeneous soil profile other factors may contribute to the mismatch between the various predictions illustrated above. Firstly, the correlation, $\mathrm{k}_{\mathrm{s}}=1.8 \mathrm{~N}(\mathrm{kPa} / \mathrm{mm})$, may not be appropriate for the dense gravelly soils at the bridge site. In such materials there are also questions as to the validity of the SPT tests as the results could be dominated by the presence of large gravel particles. Secondly, there may be problems to do with the local calibration of SPT procedures in comparison with United States, Japanese and European practice. Finally it would not be surprising if gravels are inherently stiffer than dense sands.

\subsubsection{Mustang Island}

The Mustang Island tests were reported by Cox, Reese and Grubbs (1974), and a detailed analysis of the test data was presented in a companion paper by Reese et al (1974). The details of the test set-up and soil profile are given in Fig. 7.6. The steel pile was installed by driving with a diesel hammer. The top $12 \mathrm{~m}$ of the profile consists of sand beneath which there is clay and further sand. The pile diameter was $0.61 \mathrm{~m}$, the wall thickness $9.5 \mathrm{~mm}$, and the pile length was $24 \mathrm{~m}$.

\section{(a) Method of Budhu and Davies}

The method of Budhu and Davies for piles in sand outlined in section 7.1.2 was applied to this case by Pranjoto (1992). The comparison between the calculated and measured displacement and rotation of the pile head is given in Fig. 7.7. It is seen that the comparison is very good. Despite the fact that the sand profile is not homogeneous the inhomogeneity is not great, the calculations were done for a uniform friction angle of $34^{\circ}$.

\section{(b) Finite element method}

The comparison between the surface displacement and lateral force, between lateral force and maximum moment, and the moment profile for a particular force are given in Fig. 7.8. The friction angle of the sand was obtained from a correlation based on penetrometer resistance, giving a value of $30^{\circ}$ for the upper $2 \mathrm{~m}$ of the profile, $35^{\circ}$ between 2 and $3.5 \mathrm{~m}$, and $44^{\circ}$ from $3.5 \mathrm{~m}$ down to $11 \mathrm{~m}$. For these calculations the ultimate lateral pressure of the sand was controlled by $5 \mathrm{~K}_{\mathrm{p}}$. The small strain stiffness of the sand was assessed as explained in section 7.2.

\subsubsection{Mangere Bridge test pile}

As part of the investigation for the Mangere Bridge a full scale test was done on a test pile. The results of this test are reported by Priestley (1974). The pile was constructed by boring a $1.38 \mathrm{~m}$ diameter hole and installing a double steel liner. The exterior surface of the inner liner was strain 
gauged. A reinforcing cage was installed in the inner liner and concrete poured. At the completion of the vertical load testing to measure the base stiffness the gap between the two liners was filled with grout and the lateral load tests conducted.

The geotechnical profile at the site is given in Fig. 7.9. The complexity of the volcanic-marine profile is evident and consequently the Budhu and Davies method is not applicable because of the extreme inhomogeneity of the soil profile.
By analysing the strain gauge data Priestley was able to determine the displacements, bending moment and shear force profiles and also the distributed pressure. From these it was possible to estimate the small strain coefficient of subgrade reaction. The values are also shown in Fig. 7.9.

The comparison between the measured and computed ceflected shapes and the bending moment profiles is given in Figs. 7.10. It is seen that the computed values follow broadly the same pattern as the measured values.

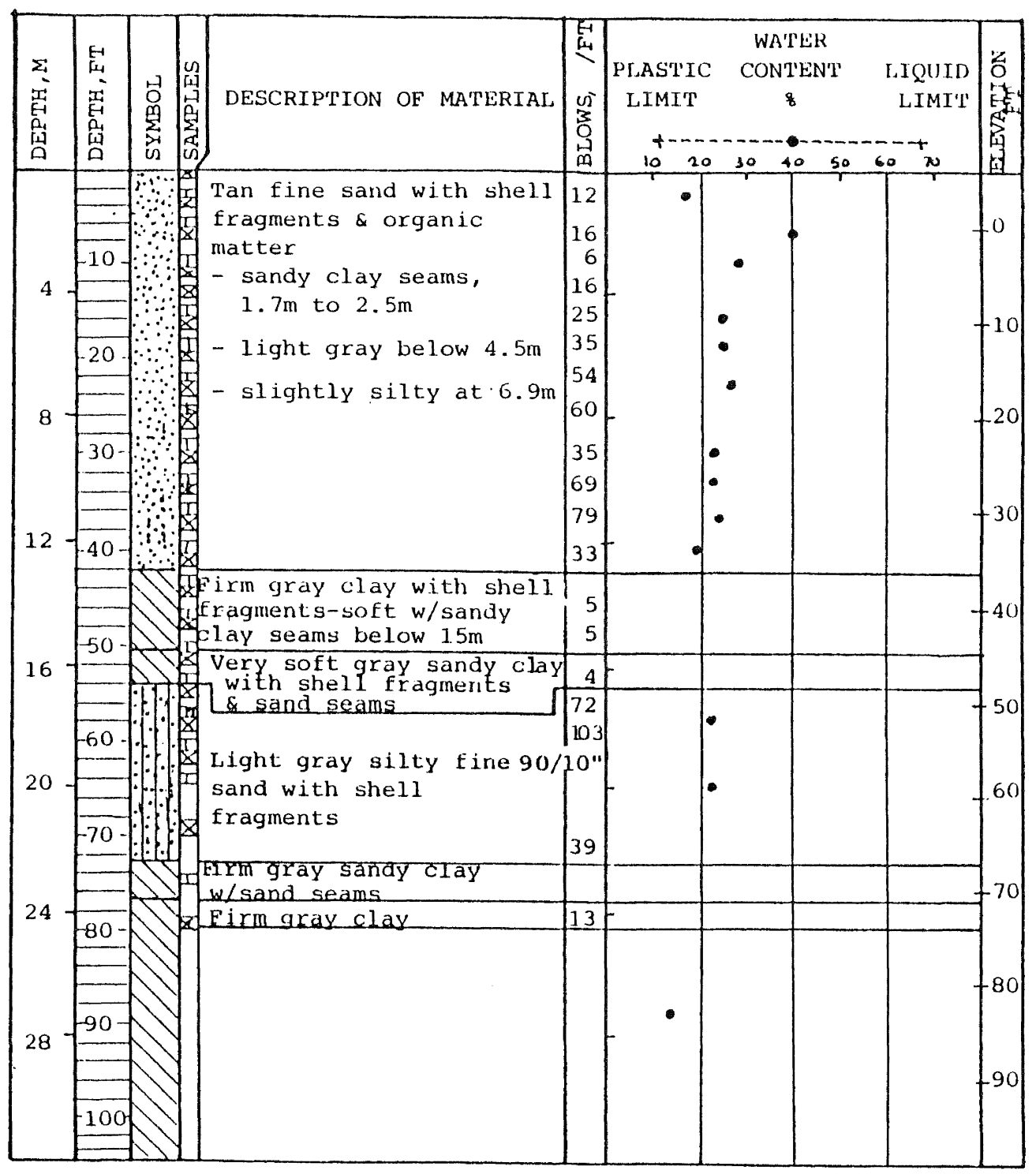

Fig. 7.6a Soil profile for the Mustang Island pile test (after Reese et al (1974)). 
ELECTRICAL LEADS FROM:

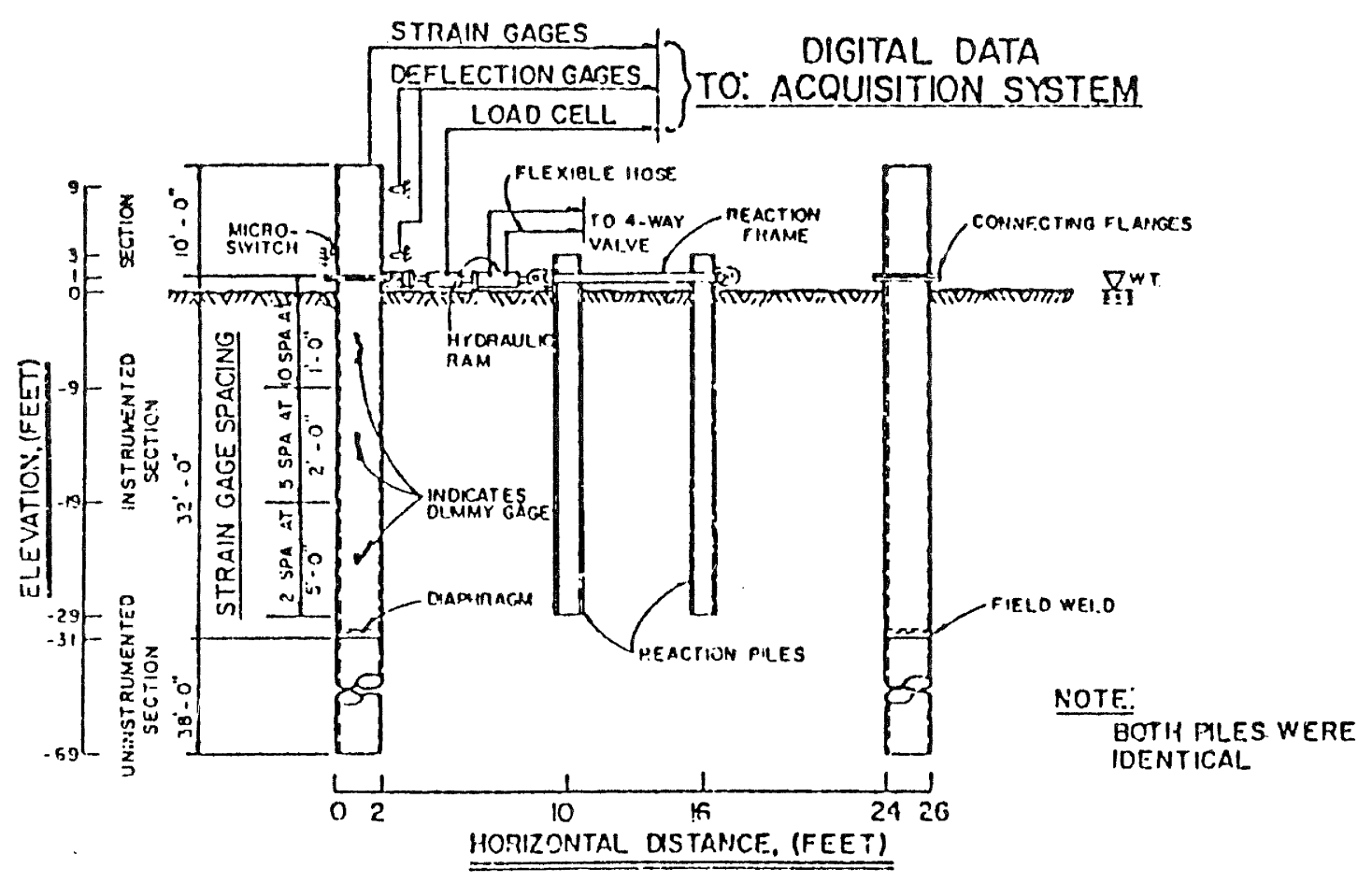

Fig. 7.6b Details of pile the layout for the Mustang Island tests (after Reese et al (1974)). 

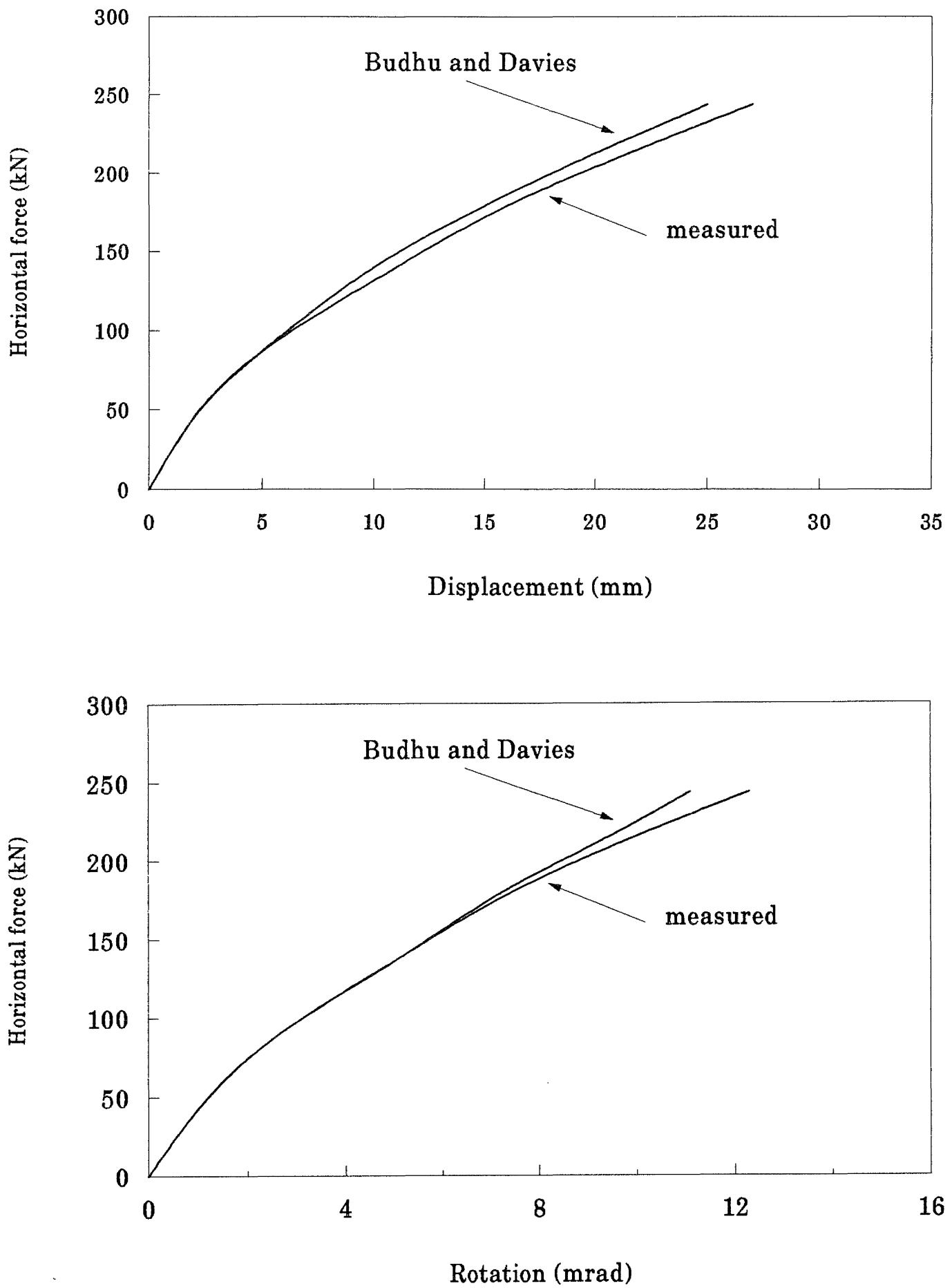

Fig. 7.7 Ground level horizontal displacement and rotation for the Mustang Island pile test calculated using the method of Budhu and Davies (after Pranjoto (1992)). 

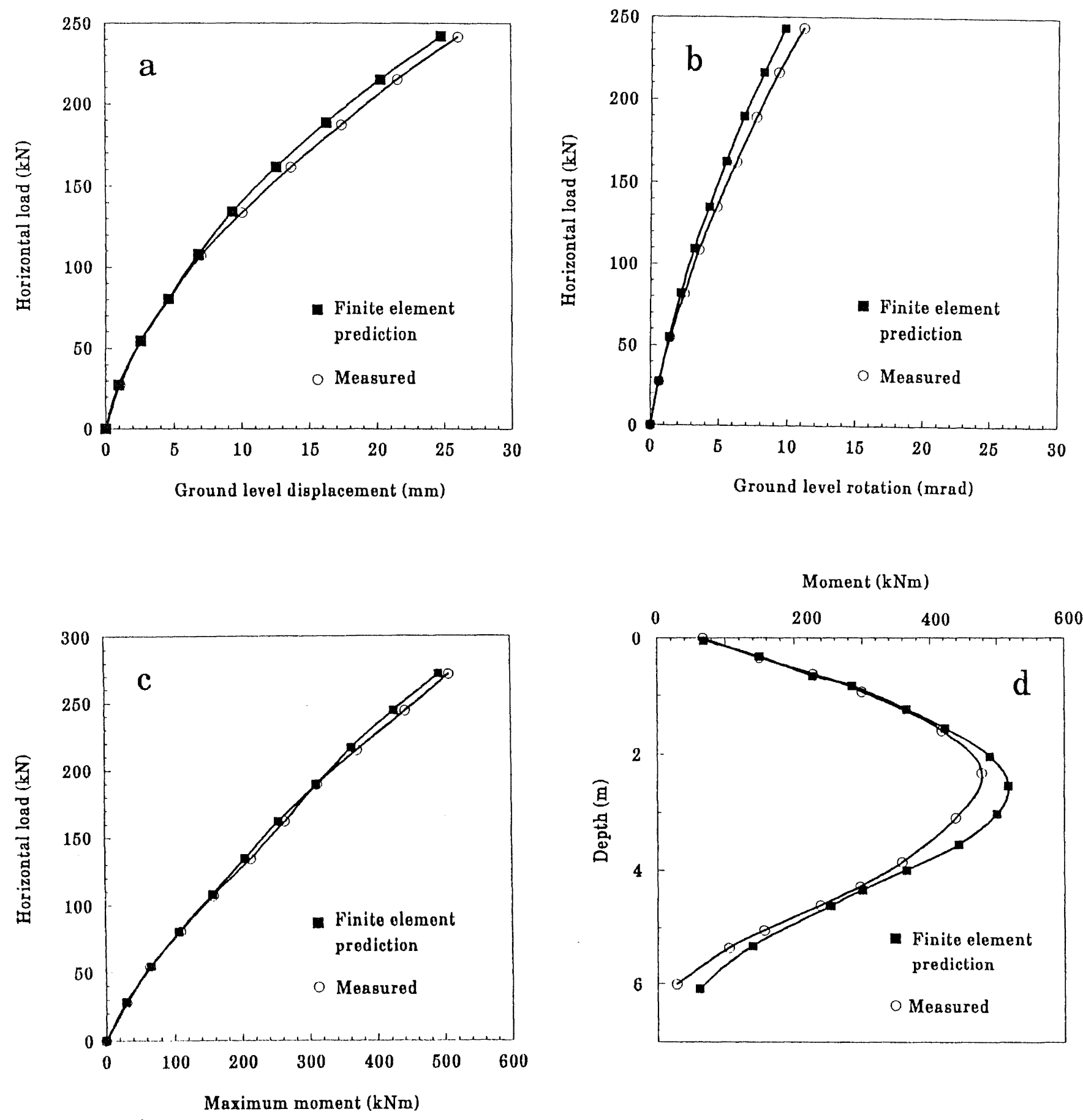

Fig. 7.8 Ground level horizontal displacement and rotation for the Mustang Island pile test calculated with the nonlinear finite element program (after Carter (1984) and Ling (1988)). 


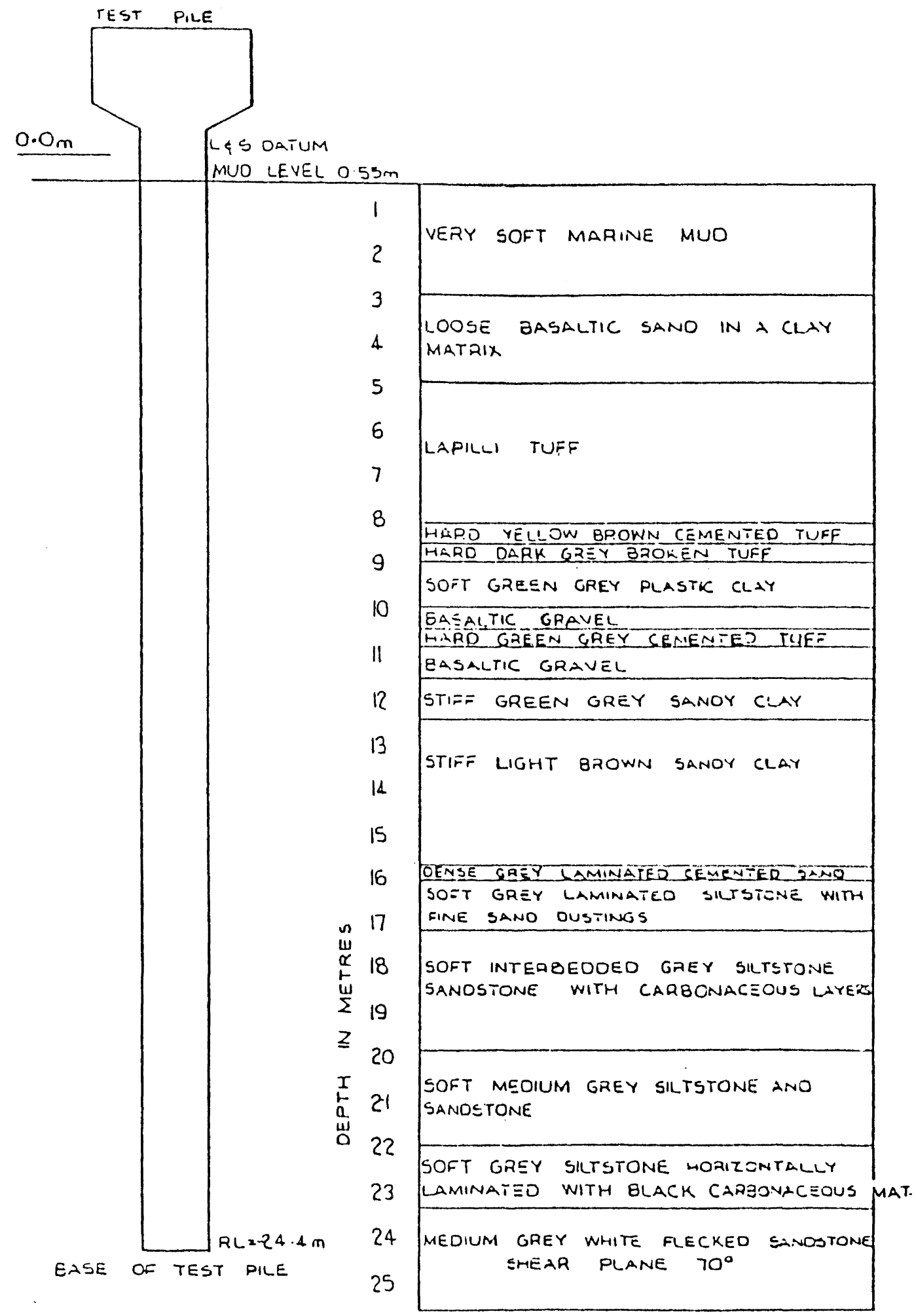

Fig. 7.9a Soil profile for the Mangere Bridge test pier (after Priestley (1974)). 


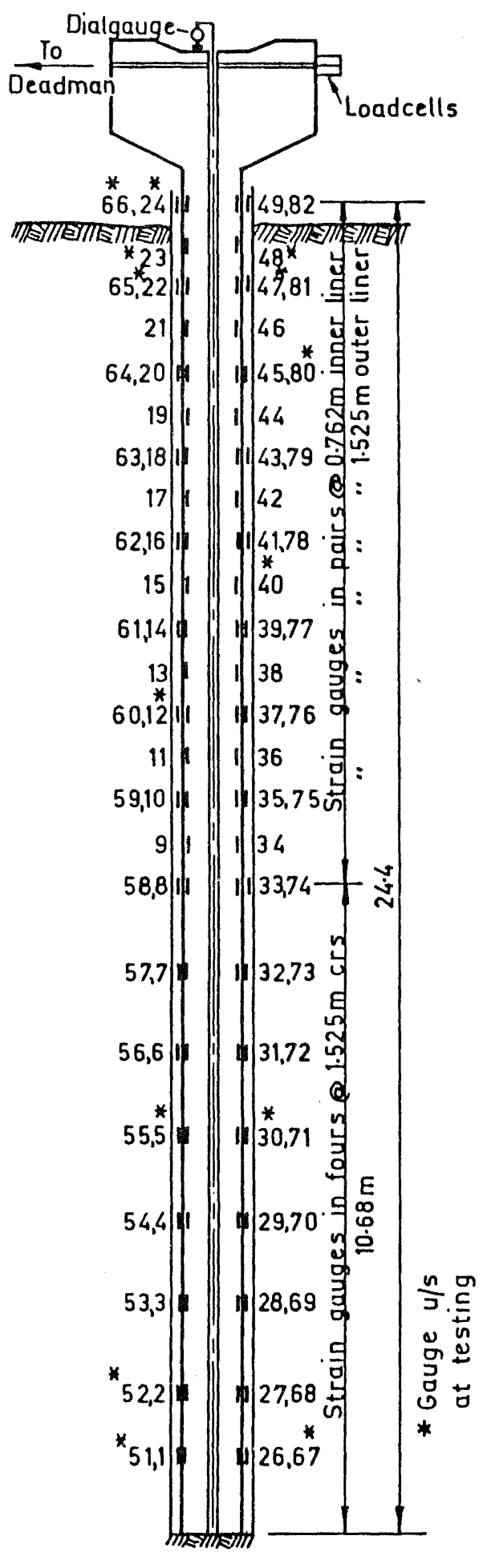

STRAINGAUGE POSITIONS

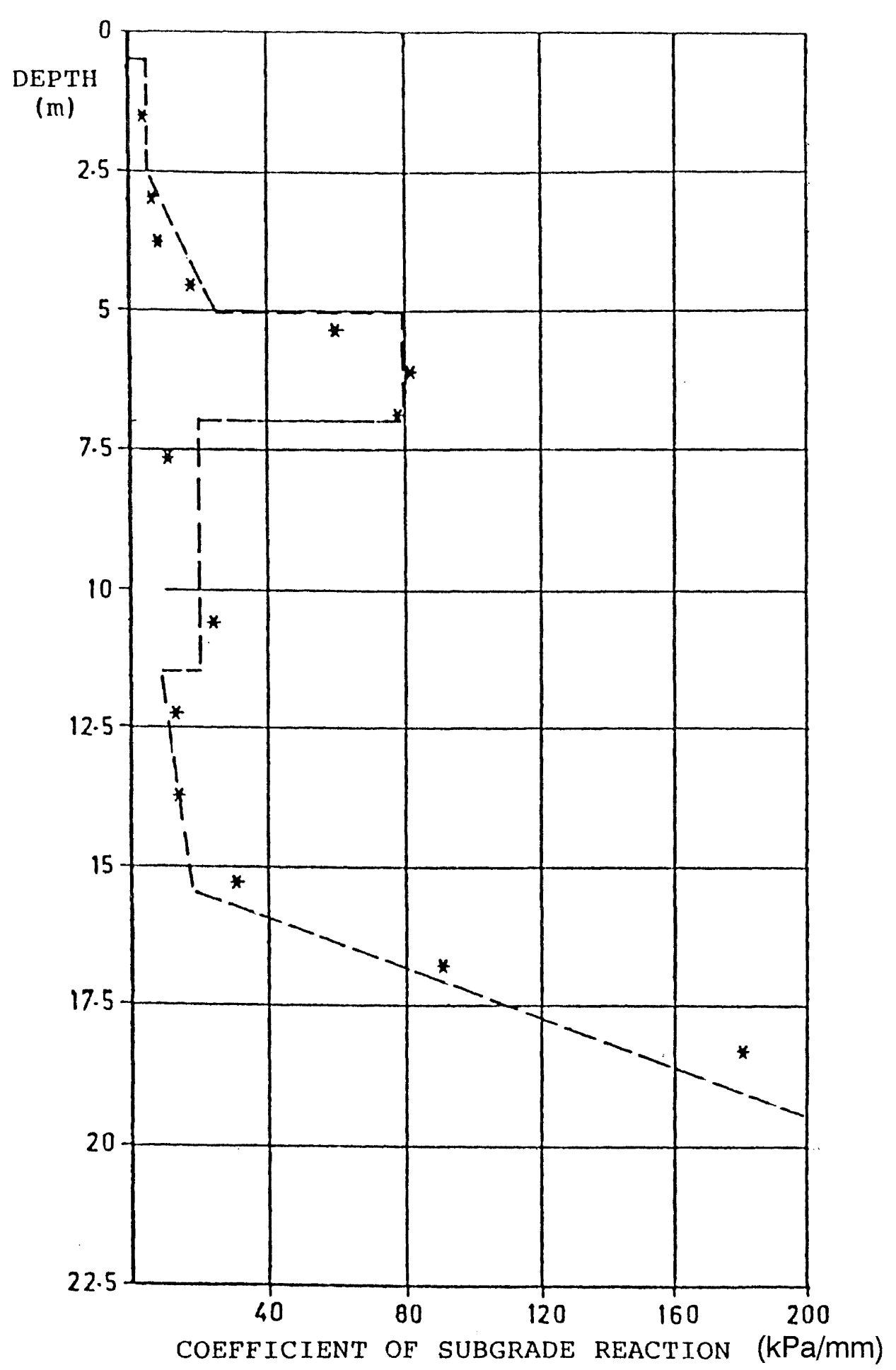

Fig. 7.9b Details of pile strain gauging and modulus of subgrade reaction values backfigured from strain readings (after Priestley (1974)). 


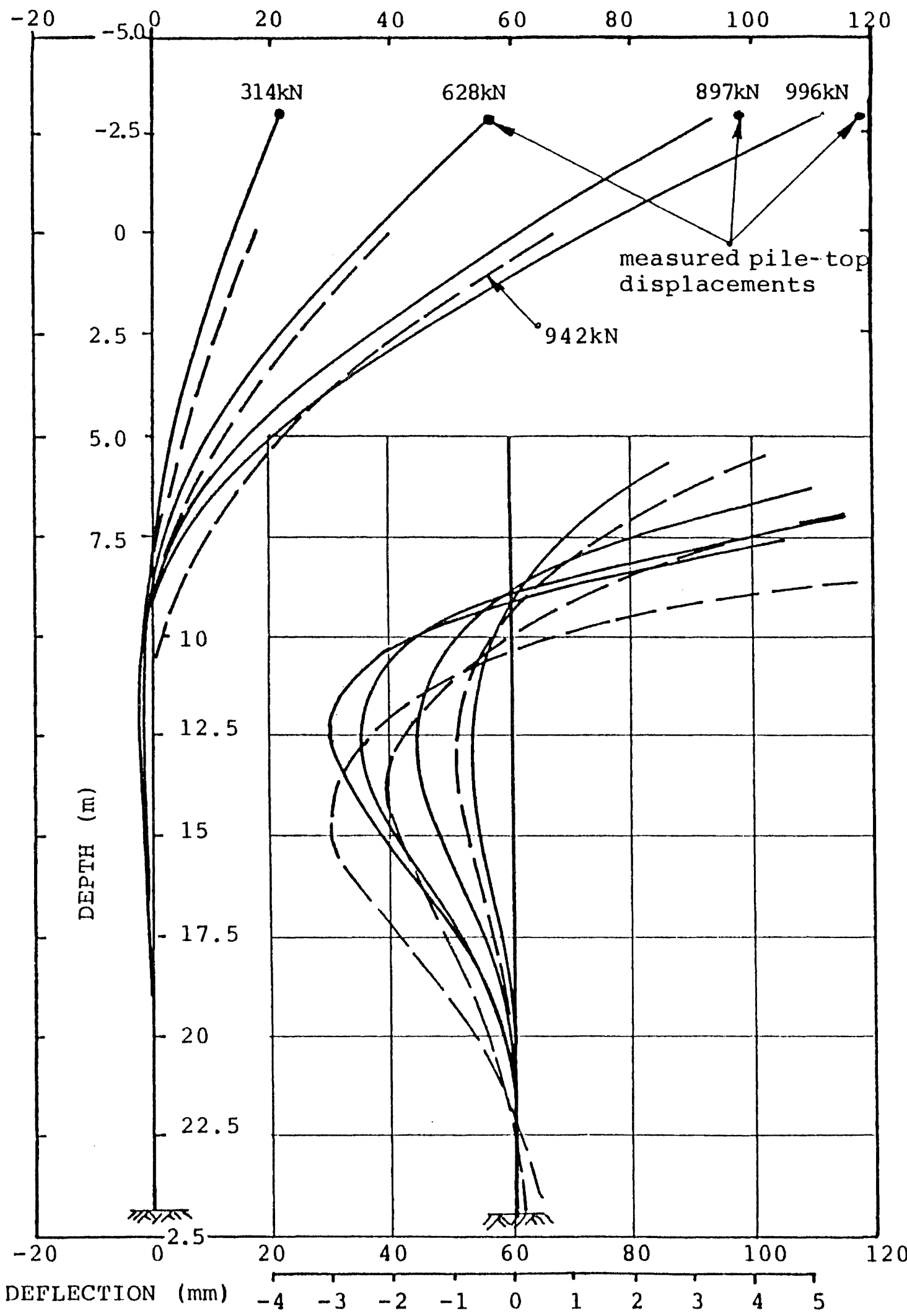

EXPANDED SCALE FOR LOWER SECTION OF CYLINDER

Fig. 7.10a Measured displacement profiles for the Mangere test pier compared with those calculated using the nonlinear finite element program (after Carter (1984)). 


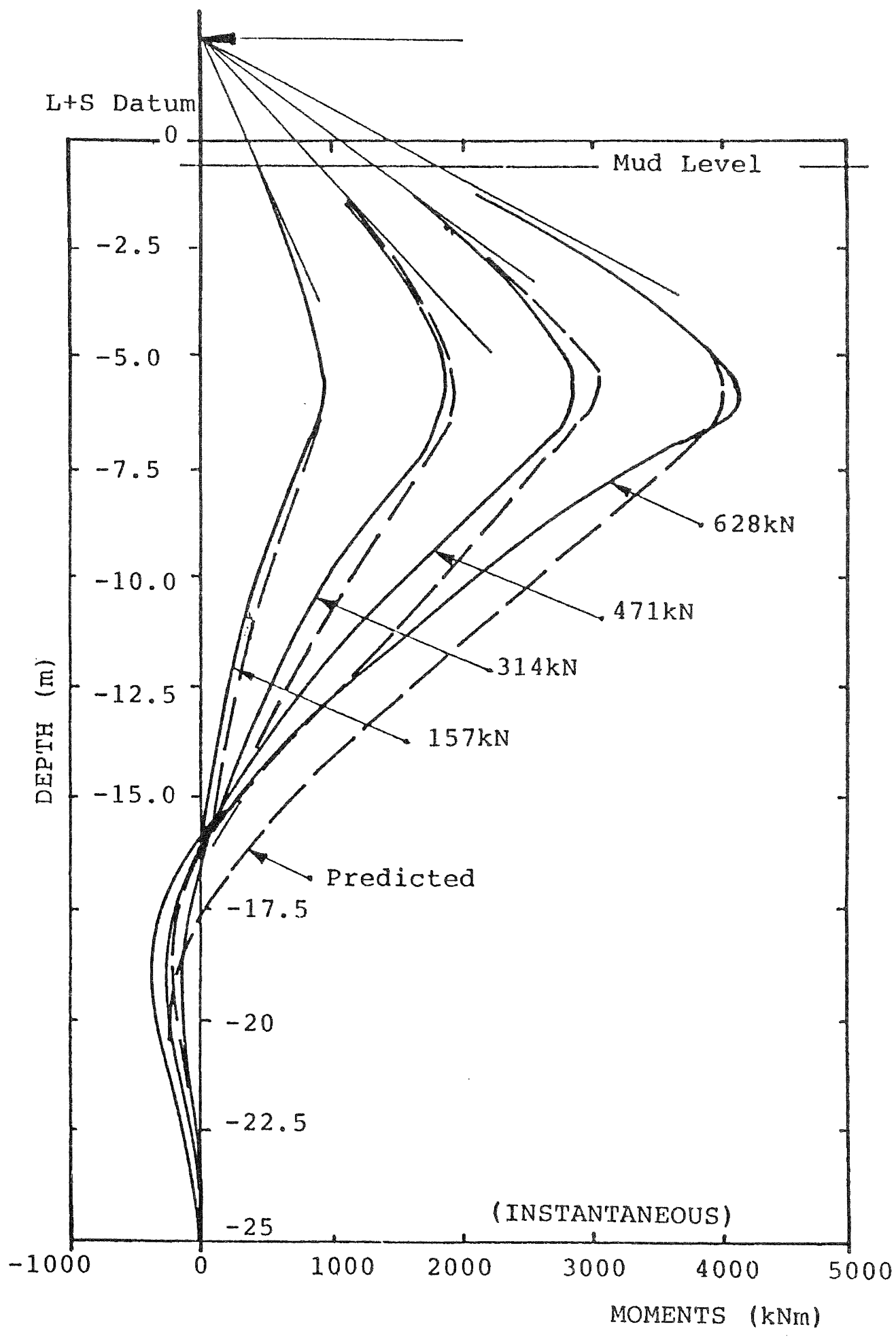

Fig. 7.10b Measured moment profiles for the Mangere test pier compared with those calculated using the nonlinear finite element program (after Carter (1984)). 


\subsection{DYNAMIC STIFFNESS OF PILE FOUNDATIONS}

We will commence our consideration of the dynamic behaviour of pile foundations by reviewing information from field tests on both single piles and pile groups. This will be followed by consideration of the dynamic stiffness of single piles after which pile groups will be covered.

8.1 Results of dynamic tests on prototype scale piles and pile groups.

The material in this section differs from that in section 2 in that here we are considering forced vibration tests on pile foundations whereas earlier we were surveying what information could be gleaned from the observed earthquake behaviour of pile foundations.

\subsubsection{Blaney and O'Neill}

Blaney and O'Neill (1985a and b) describe a field investigation of the forced vibration response of a steel tube pile driven into a deposit of clay. The pile had a $273 \mathrm{~mm}$ outer diameter and $254.5 \mathrm{~mm}$ internal diameter and

APPROXIMATE SOIL DATA

$\begin{array}{ccccc}D E P T H & S_{U} & E_{50} & G_{M A X} & \gamma \\ (F T) & (P S) & & (P S) & (P C F) \\ 0 & 16 & 0.010 & 8500 & 127 \\ 10 & 16 & 0.010 & 8400 & 127 \\ 30 & 28 & 0.004 & 18250 & 133 \\ 43 & 28 & 0.012 & 25000 & 133\end{array}$

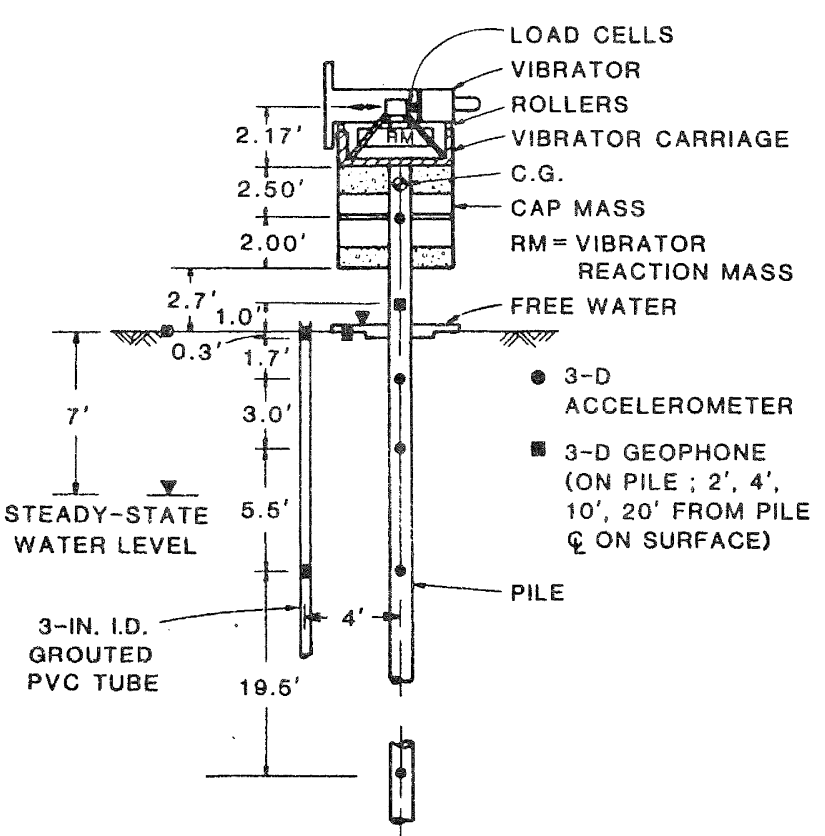

Fig. 8.1 Details of the pile-mass system and soil profile investigated by Blaney and O'Neill.
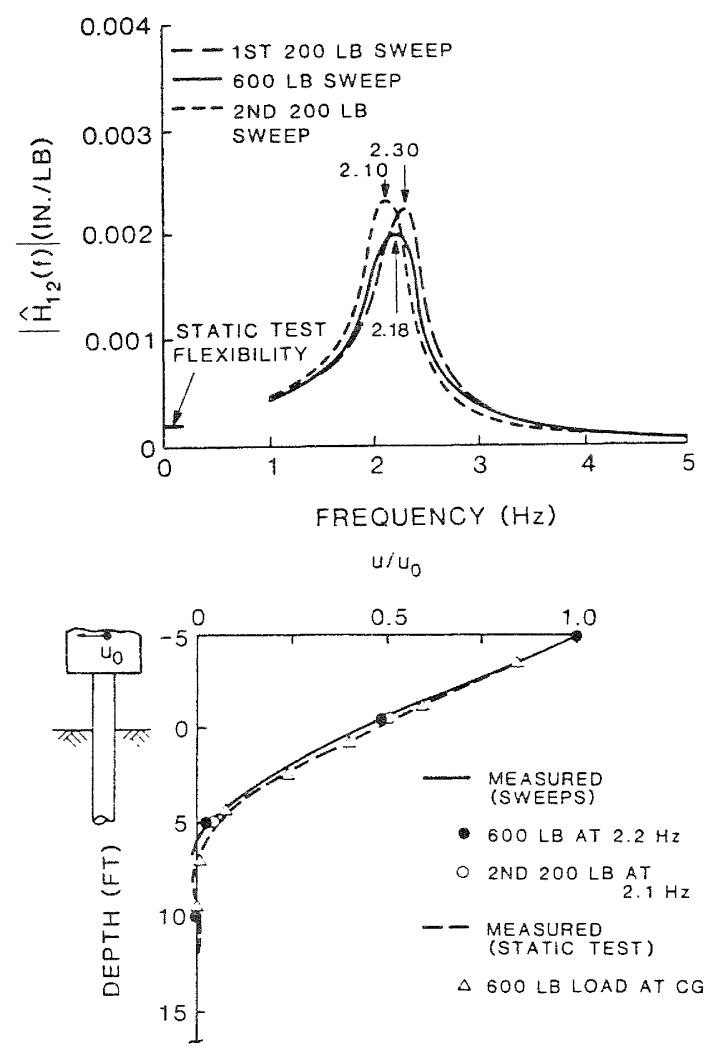

30

Fig. 8.2 Dynamic and static response of the Blaney and O'Neill test pile.

penetrated $13.4 \mathrm{~m}$ into the clay. The details of the test set up and brief soil profile information is given in Fig. 8.1. By means of a vibrator attached to the extension of the pile tube above the ground surface it was possible to apply a sinusoidal excitation at various frequencies to the pile. The response of the pile at a range of fixed force amplitudes and a sweep of frequencies is shown in Fig. 8.2. Of significance is the normalised dynamic displacement profile being similar to the static profile. Note that the natural frequency decreases slightly after the $600 \mathrm{lb}$ sweep, a possible explanation is the formation of a gap adjacent to the pile shaft near the ground surface (qv Fig. 2.8).

\subsubsection{Hall}

Aspects of the Imperial County Services building in El Centro California, Hall (1984), have been discussed in section 2.2.3 with details given in Fig. 2.9. Forced vibration tests were done after the building had been demolished. The shaker could apply dynamic forces up to $22 \mathrm{kN}$ over a frequency range of 1 to $8 \mathrm{~Hz}$. The numbering of the pile caps and the positioning of the shaker are shown in Fig. 8.3. Two pile caps, 1 and 3 , were shaken and the response of the eight pile caps that had been attached to shear walls in the building were monitored. The measured pile group compliance data are shown in Fig. 8.4 , from which it is apparent that the response has mild frequency dependence. The $f_{i j}$ notation in Fig. 8.4 uses $j$ for the pile cap being shaken and $i$ for the pile cap at which the response is measured. The dynamic response of such a 


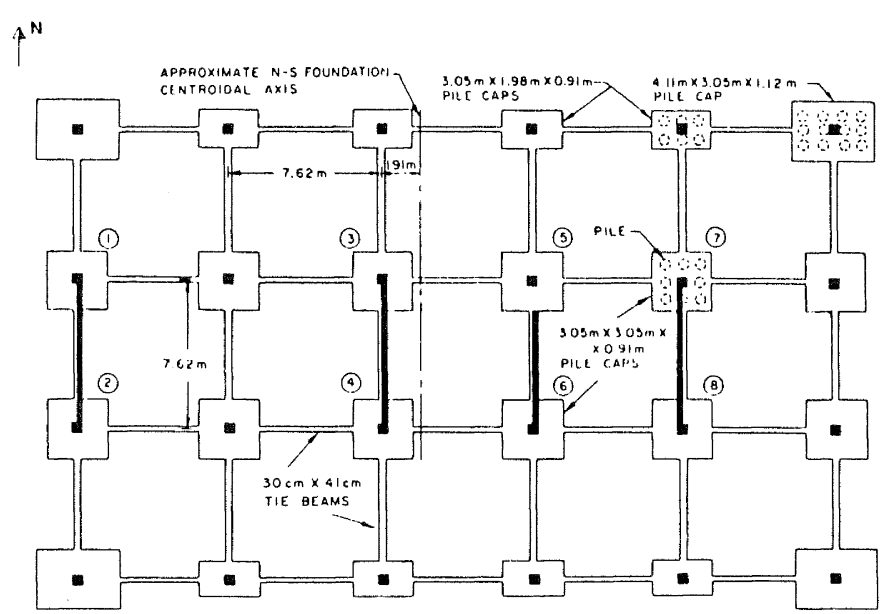

Fig. 8.3 Positioning of the shaker for the dynamic tests on the Imperial County Services building (after Hall (1984)).

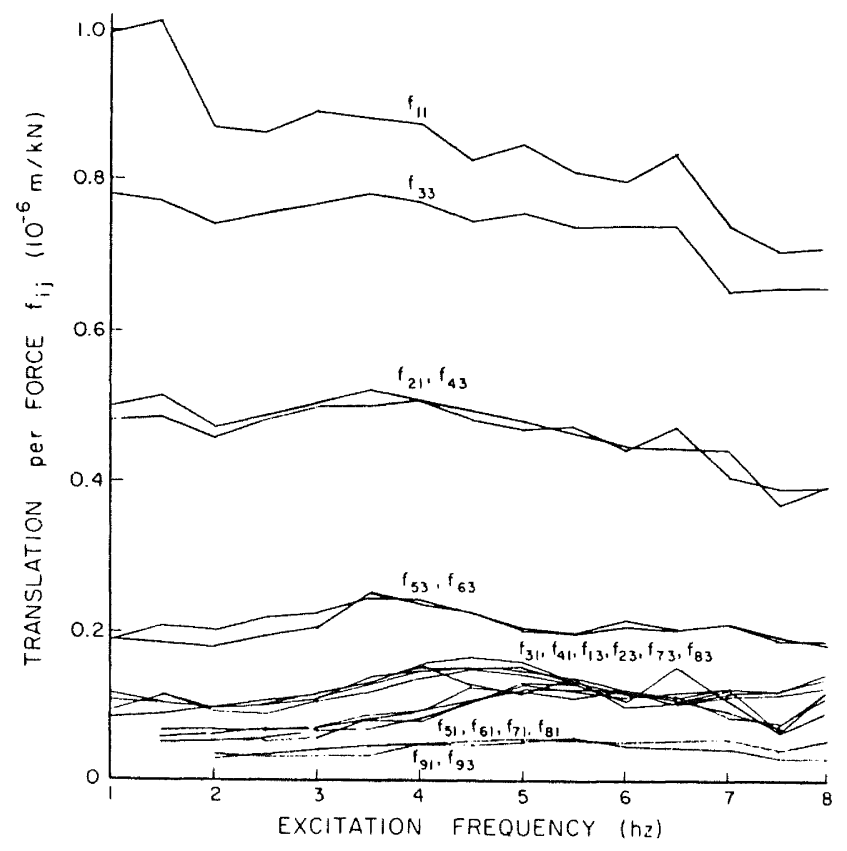

Fig. 8.4 Translational amplitude versus excitation frequency of the 9 pile caps in Fig. 8.3 with shaking applied to pile caps 1 and 3 (after Hall (1984)).

foundation can be expressed in terms of complex numbers and consists of real and imaginary parts. Figure 8.4 gives the real part of the response, the imaginary part, expressed in the form of the time lag between the excited pile and the responding pile, also shows no significant frequency dependence. From the response of the piles a shear wave velocity of $190 \mathrm{~m} / \mathrm{sec}$. was inferred for the soil at the site. The shaking tests also confirmed that the free field recording instrument, $100 \mathrm{~m}$ from the structure, was not significantly affected by the excitation of the pile foundations. This assumes that soil structure interaction effects would be polarised in the N-S direction, as was in fact observed in the recorded earthquake response.

As explained in section 2.2 .3 the response of the building computed with the measured stiffnesses differed in two ways from the recorded response. Firstly the stiffnesses inferred from the recorded response indicated that the foundation stiffness during the earthquake was about half that given by the pile cap tests. This is likely to be a consequence of much greater loads being applied to the pile caps during the earthquake shaking. Secondly during the course of the earthquake there was a decrease in stiffness of the foundation by a factor of about 4 . Hadjian et al (1990) confirm that nonlinear soil-pile stiffness would have had an important effect on the response of the structure. Cracking of the pile section further contributed to the nonlinearity.

\subsubsection{Levine and Scott}

Levine and Scott (1989) re-examined data on the behaviour of the Meloland Rd. overpass during the 1979 Imperial Valley earthquake in Southern California. The bridge, a two span continuous structure with a single column pier at the centre and diaphragm abutments, is very well instrumented. At the bridge site the peak ground acceleration was about $0.5 \mathrm{~g}$. The abutment walls are pile supported on $7 \times 1$ pile groups and the central pier is supported on a $5 \times 5$ pile group. Logs of test bores indicate that the soils consist of clays with traces of silt and sand, the average SPT value is about 14 blows/ft, being slightly lower near the surface.

The structure-foundation system is quite complex and Levine and Scott modelled the foundation using a series of springs. The stiffness of the springs was assessed by using the recommendations of Terzaghi for stiff clay discussed by Scott (1981). The conclusion reached was that the modal periods computed from the analysis correspond reasonably well with those determined from processing of the data recorded during the earthquake. These results are obtained from a numerical model that includes the properties of the structure as well as the foundation soil. Nevertheless it is of interest that the spring approach worked well using only the $\mathrm{N}$ values as basis for the stiffness properties of the soils at the site. In discussion of this analysis Norris (1991) notes that the stiffness determined from ambient vibration of the structure is much greater than the values used by Levine and Scott. The bulk of the soils at the site, stiff clays, would not have been particularly sensitive to cyclic loading although Norris suggests that liquefaction of thin sand layers might have had an important effect on recorded response of the structure.

Levine and Scott's satisfactory predictions of the response of the structure were obtained with very simple methods for estimating the soil stiffness. The good results may be a consequence of modelling the overall response of the structure rather than that of the foundation only, so that any mismatch in the foundation stiffness is masked by the other factors which contribute to the modal response of the bridge structure. Also, as suggested by Norris, the empirical relations used for the soil stiffness might be appropriate for the amplitude of the vibration of the structure during the 1979 earthquake but not for ambient or other levels of shaking. Finally as the pile groups consisted of $300 \mathrm{~mm}$ diameter piles, which relate to the $300 \mathrm{~mm}$ square plate bearing tests from which the correlations for soil stiffness were developed, the size effect discussed in section 7.3 does not arise. 

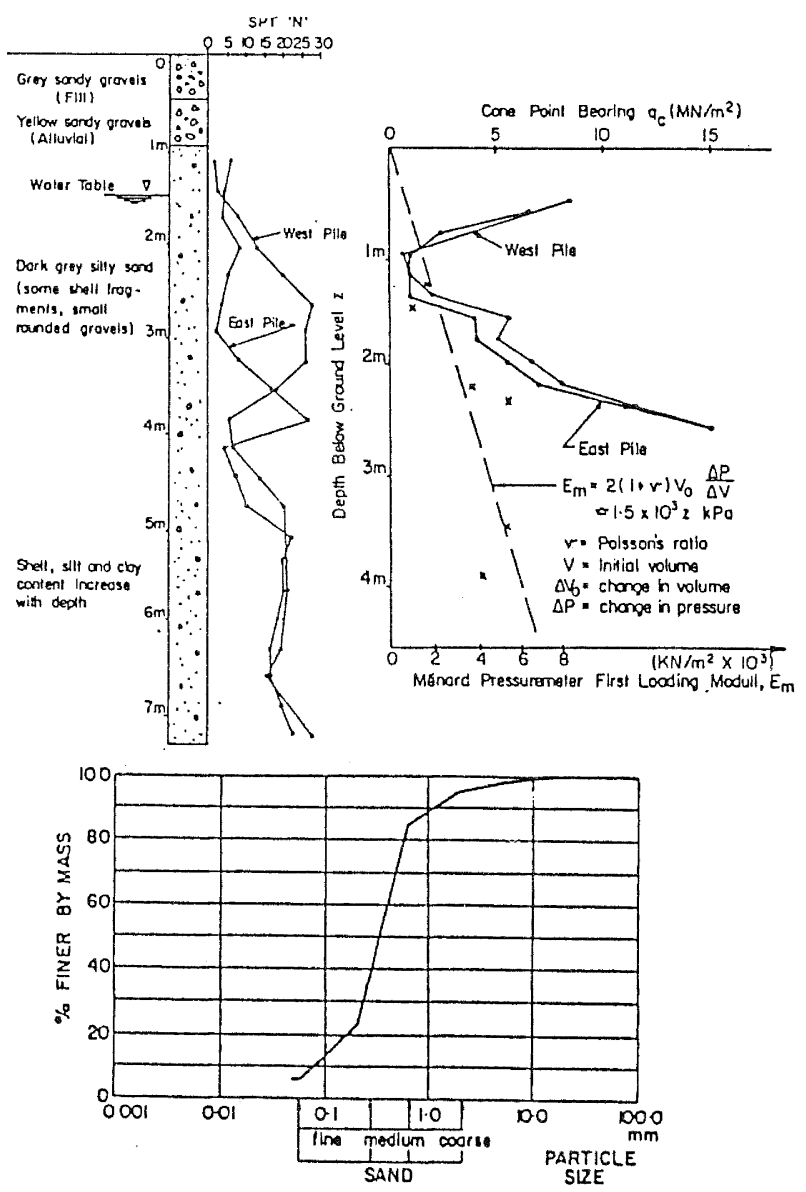

Fig. 8.5 Field data for the Central Laboratories twin pile test (after Jennings et al (1985)).

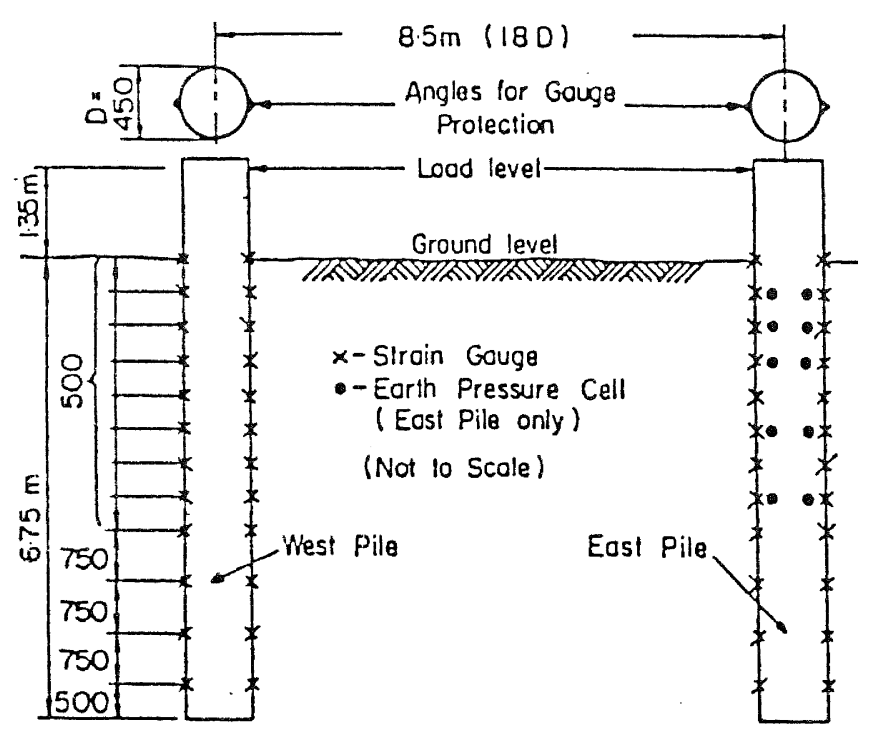

Fig. 8.6 Details of the Central Laboratories test piles (after Jennings et al (1984)).

\subsubsection{Jennings et al}

Jennings et al (1985 and 1986) report on dynamic tests on a pair of $450 \mathrm{~mm}$ diameter piles driven into saturated silty sands. Details of the soil profile are reproduced in Fig. 8.5 and the details of the piles in Fig. 8.6. Self weight was sufficient to drive the pile shells to a depth of $5 \mathrm{~m}$, gentle tapping was all that was required to get them to the required depth of $6.75 \mathrm{~m}$. After cleaning out the shells reinforcement was placed and concrete poured. Dynamic and slow cyclic loads were applied to the piles. Cyclic loads were applied by means of a jack mounted between the piles $1.35 \mathrm{~m}$ above ground level, and the dynamic loads with a shaking machine mounted on top of one of the piles. Initial testing involved dynamic shaking of the west pile. This was followed by slow cyclic loading at a rate of about one cycle per hour with the following sequence of maximum loads per cycle in each direction: $10 \mathrm{kN}, 20 \mathrm{kN}, 40 \mathrm{kN}$ ( 2 cycles), $80 \mathrm{kN}$ ( 2 cycles), $120 \mathrm{kN}$ ( 2 cycles), $160 \mathrm{kN}$ ( 2 cycles), $200 \mathrm{kN}$ ( 2 cycles).

Fig. 8.7a has the force deflection results for the slow cyclic loading and Fig. 8.7b has the resonance curve for the dynamic test on the single pile. It is clear that, as with the Blaney and O'Neill pile, there is a distinct natural frequency when the pile is loaded dynamically at low levels of excitation. It was apparent from ground surface observations during the loading that high pore water pressures were generated adjacent to the pile shafts. When piles are embedded in saturated sands gaping cannot occur along the pile shaft but there is, nevertheless, a dynamic degradation in the pile performance
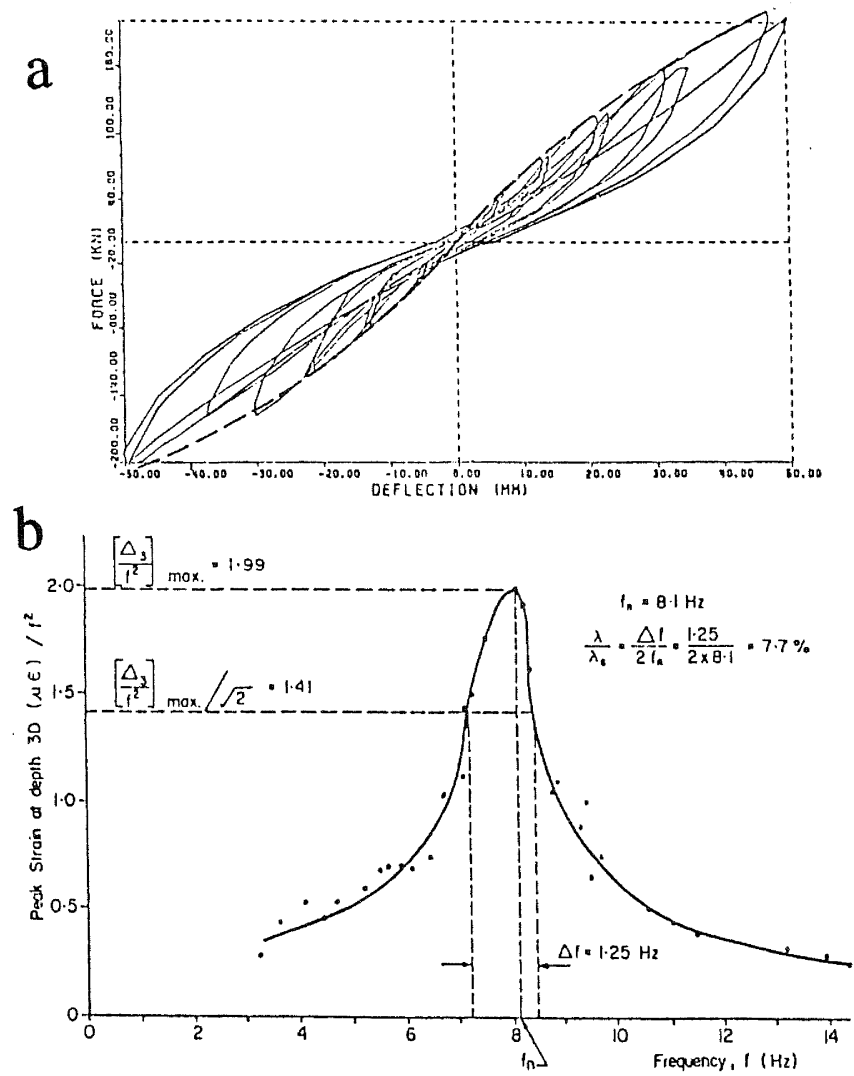

Fig. 8.7 Response of the Central Laboratories piles: (a) cyclic load deformation loops, (b) resonance curve (after Jennings et al (1984)). 

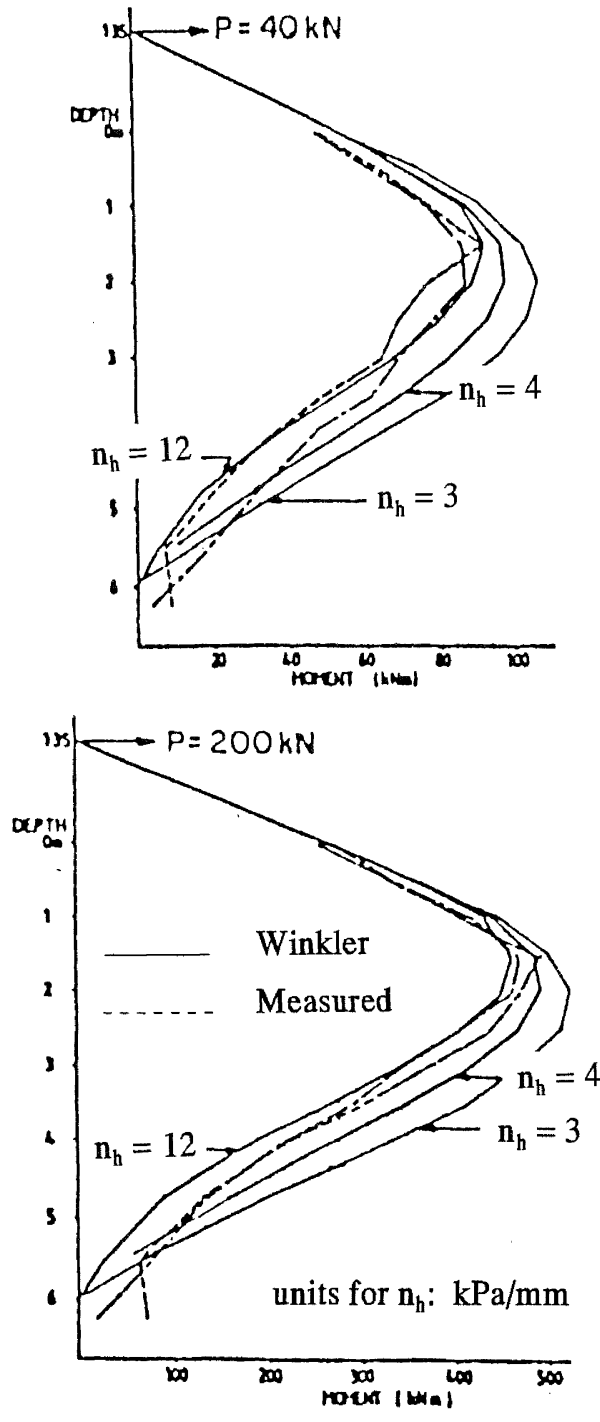

Fig. 8.8 Moment profiles during the slow cyclic loading of the Central Laboratories test piles (after Jennings et al (1985)).
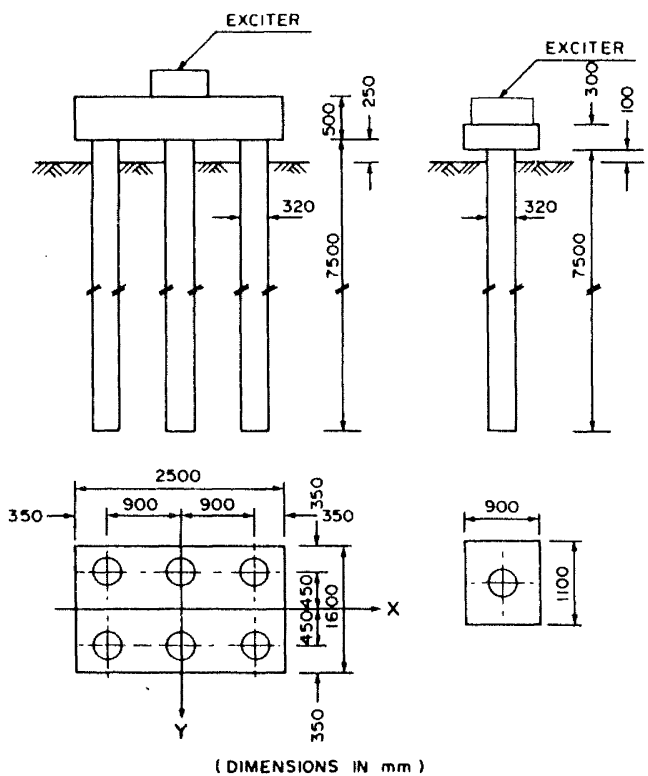

Fig. 8.9 Pile group and single pile configuration tested for dynamic response by El-Marsafawi et al (1992). because of a reduction in stiffness of the sand as a consequence of the build up in pore water pressure.

In attempts to match the observed moment profiles, shown in Fig. 8.8, a Winkler model with $\mathrm{k}$ increasing uniformly with depth was adopted, i.e. $\mathrm{k}=\mathrm{n}_{\mathrm{h}} \mathrm{z}$. The moment profiles, determined from the strain gauge readings, were the basis for the inference, using a Winkler spring approach, that towards the bottom of the piles $n_{h} \approx 12$ but near the ground surface a value of 6 is more appropriate. This was interpreted as evidence for softening of the upper sand layers due to the development of positive pore pressures.

\subsubsection{El-Marsafawi et al}

El-Marsafawi et al (1992) report on dynamic experiments on two pile group foundations, one at model scale (piles $101 \mathrm{~mm}$ in diameter and $2.75 \mathrm{~m}$ long) and one at prototype scale which will be considered here. The $3 \times 2$ cast in place pile group with $320 \mathrm{~mm}$ diameter piles $7.5 \mathrm{~m}$ long is shown in Fig. 8.9 as well as the single pile which was also tested for comparison. The soil profile consisted of relatively homogeneous sandy clay, cross hole shear wave velocity measurements were done at $1 \mathrm{~m}$ intervals to get the distribution of shear wave velocity shown in Fig. 8.10.

The response of the single pile is given in Fig. 8.11 and that of the pile group in Fig. 8.12. It is apparent that the natural frequency of the pile group is greater than that of the single pile, 23 as opposed to $17 \mathrm{~Hz}$, as is expected because of the larger lateral stiffness of the pile group. Also for the single pile it is apparent that the natural frequency decreases as the level of excitation increases, but that the same is not apparent for the pile group. El-Marsafawi et al present the results of computations based on linear elastic interaction between the piles and the surrounding soil. They found that the match between the observed and calculated response was only modest. This will be discussed further in section 8.3.

\subsubsection{Centrifuge tests}

In recent years there has been a rapid development of the use of centrifuge modelling in geotechnical engineering. The

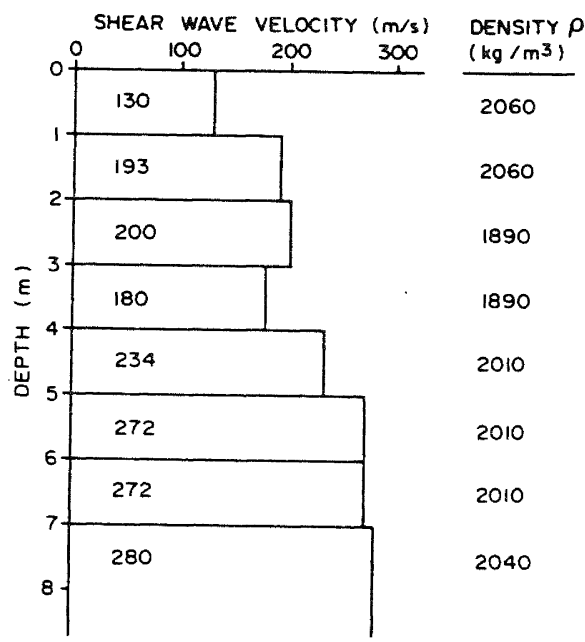

Fig. 8.10 Profile of shear wave velocities for the site of the single pile and pile group tests of El-Marsafawi et al (1992). 


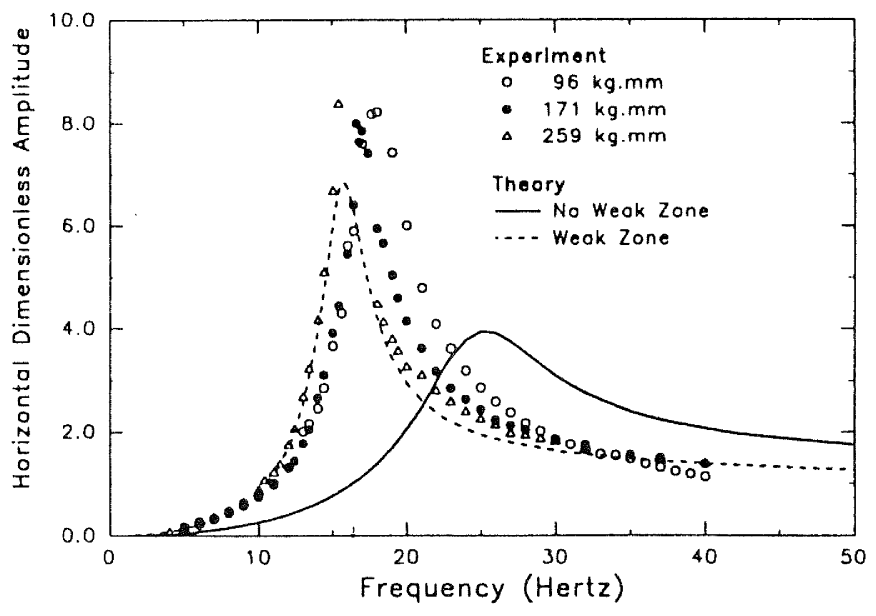

Fig. 8.11 Horizontal response of the single pile (after ElMarsafawi et al (1992)).
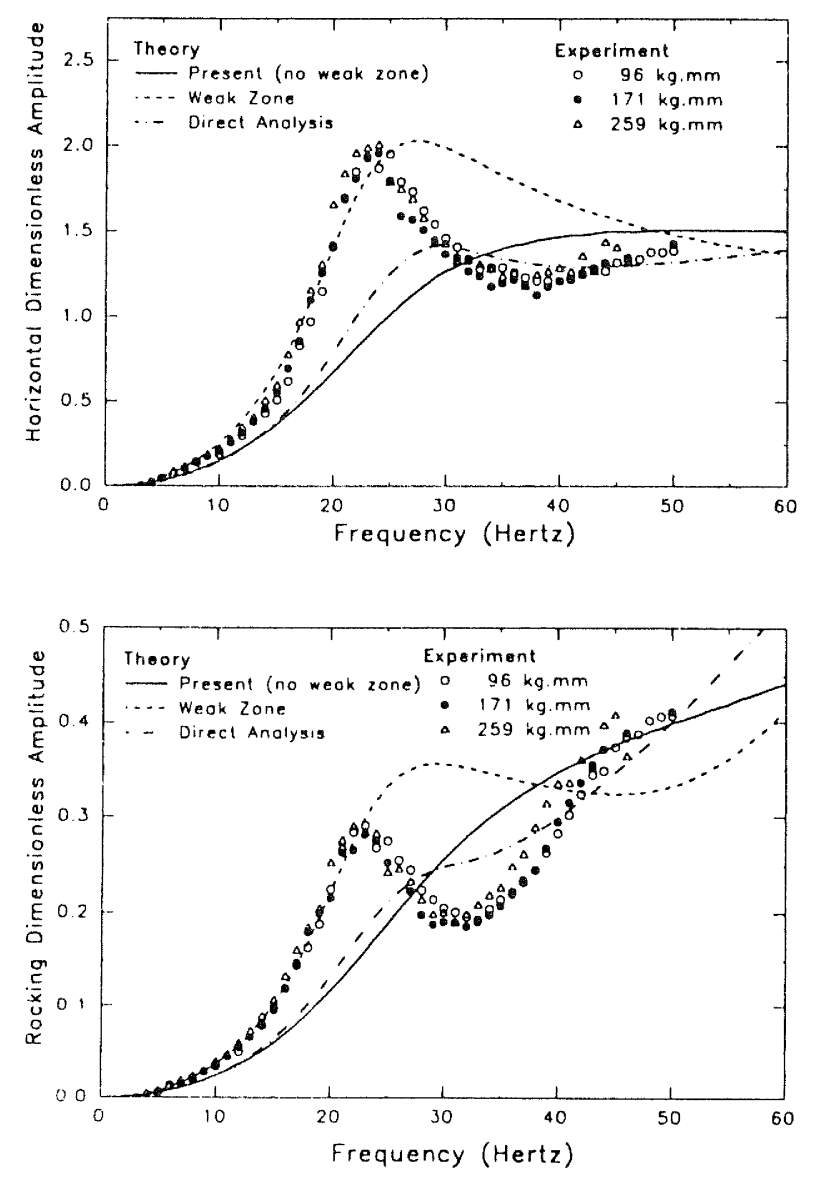

Fig. 8.12 Dynamic response of the $3 \times 2$ pile group in clay (after El-Marsafawi et al (1992)).

reason for this is that it is difficult to satisfy similarity requirements convincingly with scale models at $1 \mathrm{~g}$, particularly for sands. In a $1 \mathrm{~g}$ model constructed to a scale of $1 / 100$ the stresses in the soil will be $1 / 100$ of those in the prototype. However soil strength and stiffness depend on effective confining stress. We can measure the properties of sand in laboratory apparatus at stresses of the order of $10 \mathrm{kPa}$ and above. In the prototype stresses of this magnitude correspond to depths greater than about one metre. Now a scale model may have a depth of soil of a hundred millimetres or so with correspondingly very low stresses, consequently the soil properties in a $1 \mathrm{~g}$ model are not relevant to the prototype situation. The centrifuge overcomes all this by running a $1 / 100$ scale model at an acceleration of $100 \mathrm{~g}$, thus the stresses at a depth of $10 \mathrm{~mm}$ beneath the surface of the model soil profile are the same as those 1 metre beneath the surface of the prototype soil profile. In this way the centrifuge technique combines the attraction of scale modelling with the advantage that the model and prototype stresses are the same at corresponding points in the soil profile.

Centrifuge tests on single piles and groups are discussed by Barton (1985). She described the results for dry and saturated sand and observed that for dry sand a gap of about two diameters depth is formed but for the saturated case a shallow depression about one pile diameter deep forms. In addition Barton did tests on pile groups and found that elastic predictions of interaction do not represent what is observed to occur. At very close pile spacings elastic analysis underpredicts the amount of interaction and overpredicts it at larger spacings. This observation can be related to the discussion in section 5.7 showing that the behaviour of cyclically loaded pile groups is not modelled accurately by elastic analysis. Steedman and Maheertharan (1989) point out how dynamic response of the pile indicates that a greater length of the pile shaft is involved than in static lateral loading of the same pile. This is equivalent to the softening near the top of the pile observed by Jennings et al (1985). Ting and Scott (1984) did static and dynamic testing of one, two and four pile groups embedded in saturated sand. They observe that at small displacements the dynamic stiffness of the piles is less than the static value. Gap formation and generation of pore water pressures in the silty sands are thought to account for this. At larger deformations the dynamic stiffness is greater than the static. Ting and Scott suggest that the reason may be the pushing up of a mound of sand in front of the pile which increases the effective mass of the sand vibrating in sympathy with the pile. As far as group interactions are concerned they conclude that elastic methods give a reasonable estimate. Gohl and Finn (1987) tested single piles and two pile groups in dry sand with actual measurement of the in situ small strain shear modulus of the sand. Results of the tests on two pile groups show that interaction was negligible when the loading was offline, i. e. when $\xi$ (qv Fig. 5.4) $=90^{\circ}$. For inline loading, $\xi=0^{\circ}$, interaction effects are reduced to zero when the pile spacing is 6 diameters and in this case the pile cap provided adequate restraint so that a fully fixed condition existed.

\subsubsection{General observations from these studies}

A number of general observations can be made from the above case studies. Firstly, at loads small in relation to the pile capacity laterally excited piles have a definite resonance curve. This is apparent for the Blaney and O'Neill test and that reported by El-Marsafawi et al for piles in clay, and the Jennings et al test on piles in saturated silty sands. Secondly, there seems to be a trend for the dynamic stiffness to be less 
a

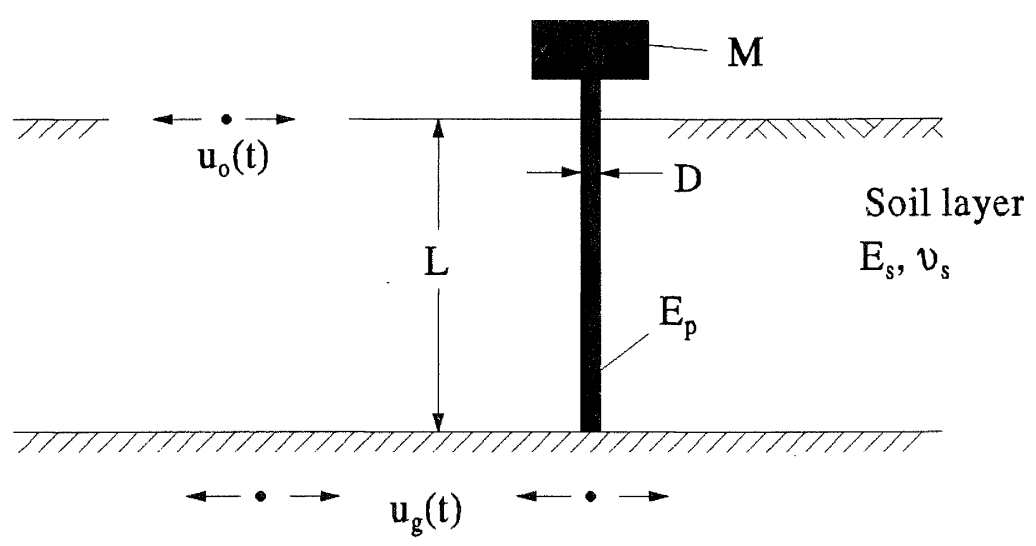

b

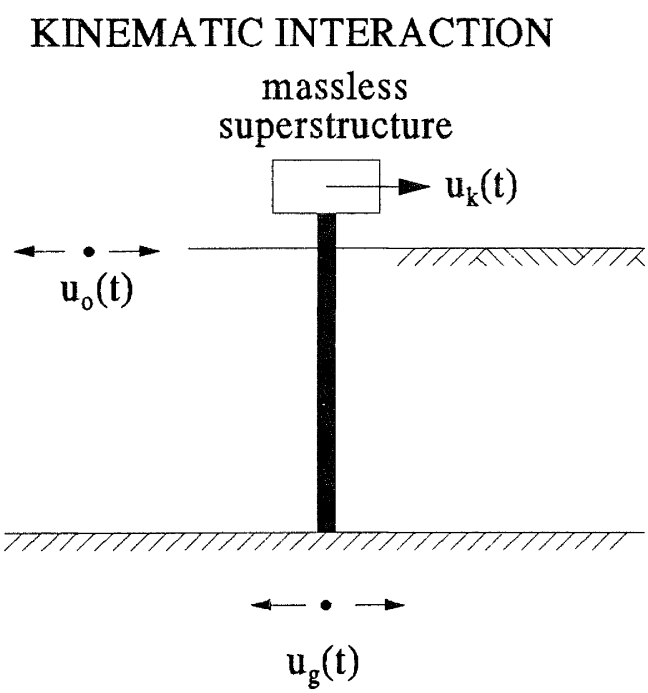

INERTIAL INTERACTION

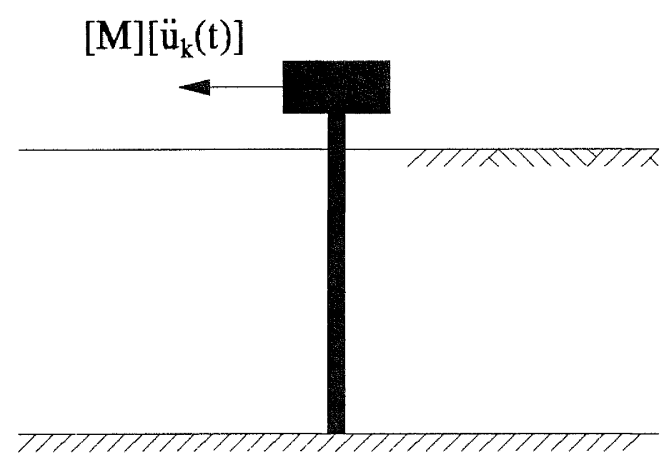

Representation of pile head stiffness for inertial interaction

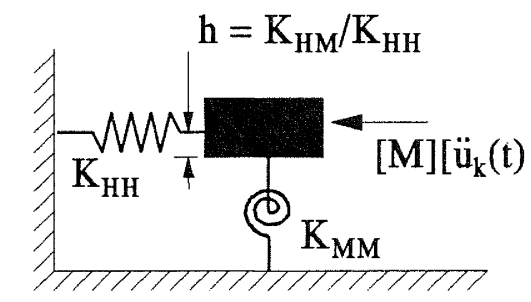

Fig. 8.13 Dynamic soil-pile interaction: (a) geometry, (b) kinematic and inertial interaction (after Gazetas (1984)).

than the value expected from the static stiffness of the pile or group (the basis for this estimate is given below in section 8.2.2). For piles in clay this is explained by the formation of gaps along the pile shaft (qv Fig. 2.8), and for piles in saturated sands it is a consequence of a decrease in stiffness due to development of pore water pressure. Thirdly, the dynamic lateral stiffness determined at low load levels is an upper bound, the case of the Imperial County Services building illustrates this. Fourthly, the results obtained by Hall for the interaction between the $3 \times 3$ pile groups at the Imperial County Services building indicate little frequency dependence on the foundation stiffness in the range 1 to $8 \mathrm{~Hz}$. On the other hand El-Marsafawi et al observed considerable frequency dependence for a $3 \times 2$ group in sandy clay. Finally, the conclusions of Levine and Scott, and possibly also those of Hall, suggest that, for insensitive cohesive and dense cohesionless soil in which positive pore water pressures are not expected to accumulate and the applied loads do not take the soil in the foundation to failure, simple methods of assessing soil stiffness produce useful results.

\subsection{Dynamic response of single piles}

Gazetas (1984) and his co-workers have conducted a number of studies of the dynamic response of piles, some of which has been summarised by Larkin (1986). Dynamic pile response is discussed below under two headings: piles in soil profiles with a smooth variation of stiffness with depth and piles in layered soil profiles.

If we consider a pile embedded in a soil profile and ask what will happen under earthquake loading two questions arise. Firstly, what effect does the presence of the pile have on the 
propagation of the earthquake motion up through the soil profile, does the pile simply follow the soil deformations or is the pile head motion different from that of the adjacent soil? A very stiff pile may not be able to flex and follow the soil motions, on the other hand a flexible pile might readily follow the soil. Secondly, how does the dynamic stiffness relate to the static stiffness of the pile. The first question is of concern for earthquake loading only, in the case of wave and wind loading, two other important dynamic loading mechanisms for pile foundations, the excitation comes from the structure attached to the top of the pile rather than from beneath the pile as in the earthquake case. Interaction between the pile and the soil is thus divided into two steps: kinematic and inertial interaction. Kinematic interaction refers to the first of the steps outlined above and inertial interaction refers to the second step. The concepts are shown diagrammatically in Fig. 8.13. In estimating the kinematic interaction we are seeking the modification to the free field ground surface earthquake motion required to get the motion appropriate to the pile head. Having obtained the pile head motion the inertial response of the structure attached to the pile head is estimated.

An important parameter for the dynamic response of a pile is the natural period, for vertical propagation of shear waves, of the soil layer in which the pile is embedded. Three modulus distributions are considered by Gazetas, these are the same as those shown in Fig. 3.4. Gazetas gives the following formulae for the fundamental frequency (the inverse of the natural period) for the soil profiles having the three modulus distributions:

$$
\begin{aligned}
& \mathrm{f}_{1 \text { con }}=\frac{0.25 \mathrm{v}_{\mathrm{sH}}}{\mathrm{H}} \\
& \mathrm{f}_{1_{\mathrm{par}}}=\frac{0.22 \mathrm{v}_{\mathrm{sH}}}{\mathrm{H}} \\
& \mathrm{f}_{1 \text { lin }}=\frac{0.19 \mathrm{v}_{\mathrm{sH}}}{\mathrm{H}}
\end{aligned}
$$

where: $f_{1 \text { con }}, f_{1 \text { par }}, f_{1 \text { lin }}$ is the fundamental frequency of the soil layer (cycles per second),

$\mathrm{v}_{\mathrm{sH}} \quad$ is the shear wave velocity at the bottom of the soil layer,

$\mathrm{H} \quad$ is the soil layer thickness,

and con, par, lin are abbreviations representing the three Young's modulus distributions.

Equation 8.1 gives the fundamental frequency, the second mode frequency for each of the profiles is obtained from:

$$
\begin{aligned}
& \left(\frac{f_{2}}{f_{1}}\right)_{\text {con }}=3.00 \\
& \left(\frac{f_{2}}{f_{1}}\right)_{p a r}=2.66 \\
& \left(\frac{f_{2}}{f_{1}}\right)_{\text {lin }}=2.33
\end{aligned}
$$

where: $f_{1}$ is the first mode frequency, and $\quad f_{2} \quad$ is the second mode frequency of the layer.

\subsubsection{Inertial interaction}

In this section we deal with dynamic loading applied to a pile head. The techniques are useful not only for earthquake loading but also for wind, wave, and any other type of cyclic loading of pile foundations.

In sections 3 and 4 various equations for evaluating the static displacement and stiffness of pile foundations were presented. In section 3 flexibility coefficients are given so that displacements can be evaluated directly from the pile head actions. The pile head stiffness matrix can be obtained by the inversion of the matrix of flexibility coefficients as given in equation 3.40 (Gazetas (1991) gives a set of formulae for estimating pile head stiffness components directly). When considering dynamic behaviour we have to ask if the dynamic stiffness is different from the static stiffness and how much damping is present. As both stiffness and damping contribute to resisting dynamic loads it is convenient to combine the stiffness and damping terms into an impedance (the dynamic

\begin{tabular}{|c|c|c|}
\hline \multirow[b]{2}{*}{ where: } & & \\
\hline & & is the impedance, \\
\hline & $\overline{\mathrm{K}}$ & is the dynamic pile stiffness, \\
\hline & $\mathrm{C}$ & is the damping coefficient, \\
\hline & $\omega$ & is the frequency in radians/second, \\
\hline & & is $\sqrt{-1}$ \\
\hline & $\begin{array}{l}P(t) \\
u(t)\end{array}$ & is the dynamic excitation force, \\
\hline
\end{tabular}
equivalent of the static resistance to displacement) defined by:

$$
\mathrm{P}(\mathrm{t})=\boldsymbol{c}(\omega) \mathrm{u}(\mathrm{t})
$$

with:

Note that the impedance, dynamic stiffness and damping coefficients are functions of frequency and that the impedance is a complex quantity. Also note there is an impedance corresponding to each component of the pile head static stiffness matrix.

The damping constant, $\mathrm{C}$, in the above equation has units of $\mathrm{MT}^{-1}$, the more familiar dimensionless frequency dependent coefficient is obtained from:

$$
\zeta_{\alpha \beta}(\omega)=\frac{\pi \mathrm{fC}_{\alpha \beta}}{\mathrm{K}_{\alpha \beta}}=\frac{\omega \mathrm{C}_{\alpha \beta}}{2 \mathrm{~K}_{\alpha \beta}}
$$

where: $\mathrm{K}_{\alpha \beta} \quad$ is the component of the stiffness matrix associated with damping component, the $\alpha \beta$ notation refers to the various damping components $\mathrm{HH}, \mathrm{HM}$ and $\mathrm{MM}$, and $\mathrm{f} \quad$ is the frequency in cycles per second.

Expressions for $\zeta_{\alpha \beta}$ are given below.

An alternative expression for the impedance in terms of the coefficient $\zeta$ is:

$$
\boldsymbol{c}_{\alpha \beta}=\mathrm{K}_{\alpha \beta}\left(\mathrm{k}_{\alpha \beta}(\omega)+2 \xi_{\alpha \beta}(\omega) \mathrm{i}\right)
$$

where: $\mathrm{K}_{\alpha \beta}$ is a component of the static pile head stiffness matrix,

$\mathbf{k}_{\alpha \beta}(\omega)$ is a frequency dependent coefficient relating the real part of $\boldsymbol{C}$ to $\mathrm{K}_{\alpha \beta}$. 
Equations 8.3 and 8.5 provide alternative expressions for the impedance, there are others also. The units associated with the damping term need to be kept in mind. In equation 8.3 the units associated with the damping term, i $\omega \mathrm{C}$, are $\mathrm{MT}^{-2}$ which are those for stiffness as is required for dimensional homogeneity of the equation, so the units of $\mathrm{C}$ are $\mathrm{MT}^{-1}$ as was mentioned earlier. In equation 8.5 the coefficient $\zeta_{\alpha \beta}$ is dimensionless but is a function of frequency. Further commonly used forms of the impedance are:

$$
\begin{aligned}
& \mathbb{E}_{\alpha \beta}=\mathrm{K}_{\alpha \beta}(\omega)+\mathrm{i} \mathrm{a}_{\mathrm{o}} \mathrm{C}_{\alpha \beta}^{\prime} \\
& \mathfrak{E}_{\alpha \beta}=\mathrm{K}_{\alpha \beta}(\omega)+\mathrm{i} \mathrm{C}_{\alpha \beta}^{\prime \prime}
\end{aligned}
$$

where: $C_{\alpha \beta}^{\prime} \quad$ has the units of stiffness, as $a_{0}$ is dimensionless,

$\mathrm{C}_{\alpha \beta}^{\prime \prime} \quad$ also has units of stiffness.

In a given reference the units of the damping term need to be checked. For example the ordinates of the damping parts of Figs. 8.26 and 8.31 have damping terms with stiffness units, ie these diagrams refer to $\mathrm{C}_{\alpha \beta}^{\prime}$.

The impedance terms in the above equations are functions of the frequency of the dynamic loading. This causes no problem if the dynamic loading occurs at a fixed frequency, such as the vibration of a machine foundation, but it suggests a major complication if the dynamic excitation contains many frequencies such as is the case with an earthquake. A response spectrum approach to the estimation of pile foundation displacements is illustrated in example 8.8 below.

\subsubsection{Lateral pile head impedance}

Gazetas and his co-workers performed dynamic finite element analysis to investigate the dynamic active pile length and impedance.

Dimensional analyses reveals that the following parameters are of significance:

where: $\rho_{\mathrm{p}} / \rho_{\mathrm{s}} \quad$ is the ratio of density of the pile

$$
\begin{aligned}
& \mathrm{K}_{\alpha \beta}=f\left[\mathrm{~K}, \mathscr{L}, \nu, \frac{\rho_{\mathrm{p}}}{\rho_{\mathrm{s}}}, \mathrm{a}_{\mathrm{o}}, \beta\right] \\
& / \rho_{\mathrm{s}} \quad \begin{array}{l}
\text { is the ratio of density of the pile } \\
\text { material to the density of the soil }
\end{array}
\end{aligned}
$$

$$
\begin{array}{ll}
\mathrm{a}_{\mathrm{o}} & \text { is the ratio } \omega \mathrm{D} / \mathrm{V}_{\mathrm{sH}}, \\
\beta & \text { is the material damping value for the soil. }
\end{array}
$$

The finite element model used a pile length of 40D, considerably greater than the dynamic active length. For the dynamic finite element analyses $\nu$ was set to $0.40, \beta$ to $5 \%$, and $\rho_{\mathrm{p}} / \rho_{\mathrm{s}}$ to 1.60 . The results are not sensitive to $\nu$ and are thought to be valid for the range $0.30 \leq \nu \leq 0.48$. Similarly the results are not sensitive to the density ratio, they apply to the range 1.40 to 2.50 .

Gazetas (1991) gives dynamic active pile lengths, estimated from finite element analyses, for the three modulus distributions:
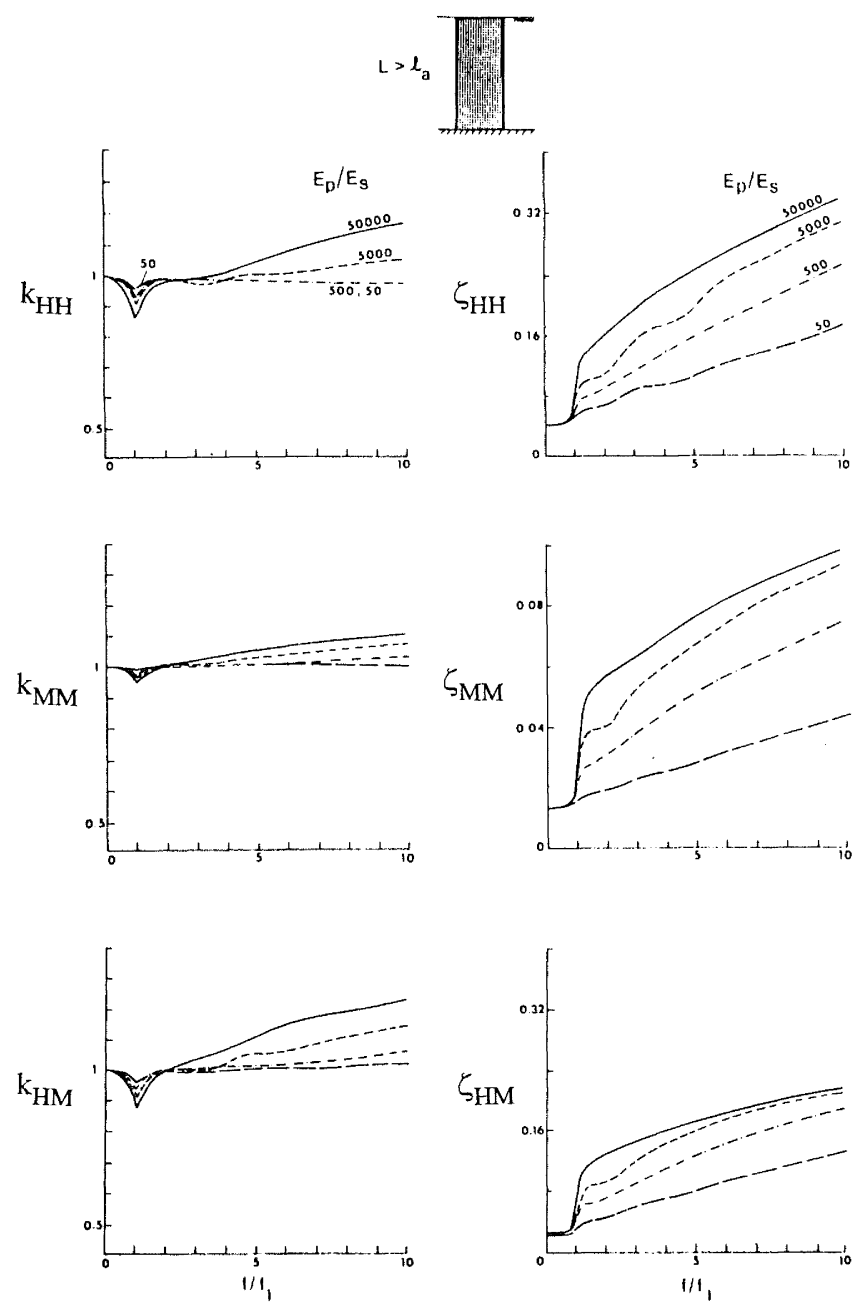

Fig. 8.14 Dynamic stiffness coefficients and damping ratios for flexible piles in a constant modulus soil profile (after Gazetas (1984)).

$$
\begin{aligned}
& \mathrm{L}_{\text {ad con }}=2 \mathrm{D} \mathrm{K}^{0.25} \\
& \mathrm{~L}_{\text {ad par }}=2 \mathrm{DK}^{0.22} \\
& \mathrm{~L}_{\mathrm{ad} \text { lin }}=2 \mathrm{DK}^{0.20}
\end{aligned}
$$

where: $\mathrm{K} \quad$ is the ratio of the pile Young's modulus to that of the soil at depth $\mathrm{D}$,

and $\mathrm{L}_{\mathrm{ad}} \quad$ is the dynamic effective pile shaft length.

Reference to section 3.2.2 reveals that the dynamic active length is greater than the static active length.

Values of $\mathrm{k}_{\alpha \beta}$ and $\zeta_{\alpha \beta}$ were evaluated for the three soil profiles for a range of modulus ratios and excitation frequencies. These results are presented in Figs. 8.14 to 8.16, the left hand part of the figures giving $\mathrm{k}_{\alpha \beta}$ for the real part of the impedance and the right hand column giving $\zeta_{\alpha \beta}$, the imaginary part. The figures show that $\mathrm{k}_{\alpha \beta}$ is usually close to unity, thus we conclude that the dynamic stiffness of a laterally loaded pile is very similar to the static stiffness.

The damping values in Figs. 8.14 to 8.16 are for radiation 
damping, that is damping that originates because energy is carried away from the pile by the propagation of elastic waves. Radiation damping, as can be seen from the figures, is a function of frequency. Dobry and Gazetas (1985) explain that the radiation damping is zero for frequencies less that the natural frequency of the soil layer in which the pile is embedded.

In addition there is the damping which occurs adjacent to the pile by inelastic deformation of the soil. This is known as material damping and the mechanism of energy loss is hysteresis, consequently material damping is independent of frequency. At low frequencies material damping is the only mechanism available for dissipation of seismic energy.

Gazetas (1991) gives the following formulae for the pile head damping, including both radiation and material damping, for a soil profile having a constant Young's modulus:

$$
\begin{aligned}
\text { when } \mathrm{f} & >\mathrm{f}_{1} \\
\zeta_{\mathrm{HH}} & =0.80 \beta+1.10 \mathrm{fDK}^{0.17} / \mathrm{V}_{\mathrm{s}} \\
\zeta_{\mathrm{HM}} & =0.80 \beta+0.85 \mathrm{fDK}^{0.18} / \mathrm{V}_{\mathrm{s}} \\
\zeta_{\mathrm{MM}} & =0.35 \beta+0.35 \mathrm{fDK}^{0.20} / \mathrm{V}_{\mathrm{s}} \\
\text { when } \mathrm{f} & \leq \mathrm{f}_{1} \\
\zeta_{\mathrm{HH}} & =0.80 \beta \\
\zeta_{\mathrm{HM}} & =0.50 \beta \\
\zeta_{\mathrm{MM}} & =0.25 \beta
\end{aligned}
$$

where: $\mathrm{K} \quad$ is defined as in equations 3.16 and 8.7.

Gazetas (1991) gives the following formulae for the pile head damping values in a soil profile with a parabolic distribution of modulus with depth:

$$
\begin{aligned}
\text { when } \mathrm{f}>\mathrm{f}_{1} \\
\zeta_{\mathrm{HH}}=0.70 \beta+1.20 \mathrm{fDK}^{0.08} / \mathrm{V}_{\mathrm{s}} \\
\zeta_{\mathrm{HM}}=0.60 \beta+0.70 \mathrm{fDK}^{0.05 / \mathrm{V}_{\mathrm{s}}} \\
\zeta_{\mathrm{MM}}=0.22 \beta+0.35 \mathrm{fDK}^{0.10} / \mathrm{V}_{\mathrm{s}} \\
\text { when } \mathrm{f} \leq \mathrm{f}_{1} \\
\zeta_{\mathrm{HH}}=0.70 \beta \\
\zeta_{\mathrm{HM}}=0.35 \beta \\
\zeta_{\mathrm{MM}}=0.22 \beta
\end{aligned}
$$

Gazetas (1991) gives the following formulae for the pile head damping values in a soil profile with a linear distribution of modulus with depth:

$$
\begin{aligned}
\text { when } \mathrm{f} & >\mathrm{f}_{1} \\
\zeta_{\mathrm{HH}} & =0.60 \beta+1.80 \mathrm{fD} / \mathrm{V}_{\mathrm{s}} \\
\zeta_{\mathrm{HM}} & =0.30 \beta+1.00 \mathrm{fD} / \mathrm{V}_{\mathrm{s}} \\
\zeta_{\mathrm{MM}} & =0.20 \beta+0.40 \mathrm{fD} / \mathrm{V}_{\mathrm{s}} \\
\text { when } \mathrm{f} & \leq \mathrm{f}_{1} \\
\zeta_{\mathrm{HH}} & =0.60 \beta \\
\zeta_{\mathrm{HM}} & =0.30 \beta \\
\zeta_{\mathrm{MM}} & =0.20 \beta
\end{aligned}
$$
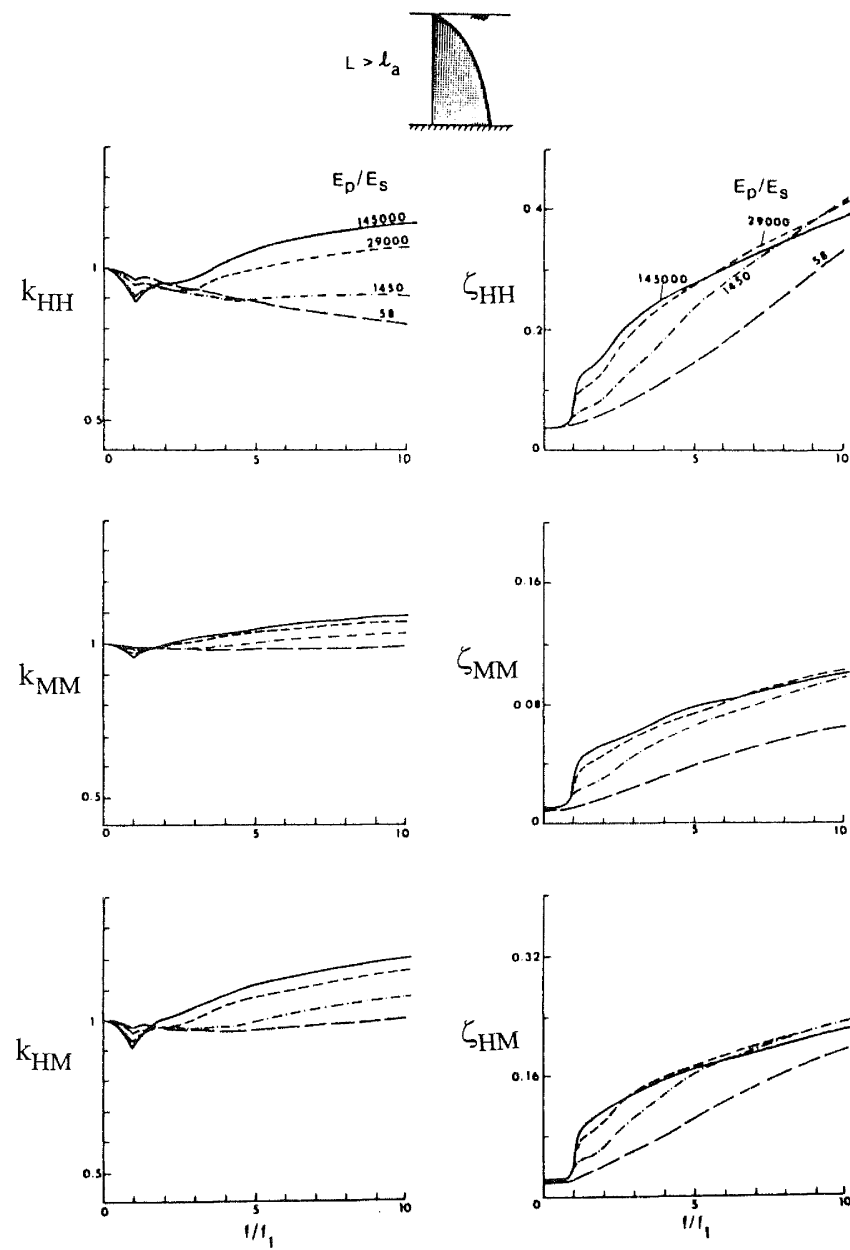

Fig. 8.15 Dynamic stiffness coefficients and damping ratios for flexible piles in soil profile having a parabolic variation of soil modulus with depth (after Gazetas (1984)).

Examination of Figs. 8.14 to 16 leads to the following comments:

Apart from $k_{\mathrm{HH}}$ at small values of $\mathrm{E}_{\mathrm{p}} / \mathrm{E}_{\mathrm{s}}$ the pile stiffnesses are not particularly sensitive to frequency so the dynamic stiffnesses are similar to the static values.

(b) At the natural frequency of the soil layer there is a dip in the elastic stiffness values, at higher modal frequencies no dip is apparent.

(c) The damping associated with rocking motions of the pile head, $\zeta_{\mathrm{MM}}$, is smaller than that for the other two modes of deformation. (Similar behaviour is familiar for the rocking response of a shallow foundation.)

(d) The general features of the stiffness behaviour do not change for the three modulus profiles investigated. However there are differences in the damping behaviour and, in particular, the linear modulus profile has a trend opposite to the constant and parabolic profiles. 


\subsubsection{Vertical pile head impedance}

Gazetas (1991) gives the following expressions for the coefficient which modifies the static vertical stiffness to get the real part of the vertical pile head impedance:

$$
\begin{aligned}
\mathrm{k}_{\text {con }} & =1.0 & & \text { for } \mathscr{L}<15 \\
& =1+\sqrt{\mathrm{a}_{\mathrm{o}}} & & \text { for } \mathscr{L} \geq 50 \\
\mathrm{k}_{\text {par }} & =1.0 & & \text { for } \mathscr{L}<20 \\
& =1+1 / 3 \sqrt{\mathrm{a}_{\mathrm{o}}} & & \text { for } \mathscr{L} \geq 50 \\
\mathrm{k}_{\text {lin }} & =1.0 & &
\end{aligned}
$$

In equation 8.11 interpolation gives $\mathrm{k}$ for $\mathscr{L}$ values in the range between the limits specified.

Gazetas (1991) reports that for vertical pile vibration the finite element studies show the plot of $\mathrm{k}$ versus excitation frequency has a narrow valley, $\mathrm{k}_{\text {minimum }}=0.8$, at the frequency:

$$
\mathrm{f}_{\mathrm{r}}=\frac{\overline{\mathrm{V}}_{\mathrm{La}}}{4 \mathrm{H}}
$$

where: $\overline{\mathrm{V}}_{\mathrm{La}} \quad$ is the average over the depth of the soil layer of the velocity $3.4 \mathrm{~V}_{\mathrm{s}} / \pi(1-\nu)$.

The imaginary part of the vertical pile head impedance, the radiation damping term, for the constant modulus soil profile is:

$$
\begin{aligned}
C_{\mathrm{V}} & =(3 / 2) \mathrm{a}_{0}^{-0.2} \rho \mathrm{V}_{\mathrm{s}} \pi D L \mathrm{r}_{\mathrm{d}} & & \text { for } \mathrm{f}>1.5 \mathrm{f}_{\mathrm{r}} \\
& =0 & & \text { for } \mathrm{f} \leq \mathrm{f}_{\mathrm{r}}
\end{aligned}
$$

where: $r_{d}$

$$
\text { is } 1-\mathrm{e}^{-\mathrm{b}} \text { with } \mathrm{b}=-\mathrm{K} \mathscr{L}^{-2} \text {. }
$$

For the parabolic modulus profile:

$$
\begin{aligned}
\mathrm{C}_{\mathrm{V}} & =(3 / 4) \mathrm{a}_{\mathrm{o}}^{-0.25} \rho \mathrm{V}_{\mathrm{sH}} \pi \mathrm{DL} \mathrm{r}_{\mathrm{d}} & & \text { for } \mathrm{f}>1.5 \mathrm{f}_{\mathrm{r}} \\
& =0 & & \text { for } \mathrm{f} \leq \mathrm{f}_{\mathrm{r}}
\end{aligned}
$$

where: $\mathrm{V}_{\mathrm{sH}} \quad$ is the shear wave velocity at the base of the soil layer,

$$
\mathrm{r}_{\mathrm{d}} \quad \text { is } 1-\mathrm{e}^{-\mathrm{b}} \text { with } \mathrm{b}=-1.5\left(\mathrm{E}_{\mathrm{p}} / \mathrm{E}_{\mathrm{sH}}\right) \mathscr{L}^{-2} \text {. }
$$

For the linear modulus profile:

$$
\begin{aligned}
\mathrm{C}_{\mathrm{V}} & =(2 / 3) \mathrm{a}_{\mathrm{o}}^{-0.33} \rho \mathrm{V}_{\mathrm{sH}} \pi \mathrm{DL} \mathrm{r}_{\mathrm{d}} & & \text { for } \mathrm{f}>1.5 \mathrm{f}_{\mathrm{r}} \\
& =0 & & \text { for } \mathrm{f} \leq \mathrm{f}_{\mathrm{r}}
\end{aligned}
$$

where: $\quad r_{d} \quad$ is $1-\mathrm{e}^{-b}$ with $b=-2\left(E_{p} / E_{s H}\right) \mathscr{L}^{-2}$.

8.2.4 Equivalent single degree of freedom structure.

For lateral motion a pile head or pile group has two degrees of freedom, it can rotate and translate. In addition the structure which is supported by the pile foundation has further degrees of freedom. If the structure itself is modelled with a single degree
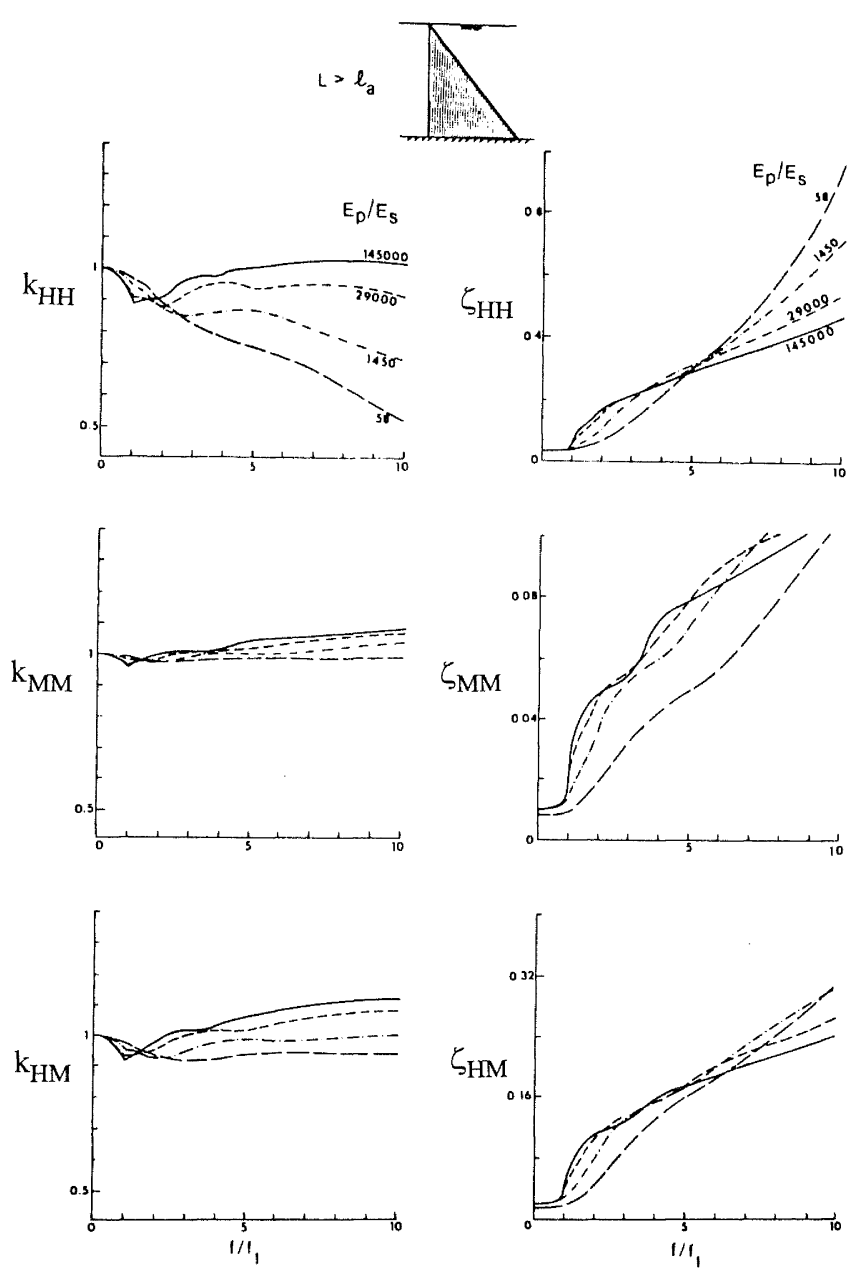

Fig. 8.16 Dynamic stiffness coefficients and damping ratios for flexible piles in soil profile having a linear variation of soil modulus with depth (after Gazetas (1984)).

of freedom the structure-foundation system then has three degrees of freedom. Wolf (1985) gives an equivalent SDOF model, illustrated in Fig. 8.17. There are three stiffness components, the structure, and the horizontal and rotational stiffness of the pile foundation, from these an equivalent natural frequency is:

$$
\tilde{\omega}=\frac{\omega_{\mathrm{s}}}{\left(1+\mathrm{k}_{\mathrm{s}} / \mathrm{K}_{\mathrm{h}}+\mathrm{k}_{\mathrm{s}} \mathrm{h}^{2} / \mathrm{K}_{\theta}\right)^{0.5}}
$$

where: $\widetilde{\omega} \quad$ is the natural frequency of the equivalent SDOF model,

$\omega_{s} \quad$ is the natural frequency of the structure supported by the foundation,

$\mathrm{k}_{\mathrm{s}} \quad$ is the stiffness of the structure,

$\mathrm{K}_{\mathrm{h}}$ is the horizontal stiffness of the pile foundation,

$\mathrm{K}_{\theta} \quad$ is the rotational stiffness of the pile foundation.

There are a number of component damping values, these are combined into a single equivalent value by: 


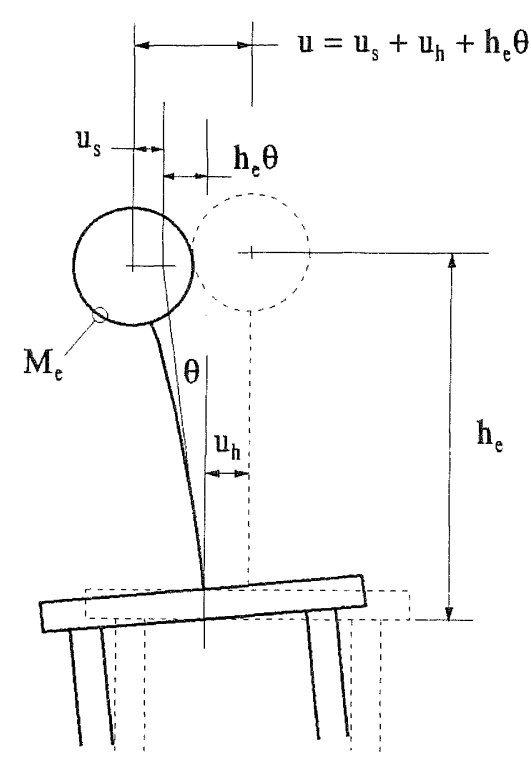

For a structure of height $h$ and mass $M$ having a uniform distribution of mass with height: $\mathrm{h}_{\mathrm{e}}=0.7 \mathrm{~h}, \mathrm{M}_{\mathrm{e}}=0.7 \mathrm{M}$

Fig. 8.17 Degrees of freedom for a pile supported structure.

$$
\tilde{\zeta}=\frac{\zeta_{\mathrm{s}}+\zeta_{\mathrm{h}} \frac{\mathrm{k}_{\mathrm{s}}}{\mathrm{K}_{\mathrm{h}}}+\zeta_{\theta} \frac{\mathrm{k}_{\mathrm{s}} \mathrm{h}^{2}}{\mathrm{~K}_{\theta}}}{1+\frac{\mathrm{k}_{\mathrm{s}}}{\mathrm{K}_{\mathrm{h}}}+\frac{\mathrm{k}_{\mathrm{s}} \mathrm{h}^{2}}{\mathrm{~K}_{\theta}}}
$$

where: $\xi \quad$ is the damping value for the equivalent SDOF model,

$\zeta_{\mathrm{s}} \quad$ is the damping for the structure,

$\zeta_{\mathrm{h}} \quad$ is the damping for horizontal motion of the foundation,

and $\zeta_{\theta} \quad$ is the damping associated with the rotational stiffness of the foundation.

Note that the damping value for the equivalent SDOF structure is frequency dependent.

If the structure supported by the pile foundation has a uniform distribution of mass over the height, a linear approximation to the first mode shape gives a dynamic mass of 0.7 of the total mass acting 0.7 of the height above the base, as shown in Fig. 8.17 .

Example 8.1 For the Central Laboratories test piles estimate the natural period of the piles. Some details of the piles and the test results are given in Figs. 8.5 to 8.7. The concrete modulus is 26 $\mathrm{GPa}$, the section modulus, evaluated using transformed sections, is $0.00529 \mathrm{~m}^{4}$ for the first two metres beneath the ground surface and $0.00473 \mathrm{~m}^{4}$ at greater depths. Using the properties near the ground surface this gives: $E_{p} I_{p}=137.54 \mathrm{MNm}^{2}$. This data is taken from the report by Jennings et al (1985).
Since we have a tubular pile section equation 3.17 is used to calculate an equivalent pile modulus for a solid circular section:

$\mathrm{E}_{\mathrm{p}}=137.54 /\left(\pi \times 0.450^{4} / 64\right)=68.3 \mathrm{GPa}$.

We will assume a linear increase in $\mathrm{k}$ with depth. Initially take $\mathrm{n}_{\mathrm{h}}=0.75 \mathrm{MPa} / \mathrm{m}$ (much less than the value at the lower end of the range suggested by Jennings et al as describing the distribution of bending moment in the pile with depth during the slow cyclic loading, Fig. 8.8).

We need Young's modulus at a depth of one diameter, at which depth $\mathrm{k}=2 \times(0.75 \times 0.45)=0.675 \mathrm{MPa}$. (The value of $\mathrm{k}$ is doubled to account for the soil acting on both sides of the pile shaft.) From equation 3.39, assuming $\nu=0.3$, we have:

$\mathrm{E}_{\mathrm{s}}=2.62 \mathrm{k}=1.77 \mathrm{MPa}$. This gives $\mathrm{E}_{\mathrm{p}} / \mathrm{E}_{\mathrm{s}}=38,615$.

$\mathrm{m}=1.77 / 0.45=3.93 \mathrm{MPa} / \mathrm{m}$.

For dynamic loading the equivalent length from equation 8.7 is:

$\mathrm{L}_{\mathrm{ad}}=2.0 \times 0.45 \times(38615)^{0.2}=7.44 \mathrm{~m}$

(For a comparison the static active length calculated with equation 3.27 gives:

$\left.\mathrm{L}_{\mathrm{a}}=1.33 \times 0.45 \times(38615)^{0.2}=4.95 \mathrm{~m}\right)$

From equation 3.28 we obtain the pile head flexibility coefficients:

$$
\begin{aligned}
& f_{u H}=3.2 \times 38615^{-0.333} / 3.93 \times 0.45^{2}=0.119 \\
& f_{u M}=5.2 \times 38615^{-0.556 / 3.93 \times 0.45^{3}=0.039} \\
& f_{\theta M}=13.6 \times 38615^{-0.778} / 3.93 \times 0.45^{4}=0.023
\end{aligned}
$$

To evaluate the natural frequency of the system we need the effective horizontal stiffness at the position of the shaker attached to the top of the pile. This is $1.25 \mathrm{~m}$ above the ground surface. If we consider a horizontal force $\mathrm{H}$ applied a distance e $(1.25 \mathrm{~m})$ above the pile head, the horizontal displacement and rotation at the pile head are:

$$
\begin{aligned}
& \mathrm{u}=\mathrm{f}_{\mathrm{uH}} \mathrm{H}+\mathrm{f}_{\theta \mathrm{H}} \mathrm{He} \\
& \theta=\mathrm{f}_{\theta \mathrm{H}} \mathrm{H}+\mathrm{f}_{\theta \mathrm{M}} \mathrm{He}
\end{aligned}
$$

At the distance e above the ground surface there will be additional displacement from cantilever bending, this is:

$$
u_{\text {cantilever }}=\mathrm{e} \theta+\frac{\mathrm{He}^{3}}{3 \mathrm{E}_{\mathrm{p}} \mathrm{I}_{\mathrm{p}}}
$$

We can now express the horizontal displacement at the level of the shaking machine in terms of a flexibility coefficient:

$$
\frac{\mathrm{u}}{\mathrm{H}}=\mathrm{f}_{\mathrm{uH}}+2 \mathrm{f}_{\mathrm{uM}} \mathrm{e}+\mathrm{f}_{\theta \mathrm{M}} \mathrm{e}^{2}+\frac{\mathrm{e}^{3}}{3 \mathrm{E}_{\mathrm{p}} \mathrm{I}_{\mathrm{p}}}
$$

Making the appropriate substitutions we find that the equivalent horizontal stiffness at the shaking machine is: 


$$
\mathrm{K}_{\mathrm{h}}=3.88 \mathrm{kN} / \mathrm{mm}
$$

The mass of the $1.5 \mathrm{~m}$ pile extension and the shaking machine is $969 \mathrm{~kg}$. To calculate the natural frequency we need to be careful with units. A consistent set has the mass in tonnes and the stiffness in $\mathrm{kN} / \mathrm{m}$. Using these the natural frequency of the system is:

$$
f_{n}=\frac{1}{2 \pi} \sqrt{\frac{3.88 \times 10^{3}}{0.968}}=10.1 \mathrm{~Hz}
$$

The observed natural frequency was $8.1 \mathrm{~Hz}$, the response curve is reproduced in Fig. 8.7. There are two possible explanations as to why the predicted frequency is greater than that measured. Firstly the cyclic loading might have caused further softening of the soil adjacent to the pile shaft. The report on the test mentions the occurrence of liquefaction near the surface. Secondly the work from which Gazetas developed his equations assumes long piles so that the lower end is fixed. The length required for dynamic fixity is calculated above to be about 7.5 metres whereas the embedded length of the pile is 6.75 metres. Thus it is not surprising that the measured dynamic lateral stiffness of the pile is less than the calculated value.

The value of $n_{h}$ used in these calculations is appropriate for the silty sand when high pore water pressures have been generated. It is of interest to recalculate the natural frequency using a value from the range for $n_{h}$ that Jennings et al (1986) suggest is appropriate for modelling the moment distribution during the slow cyclic loading. Taking $\mathrm{n}_{\mathrm{h}}=4 \mathrm{MPa} / \mathrm{m}$ gives the stiffness of the system as $8.19 \mathrm{kN} / \mathrm{mm}$. The natural frequency is then:

$$
f_{n}=10.1 \times(8.19 / 3.88)^{0.5}=14.7 \mathrm{~Hz} \text {. }
$$

A five-fold increase in the stiffness of the soil leads to only a two-fold increase in stiffness of the system because the flexibility of that part of the pile shaft extending above the ground surface makes a significant contribution to the overall stiffness of the system.

In the above calculations the flexibilities calculated from equations 3.28 have not been converted to stiffnesses and modified to account for dynamic effects. This could be done using the curves in Fig. 8.16, but as the effect is small, typically a $10 \%$ reduction in stiffness at the natural frequency, no change has been made.

Example 8.2 Consider the test pile of Blaney and O'Neill, with the data given in Figs. 8.1 to 8.2 estimate the natural period of the pile and the response curve. Assume that the damping for the steel pile is $5 \%$ and the material damping for the soil is $5 \%$.

The data for this test are given by Blaney and O'Neill (1986a \& b). The steel tube pile had an outside diameter of $273 \mathrm{~mm}$ and inside diameter of $254.5 \mathrm{~mm}$, the second moment of area of the pile section is then $6.7 \times 10^{-5} \mathrm{~m}^{4}$. The embedded length of the pile shaft was $13.4 \mathrm{~m}$. For the pile shaft $\mathrm{E}_{\mathrm{p}} \mathrm{I}_{\mathrm{p}}$ was $15.05 \mathrm{MNm}^{2}$. The second moment of area for a solid pile shaft $273 \mathrm{~mm}$ in diameter is $2.73 \times 10^{-4} \mathrm{~m}^{4}$, so the pile modulus for use in the Gazetas equations is $55.2 \mathrm{GPa}$.
The centre of gravity of the attached mass was $2.21 \mathrm{~m}$ above the ground surface. The total mass at this level was 11.3 tonne.

Some preliminary calculations along the lines of those outlined in example 8.1 and using the data from Fig. 8.1 gave a natural frequency of $2.08 \mathrm{~Hz}$ in comparison with $2.30 \mathrm{~Hz}$ measured during the first dynamic test. Initially it was thought that the soil modulus chosen might have been a little low and did not reflect the increase in stiffness with depth evident from the data presented in Fig. 8.1. However, reasonable estimates of this increase did not lead to the required increase in the natural frequency. Next it was considered that the way the shaker and mass were attached to the pile shaft might not have been unrestrained as was assumed in the calculations. Rather than model this in detail it was decided to represent it by reducing the length of the pile shaft extension. It was found that a value of $2.02 \mathrm{~m}$ gave a natural frequency of $2.30 \mathrm{~Hz}$. Thus in the remainder of this example the pile shaft extension of $2.02 \mathrm{~m}$ is assumed.

The pile was installed in a clay profile. Details are given by Blaney and O'Neill (1986a), some of which are reproduced in Fig. 8.1. Crosshole shear wave velocity measurements gave a velocity of $150 \mathrm{~m} / \mathrm{sec}$ for the clay near the top of the pile shaft. The small strain Young's modulus of the soil was thus $134 \mathrm{MPa}$ and $\left(\mathrm{E}_{\mathrm{p}} / \mathrm{E}_{\mathrm{s}}\right)=412$.

Since the test pile was installed in an overconsolidated clay profile we will assume a constant modulus distribution. The dynamic active length of the pile from equation 8.7 is:

$$
\mathrm{L}_{\mathrm{ad}}=2.0 \times 0.273 \times(412)^{0.2}=2.5 \mathrm{~m} .
$$

Examination of the deflected shapes for the pile in Fig. 8.2 confirms that this is a reasonable estimate of the length of pile shaft involved in lateral deformation.

We are not given the depth of the soil layer in which the piles are embedded. It is at least $13.4 \mathrm{~m}$, the depth of embedment, and, as there is no mention of the bottom of the clay layer, we will assume a depth of $20 \mathrm{~m}$ to estimate the natural frequency of the layer and use this in the calculation of frequency dependent damping. From equation 8.1 the natural frequency of a layer $20 \mathrm{~m}$ deep is:

$$
\mathrm{f}_{1}=0.25 \times 150 / 20=1.9 \mathrm{~Hz}
$$

For this example we will use the equivalent SDOF model of Fig. 8.17 and equations 8.16 and 8.17 .

From equations 3.21 we obtain the pile head flexibility coefficients:

$$
\begin{aligned}
& f_{u H}=1.3 \times 412^{-0.18} / 134.0 \times 0.273=0.012 \\
& f_{u M}=2.2 \times 412^{-0.45} / 134.0 \times 0.273^{2}=0.015 \\
& f_{\theta M}=9.2 \times 412^{-0.73} / 134.0 \times 0.273^{3}=0.042
\end{aligned}
$$

Inverting the matrix of pile head flexibilities gives the stiffness components: 
$\mathrm{K}_{\mathrm{HH}}=145.9 \mathrm{kN} / \mathrm{mm}, \mathrm{K}_{\mathrm{MH}}=-51.4 \mathrm{kNm} / \mathrm{mm}$, and $\mathrm{K}_{\mathrm{MM}}=42.1 \mathrm{kNm} / \mathrm{mrad}$.

Using equation 3.41 we find that the horizontal stiffness at the pile head is:

$$
\begin{aligned}
\mathrm{K}_{\mathrm{h}} & =\left(145.9 \times 42.1-51.4^{2}\right) /(42.1-2.02 \times(-51.4)) \\
& =24.0 \mathrm{kN} / \mathrm{mm} .
\end{aligned}
$$

From equation 3.42 the rotational stiffness of the pile head is:

$$
\begin{aligned}
\mathrm{K}_{\theta} & =\left(42.1 \times 145.9-51.4^{2}\right) /(145.9-(-51.4) / 2.02) \\
& =20.4 \mathrm{kNm} / \mathrm{mrad} .
\end{aligned}
$$

The stiffness of the extension of the pile shaft above the ground surface is:

$\mathrm{k}_{\mathrm{s}}=3 \times 15.05 / 2.02^{3}=5.5 \mathrm{kN} / \mathrm{mm}$.

The natural frequency of the mass on the extension of the pile shaft is:

$\omega_{\mathrm{s}}=\sqrt{(5.5 \times 1000 / 11.3)=22.0 \mathrm{rads} / \mathrm{sec} .}$

The equivalent natural frequency of the system is:

$$
\begin{aligned}
\tilde{\omega} & =\left\{22.0 /\left(1+5.5 / 24.0+5.5 \times 2.02^{2} / 20.4\right)^{0.5}\right) \\
& =14.45 \mathrm{rad} / \mathrm{sec} . \\
\mathrm{f}_{\mathrm{n}} & =14.45 / 2 \times 3.1412=2.30 \mathrm{~Hz} .
\end{aligned}
$$

The equivalent damping values are now calculated.

We need the natural frequencies for horizontal displacement and rotation of the pile head, which are obtained from the equivalent stiffnesses $\mathrm{K}_{\mathrm{h}}$ and $\mathrm{K}_{\theta}$ :

$\omega_{\mathrm{h}}=(24.0 \times 1000 / 11.3)^{0.5}=46.1 \mathrm{rad} / \mathrm{sec}$.

$\omega_{\theta}=\left(20.4 \times 1000 / 11.3 \times 2.02^{2}\right)^{0.5}=21.1 \mathrm{rad} / \mathrm{sec}$.

Since the frequency at which these calculations are being done, $2.30 \mathrm{~Hz}$, is greater than the frequency of the soil layer, $1.9 \mathrm{~Hz}$, both the radiation and material damping contributions of equation 8.8 apply.

From equation 8.8 the damping values for the piles are:

$$
\begin{aligned}
\zeta_{\mathrm{HH}} & =0.80 \times 0.05+1.10 \times 2.30 \times 0.273 \times 412^{0.17} / 150.0 \\
& =0.053 \\
\zeta_{\mathrm{MM}} & =0.35 \times 0.05+0.35 \times 2.30 \times 0.273 \times 412^{0.20} / 150.0 \\
& =0.022 \\
\zeta_{\mathrm{HM}} & =0.80 \times 0.05+0.85 \times 2.30 \times 0.273 \times 412^{0.18} / 150.0 \\
& =0.051
\end{aligned}
$$

Using these values it was found that the peak amplification was overpredicted. This suggests that the Gazetas equations are conservative and underpredict the damping. It was found that increasing $\zeta_{\mathrm{HH}}$ and $\zeta_{\mathrm{MM}}$ by $30 \%$ gave the required peak amplification. Thus the damping values to be used in subsequent calculations are:

$\zeta_{\mathrm{HH}}=0.069, \zeta_{\mathrm{MM}}=0.029$ and $\zeta_{\mathrm{HM}}=0.051$.

Having the damping values we can now assemble the various components of the pile head impedance matrix (we will assume that $\mathrm{k}_{\alpha \beta}=1.0$ ):

$$
\begin{array}{lll}
\mathfrak{\mho}_{\mathrm{HH}} & =\mathrm{K}_{\mathrm{HH}}\left(1+2 \zeta_{\mathrm{HH}} \mathrm{i}\right)=145.9(1+0.138 \mathrm{i}) \\
\mathfrak{\Xi}_{\mathrm{MM}} & =42.1(1+0.058 \mathrm{i}) \\
\mathfrak{\mho}_{\mathrm{HM}} & =-51.4(1+0.102 \mathrm{i})
\end{array}
$$

At this point the advantage of the complex impedance becomes evident as we can substitute these terms directly into equations 3.41 and 3.42 , which give the static pile head stiffness, to get the equivalent pile head impedances. Equation 3.41 with the complex impedances inserted becomes:

$$
\mho_{\mathrm{h}}=\frac{\mathfrak{c}_{\mathrm{HH}} \mathfrak{c}_{\mathrm{MM}}-\mathfrak{\mho}_{\mathrm{HM}}^{2}}{\mathfrak{\mho}_{\mathrm{MM}}-\mathrm{e} \mathfrak{\mho}_{\mathrm{HM}}}
$$

Evaluating the parts of this equation term by term, we obtain:

$$
\begin{aligned}
\mathfrak{S}_{\mathrm{HH}} \mathfrak{\complement}_{\mathrm{MM}} & =145.9(1+0.138 \mathrm{i}) \times 42.1(1+0.058 \mathrm{i}) \\
= & 6093.0+1204.0 \mathrm{i} \\
\mathfrak{\Im}_{\mathrm{HM}}^{2} & =(51.4(1+0.102 \mathrm{i}))^{2} \\
= & 2614.0+534.0 \mathrm{i}
\end{aligned}
$$

Thus the top line of the expression for $\mathbb{E}_{\mathrm{h}}$ is:

$$
\begin{gathered}
6093.0+1204.0 \mathrm{i}-(2614.0+534.0 \mathrm{i})= \\
3479.0+670.0 \mathrm{i}
\end{gathered}
$$

The bottom line is:

$$
\begin{gathered}
42.1(1+0.058 \mathrm{i})-(-51.4)(1+0.102 \mathrm{i}) \times 2.02= \\
145.9+13.0 \mathrm{i}
\end{gathered}
$$

Thus $\sqrt{H H}_{\mathrm{HH}}$ expressed as a complex fraction is then:

$$
\mathfrak{c}_{\mathrm{HH}}=\frac{3479.0+670.0 \mathrm{i}}{145.9+13.0 \mathrm{i}}
$$

Multiplying the top and bottom lines by the complex conjugate of the bottom line gives:

$$
\mathfrak{S}_{\mathrm{HH}}=\frac{(3479.0+670.0 \mathrm{i})(145.9-13.0 \mathrm{i})}{(145.9+13.0 \mathrm{i})(145.9-13.0 \mathrm{i})}
$$


Performing the calculations required, this gives:

$\Im_{\mathrm{HH}}=(24.1+2.5 \mathrm{i}) \mathrm{kN} / \mathrm{mm}$ and $\zeta_{\mathrm{h}}=2.5 / 2 \times 24.1=0.052$

Proceeding similarly the damping value $\zeta_{\theta}=0.029$

To calculate the equivalent damping value we need the following:

$\mathrm{k}_{\mathrm{s}} / \mathrm{K}_{\mathrm{h}}=5.5 / 24.0=0.23$

$\mathrm{k}_{\mathrm{s}} \mathrm{h}^{2} / \mathrm{K}_{\theta}=5.5 \times 2.02^{2} / 20.4=1.10$

From equation 8.17 the equivalent damping value is:

$$
\begin{aligned}
\tilde{\zeta} & =(0.05+0.052 \times 0.23+0.029 \times 1.10) /(1+0.23+1.10) \\
& =0.040
\end{aligned}
$$

The amplification is calculated from standard equation for a SDOF system in which the damping is expressed as a fraction of the critical damping $\left(2 \mathrm{k} / \omega_{\mathrm{n}}\right)$ :

$$
A m p=\frac{1}{\left(\left[1-\left[\frac{\omega}{\tilde{\omega}}\right]^{2}\right]^{2}+\left[2 \tilde{\zeta}\left(\frac{\omega}{\tilde{\omega}}\right)\right]^{2}\right]^{0.5}}
$$

At $\mathrm{f}=2.30 \mathrm{~Hz} \omega=\widetilde{\omega}$, so the amplification is:

$$
\text { Amp }=1 / 2 \times 0.040=12.5
$$

Measurement of Fig. 8.2 gives an amplification at the natural frequency of the pile of 12.5 .

The set of values calculated for the various frequencies are given in the table and diagram below. Values for the damping coefficients are constant for frequencies less than the natural frequency of the layer, $f_{1}$. Also the table shows how $\zeta_{\mathrm{HH}}$, a component of the pile head impedance matrix, increases with frequency, in accordance with Fig. 8.14. This trend is less evident for the damping of the free head pile, $\zeta_{\mathrm{h}}$, and even less apparent for the overall damping value for the pile, $\zeta$.

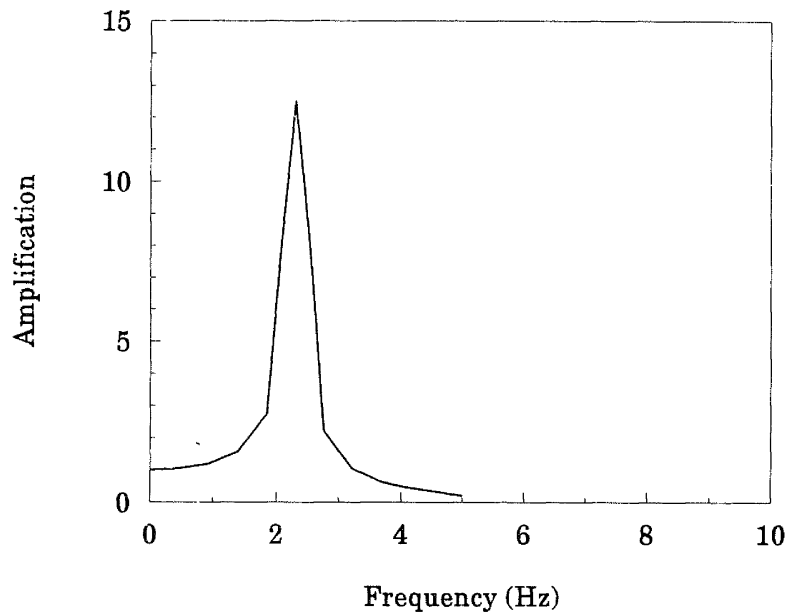

\begin{tabular}{|c|c|c|c|c|}
\hline $\mathrm{f}(\mathrm{Hz})$ & $\zeta_{\mathrm{HH}}$ & $\zeta_{\mathrm{h}}$ & $\zeta$ & Amplif. \\
\hline 0.46 & 0.052 & 0.040 & 0.038 & 1.04 \\
\hline 0.92 & 0.052 & 0.040 & 0.038 & 1.19 \\
\hline 1.38 & 0.052 & 0.040 & 0.038 & 1.56 \\
\hline 1.84 & 0.052 & 0.040 & 0.038 & 2.74 \\
\hline 2.30 & 0.069 & 0.051 & 0.040 & 12.50 \\
\hline 2.76 & 0.072 & 0.054 & 0.041 & 2.22 \\
\hline 3.22 & 0.075 & 0.057 & 0.043 & 1.03 \\
\hline 3.68 & 0.079 & 0.060 & 0.044 & 0.64 \\
\hline 4.14 & 0.082 & 0.063 & 0.045 & 0.45 \\
\hline 4.60 & 0.085 & 0.066 & 0.046 & 0.33 \\
\hline
\end{tabular}

For the test pile much of the response of the system comes from the projection of the pile shaft above the ground surface as this is so much less stiff than the pile head. Note also that the overall damping is small, once again being dominated by the pile shaft.

An acceptable alternative to the dynamic pile response curve plotted in the above diagram could have been obtained by estimating the damping at the natural frequency and applying this value at all frequencies. The purpose of the lengthier approach employed above was to illustrate the manner in which the various damping components vary with frequency.

Another alternative to the above damping calculations would be to use the impedance at all stages of the calculation rather than separating out stiffness and damping as is done with equation 8.16 and 8.17. If this method is followed the impedance calculated with equation 8.16 contains the equivalent damping implicitly. Performing these calculations gives a response curve very nearly identical to that plotted above. This calculation process is illustrated in Example 8.8.

\subsubsection{Inertial interaction in layered soil profiles}

The ideas presented here follow the paper of Gazetas and Dobry (1984). When we have to deal with a layered soil profile the convenient stiffness expressions presented above and in section 3 are no longer applicable. However, we observe from Fig. 8.2 that at resonance the normalised deflected shape of the Blaney and O'Neill test pile is very similar to that for static deformation. In Fig. 8.18 the deflected shape of a flexible pile in soil profile with a linear modulus distribution is plotted from Krishnan et al (1983) for a range of frequencies. The properties are such that the natural frequency of the soil layer corresponds to $\mathrm{a}_{\mathrm{o}}=0.31$. It is apparent from the diagram that for frequencies up to $f_{1}$ the deflected shape of the pile has the same form as the static deflected shape shown in Fig. 8.2. At higher frequencies the pile shaft undergoes small excitation at greater depths.

Gazetas and Dobry use this observation as the basis for their 

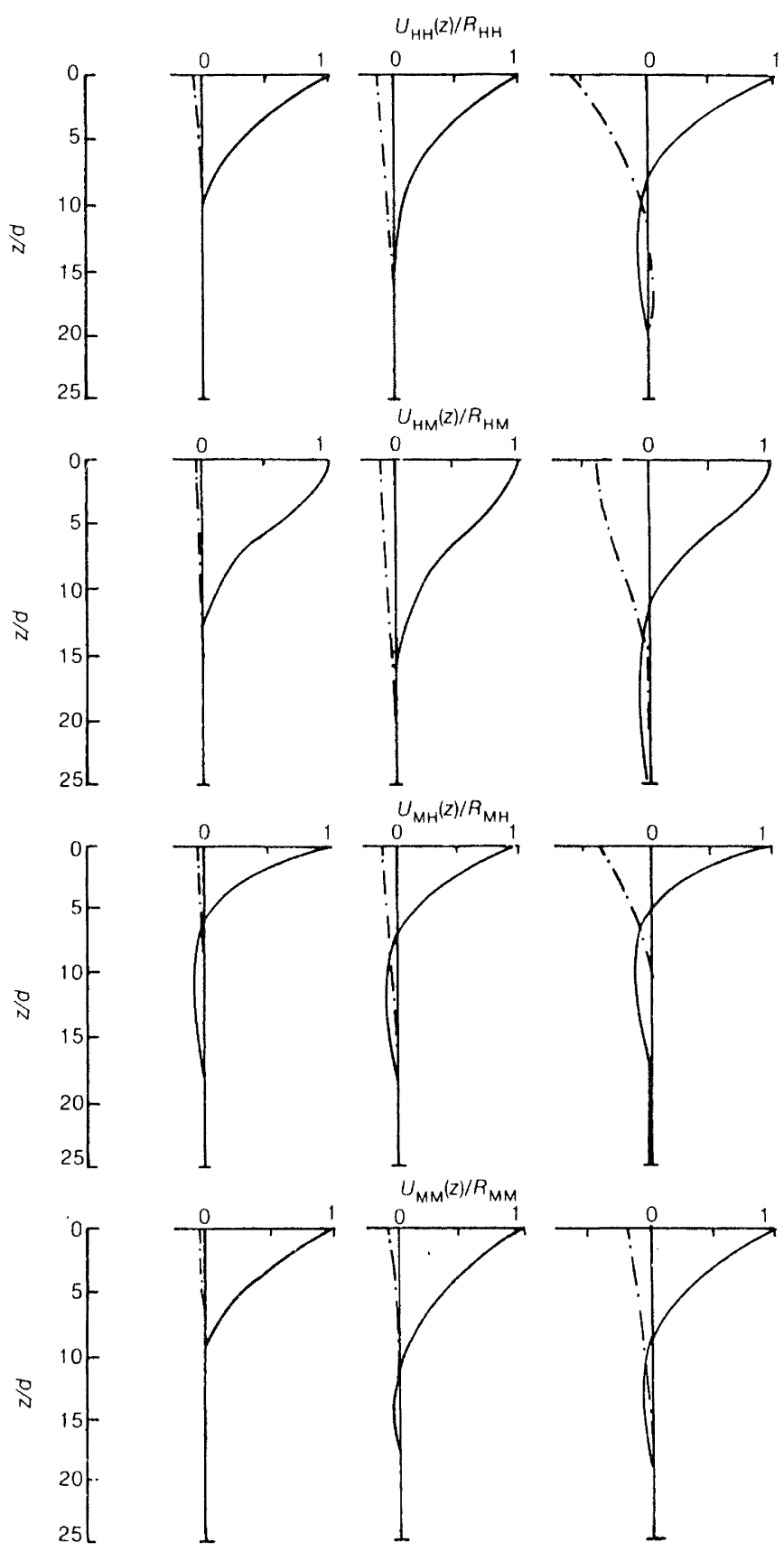

$a_{\mathrm{s}}=0.056$

$a_{\mathrm{s}}=0.238$

$a_{\mathrm{s}}=0.842$

Reai component

- . - - Imaginary component

Fig. 8.18 Distribution of dynamic deformations with depth in a flexible pile at a range of frequencies (after Krishnan et al (1983)).

method for estimating the dynamic stiffness of flexible piles in layered media. They start with an estimate of the static deflected shape of the pile. This is obtained by any convenient method. The finite element Winkler approach discussed in section 7 is a possible method. From this the static stiffness of the pile head is obtained. Next the damping values are assigned to the soil surrounding the pile shaft by approximate methods outlined below. The overall damping value for the pile shaft is obtained
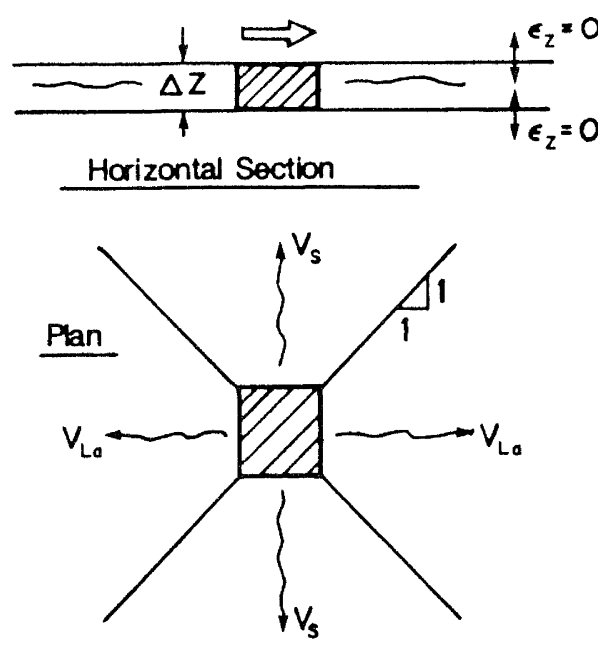

Fig. 8.19 The pile shaft radiation damping model (after Gazetas and Dobry (1984).

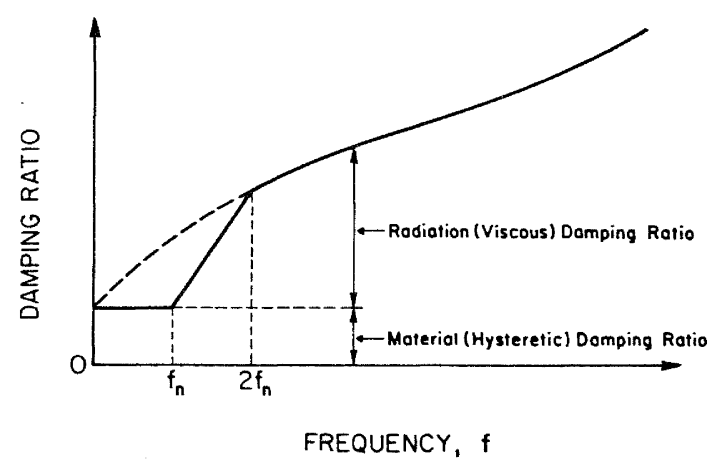

Fig. 8.20 Pile shaft damping versus frequency near resonance (after Gazetas and Dobry (1984)).

from a weighted averaging process. In this way the soil surrounding the top of the pile shaft makes the greatest contribution to the damping, thus the approximation involved in using the static deflected shape is justified as the small high frequency deflections at depth will a have negligible effect. Thirdly the dynamic modification of the static stiffness must be assessed. Diagrams such as Fig. 8.14 to 16 will be helpful here if one can make some approximation of the actual soil profile on the basis of the three profiles in Fig. 3.4.

Gazetas and Dobry propose a simplified method for estimation of the radiation damping coefficient at various positions along the pile shaft. As is shown in Fig. 8.19 it is assumed that energy is radiated away from the pile shaft in orthogonal directions, the velocity of propagation in the direction in which the pile is loaded is related to the p-wave velocity, and at right angles the propagation velocity is the shear wave velocity. Based on this concept they arrive at the following expressions for the radiation damping adjacent to the pile shaft: 


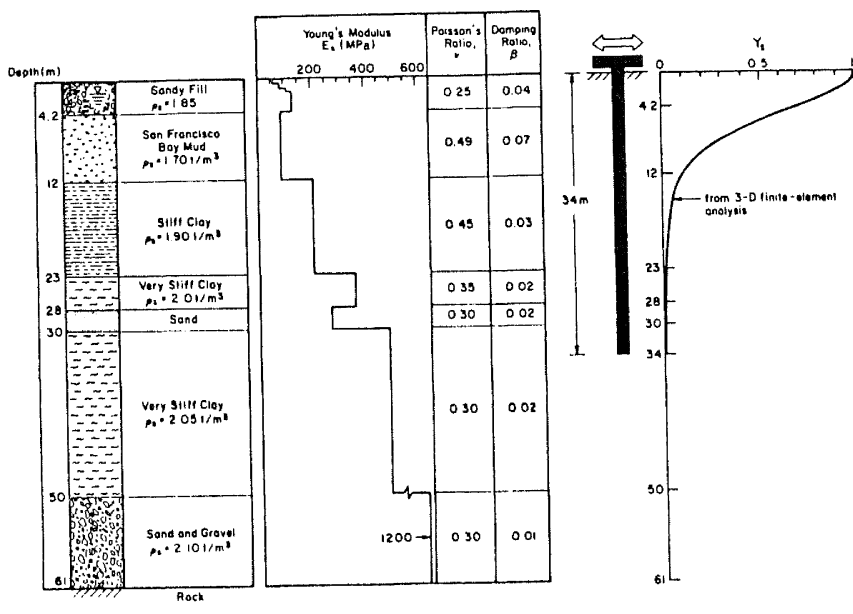

Fig. 8.21 Layered soil profile for pile lateral stiffness example (after Gazetas and Dobry (1984)).

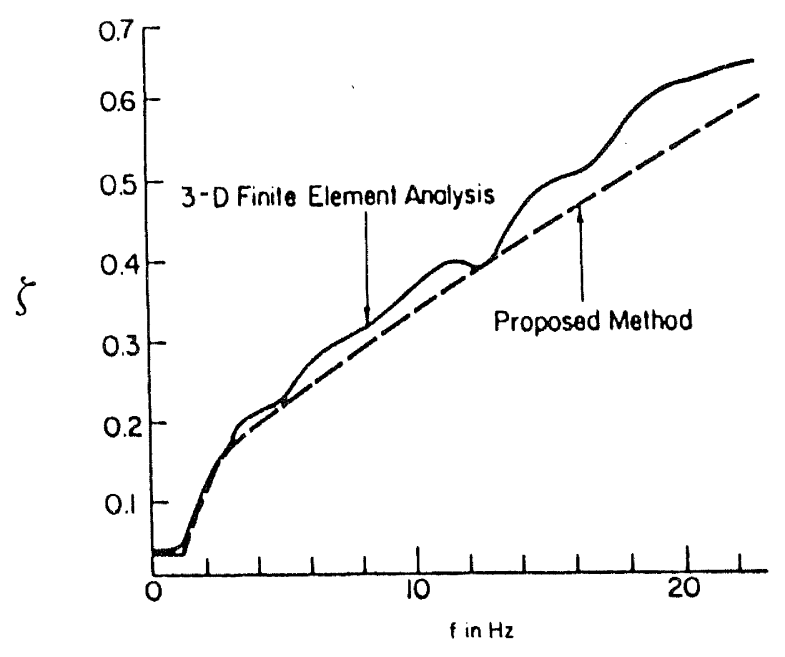

Fig. 8.22 Comparison of finite element results with the Dobry and Gazetas pile stiffness and damping predictions (after Gazetas and Dobry (1983)).

for $z>2.5 \mathrm{D}$

$$
\mathrm{C}_{\mathrm{rz}}=6.67 \mathrm{D} \rho_{\mathrm{s}} \mathrm{V}_{\mathrm{s}} \mathrm{a}_{\mathrm{o}}^{-0.25}
$$

for $\mathrm{z} \leq 2.5 \mathrm{D}$

$$
\mathrm{C}_{\mathrm{rZ}}=1.69 \mathrm{D} \rho_{\mathrm{s}} \mathrm{V}_{\mathrm{s}}\left(1+\left(\frac{3.4}{\pi(1-\nu)}\right)^{1.25}\right) \mathrm{a}_{\mathrm{o}}^{-0.25}
$$

where: $z \quad$ is the distance beneath the ground surface, and $\quad \mathrm{C}_{\mathrm{rz}} \quad$ is the radiation damping value at depth $\mathrm{z}$.

As explained above at frequencies less than the natural frequency of the system there is no radiation damping. Thus Gazetas and Dobry propose that the distribution of damping coefficients used be as shown in Fig. 8.20. They also explain how a strain dependent material damping coefficient might be estimated. The above relations consider assigning a damping value to various positions along the pile shaft. The next step is to obtain the effective damping value at the pile head. This is achieved by weighting the damping values in accordance with the static deflected shape of the pile shaft, using:

$$
C=\int_{0}^{L}\left(c_{r}+c_{m}\right) \Upsilon_{s}^{2}(z) d z
$$

where: $\Upsilon$

is the static deflected shape of the pile normalised with respect to displacement at the pile head.

An example of the calculation process taken from Gazetas and Dobry (1984) is reproduced in Fig. 8.21. Despite the fact the pile is of unusually large diameter it is still flexible, i. e. the active length is somewhat less than the actual length of $34 \mathrm{~m}$. In Fig. 8.22 a comparison is made between the damping and stiffness values obtained for this pile with the method of Gazetas and Dobry and those from a three dimensional dynamic finite element analysis, the agreement is very good.

\subsubsection{Nonlinear aspects of dynamic pile behaviour}

The two dynamic tests analysed in examples 8.1 and 8.2 applied forces small in relation to the lateral capacity of the piles. At larger force levels the soil adjacent to the top of the pile shaft will be repeatedly stressed beyond the elastic limit during the cyclic loading. For sands, particularly, saturated sands, this will cause a decrease in the stiffness of the sand adjacent to the pile shaft. For clay soils it may lead to the opening up of a gap adjacent to the pile shaft. Such a gap will reduce the stiffness at the pile head and consequently reduce the natural frequency of the system. These two aspects are discussed briefly in this section.

\section{Degradation of soil stiffness}

During cyclic loading it is possible that local failure will occur at the pile-soil interface and a nonlinear force deformation response will occur. This will follow the general trends established for static lateral loading in section 7.1. However cyclic loading will be more complex because the stiffness of the soil surrounding the pile shaft may degrade during the cycling. For piles in saturated sands this degradation is a consequence of a build up in pore water pressure. Poulos (1982) has analysed the effect of soil modulus degradation on cyclically loaded piles in clay. The main difficulty in the application of these ideas is obtaining data on the amount of degradation for a particular soil. Related studies have been reported by Angelides and Roesset (1981), Grashuis et al (1990), and Trochanis et al (1991).

\section{Gapping}

The phenomenon of gapping is illustrated in Fig. 2.8. Swane and Poulos (1984) have used the Winkler model to represent this phenomenon. The pile shaft is envisaged as having Winkler springs on each side. At the start of the lateral loading these springs are precompressed with forces representing the in situ horizontal stresses in the soil adjacent to the pile shaft. Consider a pair of these springs close to the top of the pile shaft. Prior to the commencement of lateral loading the springs will carry the same force and the displacement of each is zero. During lateral loading the spring on one side is compressed 


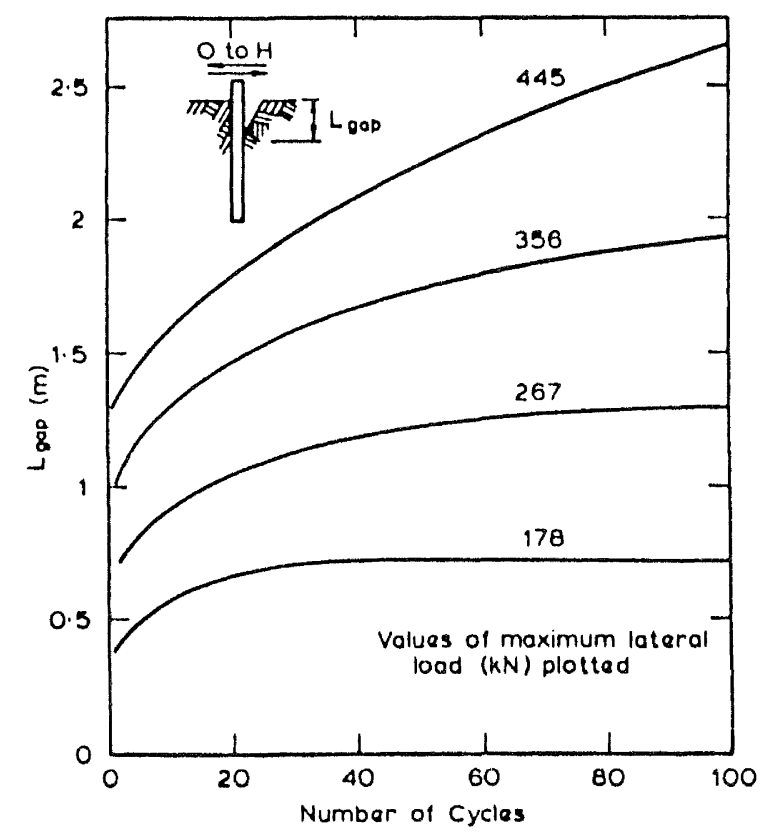

Fig. 8.23 Development of a gap adjacent to the shaft of a pile subject to cyclic lateral load in clay (after Swane and Poulos (1984)).

further and that on the opposite side unloads. At some lateral load the force in the spring on the unloading side reaches zero and a gap begins to open. Further lateral loading will increase the width of the gap and it will move deeper effecting other springs. When the load is reversed the situation is reversed with the springs which were previously being compressed now unloading. At some stage the pile shaft will cross the gap and commence to re-engage the previously unloaded springs.

This cyclic process will continue and, at loads small in relation to the lateral capacity of the pile, a stable gap length may be generated at which stage there will be no further reduction in pile stiffness or growth in gap length. This is known as shakedowm. At greater cyclic loads shakedown may take a many more cycles to occur, or at larger loads still there may be a tendency for continuous growth of the gap length. The results of one of the Swane and Poulos calculations are presented in Fig. 8.23. This was for a $610 \mathrm{~mm}$ diameter steel tube pile in stiff clay. The numbers of cycles in Fig. 8.23 refer to cyclic loading of a foundation for an offshore platform. For earthquake loading of a pile foundation one would expect a few tens of cycles at most. It is apparent from Fig. 8.23 that at large lateral forces gaps several pile diameters in length could form with a consequent reduction in the pile stiffness and increase in the maximum moment in the pile shaft.

\subsection{Kinematic interaction}

The majority of the discussion is this section is based on the work of Gazetas and his co-workers who obtained most of their earlier results with finite element analyses. Tajimi (1977) has obtained similar understanding using the Winkler model of soilpile interaction.

Kinematic interaction is expressed in terms of the following kinematic amplification factors:

$$
\begin{aligned}
& A_{u}=\frac{u_{p}}{u_{g}} \\
& A_{\theta}=\frac{\theta_{p} D}{2 u_{g}}
\end{aligned}
$$

where: $u_{p}$ is the amplitude of the horizontal displacement of the pile head relative to the input at the base of the pile $u_{\mathrm{g}}$, the total displacement of the pile head is $u_{\mathrm{g}}(t)$ $+u_{\mathrm{p}}(\mathrm{t})$,

and $\quad \theta_{\mathrm{p}}$ is the rotation of the pile head.

Perhaps a clearer way of indicating the effect of the pile shaft is to consider the relation between the motion of the pile head and that of the ground surface sufficiently distant that there is no effect from the pile head movement, the so-called free field motion. This is achieved with the following kinematic interaction factors:

$$
\begin{aligned}
& I_{u}=\frac{u_{p}}{u_{o}} \\
& I_{\theta}=\frac{\theta_{p} D}{2 u_{o}}
\end{aligned}
$$

where: $u_{0}$ is the amplitude of the free field motion of the ground surface adjacent to the pile head.

The amplitudes $u_{p}$ and $u_{o}$ are calculated for steady state sinusoidal excitation, $u_{\mathrm{g}}$, at the base of the pile. Application to a response spectrum will be illustrated below.

Gazetas having obtained a large number of individual results for free head piles in the various soil profiles, found that they depend on the ratios $E_{\mathrm{p}} / \mathrm{E}_{\mathrm{s}}$ and $\mathscr{L}$ (the length to diameter ratio of the pile, $L / D$ ), as well as the Poisson's ratio for the soil, the soil damping factor, and the ratio of the density of the pile material to that of the soil. The first two of these are the most important, in the remainder of this section a Poisson's ratio of 0.4 and a density ratio of 1.6 will be assumed. In the majority of cases the soil damping ratio will be taken as $5 \%$. Some typical kinematic interaction results are given in Fig. 8.24. The kinematic amplification factors peak, as expected, at the natural , frequencies of the layer, and the displacement interaction is large whilst the rotational interaction factor is small. The kinematic interaction factor for horizontal displacement, $I_{u}$, is unity for static displacement and less than unity at frequencies much greater than the natural frequency of the layer. The shape of the curves is very dependent on the distribution of soil modulus with depth. For the linear profile $I_{u}$ is less than unity when $f>f_{1}$. On the other hand for the constant modulus profile there is a range of frequencies for which $I_{u}>1$ before it decreases below unity. The rotational kinematic interaction factors, $\mathrm{I}_{\theta}$, are sufficiently small that they can be neglected. Gazetas found that with suitable dimensionless frequency parameters it is possible to express the kinematic interaction factors for free head piles in each soil profile as a unique curve. The results for the three distributions are shown in Fig. 8.25. The frequency parameters for the three soil profiles are given by: 

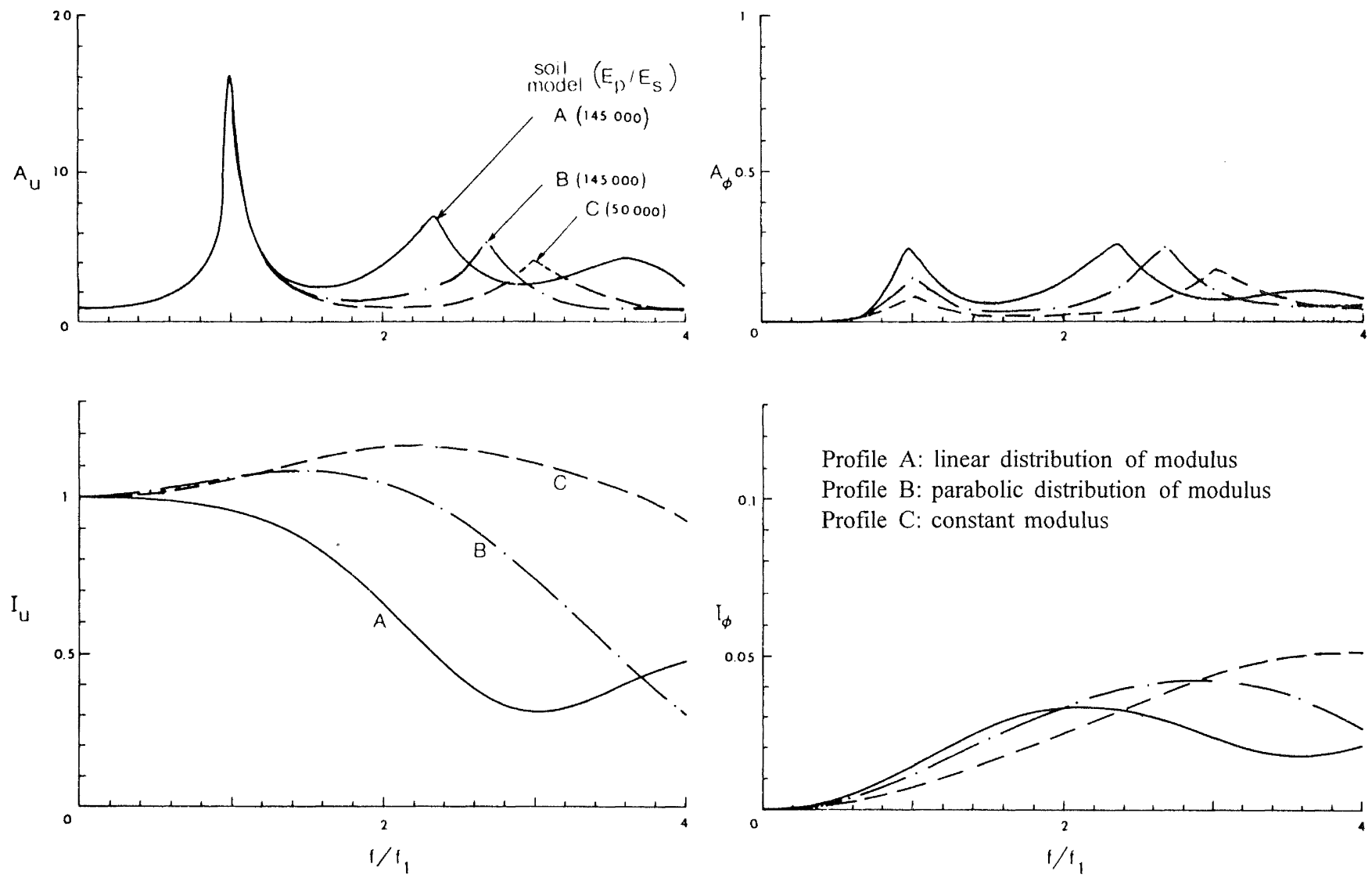

Fig. 8.24 Kinematic interaction effects for the three soil profiles $(L / D=40)$ (after Gazetas (1984)).

$$
\begin{aligned}
& F_{\text {con }}=\left[\frac{\mathrm{f}}{\mathrm{f}_{1}}\right] \mathrm{K}^{0.30} \mathscr{L}^{-0.50} \\
& \mathrm{~F}_{\text {par }}=\left[\frac{\mathrm{f}}{\mathrm{f}_{1}}\right] \mathrm{K}^{0.16} \mathscr{L}^{-0.35} \\
& \mathrm{~F}_{\text {lin }}=\left[\frac{\mathrm{f}}{\mathrm{f}_{1}}\right] \mathrm{K}^{0.10} \mathscr{L}^{-0.40}
\end{aligned}
$$

where: as in equation $3.16, \mathrm{~K}$ is the ratio $\mathrm{E}_{\mathrm{p}} / \mathrm{E}_{\mathrm{SD}}$, and $\mathrm{E}_{\mathrm{SD}}$ is the soil modulus at a depth equal to the pile diameter, D.

The average curves for the three soil profiles in Fig. 8.25 can be expressed in terms of the following convenient formulae:

$$
I_{U}=a F^{4}+b F^{3}+c F^{2}+e
$$

where: $F$ represents the value from equation 8.22 for the respective soil profile.

The values of the coefficients $a, b, c$, and $e$ which give a reasonable fit to the curves in Fig. 8.25 are given in Table 8.1.

When the value of $I_{u}$ calculated with equation 8.23 is less than 0.5 a value of 0.5 is used.

Makris and Gazetas (1992) give an alternative method for estimating kinematic soil-pile interaction. Ke Fan et al (1991) provide an extensive series of parametric studies of kinematic
Table 8.1 Coefficients for use in equation 8.23 to estimate kinematic interaction factors for the three soil profiles.

\begin{tabular}{|c|c|c|c|}
\hline Coefficient & Constant & Parabolic & Linear \\
\hline $\mathrm{a}$ & 0 & $3.64 \times 10^{-6}$ & $-6.75 \times 10^{-5}$ \\
\hline $\mathrm{b}$ & 0 & $-4.36 \times 10^{-4}$ & -0.007 \\
\hline $\mathrm{c}$ & -0.21 & 0.006 & 0.033 \\
\hline $\mathrm{e}$ & 1.0 & 1.0 & 1.0 \\
\hline
\end{tabular}

interaction. These cover both free head and fixed head piles, they show that for fixed head piles the range of frequencies for $I_{u}$ is less than unity is more extensive than for the free head case. Thus the free head results presented in Fig. 8.25 and given in equation 8.23 will be a conservative assessment of the kinematic interaction for fixed head piles.

Strictly speaking the kinematic interaction factors should be applied to Fourier spectra, but useful insight into the interaction can be expected by applying the factors to response spectra. The justification for this approximation is that if the amplitude of the Fourier spectrum is suppressed continuously across a range of frequencies then the response spectrum ought to be similarly suppressed over a similar frequency range. The practical application of the curves in Fig. 8.25 is then very simple. One simply multiplies the free field design response spectrum with the appropriate interaction curve to derive the design response spectrum to be input at the pile head for the calculation of inertial interaction. This is illustrated in example 8.5 below. 

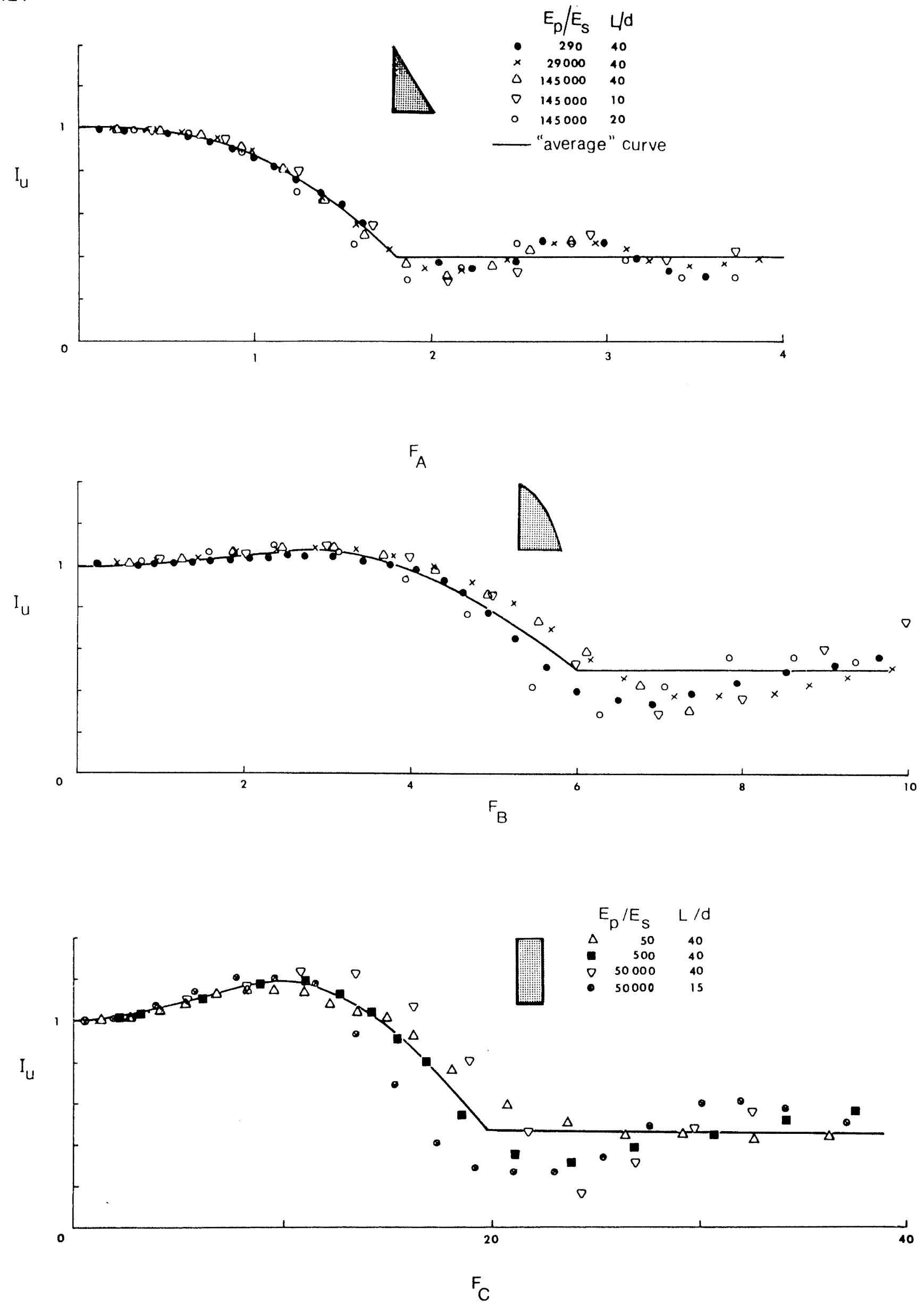

Fig. 8.25 Kinematic interaction factors $\left(I_{u}\right)$ for free head piles in terms of dimensionless frequency factors (after Gazetas (1984)). 
Example 8.3 Consider a $0.75 \mathrm{~m}$ diameter end bearing pile of length $20 \mathrm{~m}$ embedded in a saturated soil profile. Take the modulus of the pile material to be $25 \mathrm{GPa}$. Assume that Poisson's ratio for the soil is 0.4 and that the density of the soil is $1800 \mathrm{~kg} / \mathrm{m}^{3}$. Consider the three cases of modulus distribution shown in Fig. 3.4. Calculate the kinematic interaction for a natural period of the soil layer of 0.25 and 1.0 seconds.

The length to diameter ratio of the pile is:

$\mathscr{L}=20 / 0.75=26.7$

(a) Period of the soil layer 1 second.

The frequency corresponding to a natural period of 1 second is $1 \mathrm{~Hz}$.

\section{Constant modulus profile:}

From equation 8.1 the shear wave velocity required to give the natural frequency of $1 \mathrm{~Hz}$ is:

$\mathrm{V}_{\mathrm{s} \text { con }}=1 \times 20 / 0.25=80 \mathrm{~m} / \mathrm{sec}$.

Converting this to Young's modulus $\left(\mathrm{G}=\rho \mathrm{V}_{\mathrm{s}}^{2}\right.$,

$\mathrm{E}=2(1+\nu) \mathrm{G})$ :

$\mathrm{E}_{\mathrm{s} \text { con }}=2 \times 1.4 \times 1.8 \times 80^{2}=32.2 \mathrm{MPa}$.

$\mathrm{K}_{\mathrm{con}}=25 \times 1000 / 32.2=775$

\section{Parabolic profile:}

From equation 8.1 the shear wave velocity, at a depth of one pile diameter, required to give the natural frequency of $1 \mathrm{~Hz}$ is:

$\mathrm{V}_{\text {s par }}=1 \times 20 / 0.56=35.7 \mathrm{~m} / \mathrm{sec}$.

Converting this to the Young's modulus:

$\mathrm{E}_{\mathrm{spar}}=2 \times 1.4 \times 1.8 \times 35.7^{2}=6.4 \mathrm{MPa}$.

$\mathrm{K}_{\mathrm{par}}=25 \times 1000 / 6.4=3889$

\section{Linear profile:}

From equation 8.1 the shear wave velocity, at a depth of one pile diameter, required to give the natural frequency of $1 \mathrm{~Hz}$ is:

$\mathrm{V}_{\mathrm{s} \text { lin }}=1 \times 20 / 1.21=16.5 \mathrm{~m} / \mathrm{sec}$.

Converting this to Young's modulus at a depth of one pile diameter:

$\mathrm{E}_{\mathrm{s} \text { lin }}=2 \times 1.4 \times 1.8 \times 16.5^{2}=1.4 \mathrm{MPa}$.

$\mathrm{K}_{\text {lin }}=25 \times 1000 / 1.4=18,250$

With these terms evaluated we can use equations 8.22 and 23 to evaluate the kinematic interaction factors for the three soil profiles. The results of this are presented in the following table and diagram.
Kinematic interaction factors for a 1 second period.

\begin{tabular}{|c|c|c|c|}
\hline Period & $\mathrm{I}_{\mathrm{u} \text { con }}$ & $I_{u}$ par & $I_{u \operatorname{lin}}$ \\
\hline 0.05 & 0.50 & 0.50 & 0.50 \\
\hline 0.10 & 1.11 & 0.50 & 0.50 \\
\hline 0.15 & 1.20 & 0.50 & 0.50 \\
\hline 0.20 & 1.16 & 0.61 & 0.50 \\
\hline 0.25 & 1.12 & 0.96 & 0.50 \\
\hline 0.30 & 1.09 & 1.07 & 0.50 \\
\hline 0.35 & 1.07 & 1.10 & 0.50 \\
\hline 0.40 & 1.06 & 1.10 & 0.50 \\
\hline 0.50 & 1.04 & 1.09 & 0.58 \\
\hline 0.60 & 1.03 & 1.07 & 0.71 \\
\hline 0.70 & 1.02 & 1.06 & 0.78 \\
\hline 0.80 & 1.02 & 1.05 & 0.83 \\
\hline 0.90 & 1.01 & 1.04 & 0.97 \\
\hline 1.00 & 1.01 & 1.04 & 0.89 \\
\hline 1.10 & 1.01 & 1.03 & 0.91 \\
\hline 1.20 & 1.01 & 1.03 & 0.93 \\
\hline 1.40 & 1.01 & 1.02 & 0.95 \\
\hline 1.60 & 1.00 & 1.02 & 0.96 \\
\hline 1.80 & 1.00 & 1.01 & 0.97 \\
\hline 2.00 & 1.00 & 1.01 & 0.97 \\
\hline
\end{tabular}

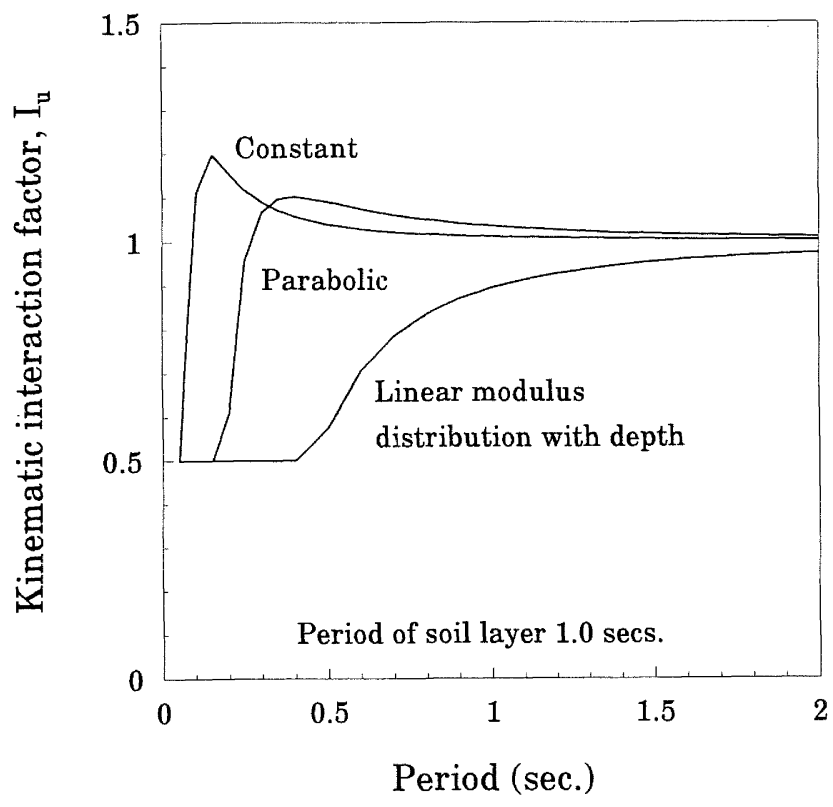


(b) Period of soil layer 0.25 second.

The frequency corresponding to a natural period of 0.25 second is $4 \mathrm{~Hz}$.

Constant modulus profile:

From equation 8.1 the shear wave velocity required to give the natural frequency of $1 \mathrm{~Hz}$ is:

$\mathrm{V}_{\mathrm{s} \text { con }}=4 \times 20 / 0.25=320 \mathrm{~m} / \mathrm{sec}$.

Converting this to Young's modulus:

$\mathrm{E}_{\mathrm{S} \text { con }}=2 \times 1.4 \times 1.8 \times 320^{2}=516 \mathrm{MPa}$.

$\mathrm{K}_{\mathrm{con}}=25 \times 1000 / 516=48$

\section{Parabolic profile:}

From equation 8.1 the shear wave velocity, at a depth of one pile diameter, required to give the natural frequency of $4 \mathrm{~Hz}$ is:

$\mathrm{V}_{\mathrm{spar}}=4 \times 20 / 0.56=142.8 \mathrm{~m} / \mathrm{sec}$.

Converting this to Young's modulus:

$\mathrm{E}_{\mathrm{spar}}=2 \times 1.4 \times 1.8 \times 142.8^{2}=103 \mathrm{MPa}$.

$\mathrm{K}_{\mathrm{par}}=25 \times 1000 / 103=243$

\section{Linear profile:}

From equation 8.1 the shear wave velocity, at a depth of one pile diameter, required to give the natural frequency of $4 \mathrm{~Hz}$ is:

$\mathrm{V}_{\mathrm{s} \text { lin }}=4 \times 20 / 1.21=66.1 \mathrm{~m} / \mathrm{sec}$.

Converting this to Young's modulus:

$\mathrm{E}_{\mathrm{s} \operatorname{lin}}=2 \times 1.4 \times 1.8 \times 66.1^{2}=22 \mathrm{MPa}$.

$\mathrm{K}_{\text {lin }}=25 \times 1000 / 22=1136$

With these terms evaluated we can use equations 8.22 and 23 to evaluate the kinematic interaction factors for the three soil profiles. The results of this are presented in the table above and in the following diagram.

The above results show that the linear distribution of soi modulus gives the most pronounced kinematic interaction whereas the constant modulus profile has $I_{u}<1$ only at very high frequencies and $I_{u}$ is greater than unity for a considerable period range. Additional calculations similar to those above reveal that, other factors fixed, lengthening the period of the soil layer makes the kinematic interaction effect more dramatic, increasing the pile diameter has the same effect. Changing the length and modulus of the pile has a relatively minor effect.
Kinematic interaction factors for a 0.25 second period

\begin{tabular}{|c|c|c|c|}
\hline Period & $\mathrm{I}_{\mathrm{u} \text { con }}$ & $I_{\text {u par }}$ & $I_{\mathrm{u} \operatorname{lin}}$ \\
\hline 0.05 & 1.05 & 1.08 & 0.50 \\
\hline 0.10 & 1.01 & 1.07 & 0.62 \\
\hline 0.15 & 1.01 & 1.04 & 0.83 \\
\hline 0.20 & 1.00 & 1.02 & 0.91 \\
\hline 0.25 & 1.00 & 1.01 & 0.94 \\
\hline 0.30 & 1.00 & 1.01 & 0.97 \\
\hline 0.35 & 1.00 & 1.01 & 0.99 \\
\hline 0.40 & 1.00 & 1.01 & 0.99 \\
\hline 0.50 & 1.00 & 1.00 & 0.99 \\
\hline 0.60 & 1.00 & 1.00 & 0.99 \\
\hline 0.70 & 1.00 & 1.00 & 0.99 \\
\hline 0.80 & 1.00 & 1.00 & 0.99 \\
\hline 0.90 & 1.00 & 1.00 & 1.00 \\
\hline 1.00 & 1.00 & 1.00 & 1.00 \\
\hline 1.10 & 1.00 & 1.00 & 1.00 \\
\hline 1.20 & 1.00 & 1.00 & 1.00 \\
\hline 1.40 & 1.00 & 1.00 & 1.00 \\
\hline 1.60 & 1.00 & 1.00 & 1.00 \\
\hline 1.80 & 1.00 & 1.00 & 1.00 \\
\hline 2.00 & 1.00 & 1.00 & 1.00 \\
\hline
\end{tabular}

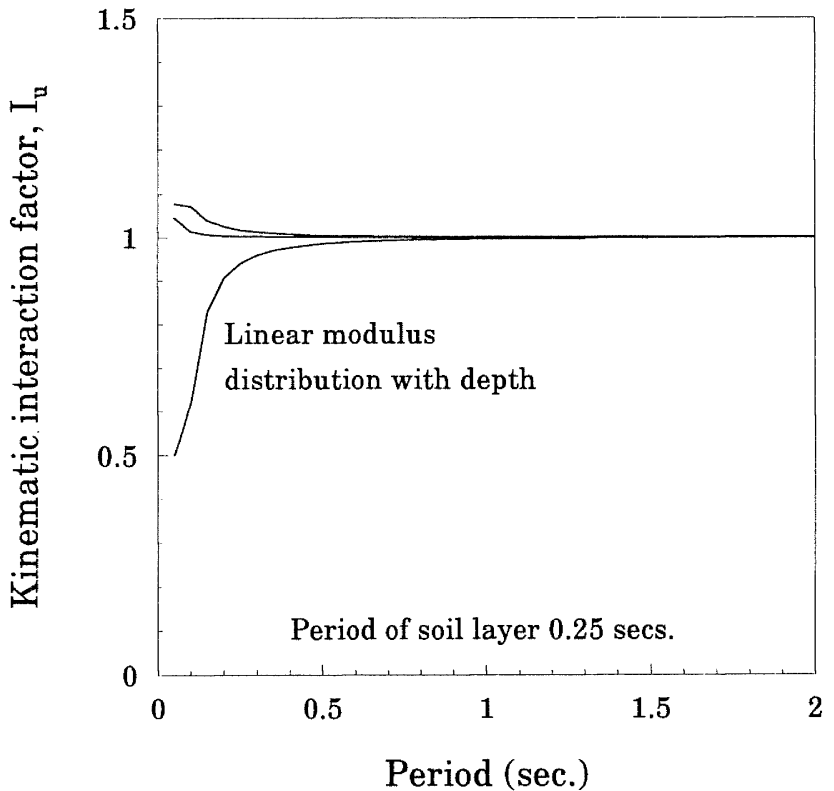

Period (sec.) 
Example 8.4 Refer back to the case of the Imperial County Services Building discussed in sections 2.2.3 and 8.1.2 and also the bridge response data reported by Ohira et al (1984) discussed in section 2.2.4 and illustrated in Figs. 2.16 and 2.17. What can one infer about kinematic interaction from the recorded motions at the base of these structures?

From our consideration of kinematic interaction we expect that for certain soil profiles the pile head response will be less than the free field response at high frequencies. Figure 2.17 certainly shows that this is the case for the bridge structure monitored by Ohira et al (1984). For the Imperial County Services building it is explained in section 2.2.3 that the high frequency response at the base of the structure is greater than that of the free field. Thus one example seems to support the expectations of kinematic interaction whereas the other does not.

Referring to Fig. 8.13 we see that the kinematic interaction is calculated for a pile without any attached mass. The pile foundations for the Imperial County Services building and the Japanese bridge have considerable mass attached. Thus what is recorded at the foundation level is a consequence of the combined kinematic and inertial interaction. In this sense kinematic interaction is not something that can be observed and the isolation of kinematic interaction effects would require a full response analysis of the pile foundation and the attached structure.

The spectral ratio from the Imperial Services building was observed to exceed unity at frequencies of about $2 \mathrm{~Hz}$ and greater. Hadjian et al (1990) report that the fundamental frequency (fixed base) of the structure itself is about $3.5 \mathrm{~Hz}$ in the $\mathrm{N}-\mathrm{S}$ direction and about $1.5 \mathrm{~Hz}$ in the $\mathrm{E}-\mathrm{W}$ direction. The spectral ratios in excess of unity for frequencies greater than 2 $\mathrm{Hz}$ may then be a consequence of the excitation of the first few modes of the structure. In the case of the bridge reported by Ohira et al no details are given of the natural period of the structure, being a bridge structure it may have a long period in which case there would be little feedback from the structure in the high frequency range of the spectrum. If this is true the ratios plotted in Fig. 2.17, which imply that the free field motion for periods less than about 1.5 secs. are greater than those at the top of the pile foundation, may well indicate kinematic interaction, with $I_{u}$ less than unity for periods up to about 1.5 seconds. This possibility is explored below.

The bridge foundations shown in Fig. 2.16 are pile groups. We will anticipate a result discussed in section 8.3 that kinematic interaction for pile groups is not much different from that for single piles, consequently we will apply the above equations to the data on the pile group bridge foundations monitored by Ohira et al (1984).

From Fig. 2.16 the length of the piles is $22 \mathrm{~m}$, the diameter is $600 \mathrm{~mm}$ so $\mathscr{L}=37$. We will assume that $\mathrm{E}_{\mathrm{p}}=25 \mathrm{GPa}$. From Fig. 2.16 the shear wave velocity of the soil near the top of the profile is about $50 \mathrm{~m} / \mathrm{sec}$. The Young's modulus of the soil (assuming a Poisson's ratio of 0.4 and a density for the soil of $1700 \mathrm{~kg} / \mathrm{m}^{3)}$ for the soil of:

$\mathrm{E}_{\mathrm{s}}=2 \times 1.4 \times 1.7 \times 50^{2}=11.9 \mathrm{MPa}$, so that $\mathrm{K}=2101$
The above properties give a natural period for the soil profile of 1.75 seconds.

Repeating calculations like those in Example 8.3 leads to the conclusion that only with the linear distribution of modulus with depth can the kinematic interaction implied by Fig. 2.17 be accounted for. As all modulus distribution models tend to get the interaction factor greater than unity for long periods, the question is over what period range the various models get the interaction factor less than unity. The constant modulus profile has $I_{u}>1$ for periods in excess of 0.1 seconds, the parabolic profile has $I_{u}>1$ for periods greater than 0.25 seconds, whilst the linear profile has $I_{u}>1$ for periods in excess of 1.4 seconds, thereafter it approaches unity.

From Fig. 2.17 it is abundantly clear from the shear wave velocities given that the velocity is not zero at the ground surface as required by the linear modulus distribution, in fact a constant modulus profile might be more appropriate. The shear wave velocities record the small strain stiffness of the soil. The peak ground acceleration measured at instrument GS1 during the earthquake was $0.12 \mathrm{~g}$. This opens the way for a possible explanation of the apparent conflict between the measured soil layer properties and those required to give kinematic interaction effects. If we consider that nonlinear interaction between the pile shafts and surrounding soil would have occurred near the ground surface during the earthquake one would expect the decrease in modulus to be greatest near the ground surface and an approximately linear distribution to have been generated (not unlike the results from the Central Laboratories test pile shown in Fig. 8.8).

Example 8.5 The first two columns of the table on the next page give the period and spectral accelerations for the free field response spectrum at the surface of a soil layer $20 \mathrm{~m}$ deep overlying much stiffer material. The natural period of the soil layer is 0.6 secs. and it is thought that the most appropriate soil model is the linear increase in modulus with depth from zero at the ground surface. A $1.5 \mathrm{~m}$ diameter pile $20 \mathrm{~m}$ long is to be installed in the soil profile. How will the acceleration response spectrum at the pile head differ from that of the free field?

As explained above the kinematic interaction factors should, strictly speaking, be applied to Fourier rather than response spectra but useful insight into the interaction can be expected by applying the factors to response spectra as is done in this example.

The calculations to get $\mathrm{I}_{\mathrm{u}}$ are essentially the same as those in example 8.3. The results of the calculations are given in the table and diagram on the next page.

This example illustrates further the comment made above that increasing pile diameter enhances the kinematic interaction. For the $1.5 \mathrm{~m}$ diameter pile considered in this example the difference between the free field and pile head spectrum is considerable at high frequencies. If the calculations are repeated for a smaller diameter pile the effect is not as dramatic. This can be thought of as a consequence of the pile having difficulty following the soil motions. In the case of a very flexible pile the pile motion and soil motion will be very similar and consequently the two spectra will be identical. On the other 


\begin{tabular}{|c|c|c|c|}
\hline Period & $\mathrm{S}_{\mathrm{a} \text { free-fld. }}$ & $\mathrm{I}_{\mathrm{u} \text { lin }}$ & $\mathrm{S}_{\text {a pile }}$ \\
\hline 0.05 & 0.36 & 0.50 & 0.18 \\
\hline 0.10 & 0.57 & 0.50 & 0.28 \\
\hline 0.15 & 0.57 & 0.50 & 0.28 \\
\hline 0.20 & 0.64 & 0.50 & 0.32 \\
\hline 0.25 & 0.91 & 0.50 & 0.46 \\
\hline 0.30 & 0.70 & 0.50 & 0.35 \\
\hline 0.35 & 0.62 & 0.56 & 0.34 \\
\hline 0.40 & 0.61 & 0.66 & 0.41 \\
\hline 0.50 & 0.83 & 0.78 & 0.65 \\
\hline 0.60 & 0.86 & 0.85 & 0.73 \\
\hline 0.70 & 0.62 & 0.89 & 0.55 \\
\hline 0.80 & 0.55 & 0.92 & 0.50 \\
\hline 0.90 & 0.54 & 0.93 & 0.50 \\
\hline 1.00 & 0.52 & 0.95 & 0.50 \\
\hline 1.10 & 0.39 & 0.96 & 0.37 \\
\hline 1.20 & 0.33 & 0.96 & 0.32 \\
\hline 1.40 & 0.18 & 0.97 & 0.18 \\
\hline 1.60 & 0.20 & 0.98 & 0.19 \\
\hline 1.80 & 0.18 & 0.98 & 0.18 \\
\hline 2.00 & 0.18 & 0.99 & 0.18 \\
\hline
\end{tabular}

hand a very stiff pile will not be able to follow the soil motion, particularly the high frequency part of the spectrum, and the high frequency components of the free field motion will be missing from the pile head motion. In this way the pile is said to filter out the high frequency motion.

\subsubsection{Effect of abrupt changes in layer properties}

The above discussion envisages a soil profile with a smooth variation in soil modulus with depth. Another factor in determining kinematic interaction is the presence of sudden changes in soil properties in a layered soil profile. It is expected that at such changes might lead to localised damage of the pile shaft that cannot be predicted with the above methods. This topic is discussed by Oweiss (1981), Margason and Holloway (1977), and Fussell (1993). Also Makris and Gazetas (1992) point out that kinematic interaction effects in layered soil profiles may be different from those presented in section 8.2.7 dealing with soil profiles having a smooth variation in modulus with depth. This is because of wave reflections from layer boundaries.

\subsubsection{Summary of kinematic interaction effects}

The question to be addressed is: How well does the pile follow the soil motion? Clearly flexible piles are more able to follow the soil than stiff piles. Even quite large diameter piles may be flexible when length is taken into account.

The following points can be made in summary:

(i) at high frequencies the pile may not be able to follow the soil in which case the high frequency motion will not appear at the pile head,

the details of the kinematic interaction are dependent on the distribution of soil modulus with depth, the effect is most significant for the linear modulus distribution and least significant for the constant modulus case,

(iii) kinematic interaction is more significant for fixed head than free head piles,

(iv) even a soil profile that from shear wave velocity data might be considered as having a constant modulus may generate behaviour like that for the linear profile because of soil modulus degradation near the top of the pile,

it is generally safe to neglect kinematic interaction for soil profiles with a smooth variation of modulus with depth,

for layered soil profiles Makris and Gazetas (1992) emphasise that the kinematic effects may be more severe because of reflections from the layer boundaries. 
In the previous section we discussed the dynamic response of a single pile under two headings - kinematic and inertial interaction between the pile and the surrounding soil. The same two questions arise for pile groups. If we are content to regard the system as responding in a linear elastic manner then there are a range of solutions available. Rigorous elastic analyses have been done using boundary element methods, results from the work of Kaynia and Kausel (1982) are quoted below. The Winkler model has also been used extensively as a route to an approximate solution that gives results very similar to those obtained from boundary element calculations. Examples of this approach are Novak (1991) and Makris and Gazetas (1992) whose methods have been shown to produce results in reasonable agreement with exact analyses.

Dealing first with kinematic interaction for pile groups. The conclusion reached by Kaynia and Kausel (1982), Ke Fan et al (1991), and Makris and Gazetas (1992) is that kinematic interaction for a pile group is similar to that for an individual pile in the group. Thus we can apply the conclusions of section 8.2.9 to estimate the kinematic interaction for a single pile in a group and assume that this is a reasonable approximation to that for the whole group.

When it comes to the inertial interaction elastic calculations reveal a major complexity in that the stiffness and damping values are very dependent on the frequency. The number of piles and the layout of the piles in the group are also important. This means that the simple picture of Figs. 8.14 to 8.16 is no longer valid and we cannot assume that the dynamic group stiffness is about the same as the static value.

Elastic inertial interaction shows complex frequency effects. The source of these effects is constructive and destructive interference between the piles because of the waves that are emitted from the shaft of each pile and propagate through the soil to neighbouring piles where reflections occur.

Earlier we have treated the three soil profiles shown in Fig. 3.4. In this section we deal only with the constant modulus (homogeneous) profile.

Figures 8.26 to 8.28 give a range of stiffness results for the vertical, lateral, and rocking dynamic stiffness of $4 \times 4$ fixed head pile groups obtained by Kaynia and Kausel (1982). In these diagrams the vertical and lateral stiffness of the group normalised with respect to $n$ (number of piles in the group) times the static stiffness of a single pile. For the rotational stiffness the normalisation is done with the vertical stiffness times the distance from the centroid of the group to each particular pile. Thus the ordinate of these diagrams is similar to the $\mathrm{k}$ values in Figs. 8.14 to 8.16 . The frequency parameter $\mathrm{a}_{0}$ is $\omega \mathrm{D} / \mathrm{V}_{\mathrm{S}}$, the ratio of the pile to soil density for all the analyses was 1.7 , Poisson's ratio is 0.4 , and all the calculations were done for $L / D=15$. The extreme sensitivity to frequency and pile spacing is evident from these diagrams.

Figures 8.29 to 8.31 give additional information for a single pile spacing at a range of pile group configurations.

The work of Kaynia and Kausel (1992) confirms that it is
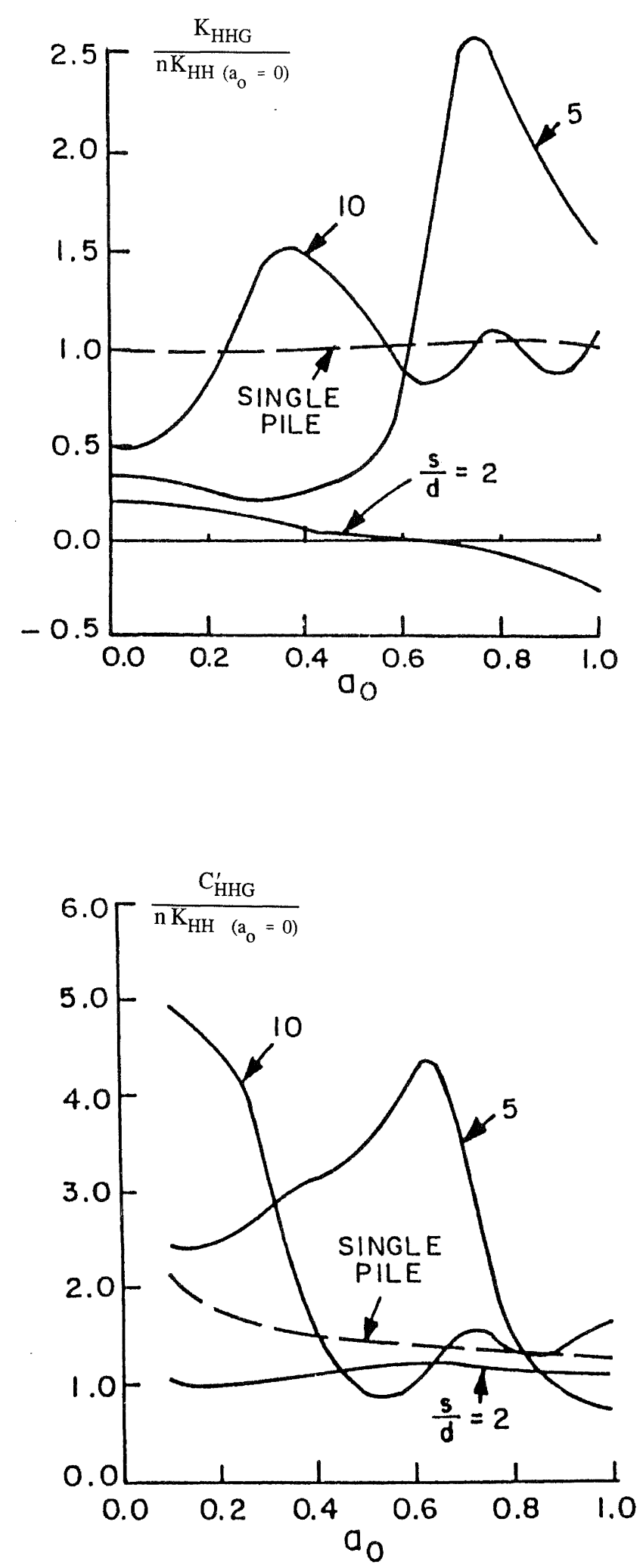

Fig. 8.26 Dynamic lateral stiffness and damping coefficients for a $4 x 4$ fixed head pile group in homogeneous soil (after Kaynia and Kausel (1982)). 

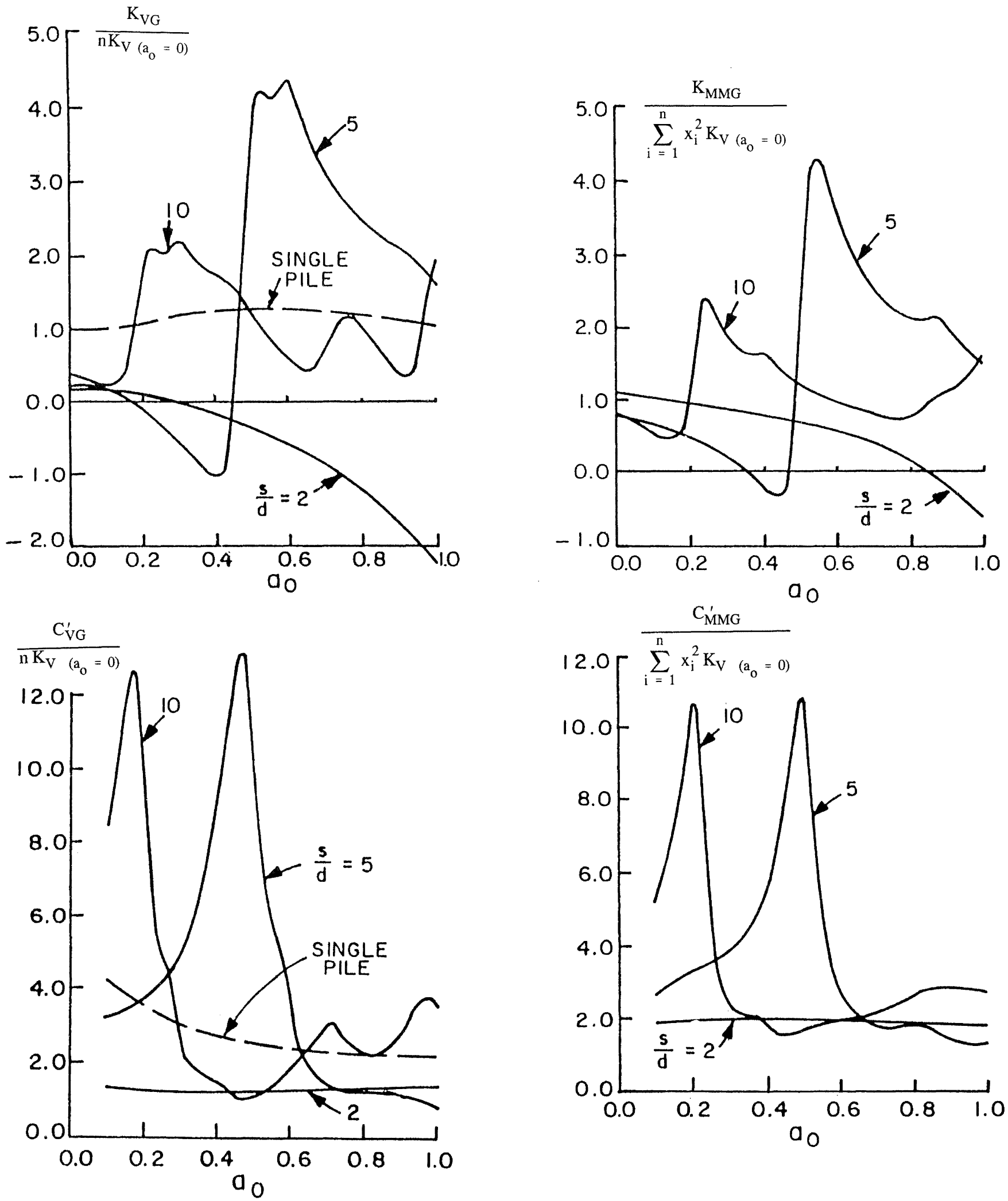

Fig. 8.27 Dynamic vertical stiffness and damping coefficients for a $4 \times 4$ fixed head pile group in homogeneous soil (after Kaynia and Kausel (1982)).

Fig. 8.28 Dynamic rocking stiffness and damping coefficients for a $4 x 4$ fixed head pile group in homogeneous soil (after Kaynia and Kausel (1982)). 

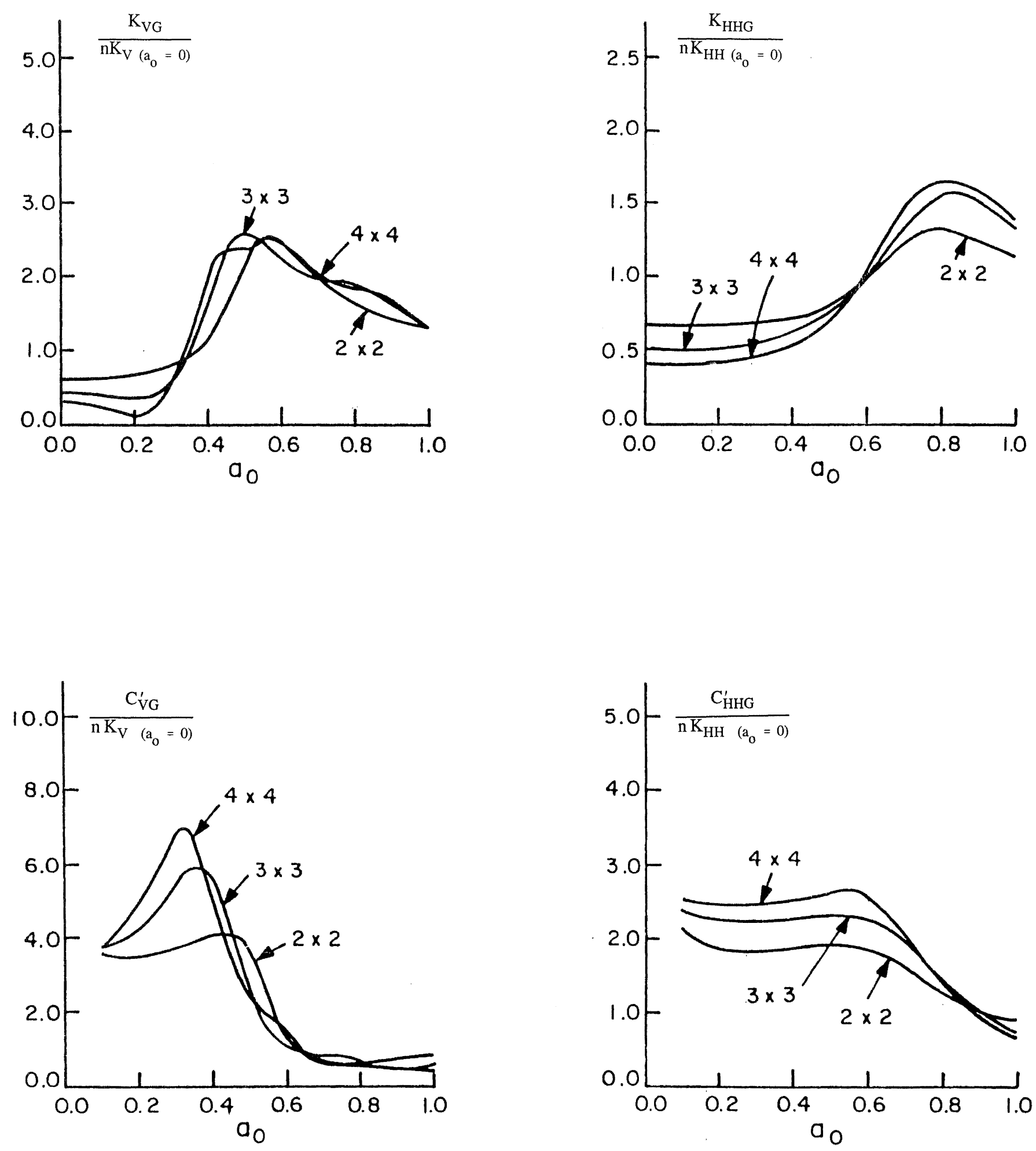

Fig. 8.29 Dynamic vertical stiffness and damping coefficients for a pile group with $s / D=5$ in homogeneous soil (after Kaynia and Kausel (1982)).

Fig. 8.30 Dynamic lateral stiffness and damping coefficients for a pile group with $s / D=5$ in homogeneous soil (after Kaynia and Kausel (1982)). 

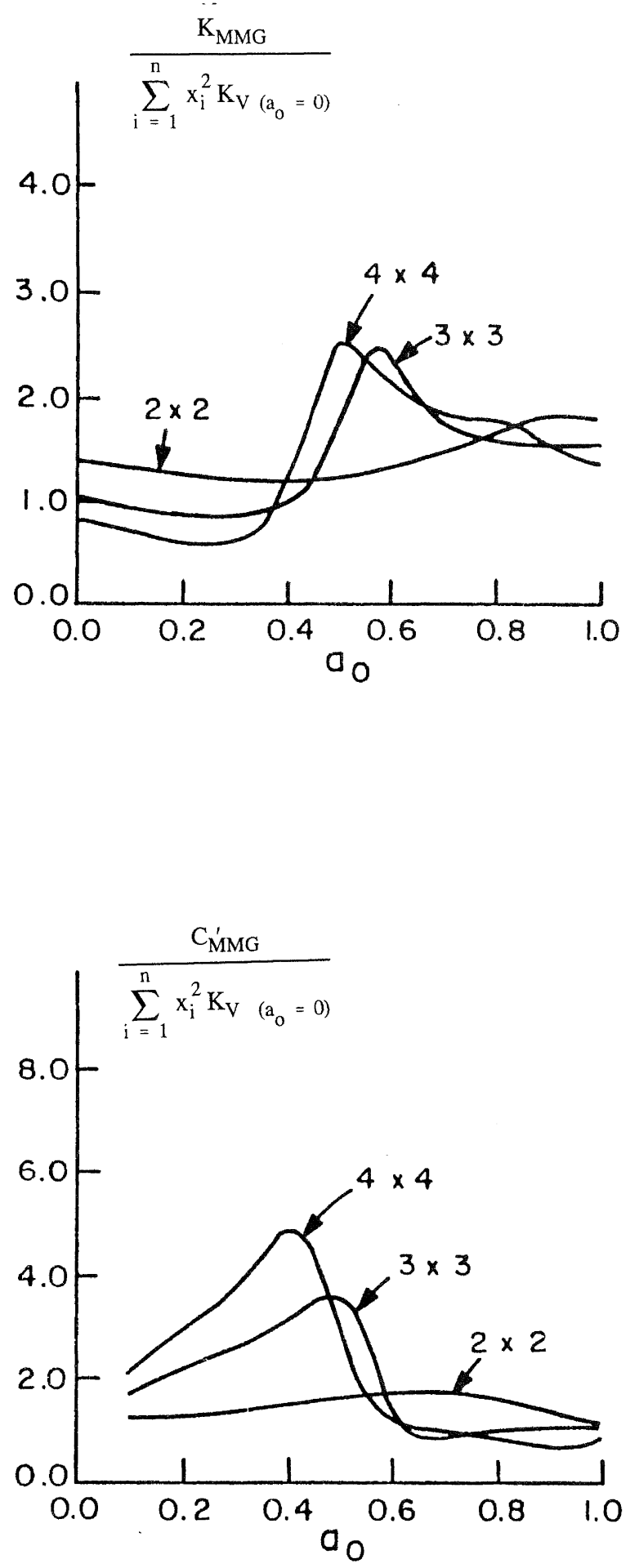

Fig. 8.31 Dynamic rocking stiffness and damping coefficients for a pile group with $s / D=5$ in homogeneous soil (after Kaynia and Kausel (1982)).

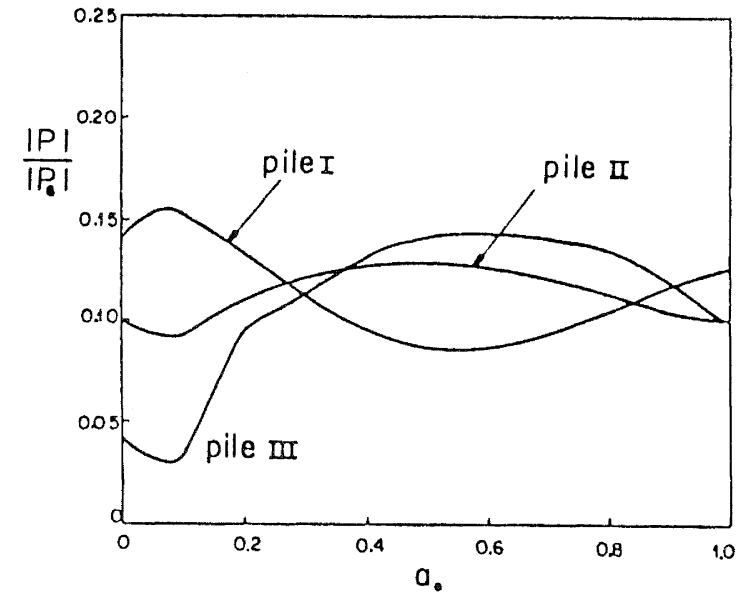

Fig. 8.32 Load distribution for a $3 \times 3$ group under vertical excitation $\left(K=10^{4}, s / D=4\right)$, pile I corner, pile II middle side, and pile III centre of the group (after Davies et al (1985)).

possible to get the response of large pile groups by superposition of solution derived for smaller numbers of piles.

Also the calculations show that the distribution of load among the piles of a group is not the same as for static loading. For static loading we found that the corner piles carried the greatest load and the centre piles the smallest, an illustration was given in Example 5.2. Computations of the dynamic response of pile groups do not show this. Load distributions calculated by Davies et al (1985) are given in Fig. 8.32. This deals with a $3 \times 3$ pile group under vertical excitation. The static case, $a_{0}=0.0$, has essentially the same result as example 5.2 despite the different $\mathrm{K}$ and $\mathscr{L}$ values. However, as $\mathrm{a}_{0}$ increases the forces become more uniformly distributed among the piles. When $\mathrm{a}_{\mathrm{o}}$ is about 0.3 and 1.0 the same load is carried by all piles in the group. This means that the approximation made in developing equation 5.12 is less serious for dynamically loaded pile groups than it is for the static case.

\subsubsection{Dynamic stiffness of pile groups}

Equations 8.3 and 8.5 introduce the impedence of a single pile. This is a complex quantity involving both stiffness and damping terms. The advantage of the complex approach is that it makes possible the use of any static pile group stiffness expression by simply substituting the complex stiffness for the static value and proceeding from there. Before we can do this though we need expressions for the dynamic interaction between the piles. These coefficients are given by Gazetas (1990), like the impedence they are complex numbers.

Makris and Gazetas (1992) give the following vertical interaction factor:

$$
\alpha_{\mathrm{z}}=\left(\frac{2 \mathrm{~s}}{\mathrm{D}}\right)^{-0.5}\left(\mathrm{e}^{-\beta \omega \mathrm{s} / \mathrm{V}_{\mathrm{s}}}\right)\left(\mathrm{e}^{-\mathrm{i} \omega \mathrm{s} / \mathrm{V}_{\mathrm{s}}}\right)
$$

For horizontal interaction Gazetas (1990) gives: 


$$
\begin{aligned}
& \alpha_{\mathrm{uH}}\left(90^{\circ}\right)=3 \alpha_{\mathrm{z}} / 4
\end{aligned}
$$

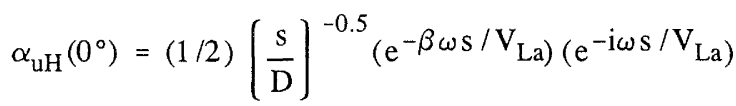

$$
\begin{aligned}
& \alpha_{\mathrm{uH}}(\theta)=\alpha_{\mathrm{uH}}\left(0^{\circ}\right) \cos ^{2} \theta+\alpha_{\mathrm{uH}}\left(90^{\circ}\right) \sin ^{2} \theta
\end{aligned}
$$

where: $\mathrm{V}_{\mathrm{La}} \quad$ is defined in equation 8.12.

For rocking interaction Gazetas(1990) gives the following:

$$
\alpha_{\theta \mathrm{H}} \approx 0 \quad, \quad \alpha_{\theta \mathrm{M}} \approx 0
$$

Gazetas (1990) also gives $\alpha_{\mathrm{v}}$ values for the linear and parabolic profiles, but declines to give expressions for $\alpha_{\mathrm{uH}}$ etc, thus we will restrict our consideration to constant modulus soil profiles.

Example 8.6 For the $2 \times 2$ pile group in example 5.1 at a pile spacing of 10 diameters evaluate the vertical impedance for the range of frequencies 0 and $10.0 \mathrm{~Hz}$. Take the density of the soil to be 2.0 tonne $/ \mathrm{m}^{3}$, Poisson's ratio to be 0.4 , and the material damping in the soil to be 0.05 .

The pile spacing is:

$\mathrm{s}=10 \times 0.75=7.5 \mathrm{~m}, \sqrt{2 \mathrm{~s}}=10.61 \mathrm{~m}$

From example $5.1 \mathscr{L}=26.7$ and $\mathrm{K}=1000$.

The shear wave velocity of the soil is:

$\mathrm{V}_{\mathrm{s}}=(25 \times 1000 / 2 \times(1+0.4) \times 2)^{0.5}=66.8 \mathrm{~m} / \mathrm{sec}$

(Note that we need to express the soil modulus in $\mathrm{kPa}$ to be consistent with the mass unit of tonnes.)

The static vertical stiffness of a single pile is evaluated in example 5.1 as $267.4 \mathrm{kN} / \mathrm{mm}$.

We will do a set of example calculations for a frequency of 5 $\mathrm{Hz}$, ie $\mathrm{a}_{\mathrm{o}}=0.35$.

$\omega=0.35 \times 66.8 / 0.75=31.2 \mathrm{rads} / \mathrm{sec}$.

From equation 8.11 we obtain:

$\mathrm{k}_{\mathrm{con}}=1+((26.7-15) / 35) \times(0.35)^{0.5}=1.20$

From equation 8.13:

$b=-1000 / 26.7^{2}=-1.403$

$r_{d}=1-e^{-1.403}=0.754$

Substituting these into equation 8.13:

$$
\begin{aligned}
C_{v} & =1.5 \times 0.35^{-0.2} \times 2 \times 66.8 \times 3.1416 \times 0.75 \times 20 \times 0.754 \\
& =8784.1
\end{aligned}
$$

From equation $8.5 \mathrm{~b}$ the vertical impedance of a single pile is:

$\mho_{\mathrm{V}}=267.4 \times 1.20+(31.2 \times 8784.1 / 1000) \mathrm{i}$
$=320.9+274.1 \mathrm{i} \mathrm{kPa} / \mathrm{mm}$

The interaction factors are obtained from equation 8.24. We need two values, for the pile spacing $\mathrm{s}$ and $\sqrt{2} \mathrm{~s}$.

For $\alpha_{\mathrm{v}(\mathrm{s})}$ the index for the first exponential in equation 8.24 is:

$$
0.05 \times 31.2 \times 7.5 / 66.8=0.175
$$

and for the second term:

$31.2 \times 7.5 / 66.8=3.50$

Recalling that: $r\left(e^{i x}\right)=r(\cos x+i(\sin x))(x$ is in radians $)$, we have:

$$
\begin{aligned}
\alpha_{\mathrm{v}(\mathrm{s})} & =(2 \times 10)^{-0.5} \times\left(\mathrm{e}^{-0.175}\right) \times\left(\mathrm{e}^{-3.50 \mathrm{i}}\right)=0.188 \mathrm{e}^{-3.50 \mathrm{i}} \\
= & 0.188 \times\{\cos (-3.50)-\mathrm{i}(\sin (-3.50))\} \\
= & -0.176+0.066 \mathrm{i}
\end{aligned}
$$

For $\alpha_{\mathrm{v}(\sqrt{2 \mathrm{~s}})}$ the index for the first exponential in equation 8.24 is:

$0.05 \times 31.2 \times 7.5 \times 1.414 / 66.8=0.248$

and $31.2 \times 7.5 \times 1.414 / 66.8=4.95$

Thus:

$$
\begin{aligned}
\alpha_{\mathrm{v}(\sqrt{2} \mathrm{~s})} & =(2 \times 10 \times 1.414)^{-0.5} \times\left(\mathrm{e}^{-0.248}\right) \times\left(\mathrm{e}^{-4.95}\right)=0.147 \mathrm{e}^{-4.95 \mathrm{i}} \\
& =0.035+0.143 \mathrm{i}
\end{aligned}
$$

To obtain the pile group vertical impedance we substitute these terms into equation 5.4. Equation 5.4 is:

$$
\mathrm{K}_{\mathrm{VG}}=4 \mathrm{~K}_{\mathrm{V}} /\left(1+2 \alpha_{\mathrm{v}(\mathrm{s})}+\alpha_{\mathrm{v}(\sqrt{2} \mathrm{~s})}\right)
$$

all that is now required is to substitute the complex form of the various terms in the equation calculated in this example. This gives:

$\mathbb{E}_{\mathrm{VG}}=4 \times(320.9+274.1 \mathrm{i}) /(0.683+0.273 \mathrm{i})$

This simplifies, after the appropriate operations, to:

$$
\mathbb{E}_{\mathrm{VG}(\mathrm{ao}=0.35)}=2174.0+736.4 \mathrm{i} \mathrm{kN} / \mathrm{mm}
$$

The value 736.4 in the this result is $C_{V G}^{\prime \prime}$ from equation $8.5 b$ having the units of stiffness.

Performing similar calculations for the other frequencies gives the results plotted in graphs on the next page, a for the real part of the impedance (stiffness) and $\mathbf{b}$ for the imaginary part (damping).

In the above plots the stiffnesses and damping values have been normalised with respect to the static pile group stiffness, that is the real part of $\mathfrak{E}_{\mathrm{VG}}$ when $\mathrm{a}_{0}=0.0$. Comparison of the above results with those in Fig. 8.29 (allowing for the fact that in the above graph the damping is $\mathrm{C}_{\mathrm{VG}}^{\prime \prime}$ whereas Fig. $8.29 \mathrm{C}_{\mathrm{VG}}^{\prime}$ is plotted) shows that the calculated curves have peaks and troughs 

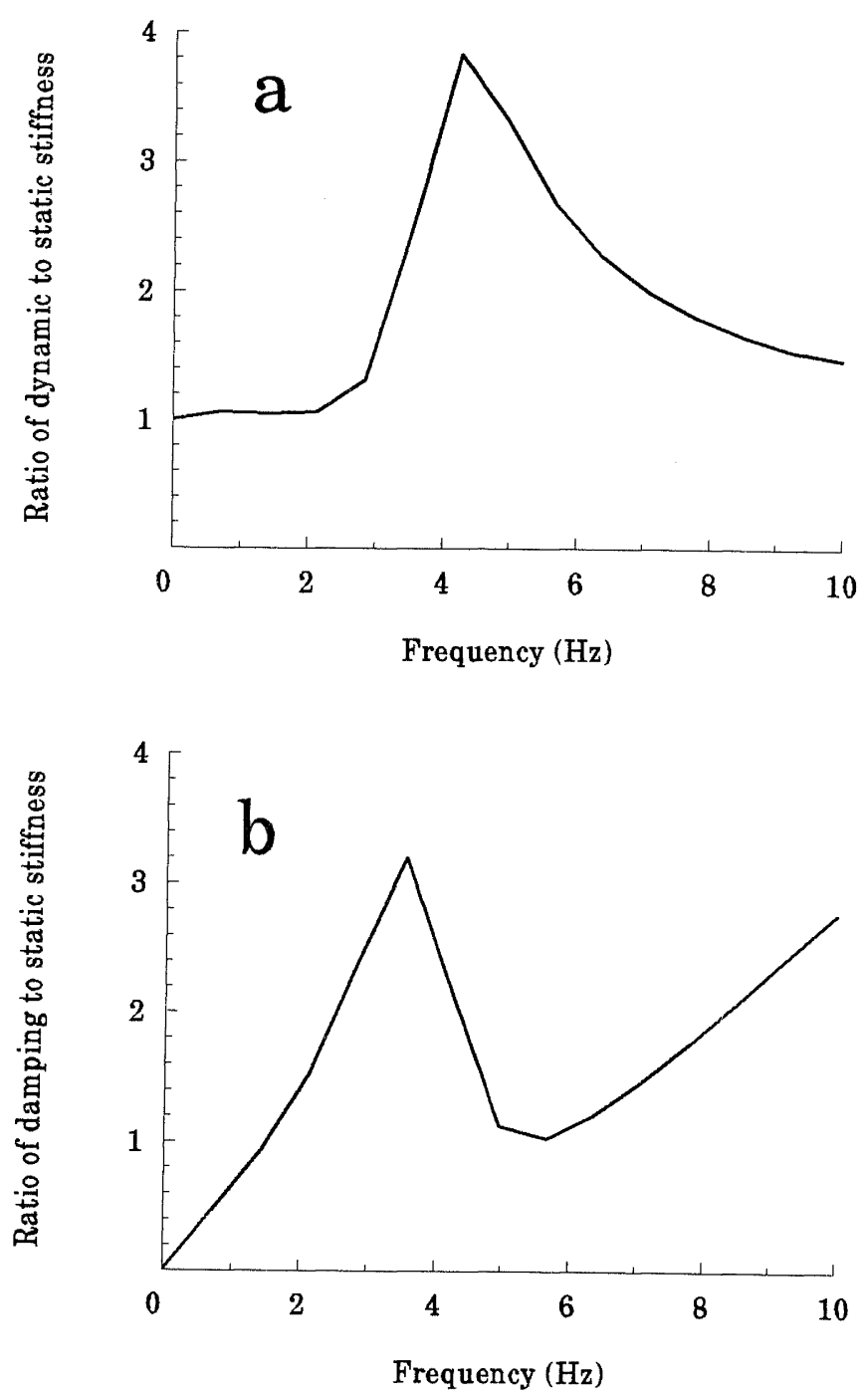

occurring at similar frequencies to those of Kaynia and Kausel (1985).

Example 8.7 Consider the same pile group as in example 8.6. Evaluate the amplitude of the cyclic displacement and rotation when the group is subjected to a sinusoidal shear of $\pm 1000 \mathrm{kN}$ and sinusoidal moment, in phase with the shear and about an axis parallel to the side of the group, of $\pm 1000 \mathrm{kNm}$. Use the same frequency range as in example 8.6. Also assume that the depth of the soil layer in which the piles are embedded is $30 \mathrm{~m}$.

As in example 8.6 we will do a set of calculations for $\mathrm{a}_{\mathrm{o}}=0.3$.

The initial calculations for this example are the same as those for example 8.6. In addition we need the velocity $\mathrm{V}_{\mathrm{La}}$ defined as part of equation 8.12 :

$\mathrm{V}_{\mathrm{La}}=3.4 \times 66.8 / 3.1216 \times 0.6=120.5 \mathrm{~m} / \mathrm{sec}$

We also need the natural frequency of the layer in which the piles are embedded. From equation 8.1:

$f_{1}=0.25 \times 66.8 / 30=0.6 \mathrm{~Hz}$.
The response of the pile group to the cyclic loading is controlled by the lateral and rocking stiffnesses of the pile heads as well as the rotational stiffness component that comes from axisymmetric vertical loading of the piles, $\mathrm{K}_{\theta \mathrm{V}}$.

From section 5 we have the following formula for the static value of this stiffness:

$$
\mathrm{K}_{\theta \mathrm{V}}=\mathrm{K}_{\mathrm{V}} \mathrm{s}^{2} /\left(1-\alpha_{\mathrm{v}(\sqrt{2} \mathrm{~s})}\right)
$$

To obtain the impedance of the group for this mode of deformation we insert the appropriate terms from example 8.6. This gives:

$\mathfrak{S}_{\theta \mathrm{V}}=7.5^{2} \times(320.9+274.1 \mathrm{i}) /(0.965-0.143 \mathrm{i})$

Performing the appropriate calculations gives:

$\aleph_{\theta \mathrm{V}}=15940+18340 \mathrm{i} \mathrm{kNm} / \mathrm{mrad}$.

Performing similar calculations for the other frequencies gives the results plotted in the diagrams at the top of the next page.

The next step is to evaluate the effective lateral and rotational impedances of the pile group, but prior to this preliminary calculations are needed for damping and interaction factors.

We will need the pile head damping values. For a soil profile having a constant Young's modulus with depth these are given in equation 8.8 and example calculations have been presented in example 8.2. The frequency associated with $\mathrm{a}_{0}=0.35$ is $5 \mathrm{~Hz}$, as this is greater than the natural frequency of the layer $\left(f_{1}=\right.$ $0.6 \mathrm{~Hz}$ ) we have both material and radiation damping. The values calculated are

$\zeta_{\mathrm{HH}}=0.238, \quad \zeta_{\mathrm{HM}}=0.204$ and $\zeta_{\mathrm{MM}}=0.095$

We need to evaluate the interaction coefficients so that the impedances can be evaluated. Working from equation 8.25 we need $\alpha_{\mathrm{uH}}\left(0^{\circ}\right)$ for the spacings $\mathrm{s}$ and $\sqrt{2 \mathrm{~s}}$. Firstly for the spacing $s$, the index for the first exponential term in the equation is:

$0.05 \times 31.2 \times 7.5 / 120.5=0.097$

and for the second term:

$31.2 \times 7.5 / 120.5=1.942$

Thus:

$$
\begin{aligned}
\alpha_{\mathrm{uH}(\mathrm{s})}\left(0^{\circ}\right) & =0.5 \times 10^{-0.5} \times\left(\mathrm{e}^{-0.097}\right) \times\left(\mathrm{e}^{-1.942 \mathrm{i}}\right)=0.143 \mathrm{e}^{-1.942 \mathrm{i}} \\
& =-0.052-0.133 \mathrm{i}
\end{aligned}
$$

Similarly:

$\alpha_{\mathrm{uH}(\sqrt{\mathrm{s}})}\left(0^{\circ}\right)=-0.107-0.045 \mathrm{i}$

Continuing with equation 8.25 we calculate $\alpha_{\mathrm{uH}}\left(90^{\circ}\right)$ from the vertical interaction factors evaluated in example 8.6:

$$
\begin{aligned}
& \alpha_{\mathrm{uH}(\mathrm{s})}\left(90^{\circ}\right)=0.75 \times(-0.176+0.066 \mathrm{i})=-0.132+0.050 \mathrm{i} \\
& \alpha_{\mathrm{uH}(\sqrt{\mathrm{s}})}\left(90^{\circ}\right)=0.75 \times(0.035+0.143 \mathrm{i})=0.026+0.107 \mathrm{i}
\end{aligned}
$$



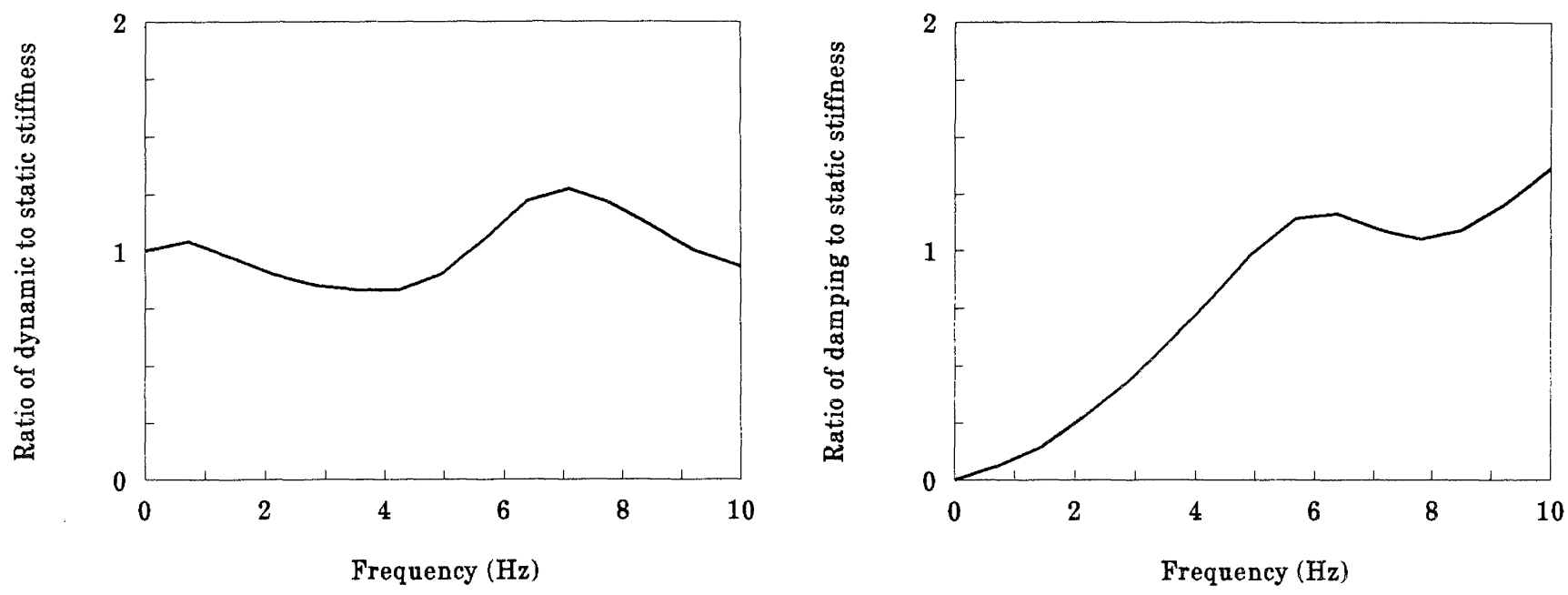

Rotational impedance $\mathfrak{S}_{\theta V}$ generated by asymmetric axial loading of the $2 x 2$ pile group analysed in example 8.7(Real part to the left and the imaginary part to the right).
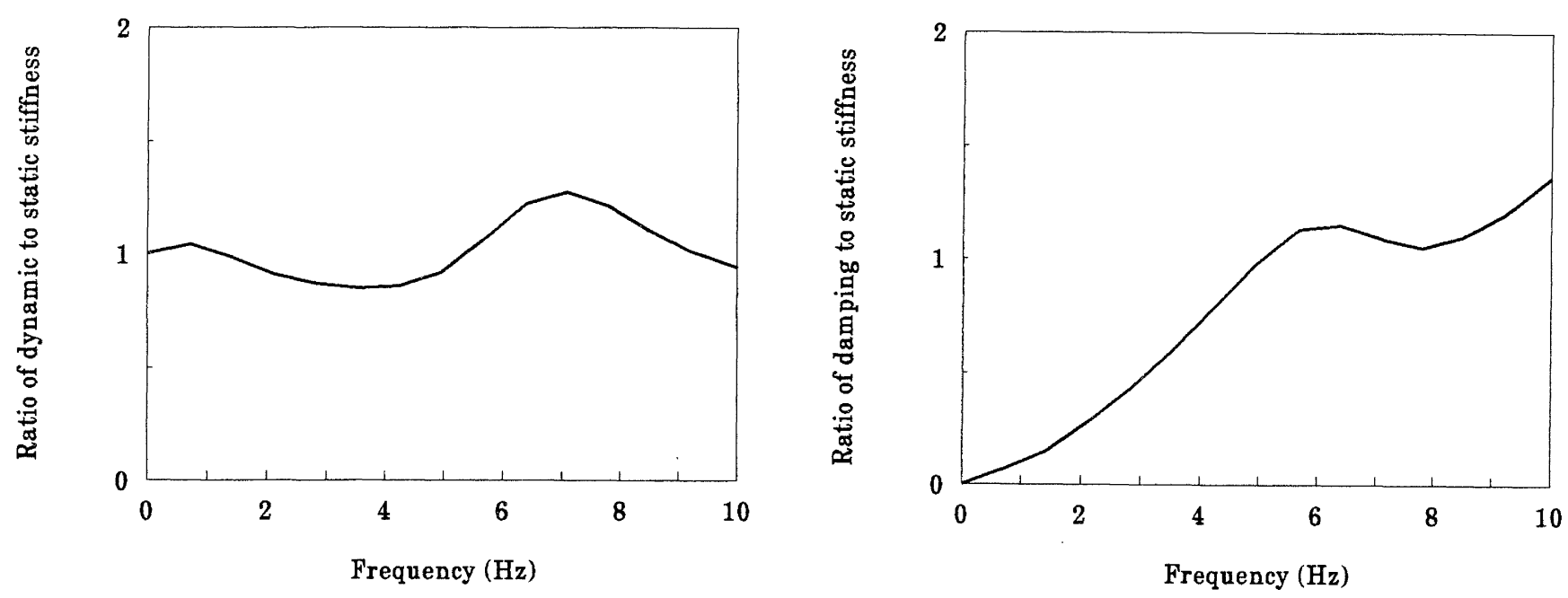

Rotational impedance, $\mho_{\theta G}$ of the $2 \times 2$ pile group analysed in example 8.7 (Real part to the left and the imaginary part to the right).
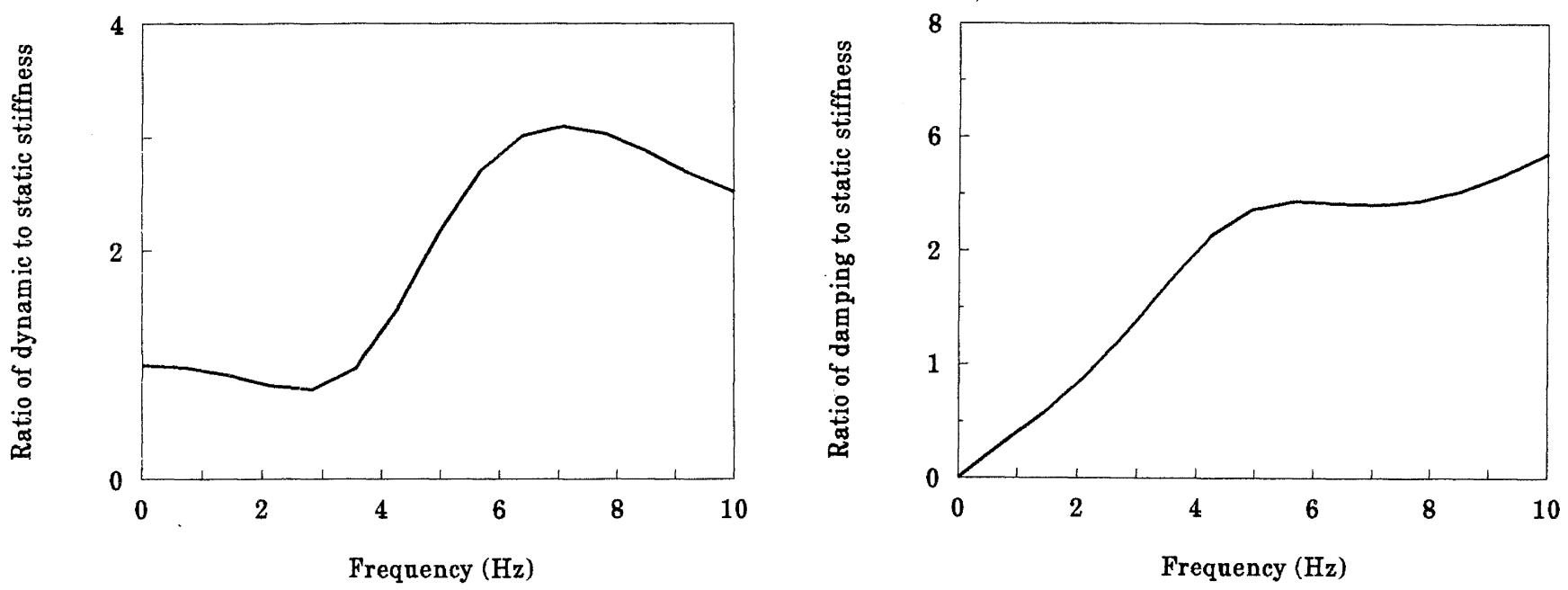

Lateral impedance, $\mathfrak{夭}_{h G}$ of the $2 \times 2$ pile group analysed in example 8.7 (Real part to the left and the imaginary to the right). 
Using the same pile numbering system as in example 5.5 (repeated in the diagram for example 8.8 two pages on from here) we have the following interaction factors:

$\alpha_{\mathrm{uH}}(1-2)=-0.052-0.133 \mathrm{i}$

$\alpha_{\mathrm{uH}}(1-4)=-0.132+0.050 \mathrm{i}$

Now the interaction between piles 1 and 3 involves a $45^{\circ}$ interaction angle, so from equation 8.25 we have:

$$
\begin{aligned}
\alpha_{\mathrm{uH}}(1-3) & =0.5 \times((-0.107-0.045 \mathrm{i})+(0.026+0.107 \mathrm{i})) \\
& =-0.040+0.031 \mathrm{i}
\end{aligned}
$$

We have the pile head flexibility coefficients from example 3.3 :

$\mathrm{f}_{\mathrm{uH}}=1.97 \times 10^{-2}, \mathrm{f}_{\theta \mathrm{H}}=6.75 \times 10^{-3}, \mathrm{f}_{\theta \mathrm{M}}=5.75 \times 10^{-3}$

We can now assemble the impedance matrix for the pile group using the complex version of equation 5.12. The flexibility matrix for each pile in the group (for a $2 \times 2$ group each pile is identical) is:

$$
\begin{aligned}
& \mathrm{F}_{\mathrm{HH}}=\mathrm{f}_{\mathrm{uH}}\left(1+\alpha_{\mathrm{uH}}(1-2)+\alpha_{\mathrm{uH}}(1-3)+\alpha_{\mathrm{uH}}(1-4)\right) \\
&=1.97 \times 10^{-2} \times(0.971-0.530 \mathrm{i})=0.0191-0.0104 \mathrm{i} \\
& \mathrm{F}_{\mathrm{HM}}=\mathrm{f}_{\mathrm{uM}}=6.75 \times 10^{-3}, \quad \text { (because of equation 8.26) } \\
& \mathrm{F}_{\mathrm{MM}} \quad=\mathrm{f}_{\theta \mathrm{M}}=5.75 \times 10^{-3} .
\end{aligned}
$$

To obtain the pile head stiffness matrix we need to invert the above flexibility matrix (following equation 3.40), the determinant of the flexibility matrix is:

$\Delta=4.232 \times 10^{-5}-6.045 \times 10^{-6} \mathrm{i}$

Now allowing for the fact that there are 4 piles in the group, and including the damping terms, we have the following for the components of the pile group impedance matrix (the calculations similar to those done in example 8.2):

$$
\begin{aligned}
\mathfrak{E}_{\mathrm{HHG}} & =4 \times(0.0191-0.0104 \mathrm{i}) \times(1+0.476 \mathrm{i}) / \Delta \\
& =496.4+329.9 \mathrm{i} \mathrm{kN} / \mathrm{mm} \\
\mathfrak{\Xi}_{\mathrm{HMG}} & =-4 \times 6.75 \times 10^{-3} \times(1+0.408 \mathrm{i}) / \Delta \\
& =-588.8-344.6 \mathrm{i} \mathrm{kNm} / \mathrm{mm} \\
\mathbb{E}_{\mathrm{MMG}} & =4 \times 5.75 \times 10^{-3} \times(1+0.190 \mathrm{i}) / \Delta \\
& =1410+376.8 \mathrm{i} \mathrm{kNm} / \mathrm{mrad} .
\end{aligned}
$$

From here we calculate the rotational and horizontal impedance of the pile group using the complex equivalents of equations 5.13 and 5.14:

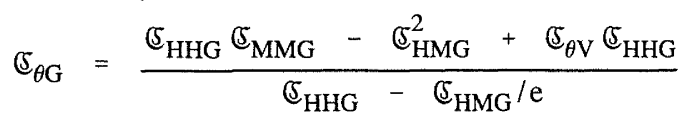

where: $\mathfrak{S}_{\theta \mathrm{G}}$ is the rotational impedance of the pile group.

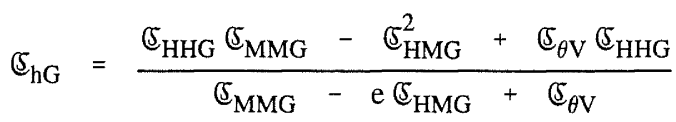

where: $\mathbb{c}_{\mathrm{hG}}$ is the horizontal impedance of the pile group.

Performing these calculations in much the same way as was done in example 8.2. Since $H=M$, we have $e=1$, and on sustitution we obtain:

$$
\begin{aligned}
& \Im_{\theta \mathrm{G}}=7505+8796 \mathrm{i} \mathrm{kNm} / \mathrm{mrad} \\
& \aleph_{\mathrm{hG}}=464.3+321.0 \mathrm{i} \mathrm{kN} / \mathrm{mm}
\end{aligned}
$$

Performing similar calculations for the other frequencies gives the results plotted in the middle graphs of the preceding page for $\varsigma_{\theta \mathrm{G}}$ and at the bottom of the page for $\S_{\mathrm{hG}}$. It is notable how the rotational stiffness is dominated by the contribution from $\mathbb{\Xi}_{\theta \mathrm{V}}$.

The next stage is to estimate the displacement and rotation amplitudes of the foundation. These are given by:

$$
\wp=\mathrm{H} / \mathfrak{\complement}_{\mathrm{hG}} \text { and } \Re=\mathrm{M} / \mathfrak{\Im}_{\theta \mathrm{G}}
$$

At $\mathrm{a}_{\mathrm{o}}=0.35$ the complex displacement under the $\pm 1000 \mathrm{kN}$ force is:

$\wp=1000 /(464.3+321.0 \mathrm{i})=1.46-1.00 \mathrm{i} \mathrm{mm}$

This converts to the following displacement amplitude:

$\mathrm{u}=\left(1.46^{2}+1.00^{2}\right)^{0.5}=1.77 \mathrm{~mm}$.

The complex rotation is:

$\Re=1000 /(7505+8796 \mathrm{i})=0.056-0.066 \mathrm{i} \mathrm{mrad}$.

The amplitude of the rotation is:

$\theta=\left(0.056^{2}+0.066^{3}\right)^{0.5}=0.086 \mathrm{mrad}$.

Performing similar calculations for the other frequencies gives the results plotted in the graphs below, a for the displacement and $\mathbf{b}$ for the rotation.

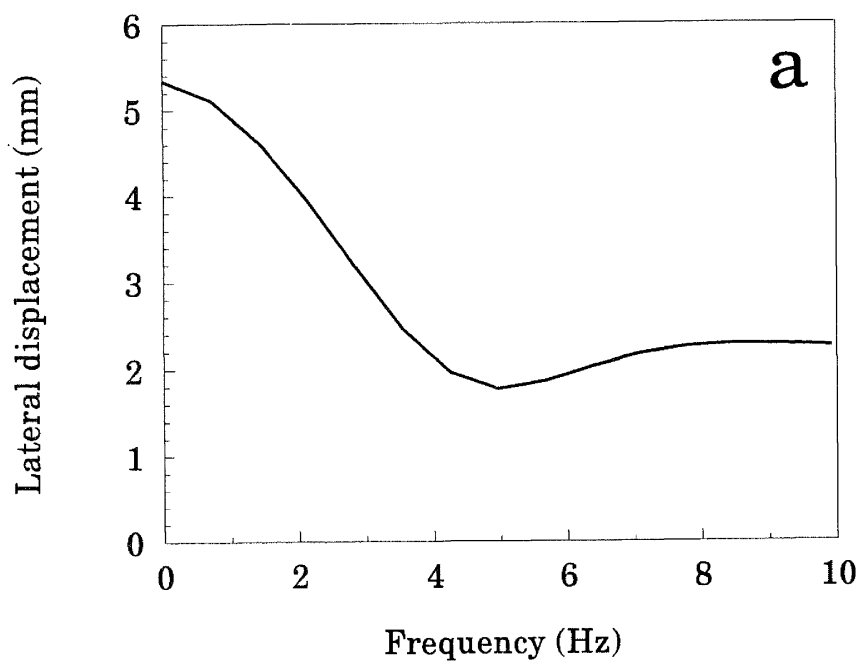




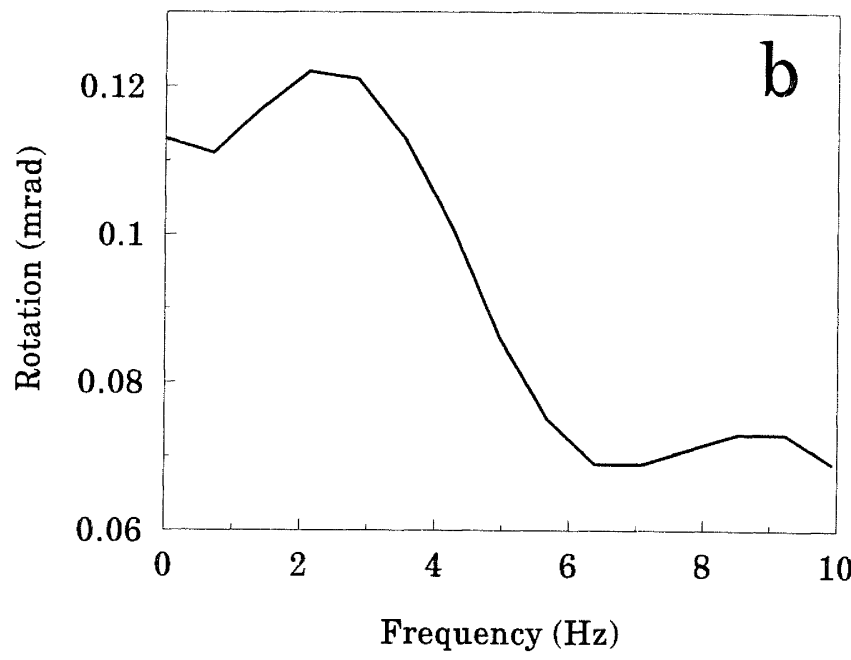

The diagrams show that the displacement and rotation decrease as the frequency increases. The values at zero frequency are the static displacements. Use of the method of example 5.8 for this pile group configuration gives displacements which are similar. The small differences are a consequence of different expressions for the static and dynamic interaction factors and because, for the dynamic case, $\alpha_{\theta \mathrm{M}}$ and $\alpha_{\theta \mathrm{M}}$ are zero.

Example 8.8 A simple "building" is shown in the diagram on the next page. The object of this example to estimate the displacements which will occur under the earthquake described by the response spectrum provided.

Since we are dealing with a constant modulus soil profile we will assume that kinematic effects are not significant, ie $\mathrm{I}_{\mathrm{u}}=$ 1.0 .

We will use a SDOF model for the structure and pile foundation shown as illustrated in Fig. 8.17. The structure is represented by a concentrated mass equal to $70 \%$ of the total mass and positioned at $70 \%$ of the height of the building.

The weight of the structure (assuming the roof loading is equivalent to that of a floor) is:

$\mathrm{W}=6 \times 8 \times 8.5^{2}=3468 \mathrm{kN}$.

The mass subject to the seismic excitation is:

$M=3468 \times 0.7 / 9.81=247.5$ tonnes.

The period of the structure is given as 0.5 seconds, consequently the stiffness of the structure is:

$\mathrm{k}_{\mathrm{s}}=(2 \times 3.1416)^{2} \times 247.5 / 0.5^{2}=39.1 \mathrm{kN} / \mathrm{mm}$

The major question that must be resolved before the response spectrum can be used to estimate the displacements of the structure under the earthquake is natural period of the SDOF model. The frequency dependence of the stiffness components for the pile foundation plotted in Fig. 8.7 means that it not immediately apparent that a natural period exists for the SDOF model. We will proceed by first evaluating the impedance for the SDOF model by recasting the complex equivalent of equation 8.16 in terms of stiffnesses and masses. We will then calculate the response curve for harmonic excitation of the model. A peak in the response curve will then indicate the natural period of the system.

Reorganisation of equation 8.16 gives the impedance of the SDOF model:

$$
\mathfrak{\Im}_{\mathrm{SDOF}}=\frac{\mathfrak{夭}_{\mathrm{s}}}{1+\frac{\mathfrak{\mho}_{\mathrm{s}}}{\mathfrak{夭}_{\mathrm{hG}}}+\frac{\mathrm{h}^{2} \mathfrak{\mho}_{\mathrm{s}}}{\mathfrak{E}_{\theta \mathrm{G}}}}
$$

In this equation $\mathrm{h}$ is $70 \%$ of the building height:

$\mathrm{h}=0.70 \times 5 \times 3.5=12.25 \mathrm{~m}$.

The impedance of the structure, at $\mathrm{a}_{0}=0.35$, is:

$\widehat{\subseteq}_{\mathrm{s}}=39.1 \times(1+2 \times 0.05 \mathrm{i})=39.1+3.9 \mathrm{i} \mathrm{kN} / \mathrm{mm}$

Substituting into the above equation, using some the impedance terms calculated in example 8.7 gives:

$\mathfrak{E}_{\mathrm{SDOF}}=29.4+8.3 \mathrm{i} \mathrm{kN} / \mathrm{mm}$

The real and imaginary components of these impedances are plotted against frequency in the following diagrams. The variation of the stiffness (real part of the impedance) with frequency is most interesting. The substantial frequency dependence evident in example 8.7 in the plots for the component stiffnesses of $\mathbb{E}_{\mathrm{SDOF}}$ is very nearly eliminated.
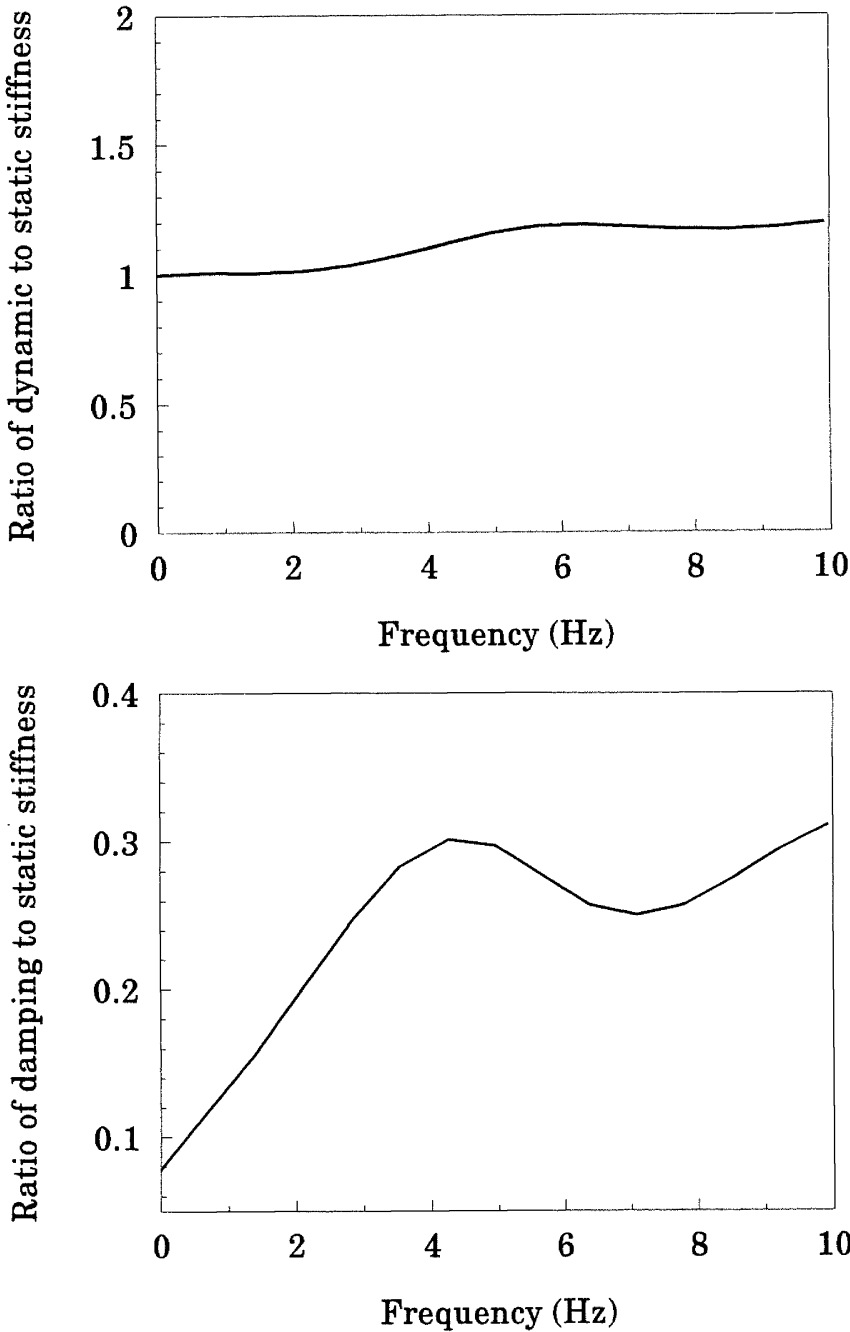


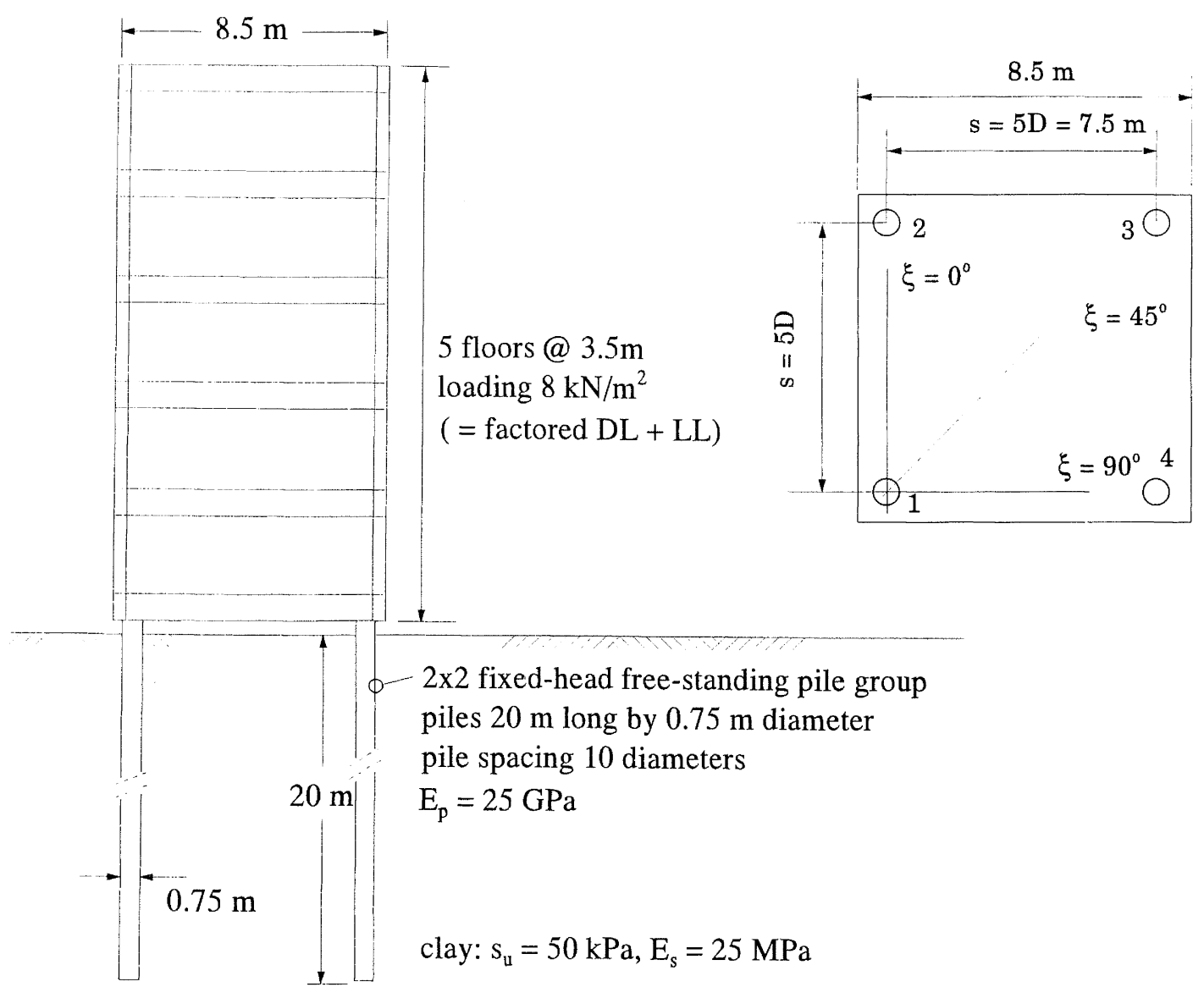

Details of the "building" supported on a $2 \times 2$ pile group foundation for example 8.8

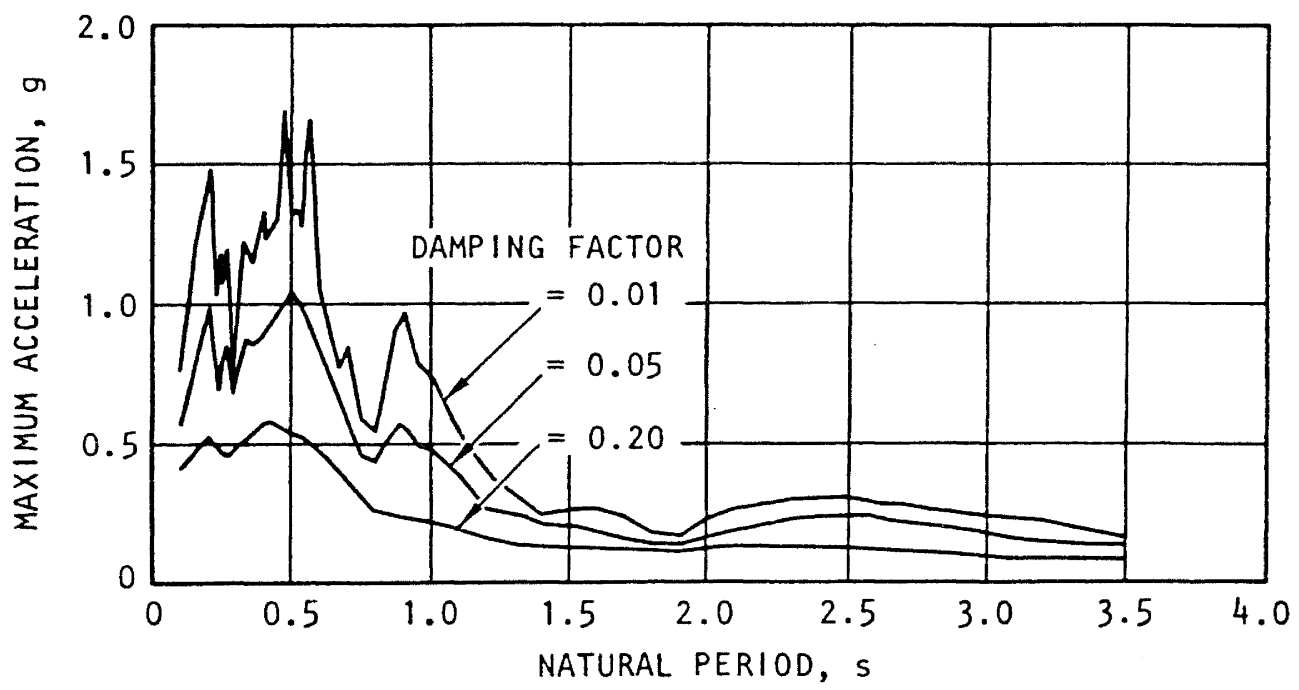

The response spectrum for use with example 8.8 . 
Having obtained the impedance we can estimate the amplification at various frequencies. This is done by expressing the displacement in terms of stiffness and mass:

$$
\wp=\frac{1000 \mathrm{H}}{1000 \widetilde{E}_{\mathrm{SDOF}}-\mathrm{M} \omega^{2}} \quad(\mathrm{~mm})
$$

A factor of 1000 occurs twice in the above equation, on the bottom line to convert the impedance to $\mathrm{kN} / \mathrm{m}$, which is required for consistency with the mass unit of tonnes, and on the top line to convert the displacement to $\mathrm{mm}$.

The calculated displacement amplitude, normalised with respect to the amplitude at the zero frequency, is plotted in the following diagram. In addition the response calculated for the building fixed to a rigid foundation is plotted. It is clear that the foundation compliance deceases the natural frequency (lengthens the period) of the system and the damping available from the foundation decreases the amplification experienced by the lumped mass positioned at 0.7 of the height of the "building".

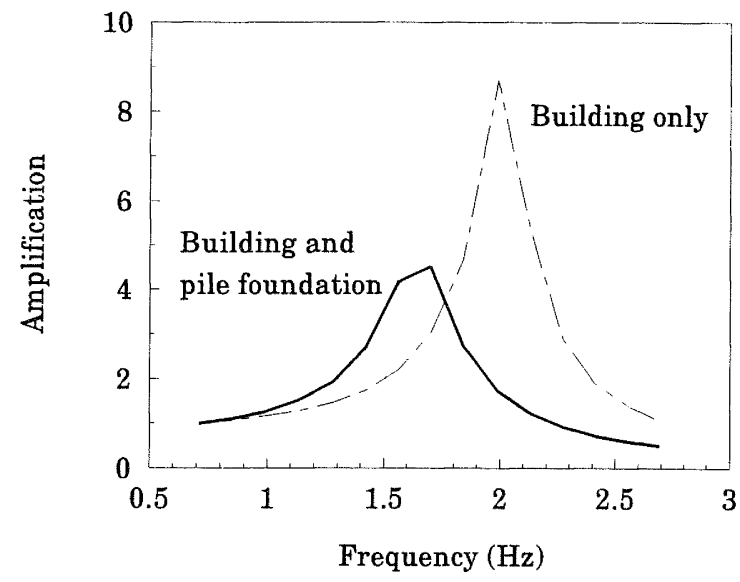

A clear natural frequency at $1.56 \mathrm{~Hz}\left(\mathrm{~T}_{\mathrm{n}}=0.64\right.$ secs., $\omega=$ $9.80 \mathrm{rads} / \mathrm{sec}$.) is apparent with a peak amplification of 4.49 . The effective damping, calculated from the peak value of the amplification is:

$\zeta_{\text {SDOF }}=(2 \times \text { Peak amplification })^{-1}=1 / 2 \times 4.49=0.11$

At the natural frequency the impedance of the SDOF model of the building is:

$\mathfrak{S}_{\mathrm{SDOF}}=25.11+4.35 \mathrm{i} \mathrm{kN} / \mathrm{mm}$

We are now in a position to use the response spectrum to estimate the displacement of the lumped mass in the SDOF structure. From the diagram on the previous page the spectral acceleration corresponding to period of 0.64 seconds and damping of 0.11 is estimated at $0.45 \mathrm{~g}$. This will generate a horizontal force at the lumped mass of:

$\mathrm{H}=0.45 \times 9.81 \times 247.5=1093 \mathrm{kN}$

With this the complex displacement of the mass is:

$$
\begin{aligned}
\wp & =\frac{1000 \times 1093}{1000 \times(25.11+4.35 \mathrm{i})-247.5 \times 9.8^{2}} \\
& =70.7-229.5 \mathrm{i}(\mathrm{mm})
\end{aligned}
$$

From this the magnitude of the maximum displacement of the mass is:

$u_{\max }=\left(70.7^{2}+229.5^{2}\right)^{0.5}=240 \mathrm{~mm}$.

This completes the example. Possibly the most interesting aspect of this is the way in which the effective stiffness of the system (the real part of the impedance) shows so little frequency dependence whilst the various components plotted in example 8.7 show significant variations.

Example 8.9 Repeat example 8.8 using the static stiffness of the various elements of the SDOF model.

Example 8.8 estimated the displacement of the structure using the impedance. The motivation for that approach was uncertainty about the natural frequency of a system having frequency dependent stiffness and damping. Now that the effective stiffness of the SDOF structure has been found to be relatively frequency independent it is of interest to estimate the displacements using the static stiffnesses.

From the calculations done for examples 8.7 and 8.8 we have the mass is 247.5 tonnes at a height of $12.25 \mathrm{~m}$, the static stiffnesses, and also the damping values. These are:

$\mathrm{k}_{\mathrm{s}}=39.1 \mathrm{kN} / \mathrm{mm}, \quad \zeta_{\mathrm{s}}=0.05$,

$\mathrm{K}_{\mathrm{hG}}=165.6 \mathrm{kN} / \mathrm{mm}, \zeta_{\mathrm{hG}}=0.29$, and

$\mathrm{K}_{\theta \mathrm{G}}=17600 \mathrm{kNm} / \mathrm{mrad}, \zeta_{\theta \mathrm{G}}=0.09$.

We need the following ratios:

$\mathrm{k}_{\mathrm{s}} / \mathrm{K}_{\mathrm{hG}}=39.1 / 165.6=0.236$

$\mathrm{h}^{2} \mathrm{k}_{\mathrm{s}} / \mathrm{K}_{\theta \mathrm{G}}=12.25^{2} \times 39.1 / 17600=0.333$

$(1+0.236+0.333)=1.569$

The static stiffness of the SDOF model, using equation 8.17 rearranged to give stiffness rather than $\omega$, is:

$\mathrm{k}_{\mathrm{SDOF}}=39.1 / 1.569=24.9 \mathrm{kN} / \mathrm{mm}$

The natural frequency of the SDOF model is:

$\omega_{\text {SDOF }}=(24.9 \times 1000 / 247.5)^{0.5}=10.03 \mathrm{rads} / \mathrm{sec}=1.60 \mathrm{~Hz}$

From this the natural period is 0.63 secs. (in example 8.8 we obtained 0.64 seconds).

The damping value, obtained with the use of equation 8.17 , is

$\zeta_{\text {SDOF }}=(0.05+0.29 \times 0.236+0.333 \times 0.09) / 1.569=0.09$

Interpolation from the response spectrum is unable to distinguish between 0.64 secs. and 0.11 for the damping and 0.63 secs. and 0.09 for the damping. Thus the spectral acceleration is the same as that used in example 8.8: $0.45 \mathrm{~g}$. The maximum displacement of the mass is obtained by first determining the static displacement and then the dynamic amplification. Firstly the static displacement: 
$u_{\text {static }}=0.45 \times 9.81 \times 247.5 / 24.9=43.9 \mathrm{~mm}$

The amplification at the natural period is:

$1 / 2 \times 0.09=5.6$

Thus the maximum displacement of the mass is:

$\mathrm{u}_{\max }=5.6 \times 43.9=246 \mathrm{~mm}$.

This is very close to the value obtained in example 8.8. It has been obtained with significantly less effort than in example 8.8 . Perhaps the contrast between the apparent effort underlying the calculations of examples 8.8 and 8.9 is misleading as the stiffness information was imported directly into example 8.9 , as was the knowledge of the natural period so the frequency at which to calculate damping was known.

Thus we conclude that, for the structure with a $2 \times 2$ pile group foundation considered in example 8.8 , use of the frequency independent static stiffness gives a satisfactory estimate of the maximum displacement. The main reason for this is the "flatness" of the variation of the stiffness of the single degree of freedom model of the building with frequency. A parametric study would be required to confirm this conclusion for a wider range of pile group configurations, soil profiles, and building heights.

\subsubsection{Final comments}

We end this section with the potentially useful conclusion that the daunting nature of Figs. 8.26 to 8.31 might not after all be such a source of complexity in estimating the seismic response of pile group foundations. This comment has to be tentative at this stage as verification is required for a range of building configurations and soil profiles.

Possibly the result of example 8.8 offers some insight into the relative lack of frequency dependence for the pile group foundation of the Imperial County Services Building, Hall (1984) and Fig. 8.4. The foundations for this structure consisted of a pile group beneath each column as well as the larger group of foundation elements supporting the columns and shear walls of the building. The response plotted in Fig. 8.2 is relatively insensitive to frequency just as is the stiffness calculated for the SDOF model in example 8.8. This frequency independence may be a consequence of the lack of constraint of the pile foundations. Figures 8.26 to 8.31 refer to the components of the pile group impedance matrix, consequently each quantity plotted in the figures is subject to particular constraints. The displacement of the pile group foundation in example 8.8 (and for the Imperial County Services pile group?) is derived from interactions of the various impedance matrix components. Some cancelling of peaks and troughs is thus possible.

Example 8.2 illustrates how sensitive the response of a pile is to the damping. The calculations suggest that the values given by Gazetas, and reproduced in equation 8.8 , are on the conservative side as $\zeta_{\mathrm{HH}}$ and $\zeta_{\mathrm{MM}}$ had to be increased by $30 \%$ to get a good match of the observed response curve.

\subsection{CAPACITY OF PILE FOUNDATIONS}

\subsection{Vertical capacity}

\subsubsection{Preliminary comments}

It is usual to distinguish between piles in sands and piles in clays. This suggests the distinction between short term and long term behaviour, in particular the difference in the response of a pile to a long term static load and that to a short term dynamic load such as earthquake or wind. This subdivision between the type of soil in which a pile is embedded can be further divided by the method of pile installation: driven or cast in situ.

The design of a pile foundation requires that the base resistance and the shaft resistance be evaluated. This is usually done on the basis of some estimate of the soil type and soil properties. The properties being determined either by taking specimens and laboratory testing or by inference from some in situ test, most commonly a penetrometer test. In Holland and Belgium the use of the cone penetration test is well developed for the direct assessment of pile capacity in sands and silts. A recent statement of the state-of-the-art of this technique is given by Verbrugge(1986)

The ultimate vertical load capacity of a pile is realised when all the shaft resistance and all the base resistance have been mobilised. Load tests have been done in which the load carried by the pile base is measured separately from the load carried by the shaft. A typical set of results is shown in Fig. 9.1.

The important feature in Fig. 9.1 is the very stiff response of the shaft resistance in comparison with the relatively soft response of the base. Typically the shaft resistance is mobilised at vertical displacements of a few per cent of the shaft diameter, whereas considerably larger displacements are needed to mobilise the base resistance. The relative contributions of the base and shaft resistance to the ultimate vertical capacity of a pile in homogeneous soil depend on the length to diameter ratio.

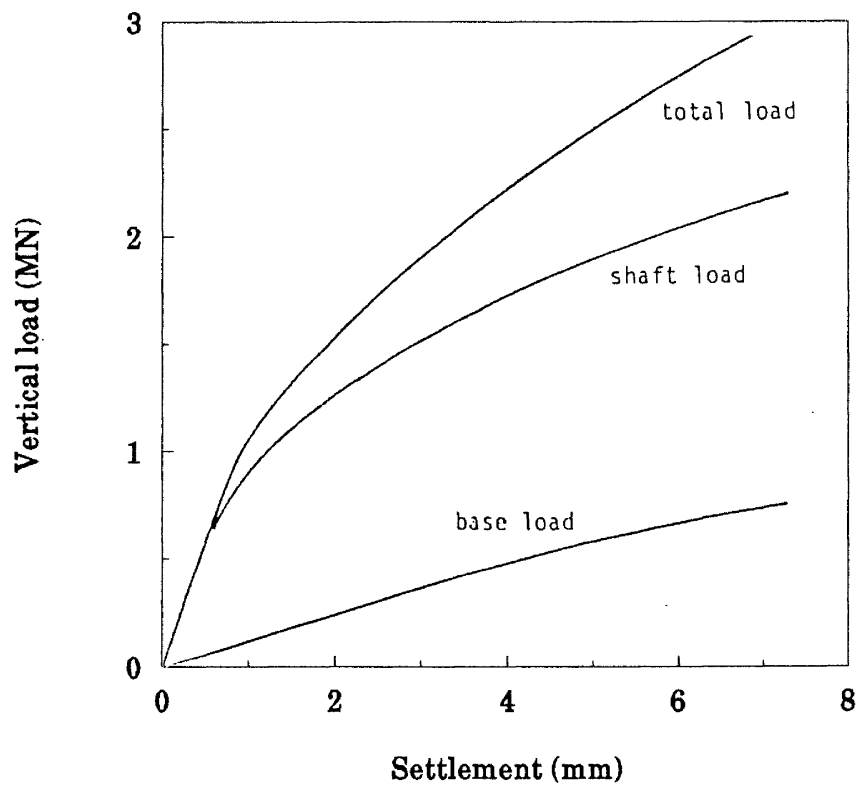

Fig. 9.1 Development with head settlement of shaft and base resistance for a pile with straight sides. 
If the pile is end bearing the base resistance will be more significant.

The ultimate capacity of a pile, $V_{u}$, is the sum of these two components less the pile weight:

$$
\mathrm{v}_{\mathrm{u}}=\mathrm{V}_{\mathrm{su}}+\mathrm{V}_{\mathrm{bu}}-\mathrm{W}
$$

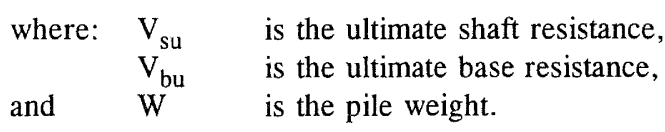

9.1.2 Shaft resistance for piles in clay

\section{Short term loading}

The traditional approach has been to use an empirical relation between the undrained shear strength of the clay and the shaft adhesion. A range of data is summarised by Poulos and Davis(1980), more data seems to be available for driven piles than for bored piles. Using this idea the shaft resistance is derived from:

$$
\mathrm{V}_{\mathrm{su}}=\int_{0}^{\mathrm{L}} \mathrm{Cc} \mathrm{a} \mathrm{dz}
$$

where: $C$ is the circumference of the pile shaft,

and $\quad c_{a}$ is the adhesion, which depends on the undrained shear strength of the clay.

Some information given by Poulos and Davis shows that the adhesion for a driven pile is a greater proportion of the undrained shear strength than it is for a bored pile. This is not surprising as there would be substantial reconsolidation of the clay adjacent to the shaft of a driven pile. For soft clays this effect outweighs the remoulding that occurs during driving as can be seen from Fig. 9.2 which suggests that the adhesion is equal to the undrained shear strength for clays with $\mathrm{s}_{\mathrm{u}}$ less than $25 \mathrm{kPa}$.

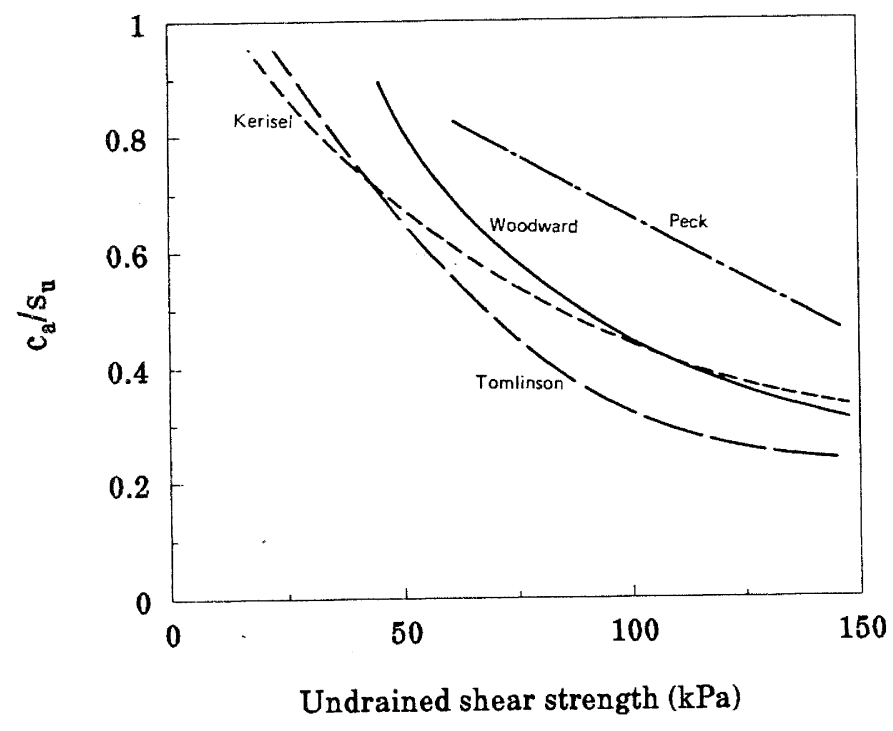

Fig. 9.2 A selection of adhesion factors for driven piles in clay (after Poulos and Davis (1980)).
Semple and Rigden(1984) propose that the adhesion is a function of the ratio of the undrained shear strength to the vertical effective stress at a given depth as well as the length to diameter ratio of the pile:

$$
\mathrm{c}_{\mathrm{a}}=\alpha \mathrm{f}_{\alpha} \mathrm{s}_{\mathrm{u}}
$$

where: $\alpha$ is the adhesion coefficient, and $\quad f_{\alpha}$ is a length factor.

Semple and Rigden's values for these coefficients are given in Fig. 9.3 from which it is apparent that the adhesion is reduced when the undrained shear strength is larger than about half of the vertical effective stress and when the pile length to diameter ratio is large.

\section{Long term loading}

An effective stress analysis is clearly the preferred approach in this situation. One approach has been suggested by Burland(1973). This requires knowledge of the coefficient of earth pressure at rest, $K_{0}$, for the soil. This is readily estimated for normally consolidated clays, $1-\sin \phi^{\prime}$, but there are difficulties with overconsolidated clays as the overconsolidation ratio is required for the usual approximation: $\mathrm{K}_{\mathrm{o}}=(1$ -

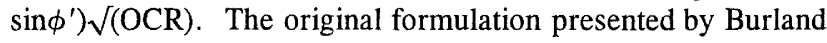
was for bored piles, it assumes that the installation of the pile has no long term effect on the in situ horizontal effective stress in the ground. For driven piles this is not the case as the thrusting aside of the soil during the driving process will increase the long term horizontal effective stresses.
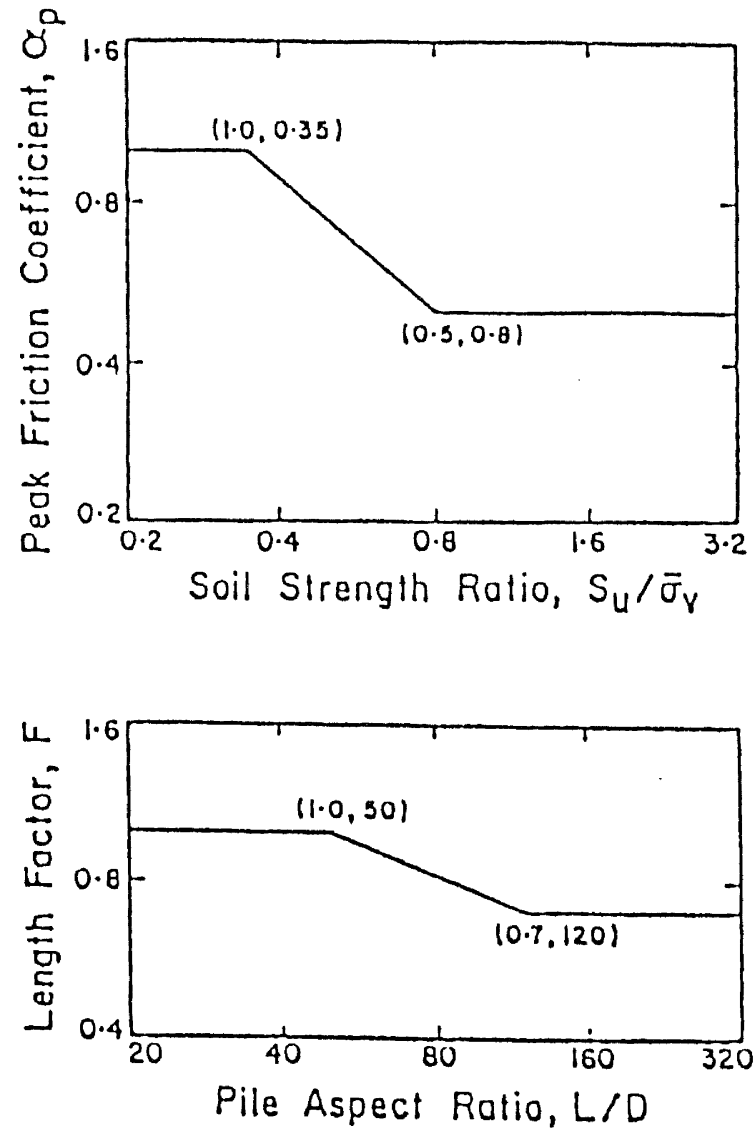

Fig. 9.3 Prediction of pile shaft adhesion in clay (after Semple and Rigden (1984)). 


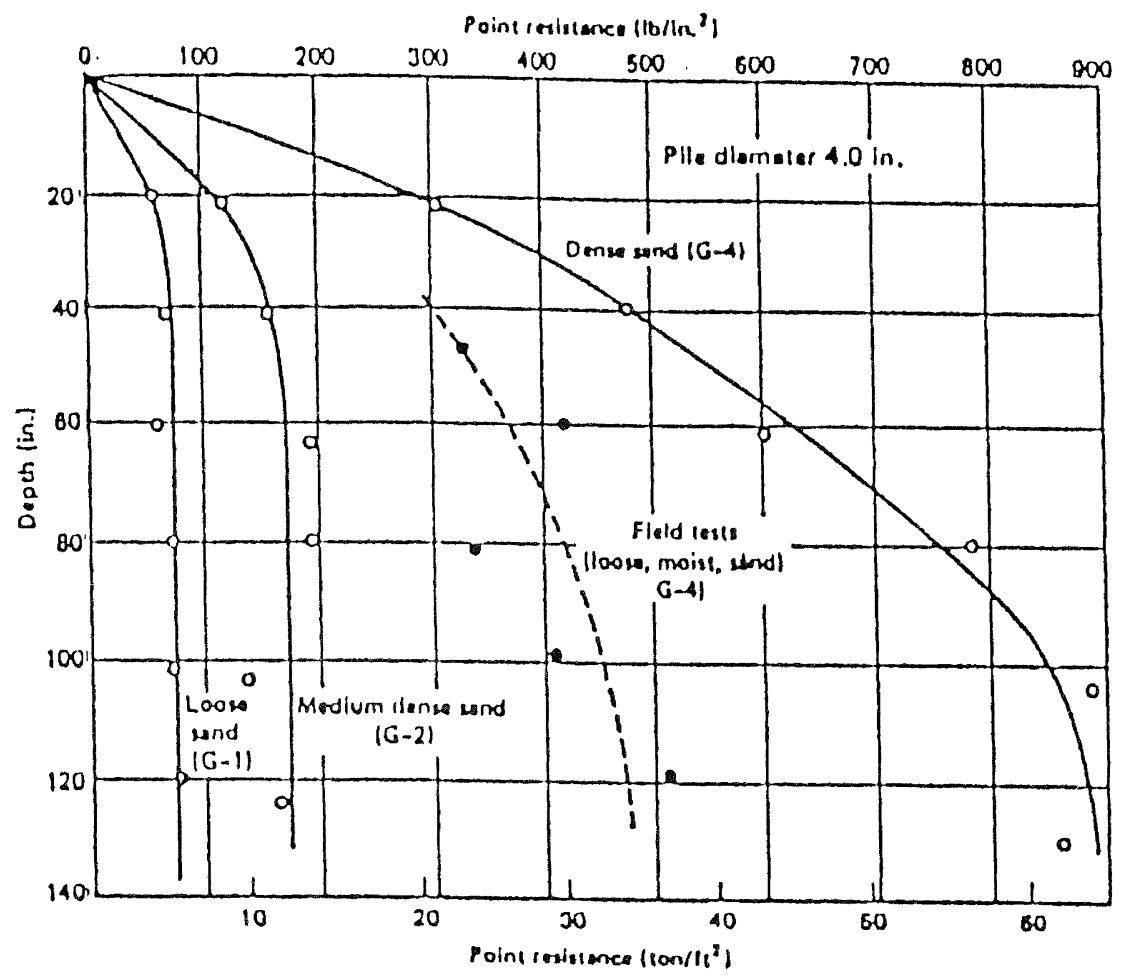

Fig. 9.4 Variation of pile point resistance with depth in dense and loose sand.

Studies of the change in pile capacity with time after driving show an almost universal tendency for an increase, usually referred to as "set-up". This is a consequence of the long term increase in horizontal effective stress mentioned in the above paragraph. Examples are given in the paper by Samson and Authier(1986). Thus the estimate given by the use of equations 9.1 and 9.2 can be taken as a lower bound on the long term drained shaft capacity.

\subsubsection{Shaft capacity for piles in sand}

Effective stresses control both the short term and long term behaviour. This requires information about the friction angle of the sand, or more correctly the angle of friction at the sand pile interface, and the in situ horizontal effective stresses in the ground. A range of correlations exist to relate Standard Penetration Resistance to friction angle. The interpretation of Cone Penetrometer results is now regarded as a more reliable method of achieving this. For dense sands the paper by Lunne and Christoffersen(1983) is one example of many that deal with the relation between CPT resistance and friction angle. Having obtained the friction angle of the sand it is still necessary to obtain the in situ horizontal effective stress. This might be done for a loose sand by using $\left(1-\sin \phi^{\prime}\right) \sigma_{\mathrm{v}}^{\prime}$, for a dense sand the value of $\mathrm{K}_{\mathrm{o}}$ is greater, just as for overconsolidated clays, some suggestions are given by Kulhawy and Mayne (1990).

The shaft resistance is estimated from:

$$
\mathrm{V}_{\mathrm{su}}=\int_{0}^{\mathrm{L}} \mathrm{C} \sigma_{\mathrm{v}}^{\prime} \mathrm{K}_{\mathrm{s}} \tan \phi_{\mathrm{a}}^{\prime} \mathrm{dz}
$$

where: $\mathrm{K}_{\mathrm{s}} \quad$ is a factor that converts the vertical effective stress to the horizontal effective stress at the pile soil interface,

and $\quad \phi_{\mathrm{a}^{\prime}} \quad$ is the interfacial friction angle.

The product $\mathrm{K}_{\mathrm{s}} \tan \phi_{\mathrm{a}^{\prime}}$ is known to increase with friction angle (or with penetration resistance).

The following suggested values for $\mathrm{K}_{\mathrm{s}}$ are given by Tomlinson (1986):

\begin{tabular}{|c|c|c|c|}
\hline Pile mater'l & $\phi_{\mathrm{a}}{ }^{\prime}$ & low $\mathrm{D}_{\mathrm{r}}$ & high $\mathrm{D}_{\mathrm{r}}$ \\
\hline steel & $20^{\circ}$ & 0.5 & 1.0 \\
\hline concrete & $3 \phi / 4$ & 1.0 & 2.0 \\
\hline timber & $2 \phi / 3$ & 1.5 & 4.0 \\
\hline
\end{tabular}

The difficulties of obtaining the soil parameters for the insertion into equation 9.4 are circumvented by the use of a direct method for estimating pile capacity based on cone penetration resistance such as that presented by Verbrugge(1986).

\subsubsection{Base resistance of piles in clay}

This is a deep bearing capacity situation. In the short term case the value of $\mathrm{N}_{\mathrm{c}}$ is set at 9.0 for depths greater than 4 pile diameters (this also sets the criterion for a deep foundation).

The effective stress case, long term, also uses the limiting value of 9.0 for $\mathrm{N}_{\mathrm{c}}$. 

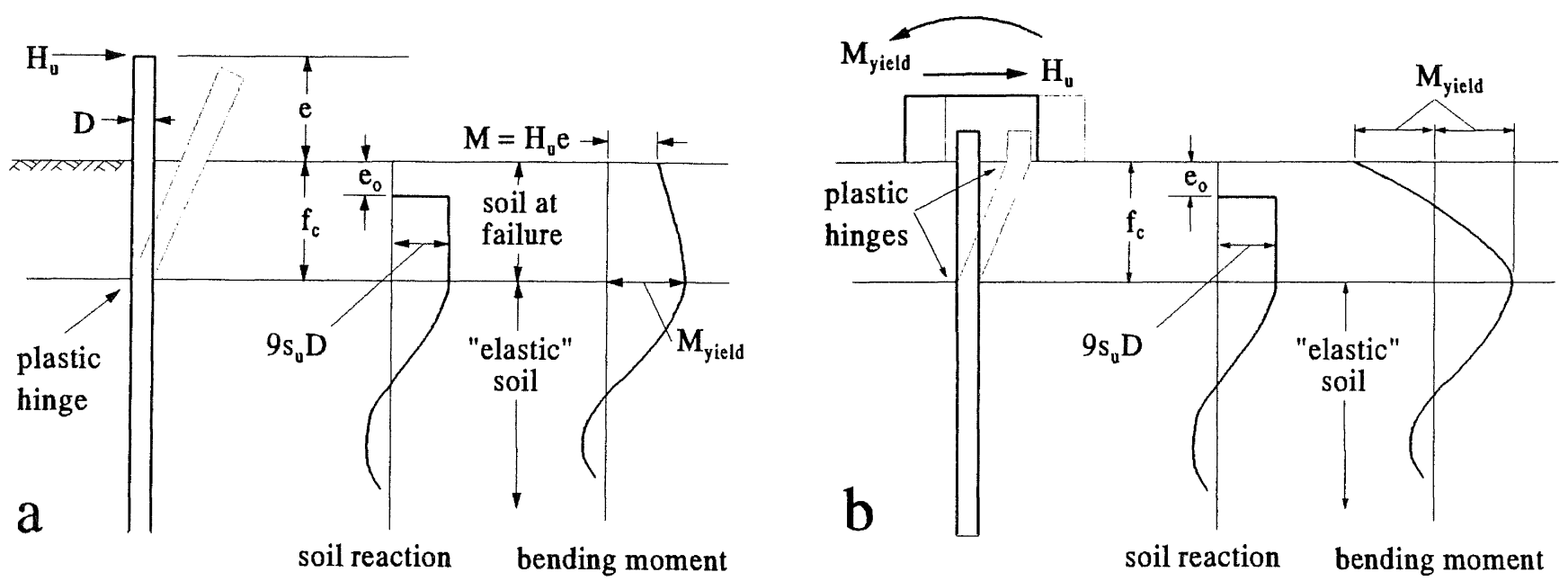

Fig. 9.5 Ultimate pressure distribution against a laterally loaded pile in cohesive soil after Broms; (a) free head and (b) fixed head pile.

\subsubsection{Base resistance of piles in sand}

This is an effective stress analysis. One approach would be to estimate the friction angle of the sand from penetrometer results and employ standard deep bearing capacity theory. The surcharge term in the bearing capacity equation suggests an indefinite increase in the bearing capacity with depth. This is not observed, and a limiting resistance is approached as is illustrated in Fig. 9.4. The effect is explained, in part, by the decrease in friction angle as the vertical effective stress increases with depth. This effect is automatically accounted for if the penetrometer method is used for estimating pile capacity.

A further study that illustrates this effect is Neeley (1990) in which the capacity of a series of expanded base piles is investigated.

\subsubsection{Pile installation}

In sands the driving of piles increases the density as indicated by the penetration resistance. Examples are given by Solymar et al (1987), and Nataraja and Cook (1983).

It has been mentioned above that the capacity of a pile increases with time after driving due to consolidation of the soil around the pile.

\subsubsection{Uplift resistance of belled piles}

The base resistance and the shaft resistance are evaluated separately and added to get the total resistance of the pile. In this case the weight of the pile contributes to the resistance. The base resistance is derived from the annulus formed by the bell. The details are set out by Poulos and Davis (p. 45 to 48).

\subsubsection{Vertical cyclic loading of single piles}

Poulos (1988 and 1989) and Turner and Kulhawy (1990) present information showing how the axial capacity of a pile is reduced with cyclic loading.

\subsection{Lateral capacity}

\subsubsection{Background}

In section 3 we discussed the elastic lateral stiffness of a pile, in section 7 this was extended to allow for local failure of the soil adjacent to part of the pile shaft. Now we need to evaluate the load and moment combinations which will mobilise the ultimate resistance of the pile-soil system.

There are two possibilities for consideration which depend on the length of the pile. Firstly, in the case of a relatively long pile at some depth the ultimate moment of the pile section will be reached and a plastic hinge formed. When this happens any further attempt to increase the lateral load will simply cause unlimited rotation at the plastic hinge. Thus the ultimate capacity of a long pile is limited by the moment capacity of the pile section. For a reinforced concrete pile this is affected by the axial load carried by the pile.

Secondly, in the case of a short pile the depth of local failure along the pile shaft reaches the pile depth before the ultimate moment capacity of the pile section is reached. In this case the ultimate lateral capacity of the system is determined by the soil properties. To distinguish the two cases herein the second is referred to as a pole rather than a pile.

The above discussion is in terms of a horizontal shear being applied at the top of the pile. No mention has been made of any constraint so this applies to a free head pile. The possibility that the pile head is restrained must also be considered. Head fixity increases the ultimate lateral capacity of a pile as a negative fixing moment equal to the yield moment of the pile section must be mobilised to generate the ultimate capacity. In the case of a short pole failure of the system occurs before the plastic moment of the pile section is reached. The transition between a pole and a pile occurs for the length at which the fixing moment reaches the plastic moment of the section at the same load as the capacity of the soil is reached. For a long pile the ultimate capacity of the system is not reached until the head moment as well as the maximum moment along the pile shaft reach the yield moment of the pile section. 

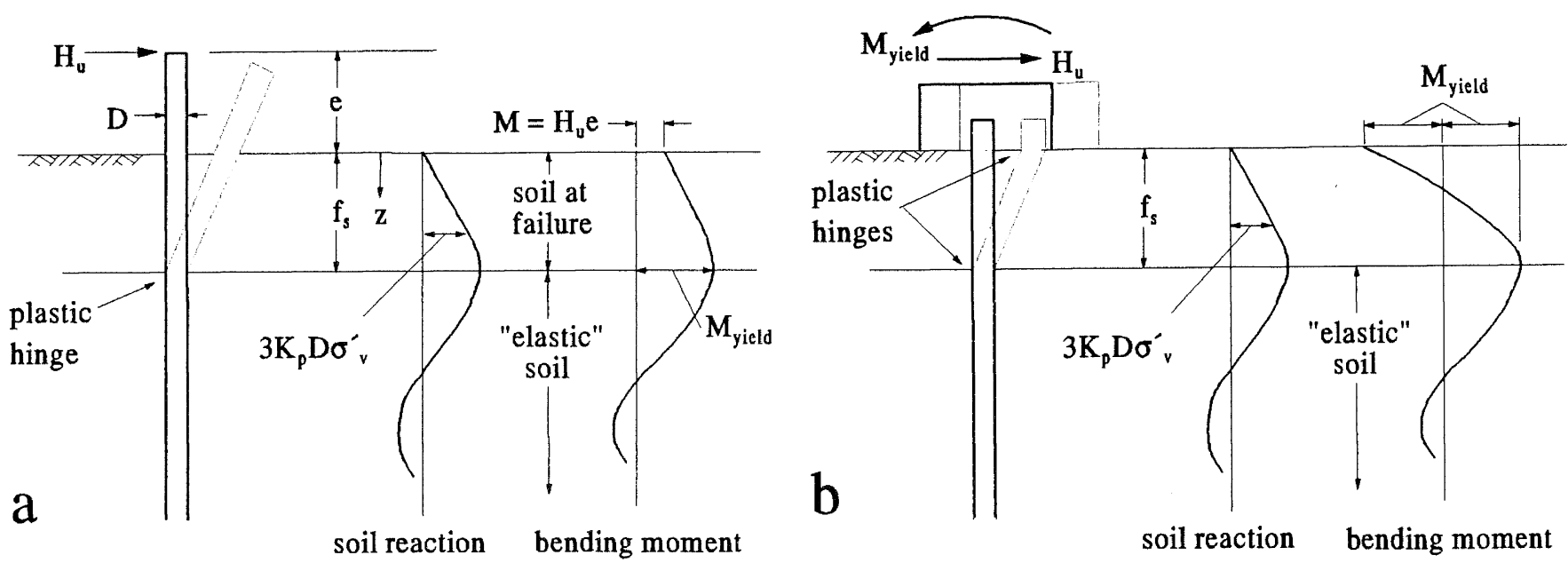

Fig. 9.6 Ultimate pressure distribution against a laterally loaded pile in cohesionless soil after Broms; (a) free head and (b) fixed head pile.

\subsubsection{The Broms and Budhu and Davies methods}

The best known approach to estimating the ultimate lateral capacity of a pile is that of Broms (1968a and b). Broms distinguishes between piles in cohesive soils and those in cohesionless soils. In each case he proposes a convenient simple method of estimating the maximum lateral pressure that the soil can mobilise. The approach is intended to account for three dimensional effects.

For piles in cohesionless soils Broms proposes that the maximum lateral pressure is $3 \mathrm{~K}_{\mathrm{p}}$ times the vertical effective stress in the soil adjacent to the pile shaft. These proposals are illustrated in Fig. 9.5.

The capacity of a given pile can be assessed from the charts given in the Broms papers. However Budhu and Davies have continued to develop simple equations and cover this case too.

Piles in cohesive soils.

Broms' proposed pressure distribution for a pile in cohesive soil is given in Fig. 9.5 for the free head and fixed head cases. Brom's recognizes that the actual distribution of lateral pressure against the pile shaft will be complex when all the soil pressure is mobilised, he simplifies this by assuming that there will be zero pressure for distance of 1.5 diameters from the ground surface below which it is $9 \mathrm{~s}_{\mathrm{u}} \mathrm{D}$. Broms gives a chart for estimating the lateral pile capacity based on the soil reaction distribution given in Fig. 9.5.

Recall from section 7 that Budhu and Davies give equations for estimating the effect of local failure of the soil along the pile shaft. They also give expressions which give the ultimate lateral capacity of piles. We discuss only those for long piles here. The ultimate lateral capacity of a free head pile embedded in saturated clay is given by:

$$
H_{u}=s_{u} D^{2}\left[\left(2 n_{c}+100 f^{2}\right)^{0.5}-10 f\right]
$$

where: $\mathrm{f}$
The ratio $n_{c}$ is defined by:

$$
n_{c}=\frac{10 M_{y}}{s_{u} D^{3}}
$$

The position of the yield moment (and the length of pile shaft over which failure occurs) is given by:

$$
f_{c}=\frac{H_{u}}{9 s_{u} D}+e_{o}
$$

For the fixed head case the ultimate lateral capacity will be given by:

$$
\mathrm{H}_{\mathrm{u}}=2 \mathrm{~s}_{\mathrm{u}} \mathrm{D}^{2} \mathrm{n}_{\mathrm{c}}^{0.5}
$$

The above four equations are based on the same assumptions as Broms with the exception the $e_{0}$ for Budhu and Davies is $0.6 \mathrm{~m}$ and 1.5D for Broms.

The length of pile shaft required for this solution to be valid is:

$$
\mathrm{L}_{\text {eff } \mathrm{c}}=0.4 \mathrm{D} \mathrm{n}^{0.5}
$$

The above equations give essentially the same prediction for the ultimate lateral capacity as those of Broms (1964a).

Example 9.1 Return to example 7.1 and estimate the ultimate lateral resistance of the pile in that example.

$\mathrm{e}=1 / 2.3=0.43$.

To this we add the $0.6 \mathrm{~m}$ that Budhu and Davies recommend Thus $\mathrm{e}=1.03 \mathrm{~m}$ and $\mathrm{f}=1.03 / 0.75=1.37$.

$\mathrm{n}_{\mathrm{c}}=10 \times 1575 / 50 \times 0.75^{3}=746.7$

The effective length of the pile shaft for the valid application of equation 9.9 is:

$\mathrm{L}_{\mathrm{c}}=0.4 \times 0.75 \times 746.7^{0.5}=8.2 \mathrm{~m}$, thus length $\mathrm{OK}$. 
$\left(2 \times 746.7+100 \times 1.37^{2}\right)^{0.5}=41.0$

$\mathrm{H}_{\mathrm{u}}=50 \times 0.75^{2}(41.0-10 \times 1.37)=768 \mathrm{kN}$

Note that this load is considerably higher than the $550 \mathrm{kN}$ which had the maximum moment in example 7.1 equal to the yield moment of the pile section.

The depth to the maximum moment is:

$f_{c}=768 / 9 \times 50 \times 0.75+0.6=2.88 \mathrm{~m}$.

Budhu and Davies give a set of equations for ultimate lateral capacity of piles embedded in normally consolidated clay which has a linear increase in strength with depth, a case not covered by Broms. The ultimate lateral capacity of a free head pile embedded in normally consolidated saturated clay is:

$$
\mathrm{H}_{\mathrm{u}}=0.5 c \mathrm{D}^{3} \mathrm{n}_{1}^{0.67} \exp \left(-2 \mathrm{f}^{0.75} \mathrm{n}_{\mathrm{l}}^{-0.25}\right)
$$

where: $c \quad$ is the rate of increase in undrained shear strength with depth $(\mathrm{kPa} / \mathrm{m})$.

The ratio $n_{l}$ is defined by:

$$
\mathrm{n}_{1}=\frac{10 \mathrm{M}_{\mathrm{y}}}{\mathrm{cD^{4 }}}
$$

The position of the yield moment (and the length of pile shaft over which failure occurs) is given by:

$$
f_{1}=\sqrt{\frac{2 H_{u}}{9 c D}}
$$

For the fixed head case the ultimate lateral capacity is given by:

$$
\mathrm{H}_{\mathrm{u}}=0.8 c \mathrm{D}^{3} \mathrm{n}_{\mathrm{c}}^{0.67}
$$

\section{Piles in cohesionless soils}

Broms' proposed pressure distribution for a pile in cohesionless soil is given in Fig. 9.6 for both the free head and fixed head cases. Brom's recognizes that the actual distribution of lateral pressure against the pile shaft will be complex and of a three dimensional nature when all the soil pressure is mobilised, he simplifies this by assuming that the soil reaction along the pile shaft is controlled by $3 \mathrm{~K}_{\mathrm{p}}$ as shown in the diagram. Broms gives a chart for estimating the lateral pile capacity based on the soil reaction distribution given in Fig. 9.6.

The Budhu and Davies expressions for the ultimate lateral capacity of a free head pile embedded in cohesionless soil are:

$$
\mathrm{H}_{\mathrm{u}}=0.35 \mathrm{~K}_{\mathrm{p}} \gamma \mathrm{D}^{3} \mathrm{n}_{\mathrm{s}}^{0.67} \exp \left(-1.6 \mathrm{f}^{0.75} \mathrm{n}_{\mathrm{s}}^{-0.25}\right)
$$

where: $\mathrm{K}_{\mathrm{p}} \quad$ is the coefficient of passive earth pressure $=$ $(1+\sin \phi) /(1-\sin \phi)$.

The ratio $n_{s}$ is defined by:

$$
\mathrm{n}_{\mathrm{s}}=\frac{10 \mathrm{M}_{\mathrm{y}}}{\mathrm{K}_{\mathrm{p}} \gamma \mathrm{D}^{4}}
$$

The position of the yield moment (and the length of pile shaft over which failure occurs) is given by:

$$
\mathrm{f}_{\mathrm{s}}=\sqrt{\frac{2 \mathrm{H}_{\mathrm{u}}}{3 \mathrm{~K}_{\mathrm{p}} \gamma \mathrm{D}}}
$$

where: $\gamma \quad$ is the unit weight of the sand chosen to give the effective vertical stresses $\left(\gamma^{\prime}\right.$ for a saturated sand).

For the fixed head case the ultimate lateral capacity will be given by:

$$
\mathrm{H}_{\mathrm{u}}=0.56 \mathrm{~K}_{\mathrm{p}} \gamma \mathrm{D}^{3} \mathrm{n}_{\mathrm{c}}^{0.67}
$$

The length of pile shaft required for this solution to be valid is:

$$
\mathrm{L}_{\text {eff } s}=0.8 \mathrm{D} \mathrm{n}^{0.33}
$$

The above equations give essentially the same predictions of pile lateral capacity as those of Broms (1964b).

Example 9.2 Return to example 7.3 and estimate the ultimate lateral resistance of the pile in that example.

$\mathrm{e}=1 / 2.3=0.43$ and $\mathrm{f}=0.43 / 0.75=0.57$

$\mathrm{K}_{\mathrm{p}}=(1+\sin 35) /(1-\sin 35)=3.69$

$\mathrm{n}_{\mathrm{s}}=10 \times 1575 / 3.69 \times 10 \times 0.75^{4}=1349$

The effective length of the pile shaft for the valid application of equation 9.18 is:

$\mathrm{L}_{\mathrm{c}}=0.8 \times 0.75 \times 1349^{0.33}=6.5 \mathrm{~m}$, thus length $\mathrm{OK}$.

$$
\begin{aligned}
& \left(-1.6 \times 0.57^{0.75} \times 1349^{-0.25}\right)=-0.17 \quad \exp (-0.17)=0.84 \\
& \mathrm{H}_{\mathrm{L}}=0.35 \times 1349^{0.67} \times 3.69 \times 10 \times 0.75^{3} \times 0.84=572 \mathrm{kN}
\end{aligned}
$$

Note that this load is slightly larger than the $540 \mathrm{kN}$ which had the maximum moment in example 7.1 equal to the yield moment of the pile section.

The depth to the maximum moment is:

$\mathrm{f}_{\mathrm{c}}=(2 \times 572 / 3 \times 3.69 \times 10 \times 0.75)^{0.5}=3.71 \mathrm{~m}$.

\subsubsection{Ultimate limit state}

It is important to note that the ultimate lateral capacity calculated with equation 9.5 is based on the assumption that the maximum moment in the pile shaft is the yield moment. However comparison with the results of example 7.1 shows that the yield moment is reached at a load somewhat less than the ultimate lateral load given by the above method. Pranjoto (1992) has found this to be generally the case for piles embedded in clays having a constant modulus with depth (the 
only exception being timber piles with a large value of the ratio of applied moment to horizontal shear).

In the case of piles in cohesionless soils the above example shows that the ultimate lateral load is quite close to that determined in example 7.3. Pranjoto (1992) found that for small values of $\mathrm{K}$ the ultimate value is less than that calculated with the methods of section 7.2. When $\mathrm{K}$ is large the ultimate lateral load is greater than that calculated with the methods of section 7.2 .

As noted in section 7.1.3 estimates of the ultimate lateral pile capacity and the serviceability limit state need to be checked with the expressions of both sections 7.2 and 9.2. In this way any incompatibility between the predictions of the two sections will be revealed.

\subsection{Pile group capacity}

\subsubsection{Vertical capacity of a pile group}

This topic is also treated in adequate detail by Poulos and Davis. There are two cases: a free standing group, which has a cap having no interaction with the underlying soil, and the pile raft in which the group cap is in contact with the underlying material. As with section 5 the pile raft case is not considered herein.

There are two modes of failure for a group. When there are a large number of closely spaced piles the soil is so heavily reinforced that it fails as a block. With fewer more widely spaced piles the capacity of the group is determined by the individual pile capacities. The concept of group efficiency arises; Poulos and Davis (1980) discuss a number of ways in which the efficiency is defined. Their preferred definition requires the evaluation of the ultimate capacity of the block of soil reinforced by the pile group assuming that it acts as a unit:

$$
\mathrm{V}_{\mathrm{B}}=\mathrm{B}_{\mathrm{G}} \mathrm{L}_{\mathrm{G}} \mathrm{s}_{\mathrm{u}} \mathrm{N}_{\mathrm{c}}+2\left(\mathrm{~B}_{\mathrm{G}}+\mathrm{L}_{\mathrm{G}}\right) \mathrm{Lc}_{\mathrm{a}}
$$

where: $V_{B} \quad$ is the ultimate capacity of the block,

$$
\mathrm{L}_{\mathrm{G}} \text { is the length (between pile extremities) of }
$$
the pile group,

$\mathrm{B}_{\mathrm{G}} \quad$ is the width (between pile extremities) of the pile group,

$\mathrm{L} \quad$ is the length of the piles, and $\quad c_{a} \quad$ is the adhesion along the block boundary.

A similar expression could be developed for an effective stress analysis.

The group efficiency is defined as:

$$
\xi=\frac{\text { ult. capacity of group }}{\text { sum of ult. caps. of individual piles }}
$$

Poulos and Davis suggest the following formula for obtaining the ultimate capacity of the group:

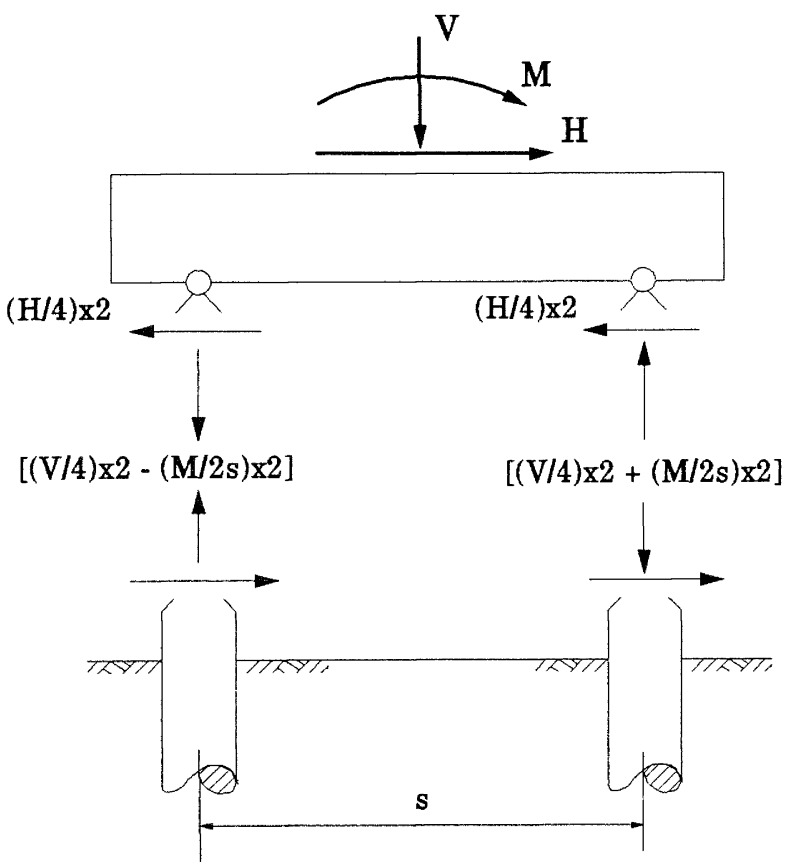

Fig. 9.7 Free body diagram for a $2 \times 2$ pile free-standing freehead group.

$$
\frac{1}{V_{G}^{2}}=\frac{1}{n^{2} V_{1}^{2}}+\frac{1}{V_{B}^{2}}
$$

where: $V_{G} \quad$ is the ultimate capacity of the group,

$\mathrm{V}_{1}$ is the ultimate capacity of the individual piles,

and $\quad \mathrm{n} \quad$ is the number of piles in the group.

The group efficiency is then obtained from:

$$
\frac{1}{\xi^{2}}=1+\frac{\mathrm{n}^{2} \mathrm{~V}_{1}^{2}}{\mathrm{~V}_{\mathrm{B}}^{2}}
$$

Note that using this approach of Poulos and Davis that the concept of group efficiency is not needed. They introduce it as other more traditional methods need to evaluate $\xi$ before the group capacity can be evaluated.

Model tests of pile groups in sand show that the group efficiency may be greater than unity, Poulos and Davis (1980, p. 36-37).

\subsubsection{Combined load capacity of a pile group}

We have considered the ultimate vertical capacity of a pile group now we need to look at the capacity of a group when subject of vertical, shear and moment loading. The challenge for this is to find a way in which the various mechanisms can contribute to the overall capacity without overlooking some mechanism that gives a smaller capacity than the one chosen. The complication is that the vertical capacity of the piles contributes to both the vertical and moment capacity of the group and that the piles also contribute to the shear capacity of the group. Thus we need to find some way of partitioning the capacity of the piles to contribute to the various mechanisms. 

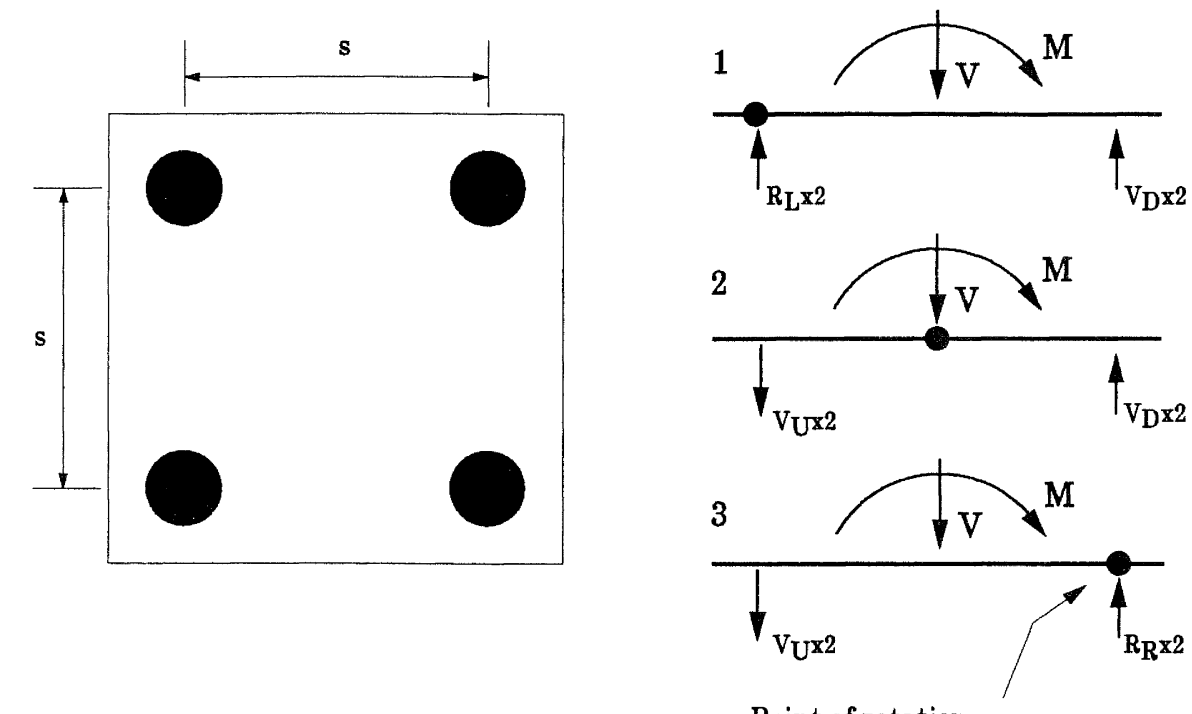

Point of rotation

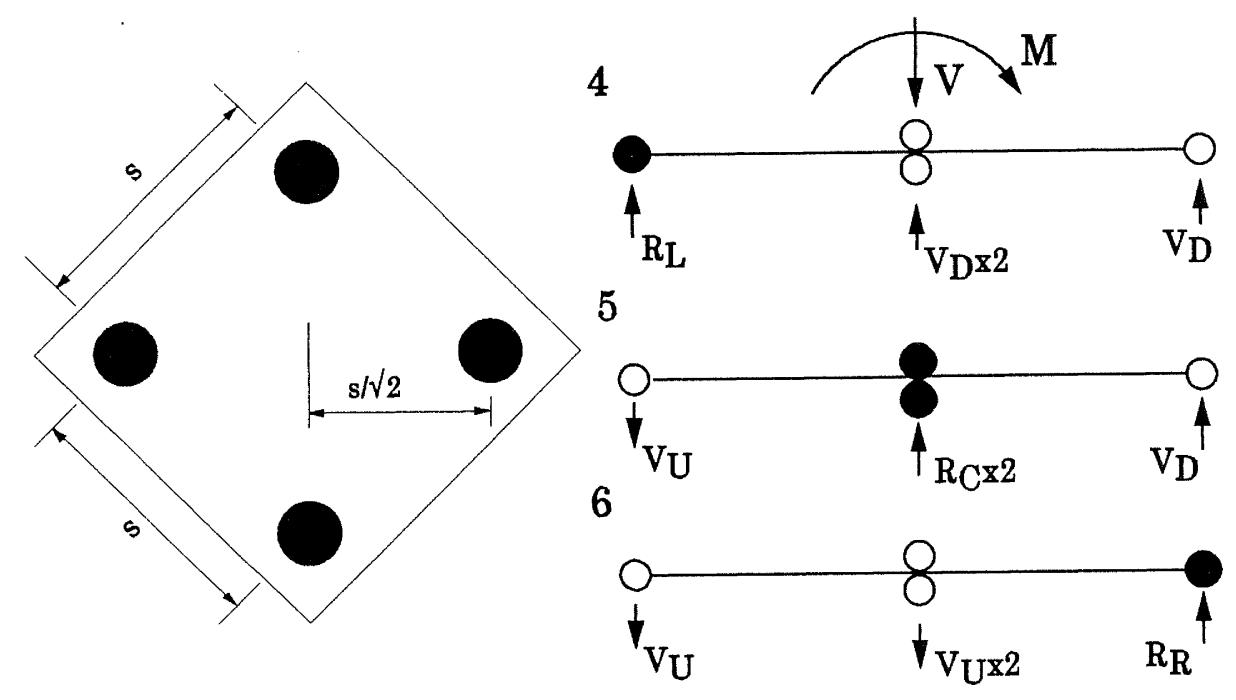

Fig. 9.8 Geometry of a $2 \times 2$ pile group subject to moment loading about an axis parallel to the side and about a diagonal of the group.

In Fig. 9.7 free body diagrams show how the various applied loads might be split between the various mechanisms. The free body diagram for the free-standing free-head group is clear enough. For the fixed-head free-standing group the diagram is very similar except that the yield moment, $\mathbf{M}_{\mathbf{y}}$, of the pile section is mobilised at the top of each pile, this in effect means that the moment applied to the pile group is: $M-4 M_{y}$ (in the general case the factor 4 is replaced by $n$, where $n$ is the number of piles in the group). In both of these mechanisms the pile shafts contribute to the moment resistance, the vertical load resistance as well as the shear capacity of the mechanism. Thus we need to place some restriction on the way the soil along the pile shaft contributes to these various mechanisms. It is proposed that no element of soil can contribute resistance to more than one mechanism. In the case of the horizontal shear this means that a certain length of the pile shaft should be dedicated to providing horizontal resistance and so makes no contribution to the vertical and moment resistance. Referring to section 9.2.2 we have expressions (equations 9.7 and 9.18) for the length of pile shaft that is required to develop the ultimate lateral pile capacity.

Note from equations $9.5,9.10$ and 9.14 that the ultimate lateral capacity of the pile is a function of the yield moment of the pile section. This means that there will be some possibility for adjusting the relative contributions of the various mechanisms by adjusting the pile section.

\section{Moment capacity of pile groups}

Firstly we need to consider the vertical capacity of the individual piles. We will assume that they are embedded in a cohesive soil and that a short term total stress assessment is required. The ultimate downward capacity is denoted as $V_{D}$ and the uplift capacity as $\mathrm{V}_{\mathrm{u}}$. These are given, using the equations of section 9.1 .2 , by: 


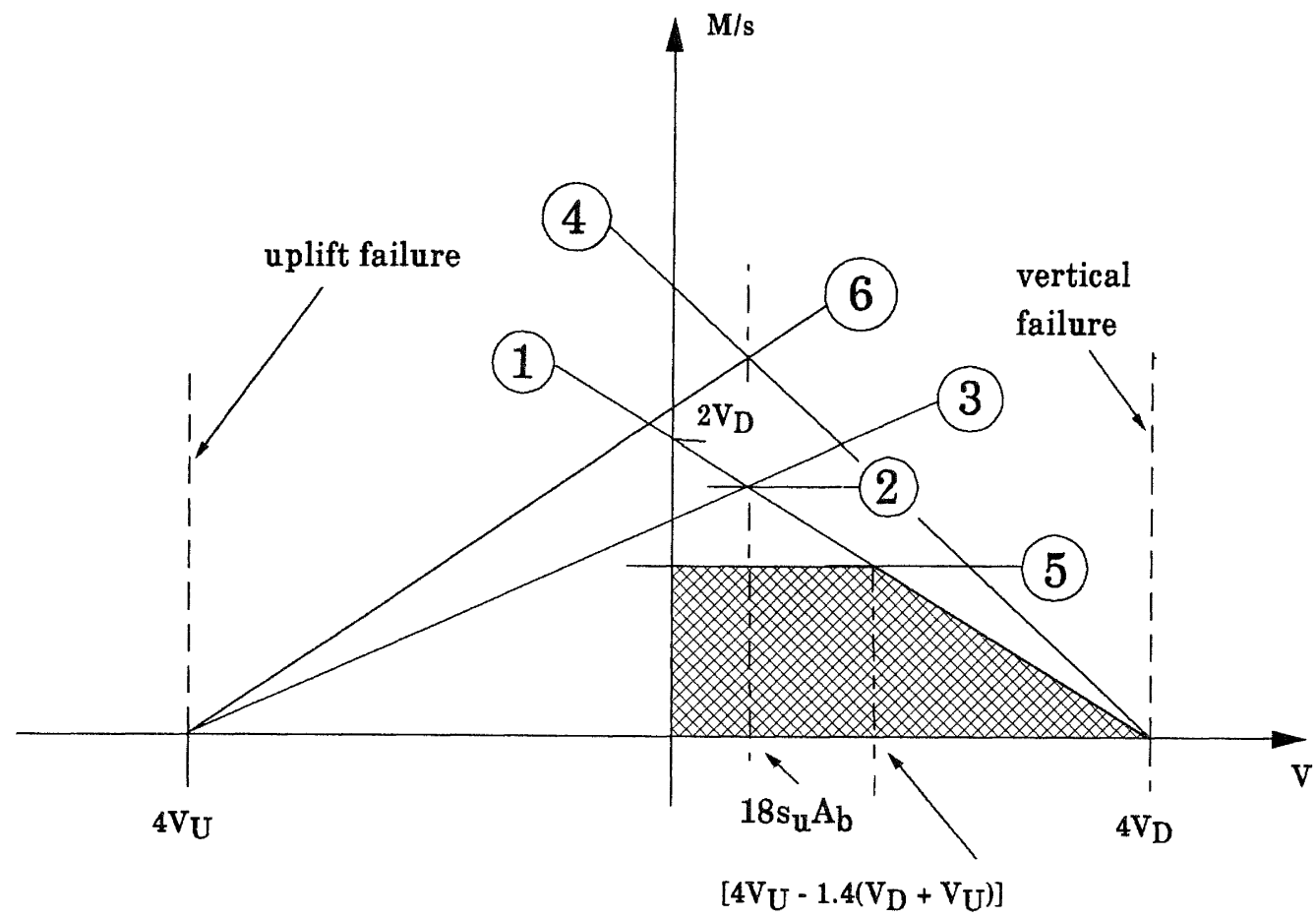

Fig. 9.9 Moment capacity for a $2 \times 2$ pile free-standing free-head pile group.

$$
V_{D}=c_{a} L C+9 s_{u} A_{b}
$$

where: $A_{b} \quad$ is the area of the pile base.

$$
V_{U}=c_{a} L C+9 s_{u}\left(A_{b}-A_{s}\right)
$$

where: $A_{s} \quad$ is the cross-sectional area of the pile shaft.

As the length of the piles increases these two capacities will tend to converge if the soil has uniform properties. On the other hand if the pile base is founded on a much stronger layer the two vertical capacities will be substantially different.

For the $2 \times 2$ pile group as illustrated in Fig. 9.7 we need to consider two limiting cases - the applied moment acting parallel to the side of the group and across the diagonal of the group. We will consider the moment parallel case first.

From Fig. 9.8 we note that there are three possible capacity mechanisms available for the group when the moment is applied about an axis parallel to the side of the group. We will look at each of these in turn.

Mechanism 1. Moment and force equilibrium give:

$$
\begin{aligned}
M_{\text {cap1p }} & =2 \mathrm{sV}_{\mathrm{D}}-\mathrm{V} \frac{\mathrm{s}}{2} \\
\mathrm{R}_{\mathrm{L}} & =\frac{\mathrm{V}}{2}-\mathrm{V}_{\mathrm{D}}
\end{aligned}
$$

Mechanism 2. Moment and force equilibrium give:

$$
\mathrm{M}_{\text {cap2p }}=\mathrm{s}\left(\mathrm{V}_{\mathrm{D}}+\mathrm{V}_{\mathrm{U}}\right)
$$

Note that this mechanism is available only for one value of $\mathrm{V}$.
Mechanism 3. Moment and force equilibrium give:

$$
\begin{aligned}
\mathrm{M}_{\text {cap3p }} & =2 \mathrm{sV}_{\mathrm{U}}+\mathrm{V} \frac{\mathrm{s}}{2} \\
\mathrm{R}_{\mathrm{R}} & =\frac{\mathrm{V}}{2}+\mathrm{V}_{\mathrm{D}}
\end{aligned}
$$

These moment relationships are plotted in Fig. 9.9, with a little manipulation it is found that $\mathrm{M}_{\mathrm{cap}(1 \mathrm{p})}=\mathrm{M}_{\mathrm{cap}(3 \mathrm{p})}$ when $\mathrm{V}=$ $18 \mathrm{~s}_{\mathrm{u}} \mathrm{A}_{\mathrm{s}}$.

From Fig. 9.8 there are three additional capacity mechanisms when the moment is applied about a diagonal axis. As above we examine each of these mechanisms in turn.

Mechanism 4. Moment and force equilibrium give:

$$
\begin{aligned}
M_{\text {cap4d }} & =\frac{s}{\sqrt{2}}\left(4 V_{D}-V\right) \\
R_{L} & =V-3 V_{D}
\end{aligned}
$$

Mechanism 5. Moment and force equilibrium give:

$$
\begin{aligned}
\mathrm{M}_{\text {cap5d }} & =\frac{\mathrm{s}}{\sqrt{2}}\left(\mathrm{~V}_{\mathrm{D}}+\mathrm{V}_{\mathrm{U}}\right) \\
\mathrm{R}_{\mathrm{C}} & =\frac{\left(\mathrm{V}+\mathrm{V}_{\mathrm{D}}-\mathrm{V}_{\mathrm{U}}\right)}{2}
\end{aligned}
$$

Mechanism 6. Moment and force equilibrium give:

$$
\begin{aligned}
M_{\text {cap6d }} & =\frac{\mathrm{s}}{\sqrt{2}}\left(4 \mathrm{~V}_{\mathrm{U}}+\mathrm{V}\right) \\
\mathrm{R}_{\mathrm{R}} & =\mathrm{V}+3 \mathrm{~V}_{\mathrm{U}}
\end{aligned}
$$

The moment relationships for mechanisms 4,5 and 6 are plotted in Fig. 9.9 along with those for mechanisms 1, 2 and 3. If we 
ask what value of $\mathrm{V}$ gives $\mathrm{M}_{\text {cap(4d) }}=\mathrm{M}_{\text {cap(6d) }}$ we get $\mathrm{V}=$ $18 s_{u} A_{s}$, which is the same value as that obtained for the equality of mechanism 1 and 3. Fig. 9.9 shows that the diagonal moment case $\mathrm{M}_{\text {cap (5d) }}$ gives the smallest moment capacity for values of $\mathrm{V}$ up to about $50 \%$ of the maximum vertical capacity of the pile group, $4 V_{D}$, and for larger values of $V$ it is $M_{\text {cap(1p) }}$ that is critical. In practice this means that $\mathrm{M}_{\text {cap(5d) }}$ will control design as one would not have a $2 \times 2$ pile group under static conditions carrying a vertical load as great as $50 \%$ of the ultimate vertical capacity of the group.

All these moment capacity relations are plotted in Fig. 9.9. It is apparent that the diagonal case $\mathrm{M}_{\text {cap5d }}$ gives the critical moment capacity for the likely range of vertical loads.

Similar calculations can be done for the ultimate moment capacity of a $3 \times 3$ group. It is found that once again the diagonal mechanism is critical but that the range of vertical loads for which it is critical is increased. If the dimensions of the pile cap are the same then the pile spacing for a $3 \times 3$ group will be about half that of a $2 \times 2$ group. This would give the $3 \times 3$ group about 40 to $50 \%$ more ultimate moment capacity than the $2 \times 2$ group for the same size of pile. On the other hand the efficiency of each pile in a $3 \times 3$ group will be smaller, so the difference between the two will be less.

\section{Free-standing fixed head groups}

The free-standing fixed-head pile group is very similar to the above case except that the moment equilibrated by asymmetric axial loading of the piles is $\mathrm{M}-\mathrm{nM}_{\mathrm{y}}, \mathrm{n}$ is the number of piles in the group.

\section{Lateral capacity of pile groups}

The lateral load capacity of a group is developed, as explained at the beginning of section 9.3 , by assigning the length of the pile shaft given in equations 9.12 and 9.16 to providing lateral resistance only. This in effect reduces $V_{D}$ and $V_{U}$ for each pile.

Example 9.3 Return to the "building" considered in example 8.8. Investigate the ultimate capacity of the pile group foundation. Take the yield moment of the pile shafts to be the same as that in example 7.1 , ie $1575 \mathrm{kNm}$. Assume that the shaft adhesion is $75 \%$ of the undrained shear strength of the clay. Use $25 \mathrm{kN} / \mathrm{m}^{3}$ for the unit weight of concrete.

From example 8.8 we have the weight of the building as 3468 $\mathrm{kN}$. The seismic mass is 247.5 tonnes. The spectral acceleration was $0.45 \mathrm{~g}$ so the base shear is $1093 \mathrm{kN}$.

The base moment is generated by the concentrated mass acting at 0.7 of the building height. Thus:

$\mathrm{M}=0.7 \times(5 \times 3.5) \times 1093=13389 \mathrm{kNm}$.

We will evaluate the ultimate lateral capacity of the pile group first. For a fixed head pile we have from equation 9.6:

$\mathrm{n}_{\mathrm{c}}=10 \times 1575 / 50 \times 0.75^{3}=746.7$

From equation 9.8 the ultimate lateral capacity is:
$H_{u}=2 \times 50 \times 0.75^{2} \times(746.5)^{0.5}=1537 \mathrm{kNm}$

The length of pile shaft required to generate this, from equation 9.7 , is:

$f_{c}=1537 / 9 \times 50 \times 0.75+0.6=5.15 \mathrm{~m}$

Note from example 7.2 the a lateral force of about $900 \mathrm{kN}$ generated the yield moment in the pile shaft. Thus we will restrict our ultimate lateral capacity to $900 \mathrm{kN}$, rather than 1537 $\mathrm{kN}$, but we will dedicate $5.15 \mathrm{~m}$ of each pile shaft to generating this with the consequence that the length of pile shaft available for axial loading is $14.85 \mathrm{~m}$.

This gives an ultimate lateral capacity for the pile group of 3600 $\mathrm{kN}$ (assuming no group action between the piles as the pile spacing, $7.5 \mathrm{~m}$, is rather greater than the length of pile shaft required to generate the lateral capacity). Thus the lateral capacity of the group is easily able to accomodate the applied base shear of $1093 \mathrm{kN}$.

The weight of each pile is:

$\mathrm{W}_{\mathrm{p}}=25 \times 20 \times 3.1416 \times 0.75^{2} / 4=221 \mathrm{kN}$

The downward vertical capacity of each pile is:

$$
\begin{aligned}
\mathrm{V}_{\mathrm{ud}}=50 \times 0.75 \times 14.85 \times 3.1416 \times 0.75 \\
\quad+(9 \times 50+18 \times 20) \times 3.1416 \times 0.75^{2} / 4-221
\end{aligned}
$$

$$
=1448 \mathrm{kN}
$$

The upward vertical capacity of each pile is:

$$
\begin{aligned}
\mathrm{V}_{\mathrm{ud}} & =50 \times 0.75 \times 14.85 \times 3.1416 \times 0.75+221 \\
& =1533 \mathrm{kN}
\end{aligned}
$$

The moment capacity of the group for the diagonal mechanism is $M_{\text {cap5d }}$ is:

$M_{\mathrm{v}}=7.5 \times(1448+1533) / 1.414=15811 \mathrm{kNm}$.

This moment capacity is generated by axial force increments in two diagonally opposite piles. Under the applied moment the force increments are:

$\Delta \mathrm{F}=13389 / 1.414 \times 7.5=1262.5 \mathrm{kN}$.

Assuming that each pile in the group continues to carry the one quarter of the weight of the building the forces in the diagonally opposite piles are:

$$
\begin{aligned}
& \mathrm{F}_{1}=3468 / 4+1262.5=2129.5 \mathrm{kN} \\
& \mathrm{F}_{2}=3468 / 4-1262.5=-395.5 \mathrm{kN} .
\end{aligned}
$$

Thus one pile would be subject to a tensile force at the head. For the other a vertical downward force of $2130 \mathrm{kN}$ is carried. However this downward force is greater than the downward capacity of $1448 \mathrm{kN}$ estimated above for the reduced pile shaft length (even with the full $20 \mathrm{~m}$ of pile shaft active the 
downward capacity is still less than the force generated). Thus the pile group does not have capacity matching or exceeding the applied actions. As there will be cyclic axial loading of the piles the realizable shaft adhesion is likely to be less than the $0.75 \mathrm{~s}_{\mathrm{u}}$ assumed. This suggests that the free-standing pile group foundation might exhibit the plunging failure mode inferred by Zeevaert (1991) to have occurred during the 1985 Mexico City earthquake. As discussed in section 2.1.2 Zeevaert's suggestion for avoiding this problem is to have a pile-raft foundation and mobilise the soil bearing capacity beneath the structure. As explained earlier the capacity of pile rafts is not discussed in this document.

\subsection{SUMMARY}

In this paper a series of tools have been presented which are useful for the preliminary aseismic design of single and pile group foundations. The emphasis has been on assembling an extensive set of simple formulae which are suitable for use in spreadsheet or similar software. In many cases dynamic analyses more sophisticated than those discussed here will be needed before design can be finalised. However such studies can hardly be commissioned and neither could the results be evaluated effectively without the insight that can be obtained from methods such as those included herein.

For similar reasons more than half of the document is concerned with the static behaviour of pile foundations as a preliminary to work on the dynamic response.

Several critical issues are not discussed in detail because they are best dealt with by geotechnical judgement or because no consensus has yet been reached on methods of approach. Among these are estimation of the stiffness of a soil layer, the relation between the Young's modulus and the modulus of subgrade reaction for a particular soil, shaft resistance for bored and driven piles in sands and clays, shaft resistance under cyclic loading, degradation of the stiffness of the soil adjacent to a pile shaft because of cyclic loading.

The substance of nearly all the methods discussed is the convenient idealisation that the soil-pile system will respond elastically to the applied actions. There is some tension between this assumption and the reality that much soil-pile interaction is inelastic. Results from field studies emphasising nonlinear effects are discussed briefly. Nevertheless the elastic idealisation is a good starting point for gaining an appreciation of likely response.

In summary the main topics covered in the document are:

(1) The elastic continuum model leads to the idea of an active pile length for lateral loading. If the length exceeds this the pile is flexible and the lateral stiffness is independent of pile length. The active length for dynamic loading is greater than that for static loading. On the other hand for vertical loading a greater length of the pile shaft contributes to the stiffness so the active length concept does not arise.

(2) The lateral stiffness of a flexible pile is less than the vertical stiffness. Piles will thus contribute to an increase in the rocking stiffness of a foundation (by mobilising the vertical stiffness of the piles) consequently reducing the earthquake response of structures. On the other hand it is difficult to get a significant increase in the horizontal stiffness of a foundation using vertical piles.

(3) The Winkler model, a bed of independent springs, provides an alternative to the elastic continuum model for lateral pile-soil interaction. It gives deflections and bending moments for flexible piles similar to those of 
the elastic continuum model. In addition it offers a useful method for modelling nonlinear lateral soil-pile interaction, for handling layered soil profiles, and recently has been an important source of insight into dynamic pile behaviour and the dynamics of pile groups.

A simple nonlinear Winkler model seems capable of predicting rather well lateral load behaviour of the type observed in many prototype scale pile tests. An added attraction of the Winkler approach is the ability to handle layered soil profiles.

It appears that there is a size effect involving pile diameter when the Winkler model is used. According to a classic paper by Terzaghi, as the diameter of the pile shaft increases the coefficient of subgrade reaction decreases whilst the modulus of subgrade reaction is constant. Back analysis of data from prototype lateral load tests on pile foundations of various diameters shows that the coefficient of subgrade reaction appears to be independent of pile diameter and that the modulus of subgrade reaction increases as the diameter increases.

A limitation of the Winkler model is the lack of interaction between adjacent piles. The elastic continuum method is needed to model interaction effects. Simple formulae are presented for the estimation of these interaction factors.

The method of handling local failure between the soil and pile shaft proposed by Budhu and Davies gives predictions of lateral load displacement in line with observed behaviour and with finite element calculations. Thus a very simple method is available for estimating the effect of nonlinear interaction between the soil and pile shaft. This nonlinearity is more significant for free head than fixed head piles.

Equations which give the ultimate lateral capacity of a pile may sometimes be misleading. In some cases the yield moment of the pile section is reached before the ultimate capacity determined by the full mobilisation of the soil strength. In other cases the ultimate lateral capacity calculated using the methods of 9.2 is reached before yield moment is reached according to the methods of section 7.2. Thus the ultimate lateral capacity estimated from the equations in section 9.2 needs to checked against the pile head actions causing the pile shaft to yield calculated in section 7.2 and vice versa.
The dynamic response of piles is conveniently divided into two parts: kinematic and inertial. The kinematic interaction addresses the question of whether or not a certain pile can be expected to follow the seismic deformations of a particular soil profile. It is found that for high frequencies the pile does not follow the soil motion and the pile head response is less than that of the free field. For soil profiles having a smooth variation in modulus with depth kinematic interaction is significant only when the soil modulus increases linearly with depth from zero at the surface. It is possible that this interaction may be significant for layered deposits.

(10) Coming to inertial interaction a most useful finding is that the lateral stiffness of a single pile is not much affected by dynamic loading, consequently the static stiffness may be used. Radiation damping increases with frequency although for frequencies less than the natural frequency of the layer in which the pile is embedded there is no radiation damping. Use of the impedance concept (involving complex numbers) provides a convenient way of combining stiffness and damping such that a solution to a static stiffness problem can be easily extended to get the solution to the corresponding dynamic problem.

(11) The results of elastic predictions of dynamic pile group effects are bewildering, showing complex and rapid variations with frequency of the components the group stiffness and damping matrices. However, quite simple methods have been proposed which follow this complexity well. In addition example 8.8 reveals, at least for the particular pile foundation geometry and soil profile investigated in the example, that these frequency effects are not manifested in the response of a single degree of freedom model of a building founded on a $2 \times 2$ free-standing pile group.

It seems that cyclic loading has a significant effect on pile shaft capacity. There is a deterioration of the interface strength with the number of cycles.

Another aspect of the effect of cyclic loading on pile foundation behaviour is the phenomenon of gapping. This is illustrated in Fig. 2.8 and effectively decreases the lateral stiffness of the pile. A related phenomenon for piles in saturated sands is the softening of the soil adjacent to the pile shaft because of increaseing pore water pressure.

Topics requiring further research are:

(1) The softening of saturated sand adjacent to a pile shaft during cyclic lateral loading. This phenomenon occurs even when the sand does not liquefy. A method for predicting the extent of this softening is needed.

(2) Another aspect of the cyclic lateral response of pile foundations requiring a method for estimation is the effect of gap formation, Fig. 2.8, adjacent to the shaft of a pile embedded in clay.

(3) It is known from work on the foundations of pile supported offshore structures that cyclically loaded interfaces exhibit degradation of strength. A method is needed for assessing this degradation on the vertical capacity of a pile shaft for the numbers of cycles 
involved in earthquake loading.

As mentioned above the estimation of soil stiffness and strength for pile foundation design remains, as always with all facets of geotechnical engineering, a challenging problem.

Two important topics not covered in the paper are:

Damage to pile foundations has often been associated with liquefaction (qv Fig. 2.1 and 2.3 ). Methods of attempting to assess the likely severity of such damage have not been covered. Some insight is given by Tajimi (1977), Miura et al (1991), Tokida et al (1992), and Miwa et al (1992).

Loading of pile foundations from the placing of fills nearby, such as occurs at the abutments of many bridges. This topic is currently being actively researched in Australia and current results are presented by Randolf and Springman (1991), and Stewart et al (1992a, 1992b and 1992c).

\subsection{ACKNOWLEDGEMENTS}

The contributions of the other three members of study group, Dr. T. Matuschka, Mr. H. Chapman and Dr. D. V. Toan, during the initial stages of the work are gratefully acknowledged.

The assistance of colleagues: Mr. L. M. Megget, Drs. J. W. Butterworth, B. J. Davidson, T. J. Larkin, and R. C. Fenwick of the Civil Engineering Department of the University of Auckland, in providing clarification of various points to do with structural behaviour, structural dynamics and soil dynamics is also gratefully acknowledged.

\subsection{REFERENCES}

Abe, Y., Sugimoto, M., Ohki, N., Suzuki, Y., Jido, J., Hayamizu, Y. and Hiromatsu, T. (1984) "Dynamic behaviour of pile foundation during earthquakes", Proc. 8th. World Conference on Earthquake Engineering, San Francisco, Vol. III, pp. 585-592.

Angelides, D. C. and Roesset, J. M. (1981) "Nonlinear lateral dynamic stiffness of piles", Jnl. Geotech. Eng., Vol. 107 GT. 11, pp. 1443-1460.

Baldi. G., Jamiolkowski, M., Lo Presti, D. C. F., Manfredi, G. and Rix, G. J. (1989) "Italian experience in assessing shear wave velocity from CPT and SPT", Proc. Discussion Session on Influence of Local Conditions on Seismic Response, 12th. ICSMFE, Rio de Janeiro, pp. 157-168.

Barton, Y. O. (1985) "Response of pile groups to lateral loading in the centrifuge", Proc. of a Symposium on the Application of Centrifuge Modelling in Geotechnical Design, edited by W. H. Craig, Balkema, pp. 457- 473 .

Bilotta, E., Caputo, V. and Viggiani, C. (1991) "Analysis of soil-structure interaction for piled rafts", Proc. 10th. European Conference on Soil Mech. and Found. Eng., Florence, pp. 315-318.

Blaney, G. W. and O’Neill, M. W. (1986a) "Measured lateral response of mass on single pile in clay", Jnl. Geotech. Eng., Proc. ASCE, Vol. 112 No. 4, pp. 443-457.

Blaney, G. W. and O'Neill, M. W. (1986b) "Analysis of dynamic laterally loaded pile in clay", Jnl. Geotech. Eng., Proc. ASCE, Vol. 112 No. 9, pp. 827-840.

Blaney, G. W. and O'Neill, M. W. (1989) "Dynamic lateral response of a pile group in clay", Geotechnical Testing Journal, Vol. 12 No. 1, pp. 22-29.

Broms, B. B. (1964a) "Lateral resistance of piles in cohesive soils", Proc. ASCE, Jnl. Soil Mech. and Found. Div., Vol. 90 SM3, pp. 27-63.

Broms, B. B. (1964b) "Lateral resistance of piles in cohesionless soils", Proc. ASCE, Jnl. Soil Mech. and Found. Div., Vol. 90 SM3, pp. 123-156.

Brown, D. A., Reese, L. C. and O'Neill, M. W. (1987) "Cyclic lateral loading of a large scale pile group", Jnl. Geotech. Eng., Proc. ASCE, Vol. 113 No.11, pp. 1326-1343.

Brown, D. A., Morrison, C. and Reese, L. C. (1988) "Lateral load behaviour of pile group in sand", Jnl. Geotech. Eng., Proc. ASCE, Vol. 114 No.11, pp. 1261-1276.

Budhu, M. and Davies, T. G. (1987) "Nonlinear analysis of laterally loaded piles in cohesionless soils", Canadian Geotechnical Journal, Vol. 24, pp. 289-296.

Budhu, M. and Davies, T. G. (1988) "Analysis of laterally loaded piles in soft clays", Jnl. Geotech. Eng., Proc. ASCE, Vol. 114 No. 1, pp. 21-39.

Burland, J. B. (1973), Shaft friction of piles in clay - a simple fundamental approach", Ground Engineering, Vol. 6 No. 3 , pp. $30,32,37,38,41,42$.

Caputo, V. and Viggiani, C. (1984) "Pile foundation analysis: a simple approach to nonlinearity effects", Rivista Italiana di Geotechnica, Vol. XVIII No. 1, pp. 32-51.

Carter, D.P., (1984) "A nonlinear soil model for predicting lateral pile response", Report No. 359, Civil Engineering Dept., University of Auckland.

Carter, J. P. and Kulhawy, F. H. (1992) "Analysis of laterally loaded shafts in rock", Jnl. Geotech. Eng., Proc. 
ASCE, Vol. 118 No. 6, pp. 839-855.

Cooper, S. E. (1991) "Ductile frames are tough for earthquakes", Civil Engineering, Vol. 61 No. 8, pp. 61-63.

Cox, W.R., Reese, L.C. and Grubbs, B.R. (1974) "Field testing of laterally loaded piles in sand", Proc. 6th Offshore Technology Conference, Houston, Texas, Vol. 2, pp 459-472.

D'Appolonia, D. J., D'Appolonia and Brisette, R. F. (1970) Discussion of the paper: "Settlement of spread footings on sand", Proc ASCE Jnl. Soil Mech. \& Found. Div., Vol. 96 SM2, pp. 754-762.

Davies, T. G., Sen, R. and Banerjee, P. K. (1985) "Dynamic behaviour of pile groups in inhomogeneous soil", Proc ASCE Jnl. Geotech. Eng., Vol. 111 SM12, pp. 13651379.

Davies, T. G. and Budhu, M. (1986) "Nonlinear analysis of laterally loaded piles in heavily overconsolidated clays", Geotechnique Vol. 36 No. 4, pp. 527-538.

Dobry, R. and Gazetas, G. (1985) "Dynamic stiffness and damping of foundations by simple methods", Proc. ASCE symposium on: Vibration Problems in Geotechnical Engineering, edited by G. Gazetas and E. T. Selig, pp. 75-107.

Dobry, R. and Gazetas, G. (1988) "Simple method for dynamic stiffness and damping of floating pile groups", Geotechnique, Vol. 38 No. 4, pp. 557-574.

Dowrick, D. J. (1987) Earthquake resistant design, Wiley, pp. 244-247.

Edmonds, F. D., Carr, A. J., Goldsmith, P. R., North, P. J., Wood, J. H. and Preston, R. L. (1980) "Seismic Design of Bridges - Section 4 - Bridge Foundations", Bulletin of the NZ National Society for Earthquake Engineering, Vol. 13 No. 3, pp. 248-261.

El-Marsafawi, H., Han, Y. C. and Novak, M. (1992) "Dynamic experiments on two pile groups", Jnl. Geotech. Eng., Proc. ASCE, Vol. 118 No. 6, pp. 839-855.

Gazetas, G. (1991) "Foundation vibrations", in Foundation Engineerng Handbook, 2nd. edition, H-Y Fang editor, Van Nostrand Reinhold, pp. 553-593.

Gazetas, G. and Dobry, R. (1984) "Horizontal response of piles in layered soils", Jnl. Geotech. Eng., Proc. ASCE, Vol. 110 No. 1, pp. 20-40.

Gazetas, G. (1984) "Seismic response of single end-bearing piles", Soil Dynamics and earthquake engineering, Vol. 3 No. 2, pp. 82-93.
Gazetas, G. and Makris, N. (1991) "Dynamic pile-soil-pile interaction. Part I: analysis of axial vibration", Earthquake Engineering and Structural Dynamics, Vol. 20, pp. 115-132.

Girault, P. (1986) "Analyses of foundation failures", Proc. Int. Conf. The Mexico City Earthquakes - 1985, ASCE pp. 178-192.

Gohl, W. B. and Finn, W. D. L. (1987) "Seismic response of pile foundations in a centrifuge", Proc: Int. Symposium on Prediction and Performance in Geotechnical Engineering, edited by Joshi, R. C and Griffiths, F. J., Balkema, pp. 419-426.

Grashuis, A. J., Dieterman, H. A., and Zorn, N. F. (1990) "Calculation of cyclic response of laterally loaded piles", Computers and Geotechnics, Vol. 10 No. 4, pp. 287-305.

Fussell, A. J., (1993) "Kinematic response of end bearing piles to vertically propagating seismic waves", M.E. thesis, University of Auckland.

Hadjain, A. H., Fallgren, R. B. and Lau, L. (1990) "Imperial County Services Building Revisited: A reevaluation of pile-soil-structure interaction", Proc. 4th. US National Conference on Earthquake Engineering, Palm Springs California, Vol. 3, pp. 835-844.

Hagio, K., Suenaga, A., Yamada, T. and Kawamura, S (1977) Earthquake motion measurement of plant towers on soft subsoil, Proc. 6th. World Conference on Earthquake Engineering, New Delhi, Vol. II, pp. $1522-1528$.

Hall, J. F. (1984) "Forced vibration and earthquake behaviour of an actual pile foundation", Soil Dynamics and Earthquake Engineering, Vol. 3 No. 2, pp. 94-101.

Hardin, B.O., and Richart, F.E. (1963) Elastic wave velocities in granular soils. Proc. ASCE, Jnl. Soil Mech. \& Found. Div., Vol. 92 SM 2, pp 352-369.

Hetenyi, (1946) "Beams on Elastic Foundations", University of Michigan Press.

Jardine, R., Potts, D. M., Hight, D. W. and Burland, J. B. (1985) "Assessing the safety of offshore piles by displacement monitoring", Conference on the Behaviour of Offshore Structures, Amsterdam, pp. 611-622.

Jennings, D. J., Thurston, S. J., Edmonds, F. D. and Millar, P. J. (1985) "The behaviour of two 450mm diameter piles subject to static and dynamic cyclic lateral loading", Ministry of Works and Development, Central Laboratories Report 5-85/17, Vol. I \& II.

Jennings, D. N., Thurston, S. J. and Edmonds, F. D. (1986) "Static and dynamic lateral loading of two piles", 
Proc. N Z National Roads Board Road Research Unit, Bridge Design and Research Seminar, Auckland. RRU Bulletin No. 73, pp. 29-38.

Kagawa, T. and Kraft, L. M. (1980) "Lateral load-deflection relationships of piles subjected to dynamic loads", Soils and Foundations, Vol. 20 No. 4, pp. 19-36.

Kagawa, T. and Kraft, L. M. (1980) "Seismic p-y responses of flexible piles", Jnl. Geotech. Eng. Div., Vol. 106 GT8, pp. 899-918.

Kawamura, S, Umemura, H. and Osawa, Y. (1977) Earthquake motion measurement of a pile supported building on reclaimed land. Proc. 6th. World Conference on Earthquake Engineering, New Delhi, Vol. II, pp. $1563-1569$.

Kaynia, A. M. and Kausel, E. (1982) "Dynamic behaviour of pile groups", Proc. 2nd. Int. Conf. on Numerical Methods in Offshore Piling, Austin, Texas, pp. 509532 .

Ke Fan, Gazetas, G., Kaynia, A., Kausel, E., and Ahmad, S. (1991) "Kinematic seismic response of single piles and pile groups", Jnl. Geotech. Eng., Vol. 117 No. 12, pp. $1860-1879$.

Krishnan, R., Gazetas, G. and Velez, A. (1983) "Static and dynamic lateral deflexion of piles in non-homogeneous soil stratum", Geotechnique, Vol. 33 No. 3, pp. 307325.

Kuhlemeyer, R. L. (1979) "Static and dynamic laterally loaded floating piles", Jnl. Geotech. Eng., Proc. ASCE, Vol. 105 No. GT2, pp. 289-304.

Kulhawy, F. W. and Mayne, P. W. (1990) "Manual for estimating soil properties for foundation design", Research Report EL-6800, Geotechnical Engineering Group, Civil Engineering Department, Cornell University (Report prepared for Electric Power Research Institute, Palo Alto, California).

Kulhawy, F. W. and Carter, J. P (1991) "Socketed foundations in rock masses", in Engineering in Rock Masses, F. G. Bell editor, Butterworth/Heinmann, pp. 509-529.

Larkin, T. J. (1986) "The seismic response of pile foundations", Proc. NZ Geomechanics Society Symposium on Pile Foundations for Engineering Structures, Hamilton, pp. $1-10$.

Lee, I. K. \& Harrison, H. B. (1970) Structure and foundation interaction theory. Proc. ASCE Jnl. Struct. Div., Vol. 96 No. 2, pp. 177-197.

Levine, M. B. and Scott, R. F. (1989) "Dynamic response verification of simplified bridge-foundation model", Jnl. Geotech. Eng., Proc. ASCE, Vol. 115 No. 2, pp. 246-260.
Ling, L. F. (1988) "Back analysis of lateral load tests on piles", M.E. thesis, Civil Engineering Department University of Auckland.

Lunne, T and Christofferson, H. P. (1983) "Interpretation of cone penetration data for offshore sands", Proc. 15th. Offshore Technology Conference, Vol. 1, pp. 181-192.

Makris, N. and Gazetas, G. (1992) "Dynamic pile-soil-pile interaction. Part II: lateral and seismic response", Earthquake Engineering and Structural Dynamics, Vol. 21, pp. 145-162.

Margasen, E. and Holloway, D. M. (1977) Pile bending during earthquakes, Proc. 6th World Conference on Earthquake Engineering, Vol. II, p. 1690 - 1696.

Matlock, H. and Reese, L. C. (1960) Generalised solutions for laterally loaded piles, Proc. ASCE, Jnl. Soil Mech. and Founds. Div., Vol. 86 SM5, pp. 63-91.

McClelland, B. and Focht, J.A. (1956) Soil Modulus for laterally loaded piles. Trans. ASCE, Paper No. 2954, pp 1049-1086.

Meyerhof, G. G. (1965) "Shallow foundations", Proc. ASCE, Vol. 91 SM2, pp. 21-31.

Miura, F., Stewart, H. E. and O'Rourke, T. D. (1991) "The effect of liquefaction induced lateral spreading on pile foundations", Soil Dynamics and Earthquake Engineering, Vol. 10 No. 5, pp. 271-279.

Miwa, S., Tazoh, T., Shimuzu, K., Uehara, S., Mikami, H., Kobayashi, K. and Kogama, I. (1992) "Study on dynamic interaction analytical methods for structures on pile foundations", Proceedings of the 4th. JapanUS Workshop on Earthquake Resistant Design of Lifeline Facilities and Countermeasures for Soil Liquefaction, Technical Report NCEER-92-0019, National Centre for Earthquake Engineering Research, State University of New York at Buffalo, Vol. 1, pp. 581-606.

Mizuno, H. (1988) "Pile damage during earthquake in Japan (1923 - 1983)" Dynamic Response of Pile Foundations - Experiment, Analysis and Observations. ASCE Geotechnical Special Publication No. 11, edited by T. Nogami, pp. 53-78.

Murff, J. D. and Hamilton, J. M. (1993) "P-ultimate for undrained analysis of laterally loaded piles", Jnl. Geotech. Eng., Proc. ASCE, Vol. 119 No. 1, pp. 91107.

Nair, K. (1969) "Dynamic and earthquake forces on deep foundations", ASTM STP 444: Performance of deep foundations, pp. 229-261.

Nataraja, M. S. and Cook, B. E. (1983) "Increase in SPT 
$\mathrm{N}$-value due to displacement piles", Proc. ASCE, Jnl. Geotech. Eng, Vol. 109 No. 1, pp. 108-113.

Neeley, W. J. (1990) "Bearing capacity of expanded base piles in sand", Proc. ASCE, Jnl. Geotech. Eng, Vol. 116 No. 1, pp. 73-87.

Nishizawa, T., Tajiri, S. and Kawamura, S. (1984) Excavation and response analysis of damaged $\mathrm{RC}$ piles by liquefaction, Proc. 8th. World Conference on Earthquake Engineering, San Francisco, Vol. III, pp. $593-600$.

Norris, G. M. (1991) Discussion of Scott and Levine (1989). Jnl. Geotech. Eng., Vol. 117 No. 8, pp. 1281-1282.

Novak, M. and Sharnouby, B. E. (1985) "Pile groups under static and dynamic loading", Proc. 11th. ICSMFE, San Francisco, Vol. 3, pp. 1449-1454.

Novak, M (1991) "Piles under dynamic loads", Proc. 2nd. International Conference on Recent Advances on Geotechnical Earthquake Engineering and Soil Dynamics, Rolla, Missouri, Vol. 3, pp. 2433-2456.

Ohira, A., Tazoh, T., Dewa, K., Shimizu, K., and Shimada, M. (1984) "Observations of earthquake response behaviours of foundations piles for road bridge", Proc. 8th. World Conference on Earthquake Engineering, San Francisco, Vol. III, pp. 577-584.

Oweis, I. S. (1981) "Evaluating pile performance during earthquakes", Proc. ASCE, Jnl. Geotech. Eng., Vol. 107 GT5, pp. 678-683.

Parry, R. H. G. (1971) "A direct method of estimating settlements in sand from SPT values", Proc. Symp. Interaction of Structures and Foundations, Midlands Soil Mech. and Found. Eng. Soc., Birmingham, U. K., pp. 29-37.

Peck, R. B. and Bazzara, A. R. S. (1969) Discussion of "Settlement of spread footings on sand", Proc. ASCE, Jnl. Soil Mech. and Found. Div., Vol. 95 SM 3, pp. 905-909.

Pender, M.J., and Robertson, T.W., (editors) (1987) "(1987) Edgecumbe Earthquake: Reconnaissance Report", Bulletin of the N.Z. National Society for Earthquake Engineering, Vol 20, No.3, pp. 201-249. (Also published in: Earthquake Spectra, Vol. 3 No. 4, pp. 659-745.

Pender, M. J. and Matuschka, T. (1988) "Interpretation of lateral load tests of poles in cohesionless soils", Proc. 5th. Australia-NZ Conference on Geomechanics, Sydney.

Poulos, H. G. and Davis, E. H. (1980) Pile Foundation Analysis and Design, Wiley.
Poulos, H. G. (1982) "Single pile response to cyclic lateral load", Jnl. Geotech. Eng., Vol. 108 GT 3, pp. 355375.

Poulos, H. G. (1988) "Some recent developments in pile design and determination of design parameters", Proc. NZ Geomechanics Society Symposium on Pile Foundations for Engineering Structures, Hamilton, pp. $1-17$.

Poulos, H. G. (1988) "Cyclic stability diagram for axially loaded piles", Jnl. Geotech. Eng., Vol. 114 No. 8, pp. $877-895$

Poulos, H. G. (1989) "Cyclic axial loading analysis of piles in sand", Jnl. Geotech. Eng., Vol. 115 No. 6, pp. 836 852.

Pranjoto, S. (1992) "A review of a method for predicting lateral pile response", Master of Engineering project report, Civil Engineering Department, University of Auckland.

Priestley, M.J.N. (1974) "Mangere Bridge foundation cylinder load tests." MWD Central Laboratories Report No. 488.

Priestley, M. J. N., Singh, J. P., Youd, T. L. and Rollins, K. L. (1991) "Bridges", Costa Rica Earthquake of April 22, 1991 Reconnaissance Report, Earthquake Spectra Supplement B to Volume 7, pp. 59-91.

Randolf, M. F. and Wroth, C. P. (1978) "Analysis of deformation of vertically loaded piles", Proc. ASCE, Jnl. Geotech. Eng., Vol. 104 GT12, pp. 1465-1488.

Randolf, M. F. and Wroth, C. P. (1979) "An analysis of the vertical deformation of pile groups", Geotechnique, Vol. 29 No. 4, pp. 423-439.

Randolf, M. F. (1981) "Response of flexible piles to lateral loading", Geotechnique, Vol. 31 No. 2, pp. 247-259.

Randolf, M. F. and Houlsby, G. T. (1984) "The limiting pressure on a circular pile loaded laterally in a cohesive soil", Geotechnique, Vol. 34 No. 4, pp. 613 623.

Randolf, M. F. and Springman, S. M. (1991) "Analysis of pile response due to external loads and soil movement", Proc. 10th. European Conference on Foundation Engineering, Florence, Vol. II, pp. 525-528.

Reese, L.C., Cox, W.R. and Koop, F.D. (1974) Analysis of laterally loaded piles in sand. Proc. 6th Offshore Technology Conference, Houston, Texas, Paper 2080, pp 473-483.

Ross, G. A., Seed, H. B. and Migliaccio, R. R. (1969) Bridge foundation failure in Alaska earthquake, Proc. ASCE, Jnl. Soil Mech. and Found. Div., Vol. 95 SM4, pp. 
$1007-1036$.

Samson, L. and Authier, J. (1986), "Change in pile capacity with time: case histories", Canadian Geotechnical Journ., Vol. 23, pp. 174-180.

Schultze, E. and Menzenbach, H. (1961) "Standard penetration tests and the compressibility of soils", Proc. 5th. ICSMFE, Paris, Vol. 1, pp. 527-532.

Scott, R. F. (1981) Foundation Analysis, Prentice Hall, p. 251.

Seed, H. B., Wong R. T., Idriss, I. M. and Tokimatsu, K. (1986) "Moduli and Damping factors for Dynamic analyses of Cohesionless Soils", Proc. ASCE, Jnl. Geotech. Eng. Div., Vol. 112, No. 11, 1016-1032.

Seed, R. B., Dickensen, S. E. and Idriss, I. M. (1991) Principal geotechnical aspects of the Loma Prieta Earthquake, Soils and Foundations, Vol. 31 No. 1, pp. 1 - 27.

Semple, R. M. \& Rigden, W. J. (1984), "Shaft capacity of driven piles in clay", Proc. ASCE Symposium: Analysis and design of pile foundations, San Francisco, pp. 59-79.

Solymar, Z. V., Samsudin, J. O. and Purnomo, B. J. (1986) "Ground improvement by deep compaction", Proc. ASCE Jnl. Geotech. Eng, Vol. 112 No. 12, pp. 1069-1083.

Steedman, R. S. and Maheetharan, A. (1988) "Modelling the dynamic response of piles in dry sand", Proc. 12th. ICSMFE, Rio de Janeiro, Vol. 2, pp. 983-986.

Stevens, J.B. and Audibert, J.M.E. (1979) Re-examination of p-y curve formulations. Proc. 11th Offshore Technology Conference, Houston, Texas, Paper 3402 , pp 397-403.

Stewart, D. P., Jewell, R. J. and Randolf, M. F. (1992a) "Embankment loading of piled bridge abutments on soft clay", Research Report No. G1022, Department of Civil and Environmental Engineering, University of Western Australia.

Stewart, D. P., Jewell, R. J. and Randolf, M. F. (1992b) "Piled bridge abutments on soft clay - experimental data and simple design methods", Research Report No. G1023, Department of Civil and Environmental Engineering, University of Western Australia.

Stewart, D. P., Jewell, R. J. and Randolf, M. F. (1992c) "Design of piled bridge abutments on soft clay for loading from lateral soil movements", Research Report No. G1056, Department of Civil and Environmental Engineering, University of Western Australia.

Sugimura, Y. (1984) "Participation factor of horizontal force applied to pile foundation", Proc. 8th. World Conference on Earthquake Engineering, San Francisco, Vol. III, pp. 443 - 450.

Sugimura, Y. (1986) "Earthquake resistant design of building foundation - Introduction and commentary on Design Guide for the Building Foundation against Seismic Force", Proc. 17th. Joint US. - Japan co-operative program in Wind and Seismic effects, edited by: N. J. Raufaste, US Department of Commerce, National Bureau of Standards, pp. 168-201.

Swane, I. C. and Poulos, H. G. (1984) "Shakedown analysis of laterally loaded pile tested in stiff clay", Proc. 4th. Australia - New Zealand Conference on Geomechanics, Perth, Vol. I, pp. 165-169.

Tajimi, H. (1977) "Seismic effects on piles", State of the Art Report 2, Specialty Session 10, IXth. International Conference on Soil Mechanics and Foundation Engineering, Tokyo.

Tazoh, T., Wakahara, T., Shimuzu, K. and Matsuzaki, M. (1988a) "Effective motion of group pile foundations", Proc. 9th. WCEQE, Tokyo-Kyoto, Vol. III, pp. 587 592.

Tazoh, T., Shimuzu, K. and Wakahara, T. (1988b) "Seismic observations and analysis of grouped piles", Dynamic Response of Pile Foundations - Experiment, Analysis and Observations. ASCE Geotechnical Special Publication No. 11, edited by T. Nogami, pp. 1-20.

Terzaghi, K. and Peck, R. B. (1948) Soil Mechanics in Engineering Practice, Wiley.

Terzaghi, K. (1955) Evaluation of coefficients of subgrade reaction, Geotechnique, Vol. 5 No. 4, pp. 297 -

Ting, J. M. and Scott, R. F. (1984) "Static and dynamic lateral pile group action", Proc. 8th. World Conf. EQ Eng., San Francisco, Vol. III, pp. 641-648.

Tokida, K., Matsumoto, H. and Iwasaki, H. (1992) "Experimental study on drag acting on piles in ground flowing by soil liquefaction", Proceedings of the 4th. Japan-US Workshop on Earthquake Resistant Design of Lifeline Facilities and Countermeasures for Soil Liquefaction, Technical Report NCEER-92-0019, National Centre for Earthquake Engineering Research, State University of New York at Buffalo, Vol. 1, pp. 511-524.

Tomlinson, M. J. (1986) "Foundation design and construction", 5th. edition, Longman Scientific and Technical.

Trochanis, A. M., Bielak, J. and Christiano, P. (1991) "Three dimensional nonlinear study of piles", Jnl. Geotech. Eng., Vol. 117 No. 3, pp. 429-447.

Trofimenkov, J. G. (1974) "General Report", Proc. 1st. 
European Symp. on Penetration Testing, Stockholm, Vol. 2:1, pp. 24-28.

Turner, J. P. and Kulhawy, F. H. (1990) "Drained uplift capacity of drilled shafts under repeated axial loading", Jnl. Geotech. Eng., Vol. 116 No. 3, pp. 470-491.

Verbrugge, J. C. (1986), "Pile foundations design using CPT results", Structural Engineering Practice, Vol. 3, pp. 93-112.

Vesic, A. (1961) Beams on Elastic Foundations. Proc. 5th. ICSMFE, Paris, Vol. 1, pp. 845-850.

Webb, D. L. (1969) "Settlement of structures on deep alluvial sand sediments in Durban, South Africa", British Geotechnical Society Conf. on In Situ Investigations of Soils and Rocks, Session 3, Paper No. 16, pp. 181188.

Webb, J. F. B. (1986) "Substructuring approach to model the behaviour of laterally loaded piles", Proc. 10th. Australasian Conference on the Mechanics of Structures and Materials, Adelaide, pp. 429-434.

Wood, J. H. and Phillips, M. H. (1987) "Lateral stiffness of bridge foundations: load tests on Newman's bridge", Report ST 87/2 Mills and Wood Consulting engineers, Lower Hutt.

Wood, J. H. and Phillips, M. H. (1988) "Lateral stiffness of bridge foundations: load tests on Wai-iti bridge", Report ST 88/1 Phillips and Wood Consulting engineers, Lower Hutt.

Wood, J. H. (1989) "Lateral stiffness of bridge foundations: load tests on Matai river bridge", Report ST 89/1 Phillips and Wood Consulting Engineers, Lower Hutt.

Wood, J. H. (1990) "Lateral stiffness of bridge foundations: load tests on the Charwell river bridge", Report ST 90/2 Phillips and Wood Consulting Engineers, Lower Hutt.

Wolf, J. P. and von Arx, G. A. (1978) "Impedance functions of a group of vertical piles", Proc. ASCE Conf. on EQ Eng. and Soil Dynamics, Pasadena, Vol. II, pp. 10241041 .

Wolf, J. P. (1985) "Dynamic soil-structure interaction", Wiley.

Zeevaert, L (1983) "Foundation Engineering for Difficult Subsoil Conditions", 2nd. edition, Van Nostrand Reinhold.

Zeevaert, L (1991) "Seismosoil dynamics of foundations in Mexico City earthquake, September 19, 1985", Jnl. Geotech. Eng., Vol. 117 No. 3, pp. 376-428.

\subsection{NOTATION}

Some symbols have been used more than once. In the following list these usages are separated with a comma.

$\mathrm{A}_{\mathrm{b}} \quad$ pile base area

$\mathrm{A}_{\mathrm{s}} \quad$ pile shaft cross-sectional area

B width of the loaded area

$\mathrm{B}_{\mathrm{G}} \quad$ width (between pile extremities) of a pile group

C pile shaft circumference,

$\cos (\omega)$,

damping coefficient having units of $\mathrm{MT}^{-1}$ associated with the term $i \omega C$ (equation 8.3)

$\mathrm{C}_{\alpha \beta}^{\prime} \quad$ is the damping coefficient having units of $\mathrm{FL}^{-1}$ associated with the term $\mathrm{ia}_{\mathrm{o}} \mathrm{C}_{\alpha \beta}^{\prime}$ (equation 8.5a)

$\mathrm{C}_{\alpha \beta}^{\prime \prime} \quad$ is the damping coefficient having units of $\mathrm{FL}^{-1}$ associated with the term $\mathrm{iC}_{\alpha \beta}^{\prime \prime}$ (equation $8.5 \mathrm{~b}$ )

$\mathrm{C}_{\mathrm{V}}$ vertical damping value having units of $\mathrm{MT}^{-1}$ (equations $8.13-8.15$ )

$\mathrm{C}_{\mathrm{rz}} \quad$ radiation damping value at depth $\mathrm{z}$ having units $\mathrm{ML}^{-1} \mathrm{~T}^{-1}$ (equation 8.18)

D pile shaft diameter

EI cantilever section property

$E_{p} \quad$ Young's modulus for the pile material

$\mathrm{E}_{\mathrm{p}} \mathrm{I}_{\mathrm{p}} \quad$ pile section properties

$E_{S} \quad$ Young's modulus of the soil

$\mathrm{E}_{\mathrm{SD}}$ soil modulus at a depth equal to the pile diameter

$E_{S L} \quad$ soil modulus at the pile tip

$\mathrm{E}_{\mathrm{SL} / 2} \quad$ soil modulus at the middle of the pile

$\mathrm{F}_{\mathrm{uH}}$

$\mathrm{F}_{\mathrm{uM}}$

$\mathrm{F}_{\theta \mathrm{M}} \quad$ pile group flexibility coefficients

$\mathrm{H}$ horizontal force, soil layer thickness

$\mathrm{H}_{\mathrm{j}} \quad$ horizontal force carried by pile $\mathrm{j}$

$\mathrm{H}_{\mathrm{p}} \quad$ horizontal load at the pile head

$\mathrm{H}_{\mathrm{u}} \quad$ pile ultimate lateral capacity

$\mathrm{I}_{\mathrm{uy}}$

$\mathrm{I}_{\theta \mathrm{y}}$ 
$\mathrm{I}_{\mathrm{My}} \quad$ yield influence factors

$\mathrm{I}_{\mathrm{p}} \quad$ pile section second moment of area

$\mathrm{K}$ ratio of the pile Young's modulus to that of the soil at depth D

$\mathrm{K}_{\alpha \beta} \quad$ component of the stiffness matrix associated with damping component, the $\alpha \beta$ notation refers to the various damping components $\mathrm{HH}, \mathrm{HM}$ and $\mathrm{MM}$

$\mathrm{K}_{\mathrm{HH}}$

$\mathrm{K}_{\mathrm{HM}}$

$\mathrm{K}_{\mathrm{MM}}$ components of the pile head stiffness matrix

$\mathrm{K}_{\mathrm{h}} \quad$ pile head horizontal stiffness

$\mathrm{K}_{\theta} \quad$ pile head rotational stiffness

$\mathrm{K}_{\mathrm{HHG}}$

$\mathrm{K}_{\mathrm{HMG}}$

$\mathrm{K}_{\mathrm{MMG}}$ components of the pile group stiffness matrix

$\mathrm{K}_{\mathrm{hG}} \quad$ pile group horizontal stiffness

$\mathrm{K}_{\theta \mathrm{G}} \quad$ pile group rotational stiffness

$\mathrm{K}_{\mathrm{o}} \quad$ coefficient of earth pressure at rest

$\mathrm{K}_{\mathrm{p}} \quad$ coefficient of passive earth pressure

$\mathrm{K}_{\mathrm{s}}$ factor which converts the vertical effective stress to the horizontal effective stress at the pile soil interface

$\mathrm{K}_{\mathrm{V}} \quad$ axial stiffness of a pile

$\mathrm{K}_{\mathrm{VG}} \quad$ pile group vertical stiffness

L pile length

$\mathrm{L}_{\mathrm{ad}} \quad$ dynamic effective pile shaft length

$\mathrm{L}_{\mathrm{C}} \quad$ cantilever length

$\mathrm{L}_{\mathrm{G}} \quad$ length (between pile extremities) of the pile group

M applied moment

$\mathrm{M}(\mathrm{z}) \quad$ bending moment

$\mathrm{M}_{\mathrm{F}} \quad$ pile head fixing moment

$M_{h} \quad$ pile shaft moment at the ground surface

$\mathrm{M}_{\mathrm{ME}} \quad$ maximum elastic pile shaft moment

$M_{p} \quad$ moment generated at the pile head

$\mathrm{M}_{\mathrm{y}} \quad$ pile shaft yield moment

$\left(\mathrm{N}_{1}\right)_{60} \quad$ corrected SPT $\mathrm{N}$ value
$\mathrm{P}(\mathrm{t})$

dynamic excitation force

S

$\sin (\omega)$

$\mathrm{S}(\mathrm{z}) \quad$ shear force

$\mathrm{V}_{1}$

ultimate capacity of the individual piles in a group

$\mathrm{V}_{\mathrm{B}}$

$\mathrm{V}_{\mathrm{bu}} \quad$ ultimate base resistance

$\mathrm{V}_{\mathrm{G}}$

ultimate vertical capacity of a pile group

$\mathrm{V}_{\mathrm{s}} \quad$ shear wave velocity of the soil

$\mathrm{V}_{\mathrm{j}} \quad$ vertical force carried by the jth pile in a group

$\mathrm{V}_{\text {su }}$ ultimate shaft resistance

$\overline{\mathrm{V}}_{\mathrm{sH}}$ average shear wave velocity over the depth of the soil layer

W pile weight

$\mathfrak{S}_{\mathrm{HH}}$

$\mathfrak{c}_{\mathrm{HM}}$

$\mathfrak{\mho}_{\mathrm{MM}}$

$\mathbb{C}_{\mathrm{h}} \quad$ pile head horizontal impedance

$\mho_{\theta} \quad$ pile head rotational impedance

$\mathfrak{s}_{\mathrm{HHG}}$

$\mathfrak{S}_{\mathrm{HMG}}$

$\mathfrak{\Im}_{\mathrm{MMG}}$

$\mathfrak{e}_{\mathrm{hG}}$

$\mathfrak{c}_{\theta \mathrm{G}}$

$\Re \quad \mathrm{E}_{\mathrm{p}} / \mathrm{E}_{\mathrm{SL}}$

$\mathscr{L} \quad$ pile length to diameter ratio

$a_{0}$ ratio $\omega D / v_{s H}$ ( $\omega$ is the excitation frequency in radians/second)

$\mathrm{c}_{\mathrm{a}} \quad$ pile shaft adhesion, adhesion along a soil block boundary

con abbreviation representing the modulus distribution for a soil profile with constant Young's modulus

e defined in equation 3.18

$e_{0} \quad$ ground surface to datum level distance $(600 \mathrm{~mm})$ 
f frequency (cycles/second), defined in equation 3.18

$\mathrm{f}_{\alpha} \quad$ pile shaft length factor

$\mathrm{f}_{1} \quad$ fundamental frequency of the soil layer

$f_{u H}$

$f_{u M}$

$\mathrm{f}_{\theta \mathrm{M}} \quad$ pile head flexibility coefficients

h $\quad \mathrm{H} / \mathrm{s}_{\mathrm{u}} \mathrm{D}^{2}$

i $\quad \sqrt{-1}$

$\mathrm{k} \quad \mathrm{K} / 1000$

$\mathrm{k}_{\alpha \beta} \quad$ coefficient relating the real part of the impedance to $\mathrm{K}_{\alpha \beta}$

$\mathrm{k}_{\mathrm{D} 1} \quad$ modulus of subgrade reaction for the pile of dimension $\mathrm{D}_{1}$

$k_{D 2} \quad$ modulus for the pile of dimension $D_{2}$

$\mathrm{k}_{\mathrm{os}} \quad$ small strain coefficient of subgrade reaction

$\mathrm{k}_{\mathrm{S}} \quad$ coefficient of subgrade reaction, stiffness of a spring at a cantilever tip

lin abbreviation representing the modulus distribution for a soil profile with a linear increase in Young's modulus with depth

the number of piles in the group,

an index that controls the extent of the nonlinearity of the Winkler spring model

$\mathrm{n}_{\mathrm{c}} \quad$ defined in equation 9.6

$\mathrm{n}_{\mathrm{h}}$ rate of increase in the modulus of subgrade reaction with depth

$n_{l} \quad$ defined in equation 9.11

$\mathrm{n}_{\mathrm{s}} \quad$ defined in equation 9.15

p contact pressure

$\mathrm{p}_{\mathrm{ult}} \quad$ maximum lateral pressure that the soil can sustain

par abbreviation representing the modulus distribution for a soil profile with a parabolic increase in Young's modulus with depth

$\mathrm{q}_{\mathrm{c}} \quad$ CPT resistance $(\mathrm{MPa})$

s pile spacing

$\mathrm{u}(\mathrm{t}) \quad$ dynamic displacement $\mathrm{u}(\mathrm{z})$

$\mathrm{u}_{1}$

$\mathrm{u}_{\mathrm{d}}$

$\mathrm{u}_{\mathrm{E}}$

$\mathrm{u}_{\mathrm{F}}$

$\mathrm{u}_{\mathrm{g}}$

$u_{o}$

$u_{\mathrm{p}}$

w

$\mathrm{w}_{1}$

$\mathrm{z}$

$\Gamma$

$\Upsilon$

$\Omega$

$\alpha_{\mathrm{uH}}$

$\alpha_{\theta \mathrm{H}}$

$\alpha_{\mathrm{uF}}$

$\alpha_{\mathrm{uHkj}}$
$\alpha_{\mathrm{uM}}$

$\alpha_{\theta \mathrm{M}} \quad$ values of $\alpha_{\mathrm{u}}$ and $\alpha_{\theta}$ for a free head pile subject

$\alpha_{\mathrm{Vkj}} \quad$ vertical interaction factor between piles $\mathrm{k}$ and $\mathrm{j}$

$\beta \quad$ material damping value for the soil

$\gamma$

$\zeta$

$\zeta_{\alpha \beta}$

$\zeta_{\alpha \beta}$ dimensionless frequency dependent damping
coefficient associated with the term $2 \zeta_{\alpha \beta}(\omega)$ i (equation 8.5) value of $\alpha_{\mathrm{uH}}$ for the two piles $\mathrm{k}$ and $\mathrm{j}$ corresponding to the spacing between them and the angle between the direction of loading and the line joining the centres of the piles, Fig. 5.4 to moment loading only

dimensionless frequency dependent damping
coefficient associated with the term $2 \zeta_{\alpha \beta}(\omega) \mathrm{i}$ (equation

values of $\alpha_{u}$ and $\alpha_{\theta}$ for a free head pile subject to horizontal load only unit weight of soil

$\ln \left[5\left(1-\nu_{\mathrm{S}}\right) \mathscr{L}\right]$ 
$\zeta_{\mathrm{MM}}$ dimensionless pile head lateral damping coefficients

$\theta(z) \quad$ rotation of the pile shaft (minus the slope)

$\theta_{\mathrm{d}} \quad$ rotation of the pile shaft at the datum level

$\theta_{\mathrm{E}} \quad$ elastic pile head rotation from equations 3.15 and 3.21

$\nu_{\mathrm{B}} \quad$ Poisson's ratio of the bearing stratum

$\nu_{S} \quad$ Poisson's ratio for the soil

$\xi \quad$ ratio of Young's modulus of the bearing

stratum to that of the soil,

pile group efficiency,

defined in Fig. 5.4

$\rho \quad$ soil density

$\rho_{\mathrm{S}} \quad$ soil density

$\rho_{\mathrm{p}} \quad$ density of the pile material

$\sigma_{\mathrm{m}}^{\prime} \quad$ mean principal effective stress in $\mathrm{kPa}$

$\sigma^{\prime}{ }_{\mathrm{v}} \quad$ vertical effective stress (MPa)

$\phi \quad$ friction angle of sand

$\phi_{\mathrm{p}} \quad$ torsional rotation of a pile group

$\omega \quad$ frequency in radians/second, pile rake angle 